OAK RIDGE NATIONAL LABORATORY

NEUTRON SCIENCES

MANAGED BY UT:BATTELLE FOR THE U.S. DEPARTMENT OF ENERGY

Annual Report
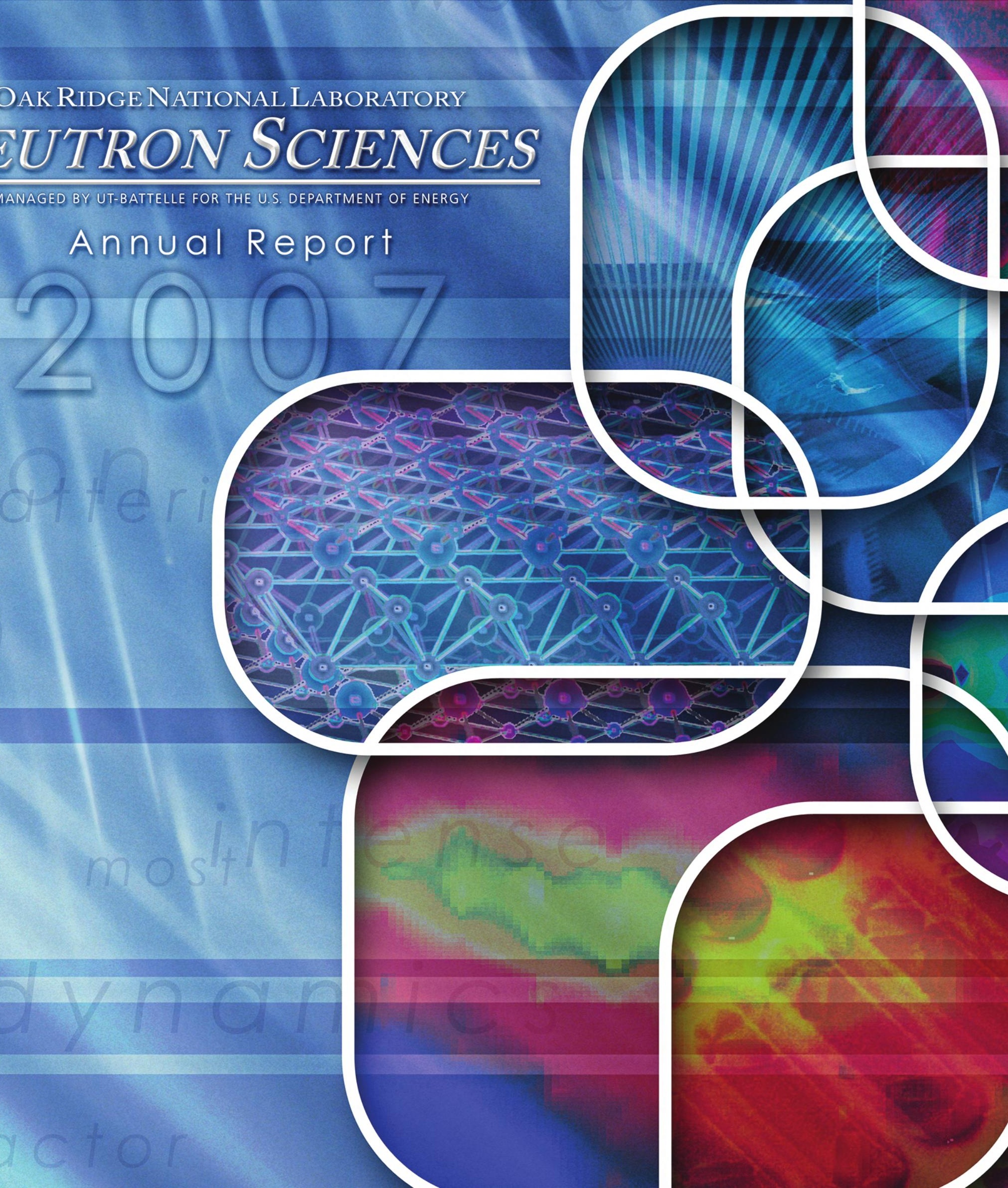
This is the first annual report of the Oak Ridge National Laboratory Neutron Sciences Directorate for calendar year 2007. It describes the neutron science facilities, current developments, and future plans; highlights of the year's activities and scientific research; and information on the user program. It also contains information about education and outreach activities and about the organization and staff.

The Neutron Sciences Directorate is responsible for operation of the High Flux Isotope Reactor and the Spallation Neutron Source.

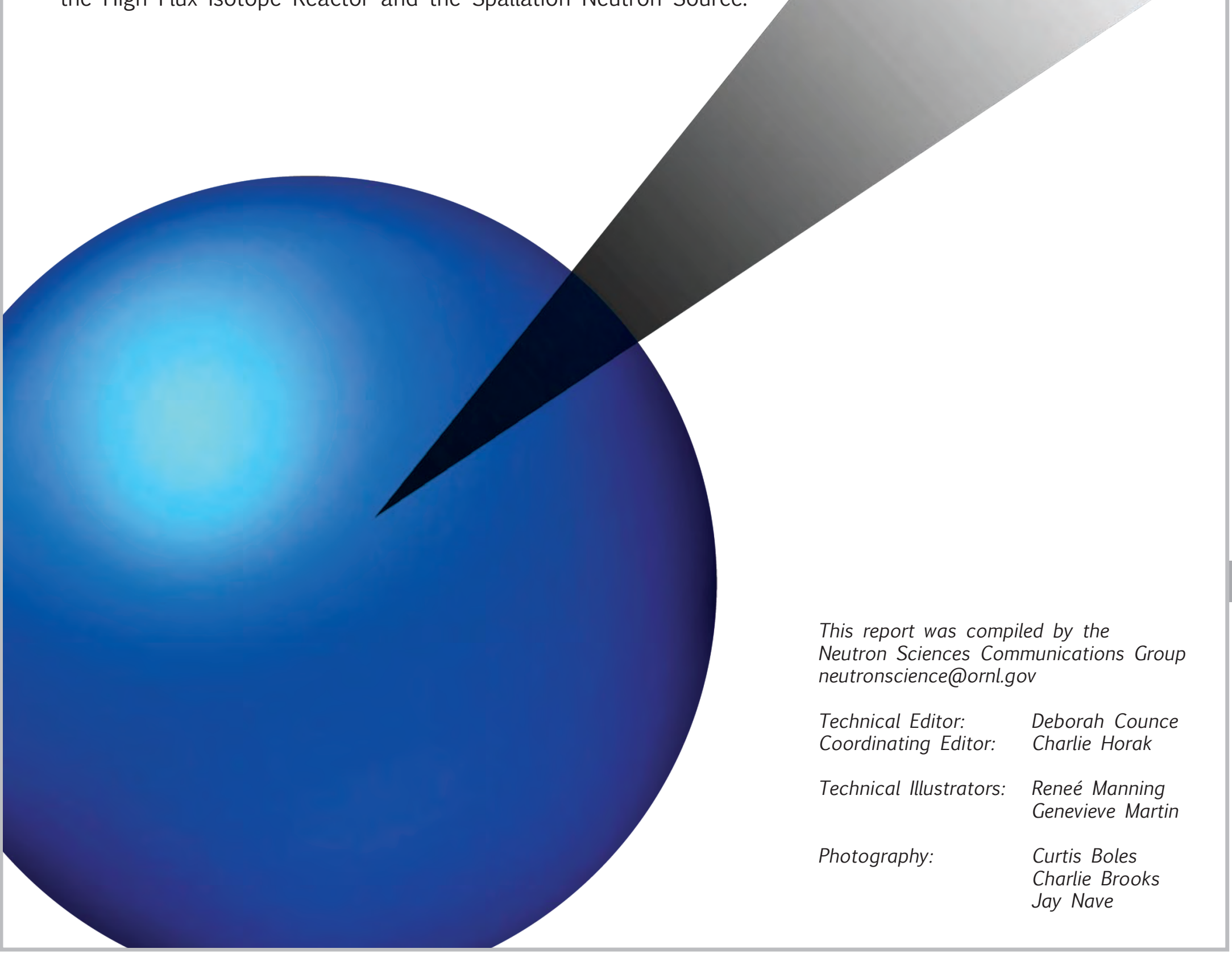




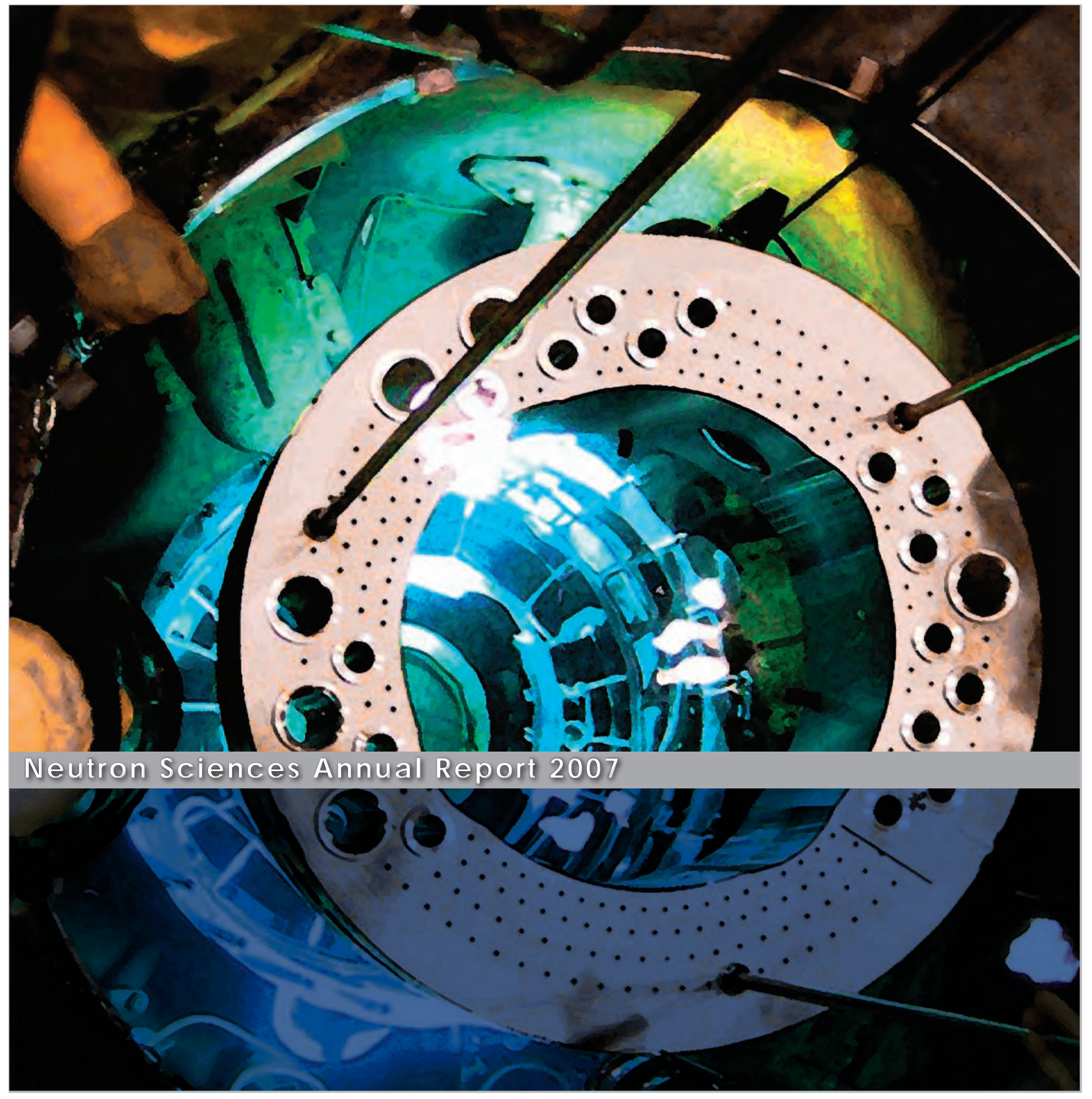




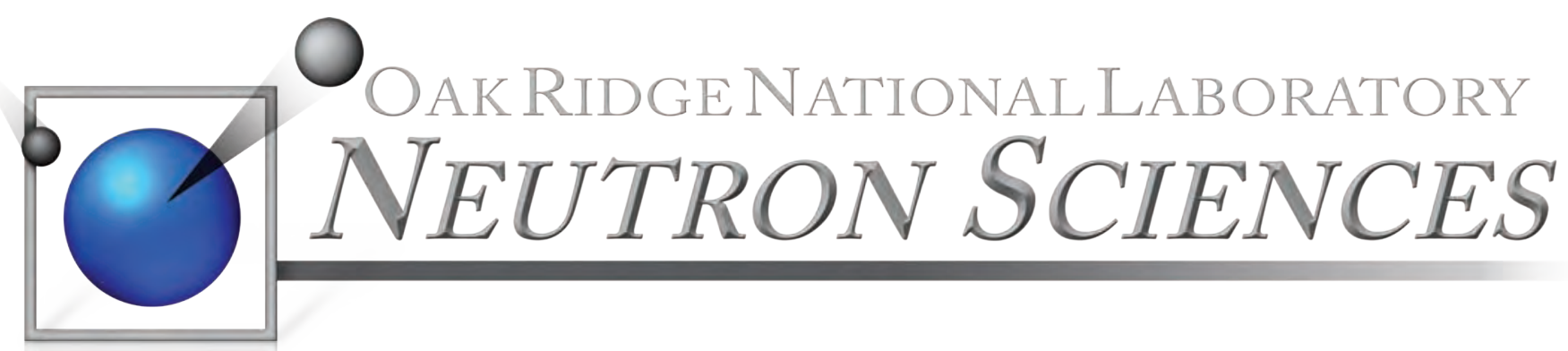

The Neutron Sciences Directorate is part of Oak Ridge National Laboratory, which is managed by UT-Battelle, LLC, under contract DE-AC05-00OR22725 for the U.S. Department of Energy.
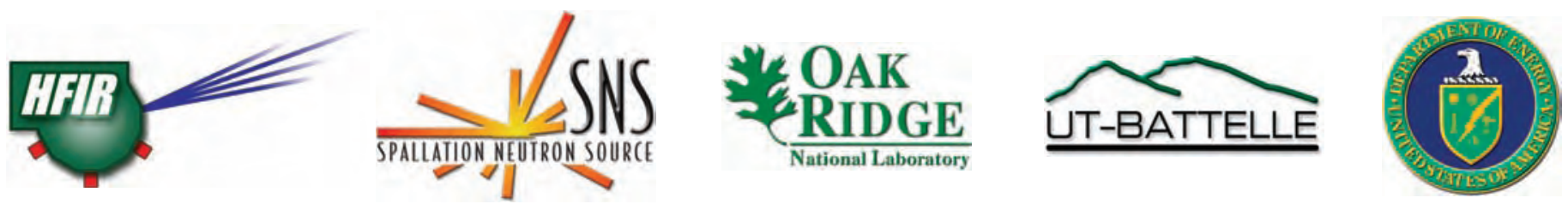

This report was prepared as an account of work sponsored by an agency of the United States government. Neither the United States government nor any agency thereof, nor any of their employees, makes any warranty, express or implied, or assumes any legal liability or responsibility for the accuracy, completeness, or usefulness of any information, apparatus, product, or process disclosed, or represents that its use would not infringe privately owned rights. Reference herein to any specific commercial product, process, or service by trade name, trademark, manufacturer, or otherwise, does not necessarily constitute or imply its endorsement, recommendation, or favoring by the United States government or any agency thereof. The views and opinions of authors expressed herein do not necessarily state or reflect those of the United States government or any agency thereof. 


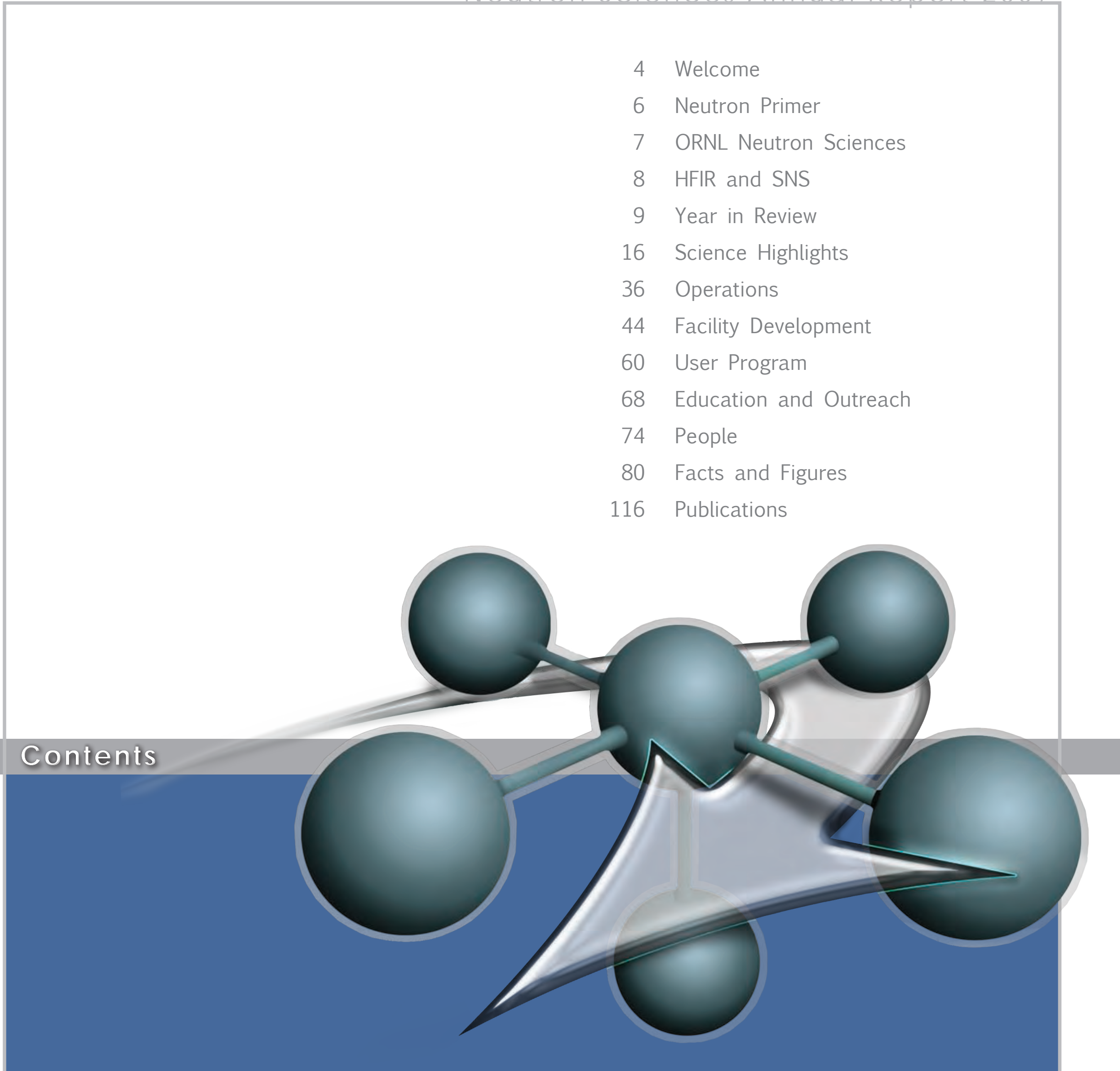

The next generation of materia ls researc $h$ 


\section{lan Anderson}

Associate Laboratory Director

for Neutron Sciences at

Oak Ridge National Laboratory

andersonian@ornl.gov

It is my pleasure to present you with the Oak Ridge National Laboratory Neutron Sciences Directorate's first annual report. This inaugural issue marks the restart of the High Flux Isotope Reactor, with its new cold source, and the first full year of operation of the Spallation Neutron Source, the world's most powerful pulsed spallation neutron source. With HFIR and SNS operating, ORNL now has two of the world's best neutron facilities and the opportunity to optimize the use of pulsed versus continuous sources, with the highest flux of both. This year also marks the beginning of my tenure as associate Laboratory director, and I am excited about the bright future for neutron sciences in Oak Ridge. 
The main highlights of 2007 were highly successful operation and instrument commissioning at both facilities. At HFIR, the year began with the reactor in shutdown mode and work on the new cold source progressing as planned. The restart on May 16, with the cold source operating, was a significant achievement. Furthermore, measurements of the cold source showed that the performance exceeded expectations, making it one of the world's most brilliant sources of cold neutrons. HFIR finished the year having completed five run cycles and 5,880 MWd of operation. At SNS, the year began with $20 \mathrm{~kW}$ of beam power on target; and thanks to a highly motivated staff, we reached a record-breaking power level of $183 \mathrm{~kW}$ by the end of the year. Integrated beam power delivered to the target was $160 \mathrm{MWh}$. Although this is a substantial accomplishment, the next year will bring the challenge of increasing the integrated beam power delivered to $887 \mathrm{MWh}$ as we chart our path toward 5,350 MWh by 2011 .

This year also saw the beginning of our combined user program at both facilities. At HFIR, users took advantage of the Neutron Residual Stress Facility and the three operating triple-axis instruments. Some notable experiments were also performed on the Wide-Angle Neutron Diffractometer, sponsored by the United States and Japan. Perhaps most noteworthy was the commissioning of the two new small-angle neutron scattering instruments, which have already starting producing excellent results and are now available to users. At SNS, three instruments were available to users: the Magnetism and Liquids Reflectometers and the Backscattering Spectrometer. During the 2007 fiscal year (October 2006 to September 2007), 96 users performed 63 experiments between the two facilities.

Another noteworthy accomplishment was the launching of our Integrated Proposal Management System. The system is used to process user proposals and was put into production in the summer. Users will soon be able to use this one system to submit proposals to four ORNL facilities-HFIR, SNS, the Center for Nanophase Materials Sciences, and the Shared Research Equipment User Facility.
As safety to our staff and users is paramount, I am proud to report that while staff at both HFIR and SNS worked hard to meet goals, they also did so with an outstanding safety record. Staff and contractors working at both facilities finished 2007 with no lost workday cases.

As we look to the future, several significant enhancements are under way for both facilities. In addition to commissioning of new instruments that take full advantage of the new cold source at HFIR, longterm plans include the possibility of a second cold source and establishment of the HFIR Neutron Science Center. At SNS, the number of SNS instruments available to users will more than double, and approval has been granted for a power upgrade that will increase proton energy by $30 \%$ and beam current by $60 \%$. Work is also proceeding to obtain funding for a second, long-wavelength target station that will double the number of available instruments as well as the scientific capabilities of the facility.

The vision for Neutron Sciences at ORNL has been and will continue to be developed in collaboration with the scientific community. Through workshops and meetings, particularly with the user community, we continually seek input from outside the Neutron Sciences Directorate and ORNL. This communication is essential to meet the needs of the scientific community. Another key to continuing to develop an effective program is our partnerships with users at universities and other neutron sources.

ORNL is uniquely placed to enable forefront research using neutrons, and in this report you will find selected highlights of the initial research conducted during the past year. The scientific results achieved thus far promise exciting work to come. You can find out more about the user program and our education and outreach activities. You can also read about recent facility developments and the support capabilities in place for a wide variety of experiments in almost any discipline. Finally, we've included information about the people in Neutron Sciences-the foundation for all of our successes. 


\section{Neutron Primer}

Neutrons are useful in research because they reveal properties of materials that other types of probes can't. Why is that?

1. Neutrality. Because they have no electrical charge, neutrons can penetrate deeply into materials without being attracted to charged particles in the atoms. This neutrality makes neutrons ideal for determining the molecular structure of materials.

2. Unique sensitivity to light atoms, such as hydrogen. Neutrons can precisely locate hydrogen atoms in a sample. Thus researchers can get a clearer view of molecular structure than with other probes. That's especially important in designing drugs. It also enables neutrons to find hidden water molecules in materials, revealing microscopic cracks and corrosion.

3. Magnetism. Neutrons act like tiny magnets pointing in a particular direction. Polarized neutrons, which all point in the same direction, let scientists probe the properties of magnetic materials and measure fluctuations in magnetic fields.

4. Energy. The energies of neutrons closely match the energies of atoms in motion. Thus they can be used to track molecular vibrations; movements of atoms during catalytic reactions; and behaviors of materials under forces such as heat, pressure, or magnetic fields.

Since neutrons are everywhere, why do we need special neutron facilities to make them?

When a stream of neutrons hits a sample of material, some of them go right through it. Others hit atomic nuclei in the material and bounce away. Where they bounce, how fast, and where they land reveal details about the structure and properties of the material. As we sometimes need to shine a bright light on something to see it clearly, researchers need "bright" beams of neutrons to see those fine details. HFIR and SNS are two of the brightest sources of neutrons in the world-opening the door to a huge realm of possibilities in materials science.

\section{Neutron Properties \\ - Neutrons are NEUTRAL particles. They \\ - are highly penetrating, \\ - can be used as nondestructive probes, and \\ - can be used to study samples in severe environments.}

N Neutrons have a MAGNETIC moment. They can be used to

- study microscopic magnetic structure,

- study magnetic fluctuations, and

- develop magnetic materials.

Neutrons have SPIN. They can be

- formed into polarized neutron beams,

- used to study nuclear (atomic) orientation, and

- used for coherent and incoherent scattering.

The ENERGIES of thermal neutrons are similar to the energies of elementary excitations in solids, making them useful in the study of

- molecular vibrations,

- lattice modes, and

- dynamics of atomic motion.

The WAVELENGTHS of neutrons are similar to atomic spacings. They can determine

- structural information from $10^{-13}$ to $10^{-4} \mathrm{~cm}$ and

- crystal structures and atomic spacings.

Neutrons "see" NUCLEI. They

- are sensitive to light atoms,

- can exploit isotopic substitution, and

- can use contrast variation to differentiate complex molecular structures.

In addition to the bright neutron sources, the ORNL facilities provide two different types of neutron beams. For some research, it's better to have neutrons available in a series of pulses (as SNS provides); for other research, it's more advantageous to have a continuous source of neutrons (as HFIR provides). Having both types of neutron beams available to users at one location provides an invaluable resource for researchers from all over the world.

For more information about neutrons and neutron scattering science, see neutrons.ornl.gov/science/ ns_primer.pdf. 


\section{High Flux Isotope Reactor ${ }^{\text {and }}$ Spallation Neutron Source}

For some research, having neutrons available in a continuous beam is advantageous; for other research, a pulsed beam is better. The availability of both types of neutron sources at one facility gives scientists unprecedented opportunities to work with some of the most advanced technology in the world. In addition, neutron scattering can provide information about the structure and properties of materials that can’t be obtained from other techniques such as $\mathrm{X}$ rays or electron microscopes.

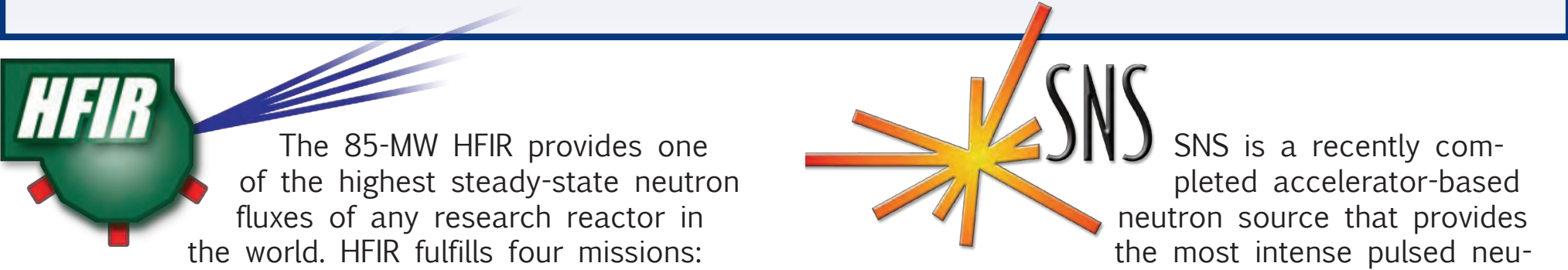
isotope production, materials irradiation, neutron activation, and neutron scattering, which is the focus of this report. The neutron scattering instruments at HFIR enable fundamental and applied research into the molecular and magnetic structures and behavior of materials. HFIR has 15 instruments planned or in operation. A new cold neutron source installed during a HFIR refurbishment in 2006-2007 greatly

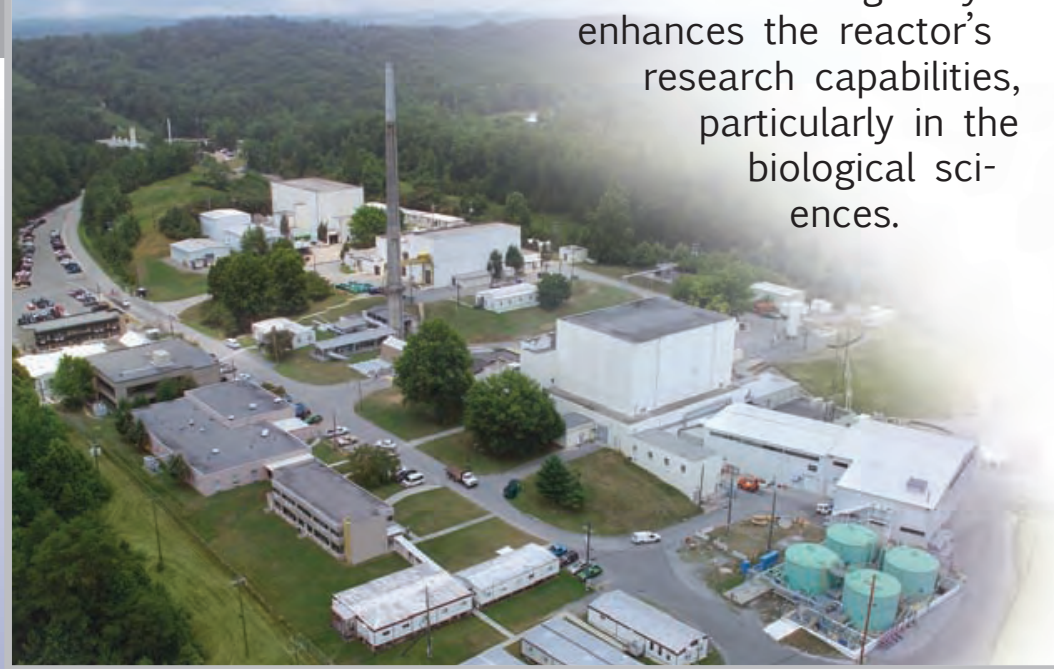
tron beams in the world for scientific and industrial research and development. With its eventual suite of up to 25 best-in-class instruments, SNS will give researchers detailed snapshots of smaller samples of physical and biological materials than previously possible. The diverse applications of neutron scattering research will provide opportunities for experts in practically every scientific and technical field.

Moreover, technological discoveries at SNS will

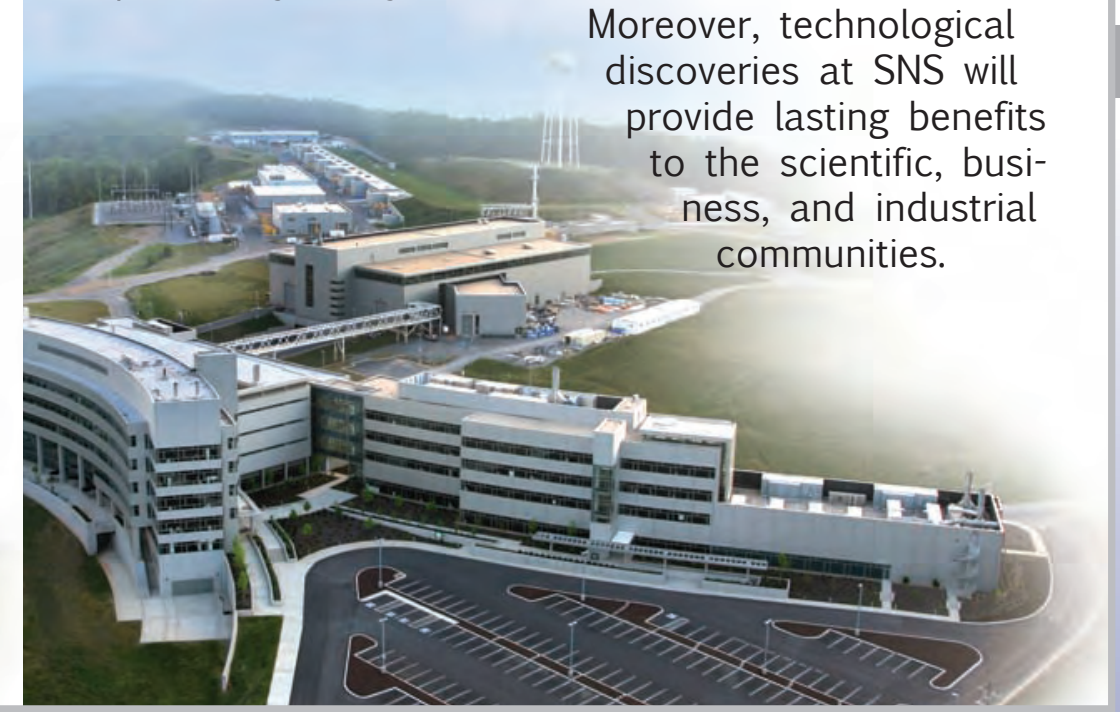
neutrons.ornl.gov 


\section{Yea rin $_{\text {Review: Highlights }}$}

The many exciting events of 2007 make it difficult to cover them all in detail. For the Year in Review, we present a few of the most significant events for neutron sciences at ORNL:

- SNS becomes the world's most powerful pulsed spallation neutron source.

- HFIR is restarted, with a newly installed cold source.

- The fourth SNS instrument-the Wide Angular-Range Chopper Spectrometer-begins commissioning.

- Two new small-angle neutron scattering (SANS) instruments, designed for use with cold neutrons, are commissioned at HFIR.

\section{HFIR Restart}

The restart of HFIR on May 16, 2007, after a 16-month outage for upgrades and the addition of new instruments, was a milestone for neutron science at ORNL. The restart began the 40-year-old HFIR's 408th run cycle. The reactor was taken to $10 \%$ power initially for confirmation of safety parameters and then was quickly increased to its peak power level of $85 \mathrm{MW}$.
Major additions to HFIR are the new guide hall facility for cold source instruments, two new cold source instruments, and the liquid hydrogen cold source itself. Installation of the cold source was especially significant to prospective HFIR users. In September, the neutron flux and brightness of the cold neutron beams were tested using time-offlight methods. Tests revealed the brightness to be significantly greater than was predicted by earlier

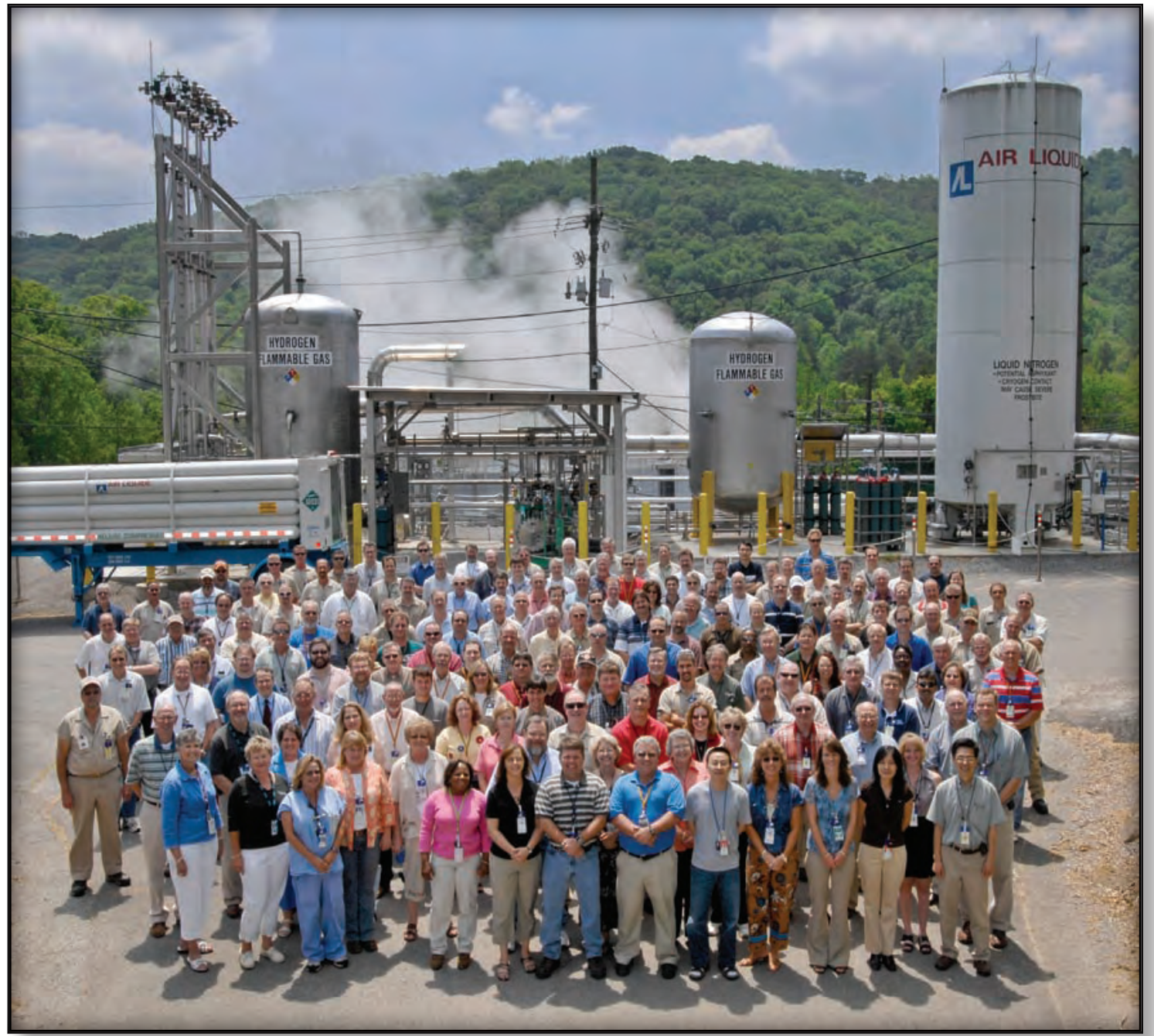

HFIR employees at the restart celebration on May 24, 2007. 
computer simulations in the highly valued 4 to $12 \AA$ range. This achievement confirms HFIR's performance as one of the highest-flux reactor-based sources of cold neutrons in the world.

\section{Why Cold Neutrons?}

For neutron scattering experiments, it is ideal to match the wavelength and energy of the neutron to the length and energy scales, respectively, of the materials under investigation. Therefore, neutrons with long wavelengths and low energies-cold neutrons-are the best for studying large-scale structures (e.g., molecular organization, nanopore-size distributions, and aggregate size and shape) and low-energy excitations (e.g., excitations in frustrated systems and various problems in magnetism, superconductivity, and correlated electron systems).

The thermal (room temperature) neutron spectrum of a reactor produces neutrons with wavelengths on the order of a few tenths of a nanometer, well matched to investigating atomic length scales and lattice vibrational energies. When thermal neutrons are passed through a container of low-temperature liquid hydrogen, they are

Source brightness of the HB-4 cold source at reactor power of $85 \mathrm{MW}$ and moderator temperature of $22.5 \mathrm{~K}$. slowed by collisions with the hydrogen. This process

Wavelength $(\AA)$ produces slower neutrons better suited for studies of soft matter. Because they reflect well from surfaces, cold neutrons can be transported over long distances with little loss. 


\section{New SANS Instruments}

Two of the four cold source guides provide beams to the now operational SANS instruments, which are among the most advanced in the world. One of these is a general-purpose SANS instrument, designed for experimentation on hard and soft condensed matter and magnetic systems. The other, the Bio-SANS, is designed especially for studying the structure and function

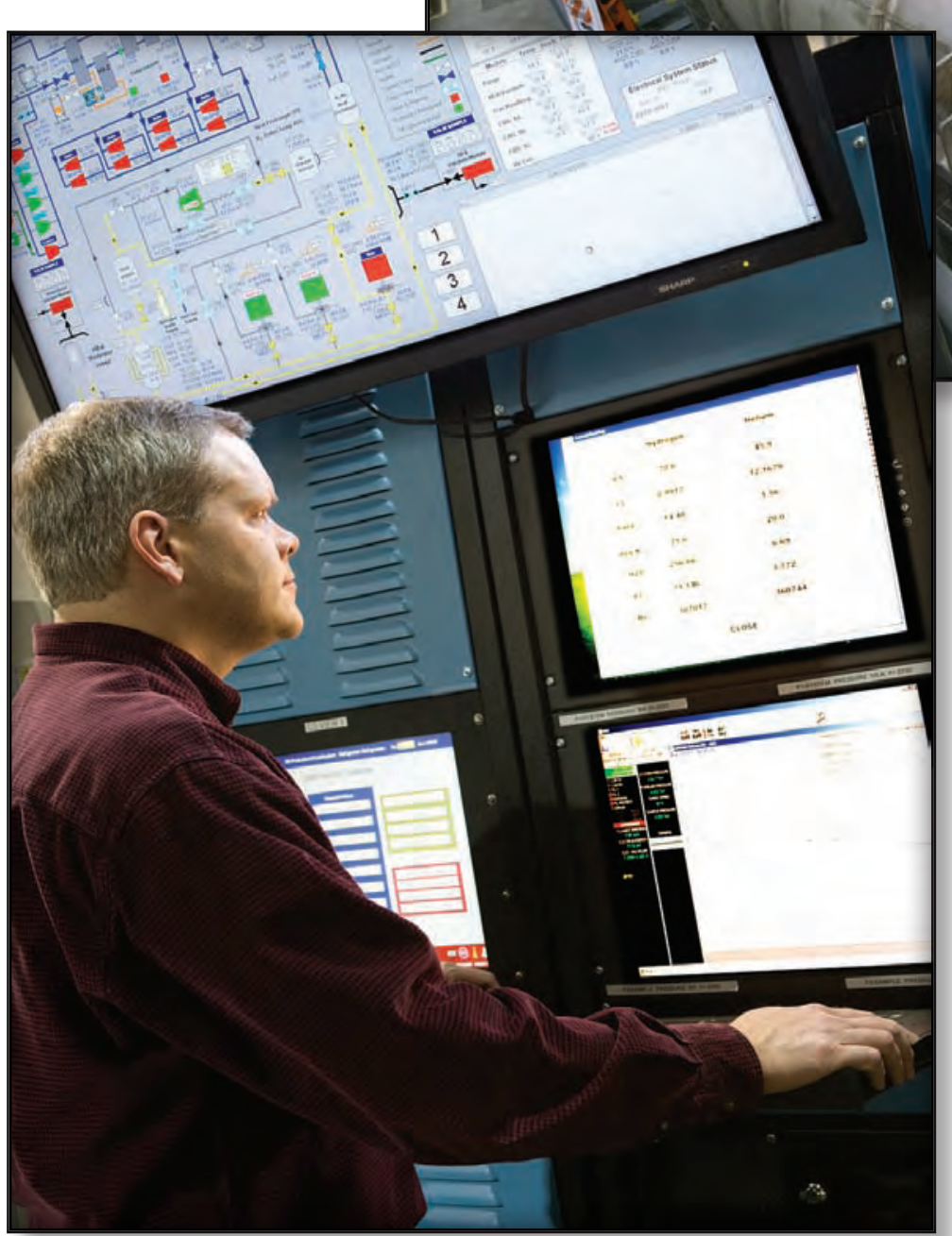

Research Reactors Division Director, Ron Crone, reviews cold source data. of biological materials and complexes, including biomacromolecules such as proteins and viruses, membranes, and biomimetic systems. Commissioning of the instruments with cold neutrons began in mid2007 and was completed in December.

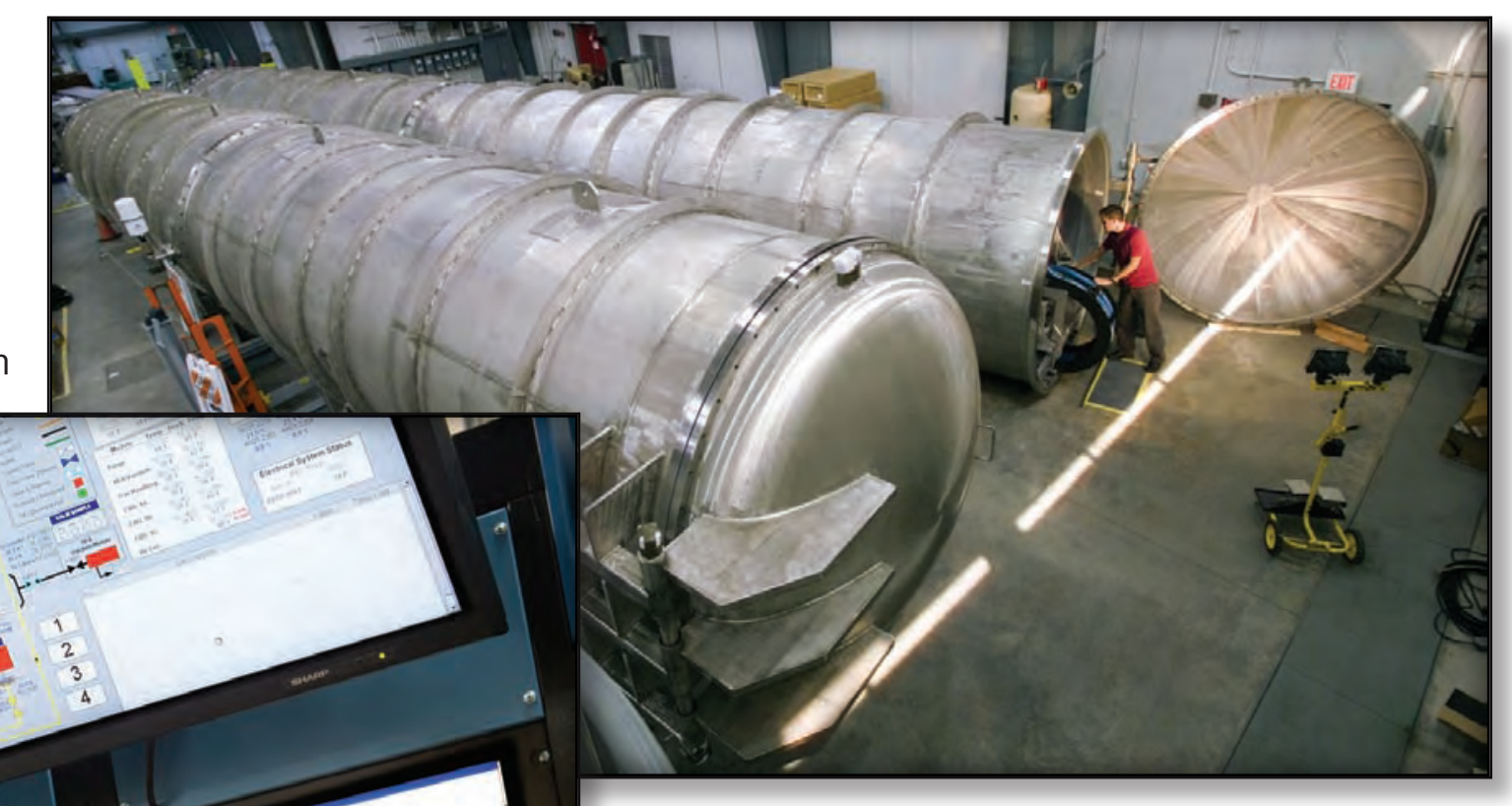

Detector tanks for the new SANS instruments. On the right is the general-purpose, high-resolution instrument; on the left is the Bio-SANS instrument, constructed specifically for biological research.

Other improvements at HFIR include an overhauled reactor, upgraded instruments, and new control systems. In addition, laboratories are being equipped for users, and plans are in place to continue improving the overall facilities. When fully instrumented, HFIR will include 15 of the most advanced neutron scattering instruments in the world, 7 of which will be designed exclusively for cold neutron experiments. With the successful commissioning of the cold source and more than $\$ 70$ million in renovations, HFIR regained its status as a world-class facility. 


\section{SNS Becomes the World's Most Powerful Pulsed Spallation Neutron Source}

On August 11, 2007, SNS set a new technological record and became the world's most powerful pulsed spallation neutron source by maintaining continuous operations at $183 \mathrm{~kW}$. Throughout the next several months, operational and neutron production goals were reached and often exceeded. In addition to offering the research community neutron beams more intense than ever before available, SNS demonstrated that it could also provide those neutrons with high reliability. After 1.4 billion dollars and five years of construction, these highly successful operations confirmed that not only could SNS operate as planned but also that it could perform above and beyond expectations, opening a new realm of possibilities to scientists all over the globe.

Plaque posted in the SNS Central Control Room commemorating SNS becoming the world's most powerful pulsed spallation neutron source. An official recognition ceremony was held on August 29 and was attended by U.S. Senator Lamar Alexander and U.S. Representatives Zach Wamp and Bart Gordon.
The Qpallation Meatron Qource at Oak Ridge Mational Qfaboratory exceeded the previous record and became the world's most powerful pulsed spallation neutron source on Shigust 11, 2007. 2
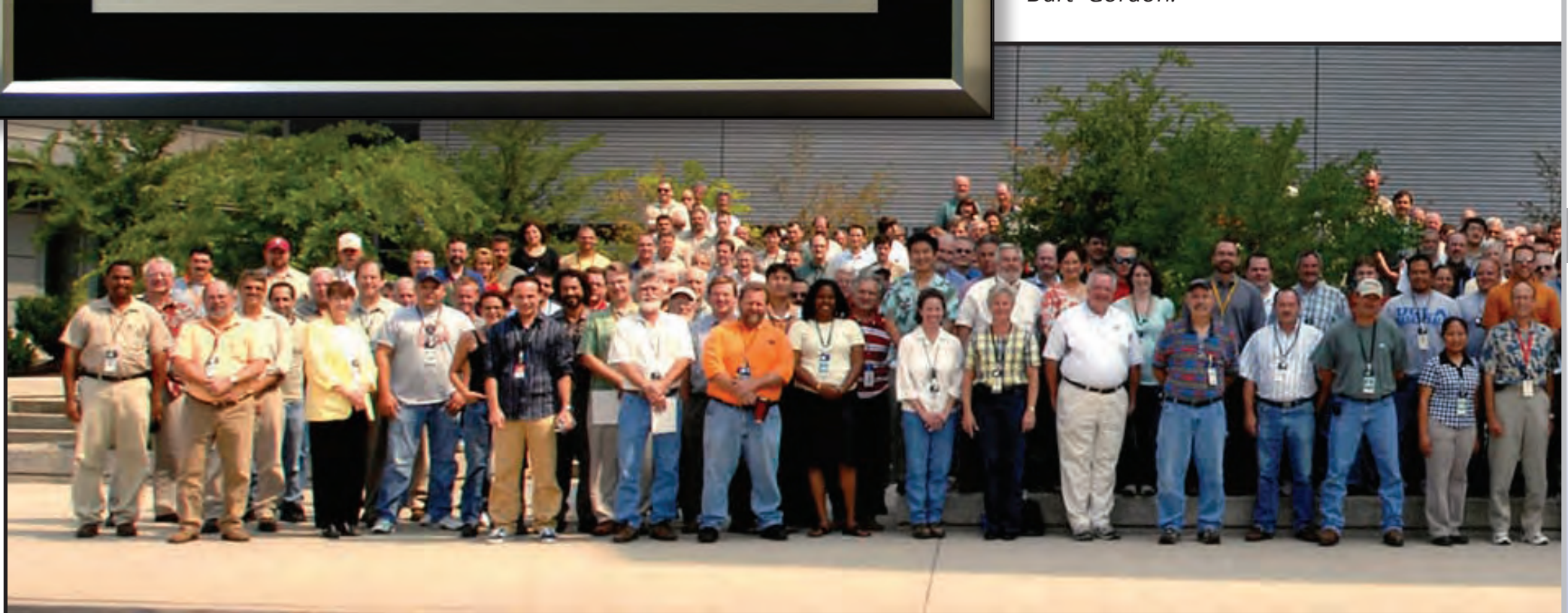

SNS staff outside the Central Laboratory and Office Building, August 11, 2007. 


\section{Wide Angular-Range Chopper Spectrometer}

In September, commissioning began for the SNS Wide Angular-Range Chopper Spectrometer (ARCS). ARCS is optimized to provide a high neutron flux at the sample and a large solid angle of detector coverage for inelastic scattering. The spectrometer is capable of selecting incident energies over the full energy spectrum of neutrons, making it useful for studies of excitations from a few to several hundred millielectron volts. An elliptically shaped supermirror guide in the incident flight path boosts the performance at the lower end of this range. The sample and detector vacuum chambers provide a window-free final flight path and incorporate a large gate valve to allow rapid sample change-

September 2007 Commissioning of ARCS in the SNS Target Building. On the left, ARCS lead instrument scientist Doug Abernathy holds the shutter key just before opening the shutter for the first time. Beside him is ARCS lead engineer Kevin Shaw. In the background is David Vandergriff, lead engineer for the SNS Fine-Resolution Fermi Chopper Spectrometer (SEQUOIA).
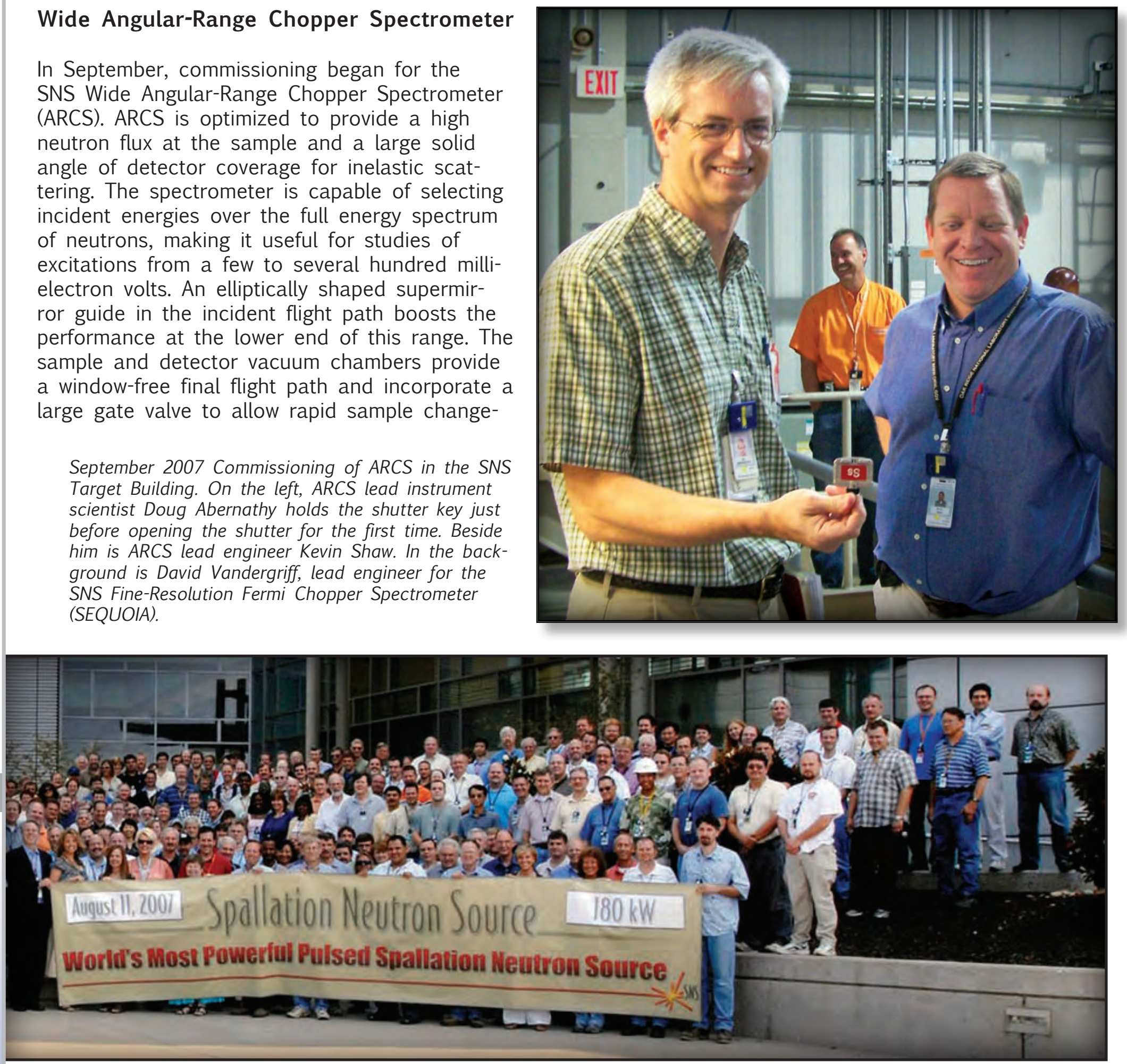
out. A new T-zero neutron chopper is being developed not only to block the prompt radiation from the source but also to eliminate unwanted high-energy neutrons from the incident beam line.

To date, inelastic neutron scattering experiments have been constrained by low neutron flux, forcing experimental compromises in energy resolution, momentum resolution, and the number of spectra that can be measured. With its high detection efficiency, ARCS will free experimenters from many restrictions caused by low flux. The ARCS team worked hard to ensure that the most robust, highly advanced hardware and software were incorporated into ARCS, enabling new experiments with a sophistication not previously achieved with chopper spectrometers. Compared with current instruments, the increased sensitivity of ARCS offers new opportunities for scientific studies in lattice dynamics, magnetic dynamics, and chemical physics.

More information about ARCS is available in the Facts and Figures section.

Contact: Doug Abernathy (abernathydl@ornl.gov)

neutrons.ornl.gov/instrument_ systems/beamline_18_arcs/
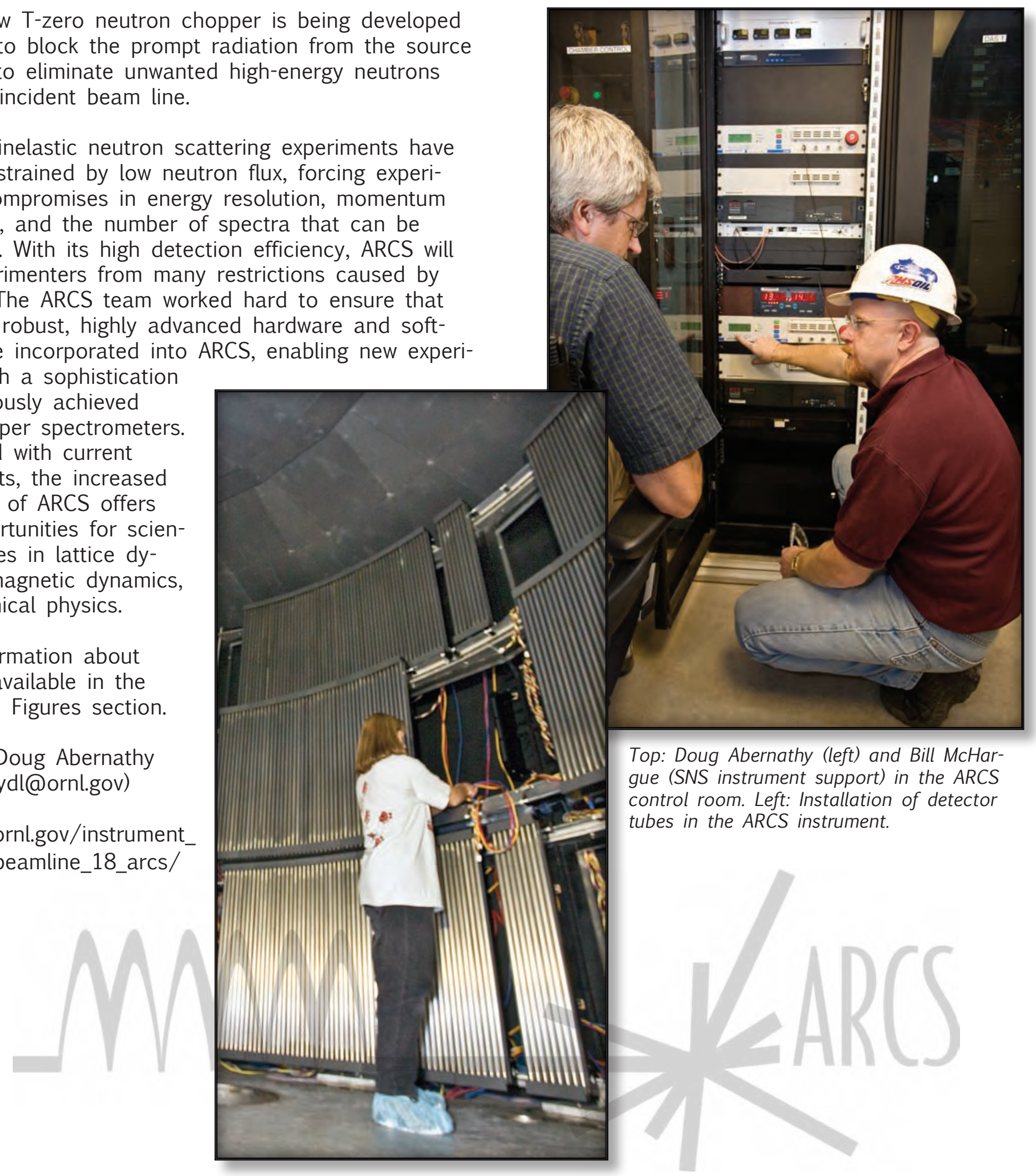

Top: Doug Abernathy (left) and Bill McHargue (SNS instrument support) in the ARCS control room. Left: Installation of detector tubes in the ARCS instrument.

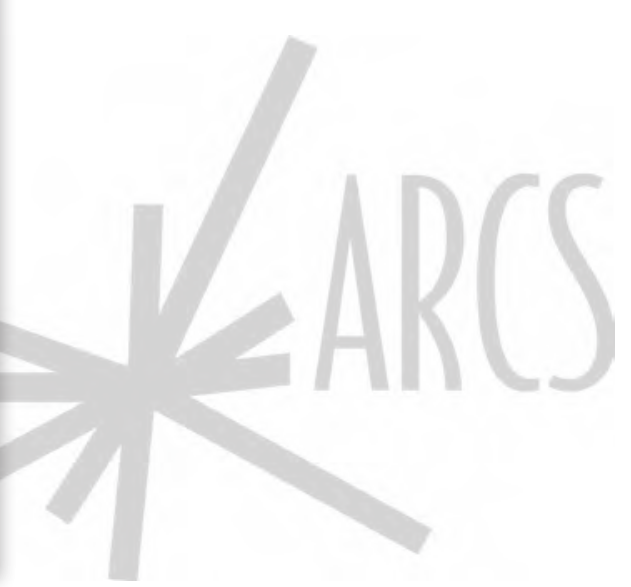




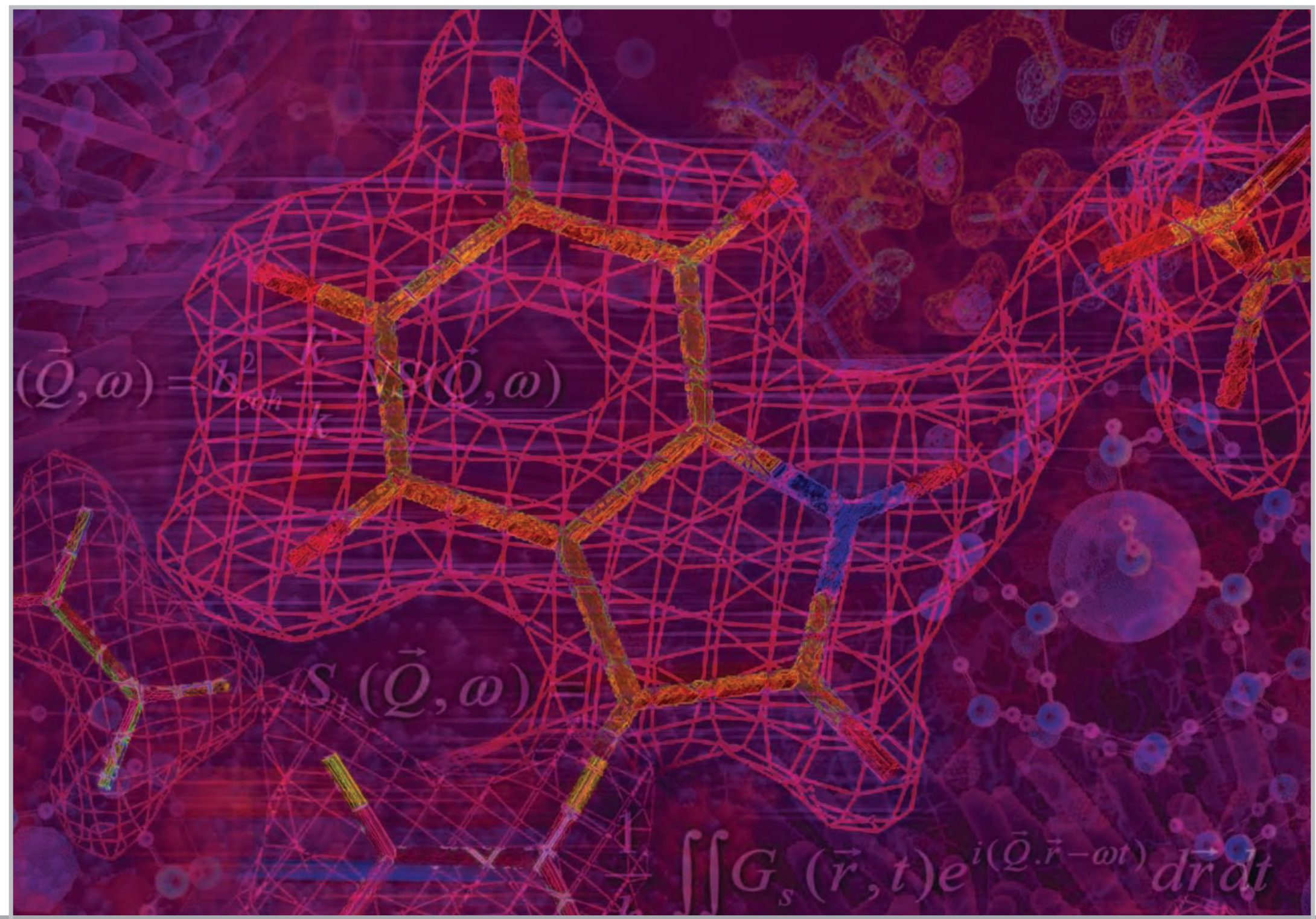

Science Highlights

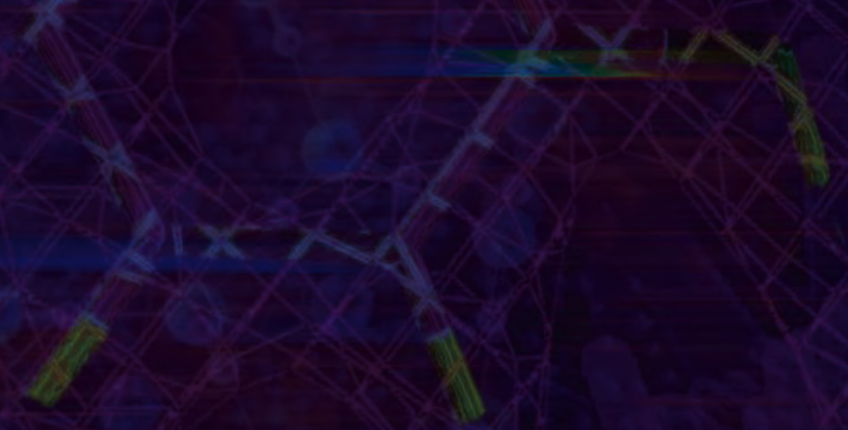




\section{from the Neutron Sc attering

It is a great pleasure to introduce the "Science Highlights" section of the first annual progress report for the ORNL Neutron Sciences Directorate. ORNL has a long tradition of excellence in neutron-related research, starting with the pioneering development of neutron diffraction by Ernest Wollan, Clifford Shull, and their colleagues. Even by these standards, the past year has been very special. HFIR has returned to operation after a long hiatus, initiating a new era of research with cold neutrons at ORNL. SNS has officially arrived as a worldclass pulsed neutron source, and neutron scattering experiments have begun on the first three instruments to enter the user program.

This year's selected science highlights offer a glimpse into a future full of robust and diverse forefront research. These are just the first baby steps for science in the new directorate, under

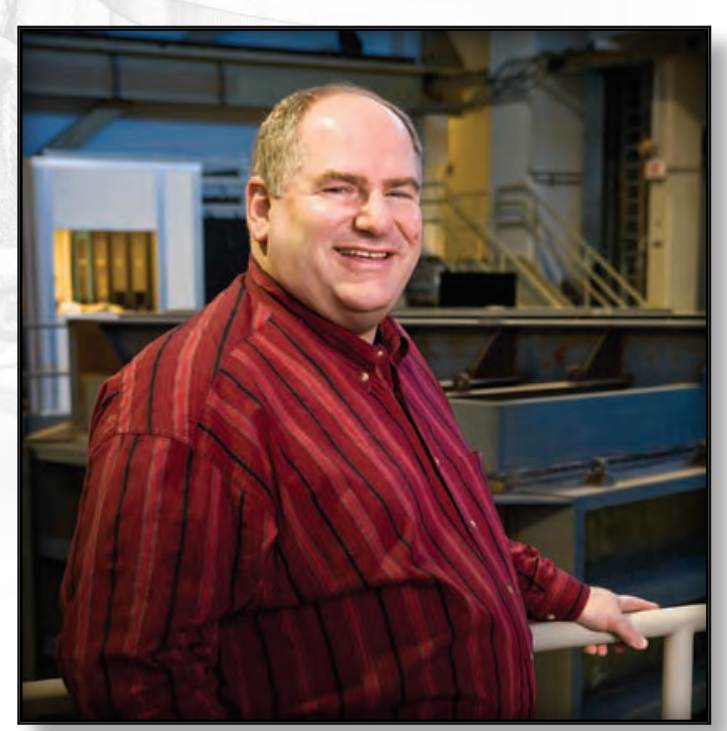

Stephen Nagler, Chief Scientist, Neutron Scattering Science Division (naglerse@ornl.gov) conditions of limited beam availability and instruments still in commissioning. Even so the results are exciting. At SNS, the dynamics of molecules tethered to a porous silica surface have been investigated using the Backscattering Spectrometer, BASIS. The results clearly illustrate this instrument's unprecedented combination of excellent energy resolution and large signal-to-background ratio. Some of the early measurements with the Liquids Reflectometer have shed light on the environmentally triggered behavior of polyelectrolyte multilayers, materials with possible widespread applications as "smart" coatings.
These measurements have resulted in the first peerreviewed publication of data from SNS.

At HFIR, the use of thermal beams for inelastic neutron spectroscopy has resumed and is represented here by an experiment on lattice dynamics in a colossal-magnetoresistive oxide material. The thermal beams have also been used to explore magnetic structures: neutron diffraction has been used to elucidate subtle magnetic correlations present in a fascinating new multiferroic material. New directions in in situ applied research are adumbrated by time-resolved diffraction measurements of ironcarbon alloys, simulating real-life processing in the presence of magnetic fields. Engineering applications of neutron diffraction are represented by a report on cracks induced by metal fatigue, a topic of great interest to the airline industry, among others. Finally, the first data have been taken using the new small-angle neutron scattering machines in the cold neutron guide hall. A fascinating study on the role of defects in high-performance ceramic materials is reported here: look for exciting highlights from these instruments in the near future!

As neutron sciences activity builds up over the next several years, we anticipate that highlights of some amazing science will appear in these pages. I hope that you, the reader, will be able to participate in the voyage of discovery that lies ahead. 


\section{Environmental Triggers for Smart Multilayer Coatings}

Polyelectrolyte multilayer (PEM) coatings have great potential for use in biosensors, drug delivery systems, antifogging or antireflection surfaces, devices for controlling nanochemical reactions, and regulators for the flow of solutions through microchannels. They will be even more valuable if researchers can develop "smart" PEM coatings that can respond to variations in the environment around them, such as temperature or pH changes. Designing PEMs with predictable, controllable responses is not yet possible, though, because the fundamental mechanisms of such environmental triggers are not fully understood. A more precise understanding of the fundamental mechanisms by which environmental changes trigger responses in PEMs could enable researchers to design PEMs whose responses can be manipulated for various applications.

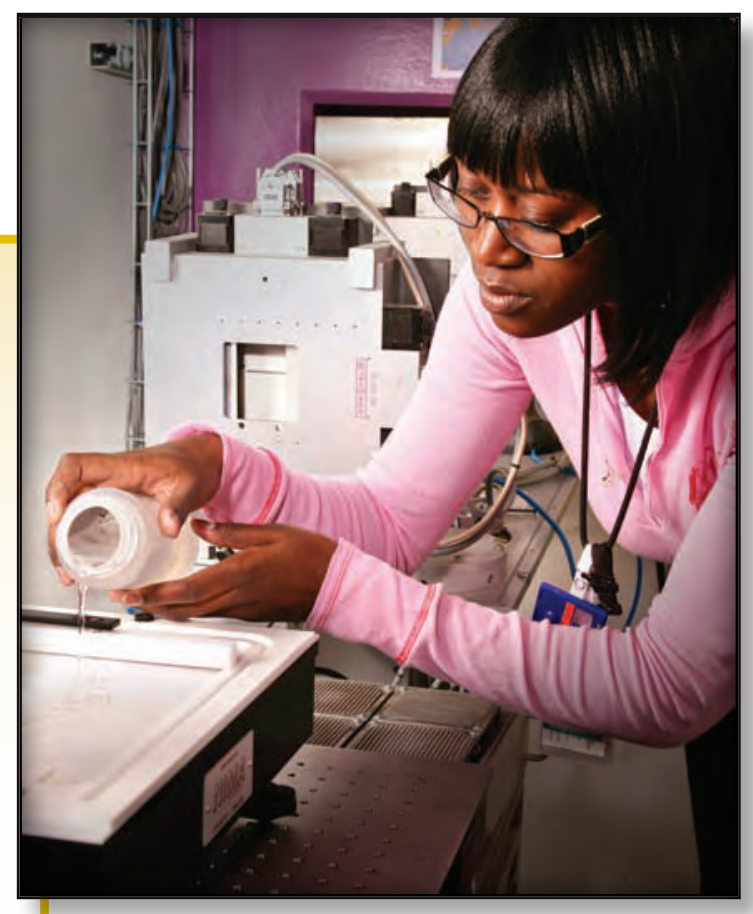

Candice Halbert, scientific associate for the Liquids Reflectometer, fills a Langmuir trough with water. The trough is essentially a Teflon pool used to form a flat surface for water. Neutrons are reflected from molecules spread on the surface.

PEM coatings can be prepared simply by immersing a substratesuch as a silicon wafer, glass

In a bid to expand understanding of how PEM coatings react to environmental changes, the Liquids Reflectometer at SNS is being used to study the effects of changes in the $\mathrm{pH}$ in the environment surrounding a PEM coating. The team-Eugenia Kharlampieva and Svetlana A. Sukhishvili of Stevens Institute of Technology, John Ankner of ORNL, and Michael Rubinstein of the University of North Carolina-Chapel Hill-is investigating the process by which polymer molecules in a coating are released and reabsorbed as the $\mathrm{pH}$ of a surrounding solution is increased and decreased. The results of this work are presented in the March 25, 2008, issue of Physical Review Letters. slide, or plastic sheet-alternately in positively and then negatively charged polyelectrolyte solutions. Weak PEM coatings respond to $\mathrm{pH}$ variation via an induced accumulation of excess charge within them. Consider that a molecule, or a functional group within a molecule, may lose or gain a proton when the molecule is placed in solution. The exact probability of this happening depends on the equilibrium constant for that reaction (the ratio of reactants to product) and the $\mathrm{pH}$ of the solution. If the $\mathrm{pH}$ of the solution changes while a weak polyacid or a polybase component of the multilayer coating is near its equilibrium constant, positive or negative charge is created within the PEM. This charge can be used to control the PEM, for example, to bind and release 
dyes or drugs or to fabricate novel, metal-containing inorganic nanocomposite materials.

As a result of $\mathrm{pH}$-induced electrostatic stress within the coating, PEM coatings swell and change shape in a discontinuous, or stepwise, manner. The $\mathrm{pH}$-induced variation of charge within PEM coatings also underlies the use of such coatings to control electroosmotic flow in microchannels (electroosmotic flow is a flow of ions in a solution through very narrow channels, caused by applying a voltage across the channels). Porous coatings can be produced from PEMs by varying the ionic strength and $\mathrm{pH}$ of the solution environment to which they are exposed. Recently, environmentally triggered changes in the morphologies of PEMs were used to produce coatings with controlled porosity for antireflection coatings.

Most other studies have considered situations in which $\mathrm{pH}$ variations do not result in the removal of material from the coatings, and the coatings remain compositionally stable. This research presents a different scenario in which coatings respond to $\mathrm{pH}$ variations by changing composition. The effort addresses the mechanism by which macromolecules in PEM coatings are released and reabsorbed in response to $\mathrm{pH}$ changes, with the emphasis on changes in the composition of the coating. Neutron reflectometry is used, which is the method of choice for elucidating the structure and function of such multilayer coatings.

One question the researchers are exploring is whether the polymer chains released by changes in $\mathrm{pH}$ are reabsorbed by the coating when the $\mathrm{pH}$ is returned to the initial value used during the self-assembly of the coating. The experiments show that the coating reabsorbs a large fraction of the polyacid released at high $\mathrm{pH}$ when the $\mathrm{pH}$ is lowered to its initial value. However, the amount of PMAA (polymethacrylic acid) reabsorbed is $20 \%$ smaller than the amount released when the $\mathrm{pH}$ changes. This incomplete reversibility is likely a result of sluggish kinetics due to the atomic reorganization required within the coating to accommodate the absorption of the polymer component.

Liquids Reflectometer.

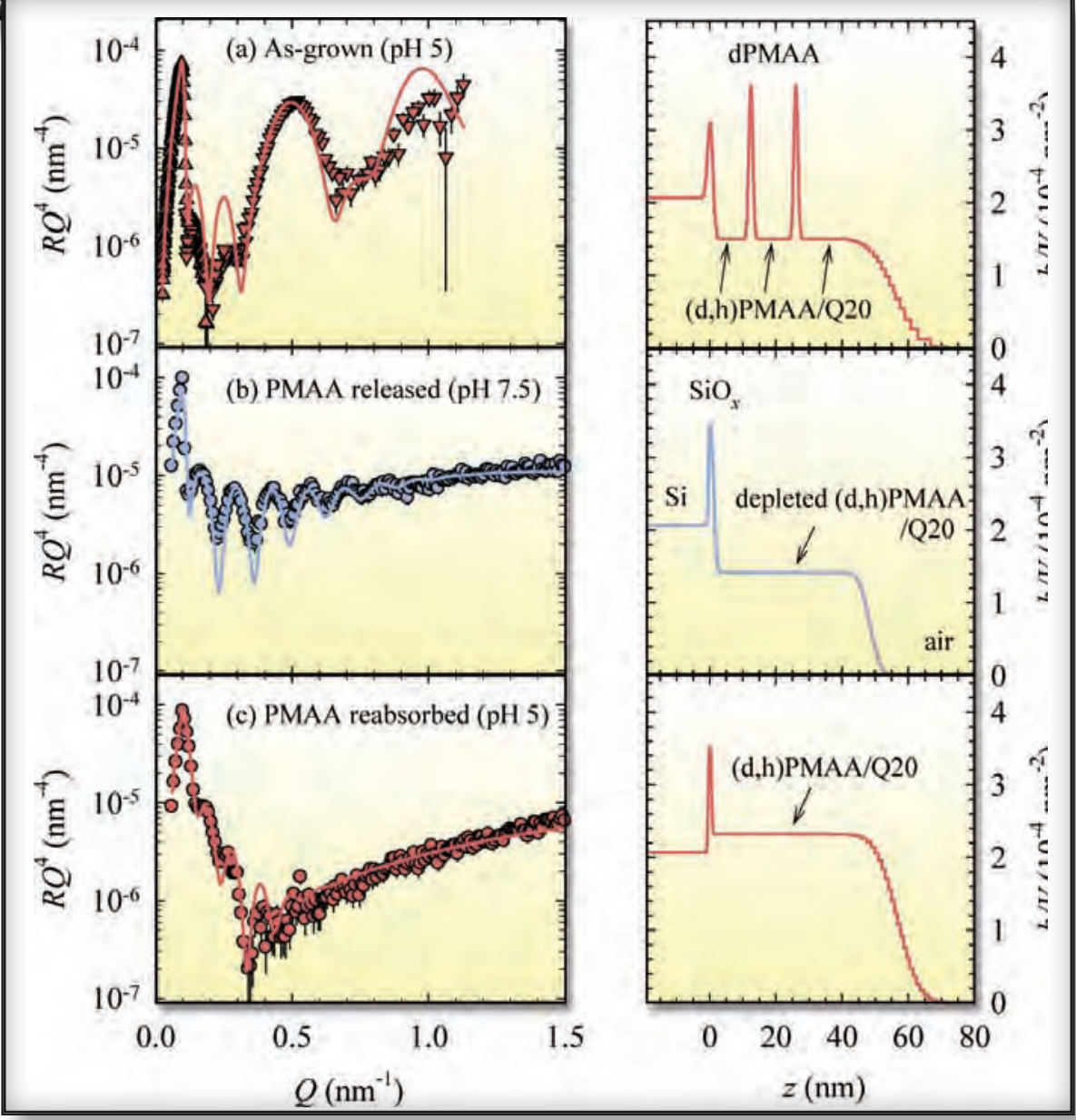

Scattering length density profiles for dry coatings. 

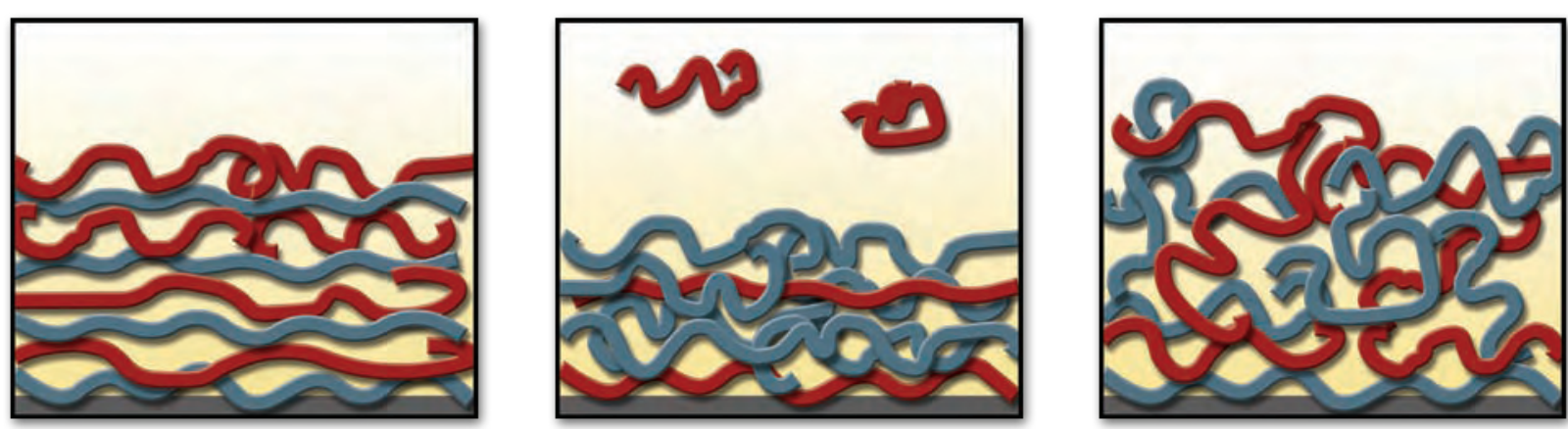

Visualization representing neutron reflectivity data obtained experimentally for dry coatings.

Finally, scientists want to know whether the $\mathrm{pH}^{-}$ triggered release of polymer chains affects the overall multilayer coating structure. The model coating consisted of 20 bilayers of PMAA and poly- 4 vinyl-pyridine (Q20) modified so that $20 \%$ of the monomers are positively charged in solution. Every fifth PMAA layer was deuterated (i.e., the hydrogen atoms were replaced by deuterium atoms to tailor the scattering contrast). Three samples were deposited under identical conditions and then dried for neutron measurements in air using the SNS Liquids Reflectometer and the NG-7 instrument at the $\mathrm{Na}^{-}$ tional Institute of Standards and Technology. All three samples were deposited on silicon substrates with 1 to $2 \mathrm{~nm}$ thick native oxide layers.

The data show that the regular multilayer structure completely disappears after a $\mathrm{pH}$-induced release of PMAA. An absence of diffraction peaks in the reflectivity profile reveals complete mixing of the Q20 and PMAA layers, and the reduced thickness of the polymer layer implies that $38 \%$ of the PMAA originally present in the as-deposited coating is released. After the $\mathrm{pH}$ returns to its original value of 5 , the coating reabsorbs all of the PMAA. The constant scattering-length-density profile of the coating after reabsorption implies that the PMAA is distributed uniformly; and the coating recovers its original thickness, implying that all of the PMAA is reabsorbed from solution. The reabsorbed material does not reconstitute the original arrangement of deuterated and protonated layers, so we cannot be certain of the organization of the reabsorbed layers.

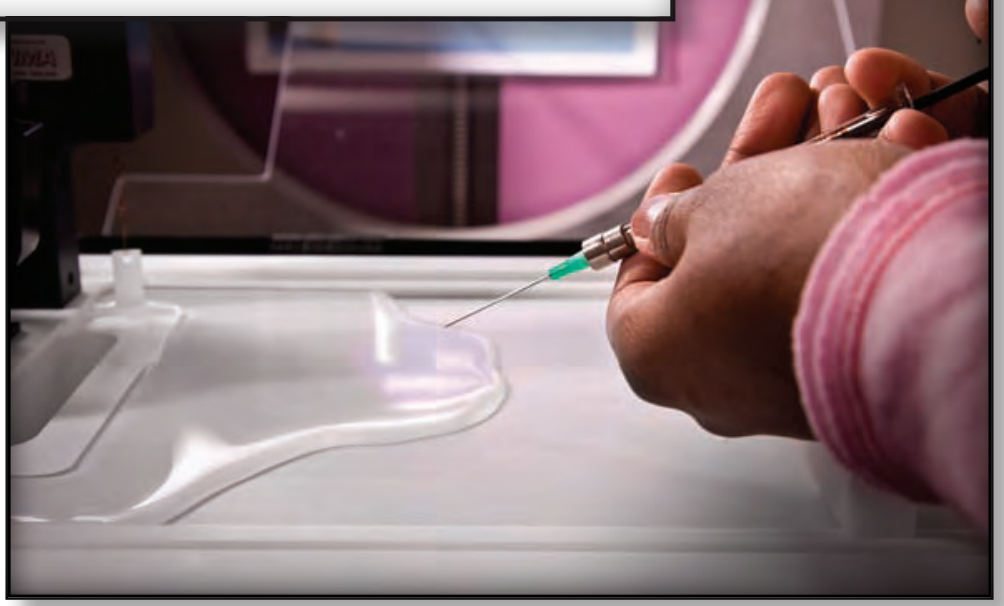

Emptying the Langmuir trough.

Most likely they form lamellar domains (thin plates) distributed randomly on the surface.

Both as-deposited and reabsorbed coatings exhibit rough surfaces; the released coating has a much smoother surface. The change from rough asdeposited surface, to smooth released surface, back to rough reabsorbed surface implies that surface roughness is controlled by electrostatic interactions intrinsic to the polymers themselves, rather than being irreversible surface damage.

Eugenia Kharlampieva, John F. Ankner, Michael Rubinstein, and Svetlana A. Sukhishvili, "pH-Induced Release of Polyanions from Multilayer Films," Physical Review Letters 85 (March 25, 2008).

Contact: John Ankner (anknerjf@ornl.gov) 


\section{Dyna mic s of Molecules Tethered to the Pore Surface of Porous Silic a}

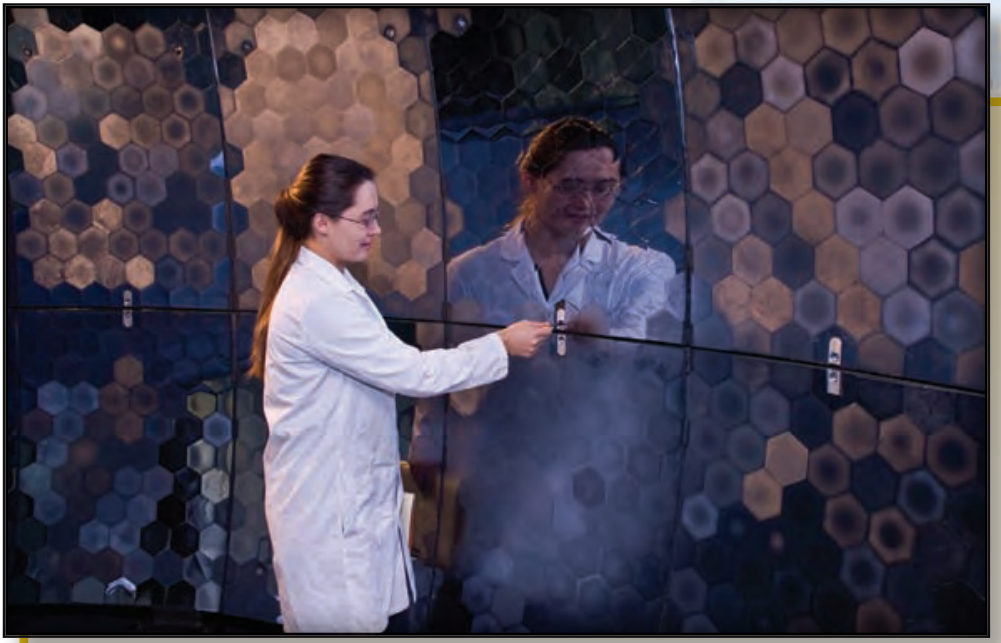

Inside the backscattering tank you can see the analyzer crystals (hexagonal Si(111) wafers)the "heart" of BASIS. Pictured is BASIS scientific associate Stephanie Hammons.

The interactions and transformations of organic molecules in the vicinity of solid interfaces form the foundation of many key technologies and fields of scientific inquiry, including catalysis, chemical sensing, and chemical separations. Investigation of the structure and dynamics at the organic-inorganic interface on the nanoscale is required to understand the physical basis of observable macroscopic phenomena such as reaction kinetics and product selectivity. A previous study reported the impact of pore confinement on both reaction kinetics and product selectivity during pyrolysis (heating in the absence of oxygen) for molecules of 1,3-diphenylpropane (DPP) immobilized by grafting to the interior pore surface of a porous silica, MCM-41. The focus of this study was to determine the influence of hydrogen bonding on molecular motion at this interface by comparing the dynamics of DPP and of phenethyl phenyl ether (PPE), in which one of the methylenes of DPP has been replaced by oxygen.
The near-backscattering spectrometer, BASIS, at SNS was used to measure the quasielastic neutron scattering from samples of DPP and PPE tethered to the interior pore surface of MCM-

41. The research was conducted by a team consisting of A. T. Ruffin of Fisk; M. K. Kidder, A. C. Buchanan, Phil Britt, and Ken Herwig of ORNL; and M. Zamponi of Institut für Festkörperforschung in Germany. Quasielastic neutron scattering is uniquely capable of simultaneously probing both the length and time scales of molecular motion. BASIS provides an unprecedented dynamic range of time scales that can be investigated from $\left\langle 10^{-12} \mathrm{~s}\right.$ to approximately $10^{-9} \mathrm{~s}$. The samples were prepared and characterized in the Chemical Sciences Division at ORNL. Both samples were prepared on MCM41 having pore diameters of $2.8 \mathrm{~nm}$ and surface areas of $913 \mathrm{~m}^{2} / \mathrm{g}$. The grafting density of the DPP sample was 0.84 molecules $/ \mathrm{nm}^{2}$, and that of the PPE sample was 1.17 molecules $/ \mathrm{nm}^{2}$. PPE-3 indicates that the location of the O-atom is farthest from the tether point. The samples were measured over a range of temperatures from 50 to $370 \mathrm{~K}$.

The figure at right shows the spectra collected on BASIS for the DPP sample at a temperature of $370 \mathrm{~K}$. The red solid lines are fits to the data for a model of a single Lorentzian line shape, along with an elastic response, both convoluted with the resolution function of the instrument. As is typi- 
cal, the resolution function was determined from a low-T ( 50 K) measurement where all diffusive motions were frozen out. A sloping background was also included in the fits. The half-width at halfmaximum of the Lorentzian component, $\Gamma$, clearly tends toward a finite value at momentum transfer, $\mathrm{Q}=0$, indicating the confined nature of the motion. As the molecules remain attached to the surface at all temperatures investigated in this study, they can explore only a restricted spatial volume.

In order to provide a physical context for a more quantitative description, a model previously employed to describe the motion of phospholipid tails and the alkyl chains of a liquid crystalline phase of dicopper tetrapalmitate was adapted for use here. In this model, each of the hydrogen atoms along the molecule backbone or alkyl chain is assumed to diffuse randomly, exploring the volume of a sphere of radius $r$. An analytic form for the dynamic structure factor, $S(Q, \omega)$ where $\omega$ is the energy transfer, is well known. In this adaptation, the radius of the sphere was taken to vary linearly with distance of the hydrogen atom from the tether point; and the diffusion constant, $D$, was taken to vary with the cube of the relevant

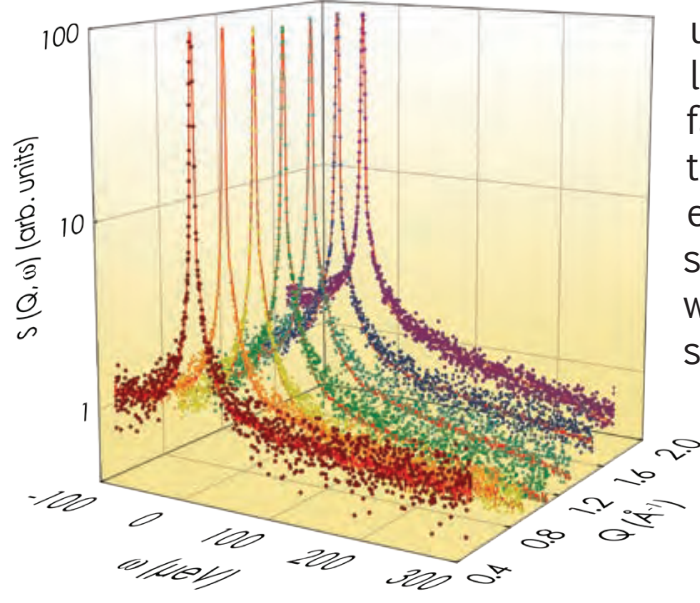
sphere radius. This allows atoms farther from the tether point to explore a larger spatial volume, while it is assumed that each hydrogen atom explores its sphere volume with the same

Spectra (colored circles) and fits (red solid lines) for the DPP sample at $370 \mathrm{~K}$.

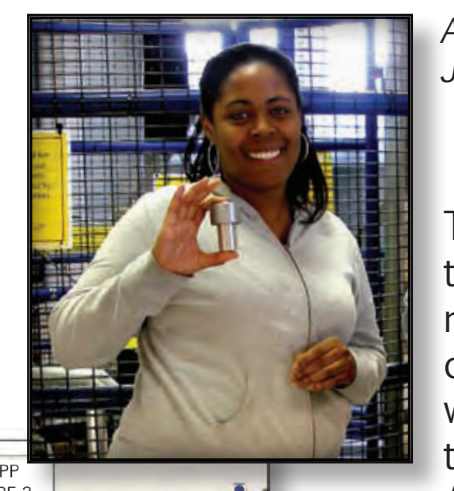

Ariel Ruffin, first user of BASIS, July 19, 2007.

The extracted parameters are then the maximum sphere radius, rmax, and diffusion constant, Dmax, associated with the hydrogen atom furthest from the tether point. Additional elastic intensity associated with hydrogen atoms immobile on the maximum time scale of this measurement and the substrate (MCM-41) was included. After the contribution from the MCM-41 was removed, the fraction of mobile molecules, fm, could be determined from the ratio of the intensity associated with the sphere diffusion model to the total scattering from either the DPP or PPE-3.

The DPP molecules clearly exhibit faster dynamics and explore larger spatial volumes than their PPE-3 counterparts, as seen in the lower two panels of the figure at left. At the lower temperatures of these measurements, a larger fraction of the DPP molecules are mobile as well.

It is interesting that there seems to be an asymptotic approach to unity for the DPP with a faster slope exhibited by the PPE-3 molecules. The difference in grafting density for the two samples may be responsible for some of the differing behavior illustrated in the figure; however, both of these samples are rather far from a typical saturation grafting density of $\sim 1.7$ molecules $/ \mathrm{nm}^{2}$, and the effects from packing density should not be dominant. The most likely explanation is that the additional hydrogen bonding interaction of the PPE-3 with either the surface or neighboring molecules results in the slower and more confined motion observed in this series of measurements. 


\section{Exploring Lattice Dynamics in CMR Manganites}

During the 1990s, some materials were discovered to have a property called "colossal magnetoresistance" (CMR) that causes them to dramatically change their level of electrical resistance under the influence of a magnetic field. Scientists were already familiar with materials capable of giant magnetoresistance, a change in resistance of $20 \%$ or so. But CMR materials can change by orders of magnitude, decreasing or increasing their resistance to electrical current by 1000 times or more as conditions change.

\section{CMR has been observed mostly in crystalline manganese oxides} called manganites. In these materials, there is a strong interplay between the magnetism, due to the electronic spins, and the electron transport. If the spins in the atoms in these materials are aligned in the same direction (as in a paramagnetic material), the resistance

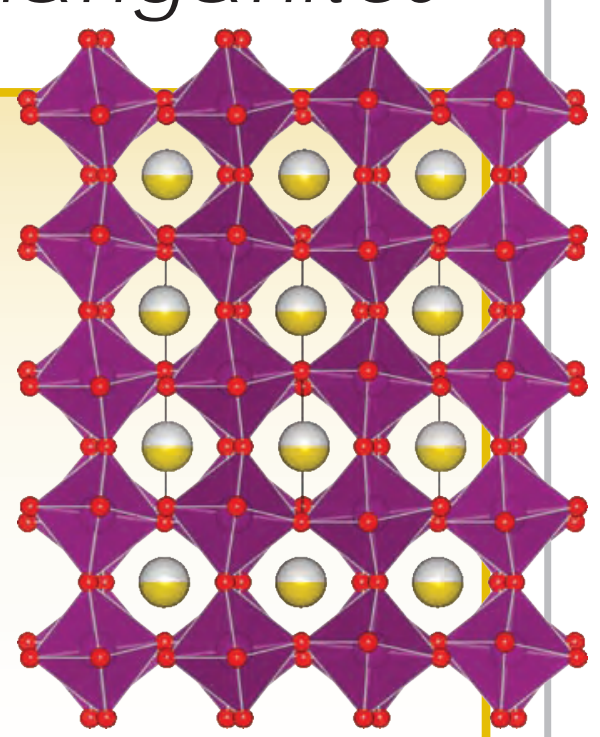

Structural drawing of perovskite-type oxide, one of the crystal phases for which researchers conducted inelastic neutron scattering. to electrical current is low and electrons can flow easily from atom to atom. If the spins are pointing in random directions, resistance is high (as in an antiferromagnetic material). In manganite crystals, the presence of a magnetic field at a threshold temperature can cause random spins to align and switch regions of higher resistance to low resistance - the CMR effect. The research discussed in this highlight describes how the lattice vibrations in CMR-related manganites change near the charge/ orbital ordered state.

A curious set of manganese-based crystalline materials called "colossal magnetoresistance" (CMR) manganites has attracted a lot of attention from materials researchers during the past decade because of their potential for use in electronics and computing applications (e.g., magnetic memory and electronic switches). These materials exhibit an enormous decrease in electrical resistance when an external high magnetic field is applied.

Researchers also are intrigued by the richness of the materials' physical properties, which arises from the competition of a multitude of electronic ground states that can lead to large responses to subtle changes in chemical doping (i.e., the intentional introduction of impurities), structural manipulation, or small changes in external stimuli such as magnetic fields. The fundamental physics behind these phenomena is related to the complexity arising from the interplay of electronic charge, spin, and orbital and crystal lattice degrees of freedom.

One of the ground states observed in CMR manganites is that in which the electric charges and as- 
sociated electronic orbitals form an ordered threedimensional pattern. The charge order/orbital order $(\mathrm{CO} / \mathrm{OO})$ in these materials is one of the most interesting collective phenomena in transition metal oxides. Although neutron scattering is not sensitive to the ordering of the charges or electronic orbitals in a material, it can easily detect the crystal lattice distortions associated with this ordering. In many cases, the $\mathrm{CO} / \mathrm{OO}$ transition is followed by a change to an antiferromagnetic state, in which the electron spins of neighboring atoms point in alternate directions in an ordered pattern.

Because of the strong interplay between different degrees of freedom in CMR manganites, researchers want to study how the lattice dynamics is affected by the CO/OO transition in these materials. To understand the effect on the lattice dynamics, Hao Sha and Jiandi Zhang of Florida International University have used the HB-3 Triple-Axis Spectrometer at HFIR to perform inelastic neutron scattering measurements on a single crystal of $\mathrm{Pr}_{065} \mathrm{Sr}_{035} \mathrm{MnO}_{3}$. This material exhibits a $\mathrm{CO} / \mathrm{OO}$ transition at a charge and orbital ordering temperature $\left(T_{C O}\right)$ of $230 \mathrm{~K}$ and an antiferromagnetic transition at $\mathrm{TN}=140 \mathrm{~K}$. (TN is Néel temperature, the temperature above which antiferromagnetic materials become disordered and cease to be antiferromagnetic.) The $\mathrm{Mn}^{3+}$ and $\mathrm{Mn}^{4+}$ ions and the Eg orbital of $\mathrm{Mn}^{3+}$ form the so-called CE-type order state below $\mathrm{T}_{\mathrm{CO}}$, which serves as the precursor state for the antiferromagnetic transition.

Sha and Zhang have observed a strong temperature ( $\mathrm{T}$ ) dependence of the Jahn-Teller (JT) active phonon modes across CO/OO transition temperature $T_{c o}$. The figure at right presents the T-dependent phonon spectra at the Brillouin zone center (G point) measured at the HB-3 spectrometer. Three bond-bending and bond-stretching modes of the $\mathrm{MnO}_{6}$ octahedra in the studied compound ap- pear in the measured energy range of the spectra. These preliminary measurements reveal well-defined phonon excitations at $\mathrm{E}=36,58$, and $74 \mathrm{meV}$ in the $\mathrm{CO} / \mathrm{OO}$ phase below $\mathrm{T}_{\mathrm{CO}}=230 \mathrm{~K}$, whereas these modes are severely broadened and damped above $\mathrm{T}_{\mathrm{CO}}$. 


\section{Proc essing Alloys Under High Magnetic Fields}

Materials scientists need to be able to see how alloys perform under the influence of high magnetic fields and high temperatures. However, previously, experiments have not been able to trace how materials react during actual simultaneous exposure to a magnetic field and high temperatures; instead, samples had to be examined after the conditions were no longer in force. In a breakthrough accomplishment for materials processing studies, researchers working at the Wide-Angle Neutron Diffractometer at HFIR designed and built a heater that can be inserted into a powerful magnet to expose samples to magnetic fields of 5 Tesla while temperatures are quickly ramped up to as high as $1200^{\circ} \mathrm{C}$. The research team used in situ neutron scattering to analyze how the microstructure of an iron-carbon alloy reacted to the influence of the magnetic field and elevated temperatures, validating previous theoretical studies.
The use of thermal-magnetic processing to manipulate alloy phase diagrams has great potential as a tool for developing the next generation of structural and functional materials. Applying a high magnetic field to an alloy alters the free energy in the material (i.e., the amount of energy that can be harnessed to do work). It also causes increases in the temperatures at which materials undergo phase transformation, or change from one state to another (i.e., solid to liquid, liquid to gas, etc.), and in the amount of a material that can be dissolved in a solvent.

A team of ORNL researchers is developing the capability to conduct neutron scattering at high magnetic fields and elevated temperatures to clarify the transformations that occur in materials when they are processed under those conditions. An interdisciplinary research team (Gerry Ludtka, Gail Mackiewicz-Ludtka, Cam Hubbard, John Wilgen, Roger Kisner, and Jaime Fernandez-Baca) is using the Wide-Angle Neutron Diffractometer (WAND) at HFIR to explore how processing alloy materials under high magnetic fields affects their behavior. 
(a)

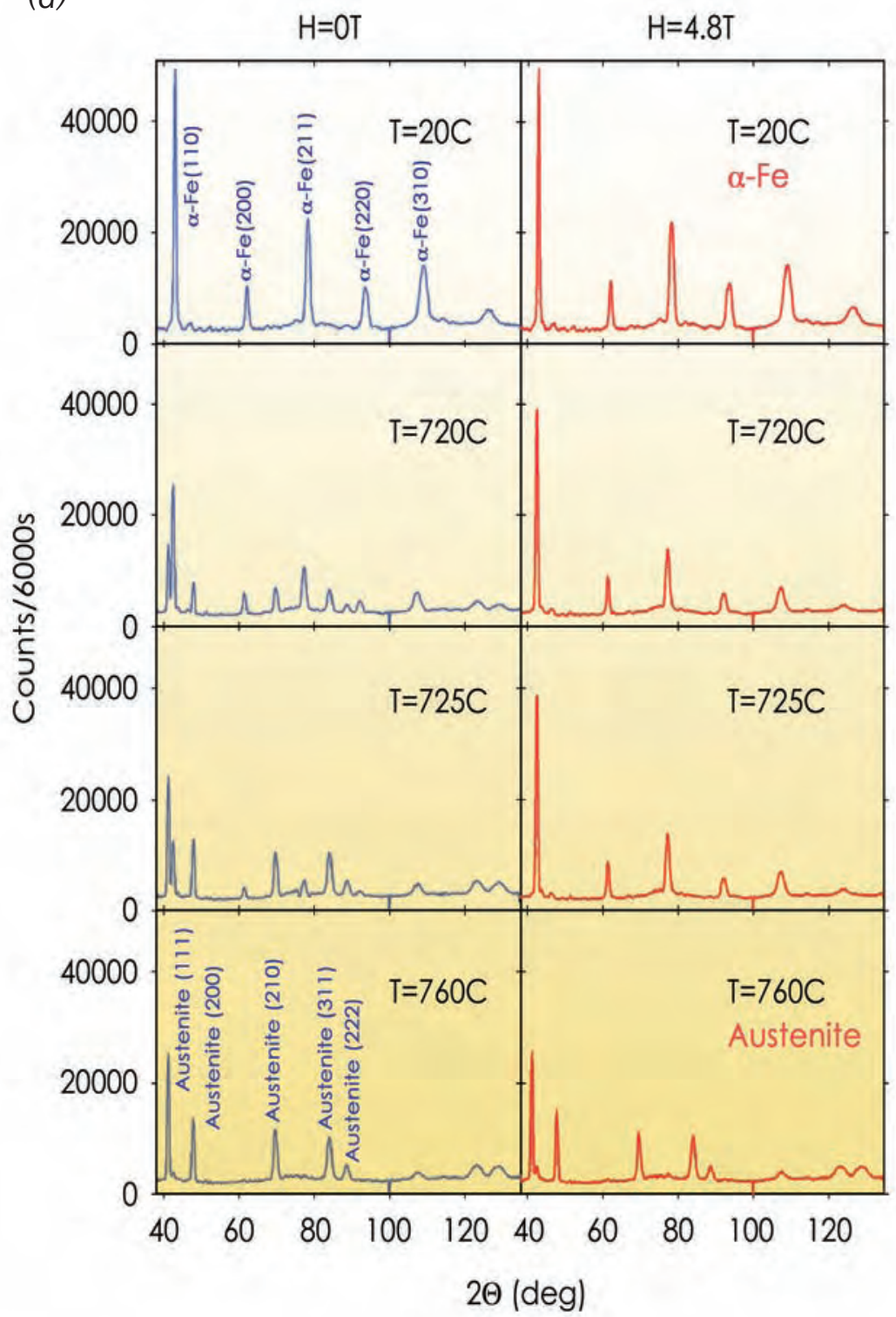

(b)

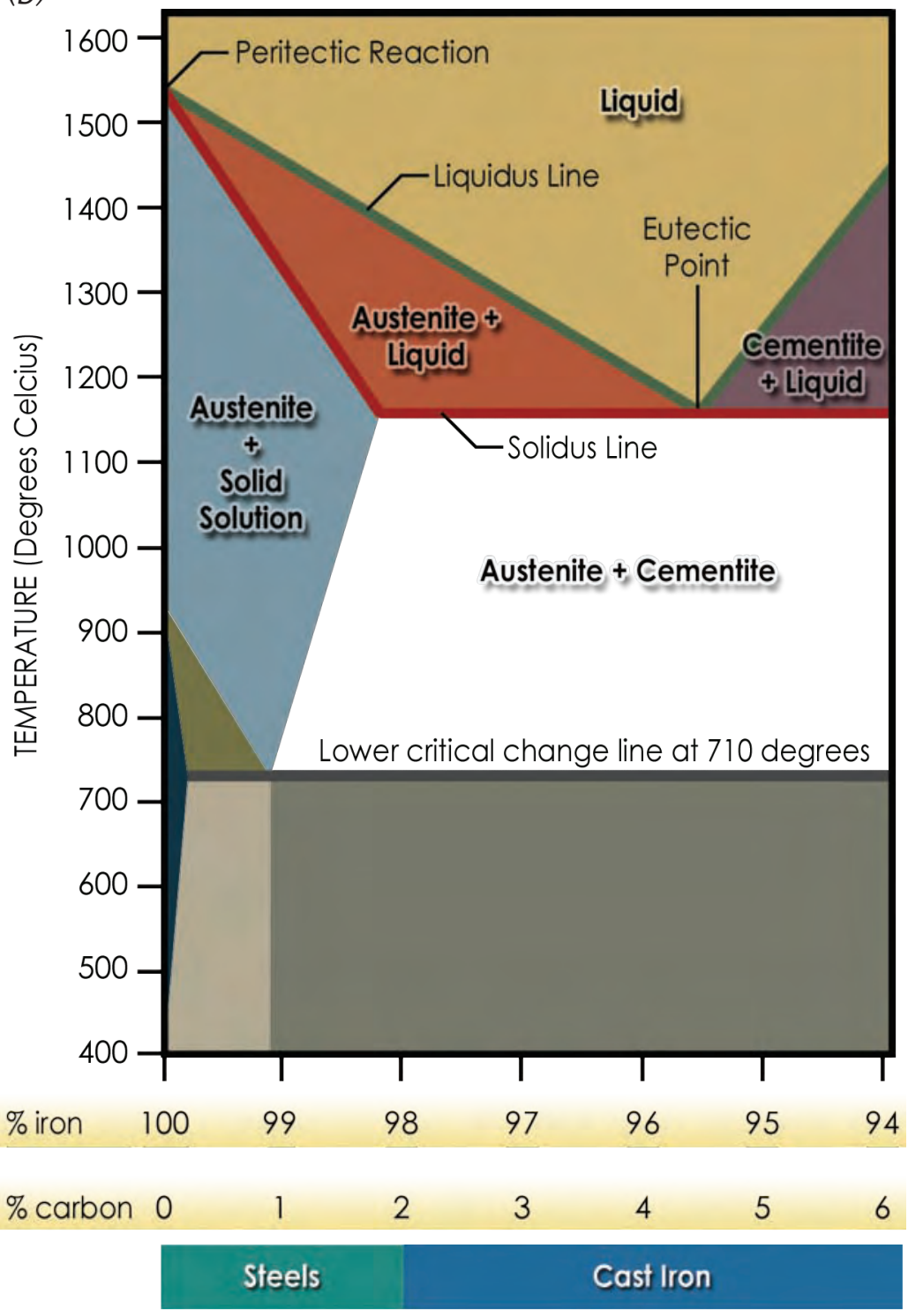

(c)

\begin{tabular}{|c|l|l|}
$\begin{array}{l}\text { Tempera- } \\
\text { ture } \\
\left({ }^{\circ} \mathrm{C}\right)\end{array}$ & $\begin{array}{l}\text { Phase(s) } \\
\text { present for } \\
H=0\end{array}$ & $\begin{array}{l}\text { Phase(s) } \\
\text { present for } \\
H=4.8 \mathrm{~T}\end{array}$ \\
\hline 25 & $\alpha$ & $\alpha$ \\
\hline 720 & $\alpha+\gamma$ & $\alpha$ \\
\hline 725 & $\alpha+\gamma$ & $\alpha$ \\
\hline 760 & $\gamma$ & $\gamma$ \\
\hline
\end{tabular}

Demonstration of in situ WAND neutron diffraction measurements on an ultrahigh purity $\mathrm{Fe}-0.75$ wt \% C binary alloy using the thermal magnetic insert. (a) Neutron powder diffraction patterns recorded for different in situ conditions. (b) Equilibrium phase diagram without applied magnetic field. (c) Table of observed phases. 
As a first step, the researchers designed and constructed an induction heater high-temperature insert for a 5-Tesla cryomagnet at HFIR. The insert provides a protective inert gas environment around the sample being studied and allows rapid temperature changes up to $1200^{\circ} \mathrm{C}$ at high magnetic fields. The insert system includes a programmable feedback temperature control system designed to meet the requirements for performing neutron scattering experiments.

Using this thermal magnetic system, the researchers used in situ, time-resolved neutron diffraction to measure the shift in equilibrium phase transformation temperatures that occur in an $\mathrm{Fe}-\mathrm{C}$ binary alloy when a high magnetic field is applied at elevated temperatures. The measurements were made using WAND, which enabled several diffraction peaks to be monitored simultaneously as the microstructure evolved under the influence of the external magnetic field.
HFIR experiments validate the predictions of theoretical calculations and substantiate prior research and development efforts at ORNL in this emerging research area of extreme sample environment science and technology.

These measurements (see page 25) showed that a 4.8-Tesla magnetic field $(\mathrm{H})$ stabilizes the roomtemperature $\alpha$-Fe phase of Fe-C to higher temperatures (see the $720^{\circ} \mathrm{C}$ and $725^{\circ} \mathrm{C}$ plots) than does the no-magnetic-field condition. Austenite $(\gamma-\mathrm{Fe})$ is normally the high-temperature stable phase for this $\mathrm{Fe}-\mathrm{C}$ binary alloy, as shown in the $760^{\circ} \mathrm{C}$ plots. $\alpha-\mathrm{Fe}$ and $\gamma$-Fe are two different phases in which the $\mathrm{Fe}$ atoms are arranged in a body-centered cubic or face-centered cubic structure, respectively.

Before this unique capability was established at $\mathrm{HFIR}$, the influence of high magnetic fields on phase equilibria had to be inferred from samples that were no longer under the applied field. Such measurements do not capture the microstructural evolution of the samples during the high magnetic field exposure. The breakthrough results from the 


\section{Three-Dimensional Magnetic Correlations in a Multiferroic Compound}

Ferromagnetism is the type of magnetism most people are familiar with-the type that makes refrigerator magnets stick. Ferromagnetism allows a material to be magnetized by exposure to a magnetic field and remain magnetized after it is removed from the field. Ferromagnetic materials are characterized by a particular type of order at the atomic level that causes the magnetic moments to line up in parallel, contributing to the magnetism. Ferroelectricity is the electrical analog to ferromagnetism in which, instead of a magnetic moment, an electric dipole moment is formed. The orientation of the dipoles of ferroelectric materials will switch direction in the presence of an electric field. Ferroelectric materials are important in applications such as energy storage devices, memory devices, telecommunication, and medical imaging systems.

\section{Multiferroic materials combine ferromagnetic and} ferroelectric properties. Such materials are rare and not well understood. Research indicates that the magnetic properties of multiferroics can be manipulated by applying an electric field and the electrical properties changed by applying a magnetic field. Scientists are intrigued by the potential for using multiferroics to create new types of multifunctional materials and devices.
Ferromagnetism and ferroelectricity are central issues for scientists investigating collective behavior in condensed matter systems, both because of the interesting physics they present and because of the technological innovations possible from exploiting the ferromagnetic or ferroelectric properties of materials. A combination of ferromagnetism and ferroelectricity in a single device is an intriguing avenue for new hi-tech applications. Indeed, there is a surge of interest in multiferroic materials, in which ferroelectric and magnetic order coexist.

To provide insight into multiferroic behavior, scientists at ORNL and the National Research Council of Canada ${ }^{1}$ have conducted neutron diffraction measurements of high-quality single crystals of the multiferroic material $\mathrm{LuFe}_{2} \mathrm{O}_{4}$ using the HB-1 Triple-Axis Spectrometer at HFIR and the N5 Triple-Axis Spectrometer at Chalk River Laboratories in Canada.

$\mathrm{LuFe}_{2} \mathrm{O}_{4}$ is an example of a new class of materials in which the origin of the observed ferroelectricity is subtle and complex. One of the contributing factors is the existence of so-called "charge order," where ions of possibly different charge valences are arranged in an ordered pattern in a crystal. In LuFe $\mathrm{O}_{4}$, for example, $\mathrm{Fe}^{2+}$ and $\mathrm{Fe}^{3+}$ ions are found in equal numbers at high temperatures but are randomly distributed. At temperatures below $320 \mathrm{~K}$, the $\mathrm{Fe}^{2+}$ and $\mathrm{Fe}^{3+}$ ions settle into a charge-ordered state leading to the formation of a ferroelectric polarization. In addition, dielectric 
constant measurements in $\mathrm{LuFe}_{2} \mathrm{O}_{4}$ under applied magnetic fields show a giant magnetocapacitance at room temperature. At $240 \mathrm{~K}$, magnetic order appears, along with a simultaneous anomaly in the electric polarization that indicates a coupling between the magnetic and ferroelectric degrees of freedom. To better understand the origin of the multiferroic behavior, it is essential to know the microscopic magnetic structure as a function of temperature and applied magnetic field. Neutron diffraction is the ideal technique for elucidating this structure.

In the figure at right, (a) shows the integrated intensity versus temperature for the $(1 / 3$ $1 / 3$ 0) magnetic peak as measured by neutron diffraction. These data clearly indicate two phase transitions, one at $240 \mathrm{~K}$ $\left(T_{N}\right)$ and another at $175 \mathrm{~K}$ $\left(T_{L}\right)$. The changes that occur at each of these transitions can be examined by comparing scans along the (1/3 1/3 L) direction, (c above), at various temperatures ( $L$ is the orientation of the crystal lattice plane). The scan at $280 \mathrm{~K}$ shows peaks at large values of $L$ with $1 / 2$ integer indices. These peaks are not magnetic and in accord with previous work are attributed to the onset of 3-dimensional (3D) charge order at $320 \mathrm{~K}$. Comparing the data at $220 \mathrm{~K}$ with those at $280 \mathrm{~K}$ (where there is no long-range magnetic order) shows new intensity appearing on peaks at integer and half-integer values of $L$, with the strongest enhancement at small $L$ values. Such enhanced scattering at small $L$ values is expected for scattering from the ordered magnetic moments of

$\mathrm{Fe}^{2+}$ and $\mathrm{Fe}^{3+}$. Thus the neutron scattering data demonstrate 3D magnetic correlations below $240 \mathrm{~K}$ in $\mathrm{LuFe}_{2} \mathrm{O}_{4}$.

A large number of reflections were measured at $220 \mathrm{~K}$ by scanning along the $(1 / 31 / 3 \mathrm{~L})$, $(2 / 32 / 3 L)$, and $(4 / 3$ $4 / 3$ L) directions to constrain models for the symmetry allowed spin configurations in $\mathrm{LuFe}_{2} \mathrm{O}_{4}$. Based on analysis of the data, the research team concluded that the spin configuration is described by a ferrimagnetic structure with an ordering wave vector $(1 / 31 / 30)$, with $1 / 2$-integer reflections occurring as a result of the charge ordering that decorates the lattice with differing magnetic moments on $\mathrm{Fe}^{2+}$ and $\mathrm{Fe}^{3+}$ sites with a periodicity of $(1 / 31 / 31 / 2)$. A model was fit to 58 observed reflections using two domain population factors, an overall scale factor, and a Debye-Waller factor yielding an overall reduced $\chi^{2}$ of 1.39 . The proposed magnetic structure shown on the following page has $2 / 3$ of the spins pointing in one direction and $1 / 3$ in the opposite direction.

Below $T_{L}$, profound changes occur in the magnetic scattering, as shown above. In particular, a component to the scattering builds up that is extremely 


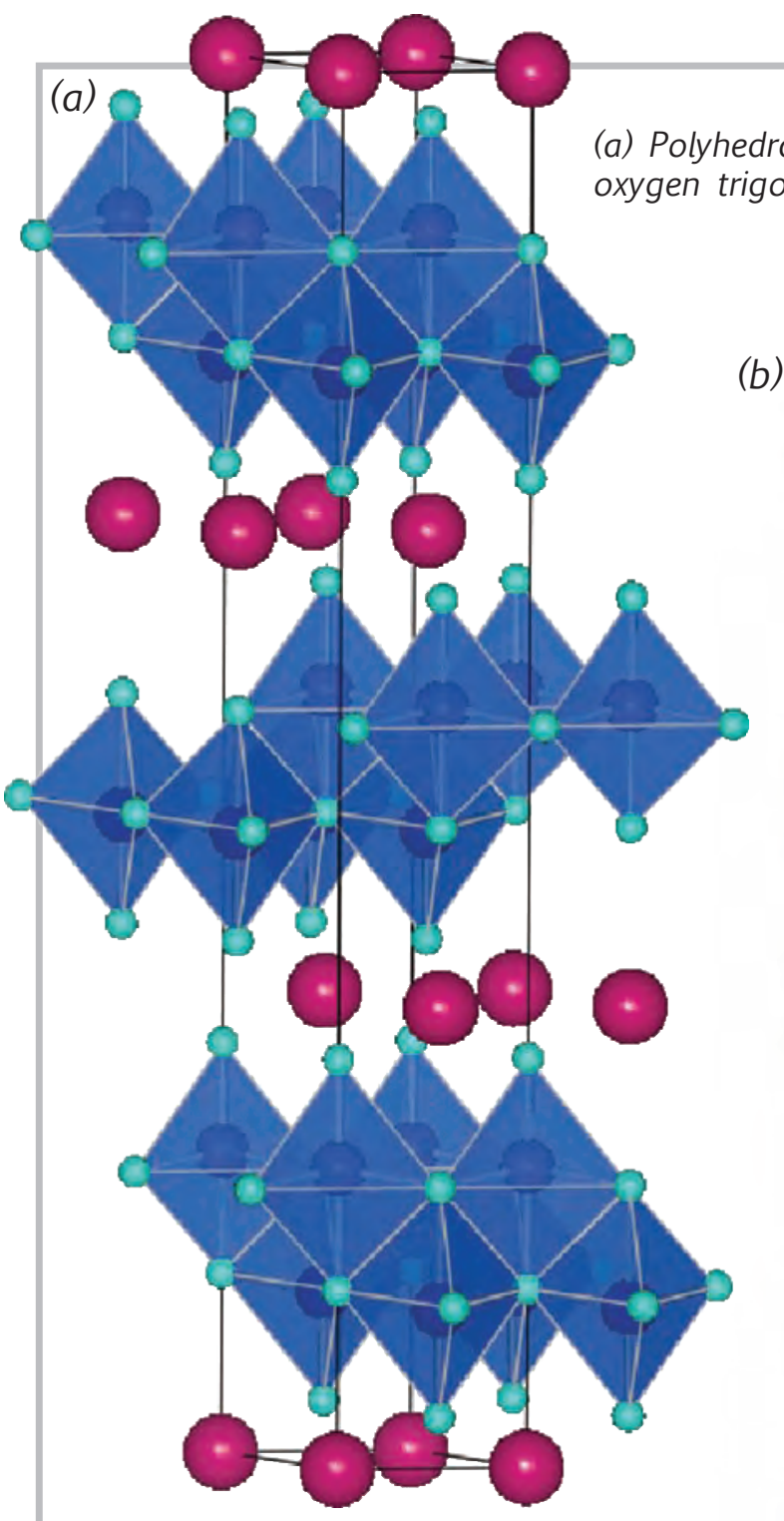

(a) Polyhedral crystal structure drawing showing the slabs of edge-sharing iron oxygen trigonal bipyramids. (b) Ferrimagnetic structure determined below $240 \mathrm{~K}$.

broad along (1/3 1/3 L) but sharp along $(\mathrm{HHO})$. Section (c) of the graph also shows that below $T_{L}$, significant changes occur in the magnetic peaks along $(1 / 31 / 3 \mathrm{~L})$. The intensity along $(1 / 31 / 3 \mathrm{~L})$ for magnetic reflections changes rather dramatically, with some peaks becoming more intense (e.g., $[1 / 3$ $1 / 31]$ ) and some becoming less intense (e.g., $[1 / 3$ $1 / 30]$ ). Thus 3D magnetic correlations persist below $T_{L}$, albeit with a shorter correlation length than found for $T_{N}$. Scans along (110) have revealed the existence of a new set of satellite peaks indexed as

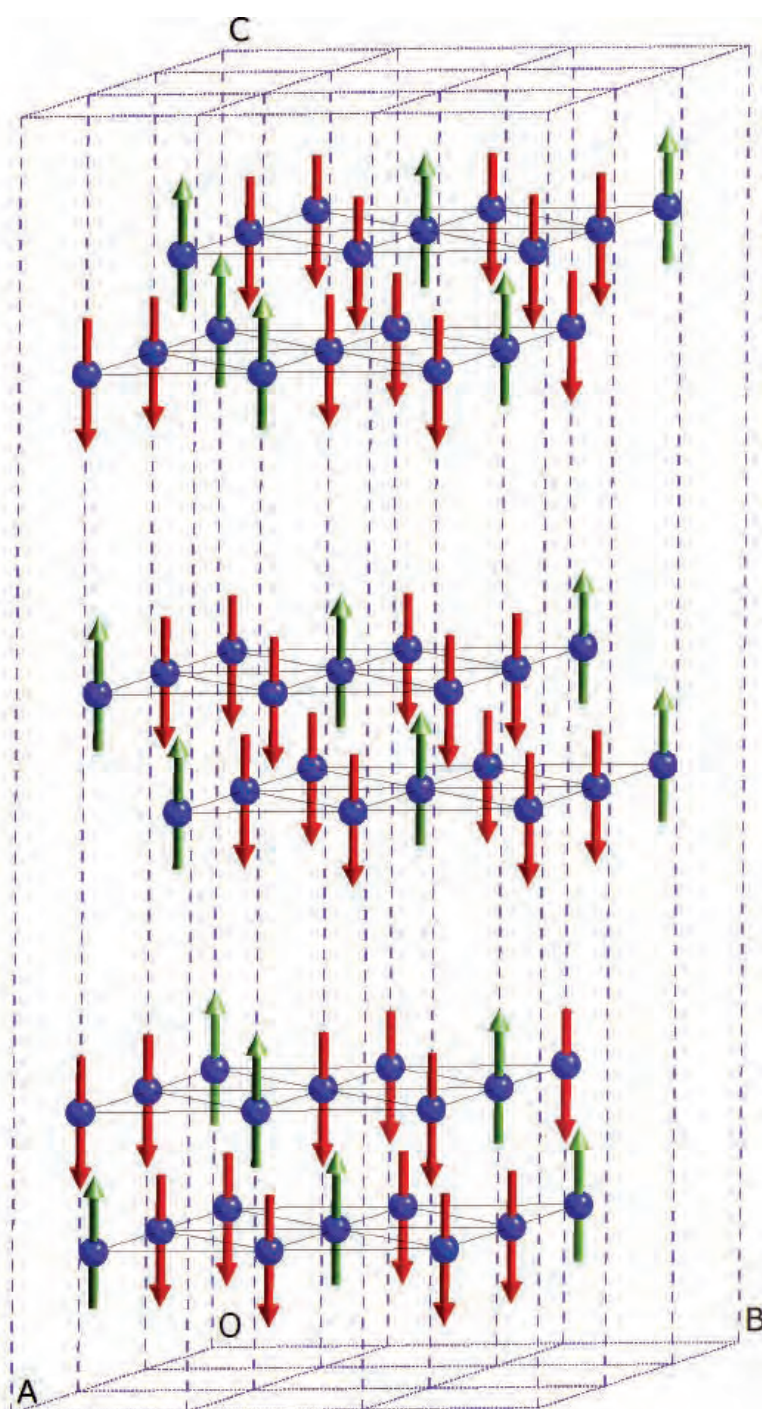

${ }^{1}$ A. D. Christianson, M. D. Lumsden, M. Angst, Z. Yamani, W. Tian, R. Jin, E. A. Payzant, S. E. Nagler, B. C. Sales, and D. Mandrus, "Three-dimensional magnetic correlations in multiferroic LeFe2O4," Physical Review Letters 100, 107601 (2008).

Contact: Andrew Christianson (christiansonad@ornl.gov)
$(1 / 3 \pm \delta 1 / 3 \pm \delta 3 \mathrm{~L} / 2)$ where $\delta \sim 0.027$ (part $b$ of graph) below $T_{L}$.

\section{These experiments have} demonstrated that $\mathrm{LuFe}_{2} \mathrm{O}_{4}$ has two transitions below $300 \mathrm{~K}$ that involve a 3D magnetically correlated structure with a finite correlation length along the c-axis. Below $T_{N}$ a ferrimagnetic spin configuration is found with a magnetic propagation vector of $(1 / 31 / 30)$ with magnetic intensity occurring at $(1 / 3$ $1 / 3 L$ ), where $L$ is a half integer arising as a result of the charge ordering at $320 \mathrm{~K}$.

Theoretical models that account for the 3D nature of the magnetic interactions and the sequence of magnetic phase transitions described should provide additional insight into the multiferroic behavior of LuFe $_{2} \mathrm{O}_{4}$. 


\section{Probing Crack Growth Retardation During Cyclic Loading}

The aircraft industry leads the effort to understand and predict the growth of cracks caused by cyclic fatigue (on-and-off stress) in materials. Aircraft makers have developed a fail-safe design approach, by which a component is designed so that if a crack forms, it will not grow to a critical size between specified inspection intervals. If the crack growth rate characteristics of materials are known and all components are inspected regularly, a cracked component may be kept in service for an extended useful life.

New materials with improved crack resistance can be designed once an understanding of the damage mechanisms is established. Two poorly understood issues are the overload effect and crack closure behavior in structural materials subjected to cyclic fatigue loading. Advances in fundamental understanding of the

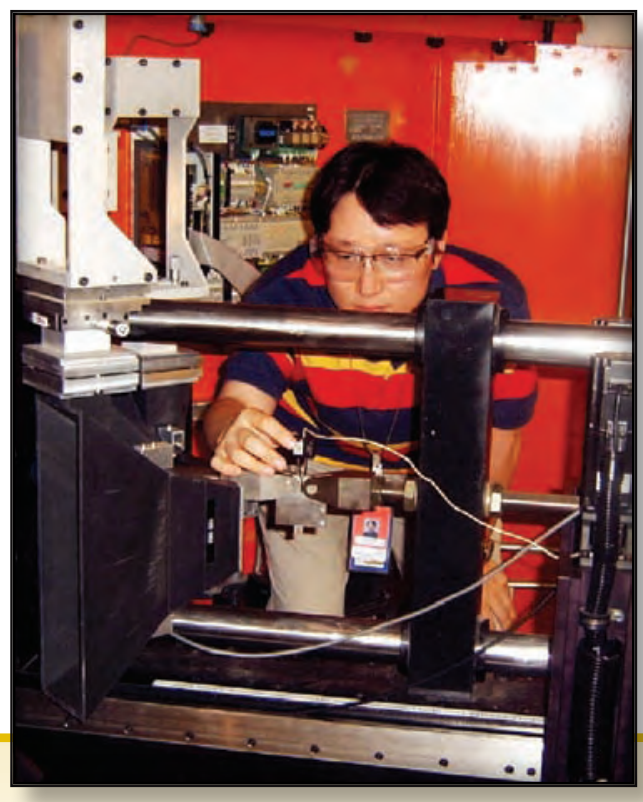

overload effect (a sudden increase in the load in the cyclic mechanical loading pattern) and the crack closure mechanism (responsible for changes in the fatigue crack growth rate) are valuable in enhancing capabilities to predict material lifetimes and improving safety models, and they help improve designs for critical applications subjected to random loading.

Cyclic fatigue is one of the most frequent causes of failure in structures and machinery. In cyclic fatigue, damage to a material accumulates not necessarily because of a heavy load but because of a dynamic load, one that stresses and then releases or waxes and wanes constantly over a prolonged period of time. Any type of machine, vehicle, or structure that stops and starts repeatedly or flexes constantly is subject to cyclic fatigue; aircraft are a prime example. Fatigued constituent materials become more damaged with each load cycle and eventually may wear out and fail if not repaired or replaced. A cyclic load may cause failure in a material that could withstand a heavier static load. In a material under cyclic fatigue, the damage typically begins as a crack on the surface, often at a point where the stress is high. The crack grows slightly every time the load is applied until the material finally fractures. 
and crack retardation has not been quantitatively established. Using the NRSF2 Engineering Neutron Diffractometer at HFIR, a team of scientists recently used neutron diffraction to probe the crack closure phenomena after an overload during fatigue crack growth. Because neutrons penetrate deeply into the interior of a component, they enable the study of bulk crack closure behavior rather than only the surface crack closure phenomena that can be observed using strain gauges. Moreover, the NRSF2 measured the changes in internal strains in situ under the applied load using a load frame as a function of the distance from the fatigue crack tip.

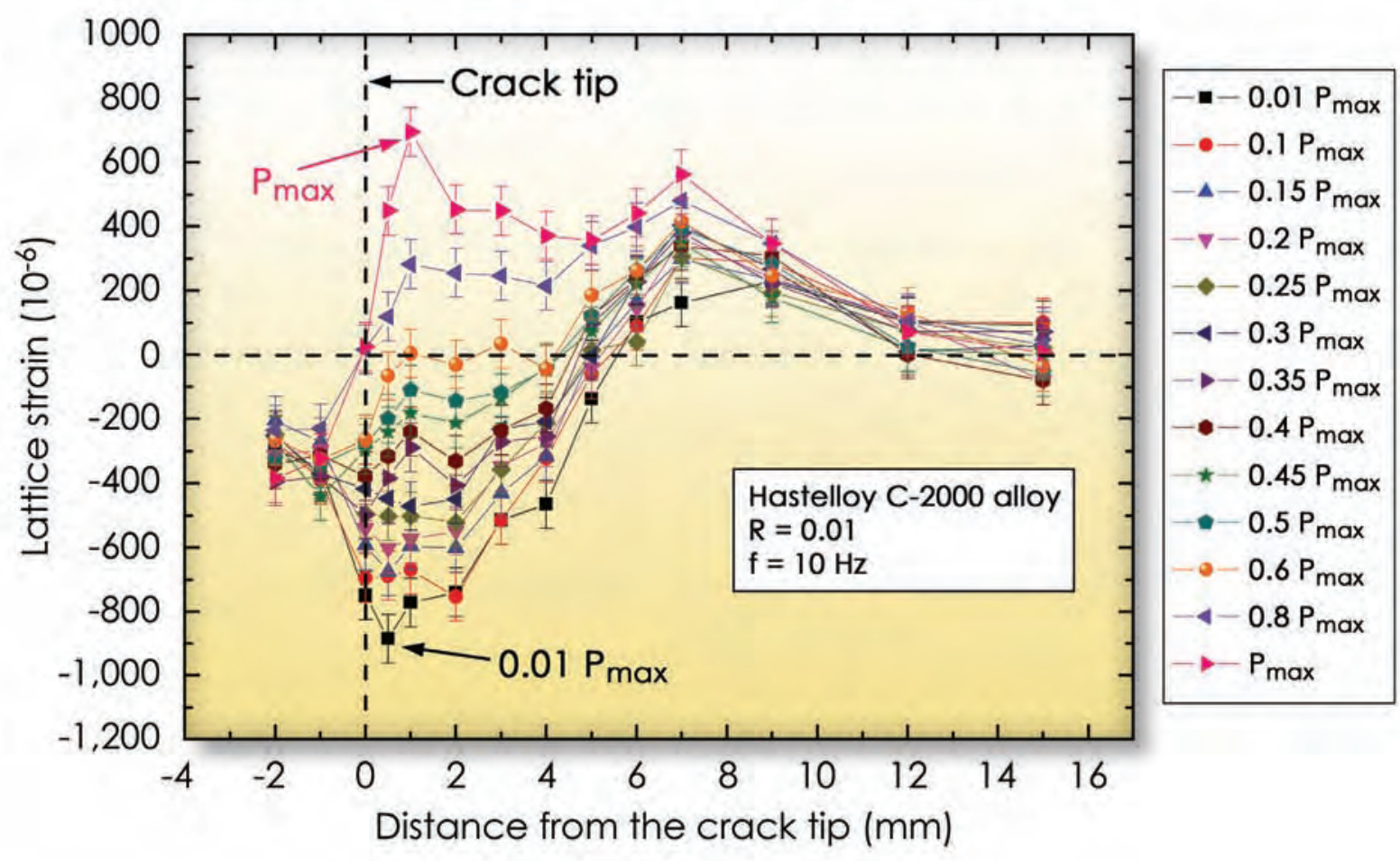

Evolution of internal lattice strains when the applied load is increased right after overload during fatigue crack growth.

The internal strain evolutions were investigated while the applied load was increased near a crack tip after overload (see graph above). After a single tensile overload was imposed following a period of cyclic loading, large compressive strains were observed within $\pm 5 \mathrm{~mm}$ near the crack tip. At $0.5 \mathrm{~mm}$ in front of the crack tip, the largest compressive strain of $-880 \mu \varepsilon$ (microstrain) was examined. As the distance from the crack tip increased, the strain changed from compressive to tensile. The maximum tensile strain was observed about $9 \mathrm{~mm}$ ahead of the crack tip. As the applied load increased, strains behind the crack tip did not change much, whereas strains in front of the tip evolved as the applied load increased. When $0.6 \mathrm{P}_{\max }(60 \%$ of maximum load) was applied, the compressive strains ahead of a crack tip disappeared and became zero. This load value corresponds to the crack opening load. As the load increased from $0.6 \mathrm{P}_{\max }$ to $\mathrm{P}_{\max }$, strain gradually increased, especially at the region in front of the crack tip. At $P_{\max }$, the maximum tensile strain of $700 \mu \varepsilon$ was observed $1 \mathrm{~mm}$ ahead of the crack tip.

From this combined in situ loading and spatially resolved strain scanning measurement, bulk internal strains were successfully measured as a function of the applied load, which allowed the researchers to determine the crack opening level at different stages of fatigue crack growth. The results will help establish the relationship between effective crack-tip driving force and crack growth rate.

Contact: Cam Hubbard (hubbardcr@ornl.gov) 


\section{Correlating Defects with Thermal Conductivity in Crysta lline Ceramics}

In nonmetallic materials such as ceramics, heat is transmitted via lattice vibrations; that is, the energy from a heat source causes nearby atoms to vibrate, in turn causing other surrounding atoms to vibrate. The vibrations propagate through the lattice of atoms in quantized waves called "phonons." The thermal conductivity in a ceramic material is degraded as the phonons scatter off tiny defects or irregularities in the structure of the material. J ust as rocks or other obstructions in a stream slow the flow of the water, so defects in a ceramic material slow the progress of the phonons by deflecting the waves. This process, called "phonon defect scattering," causes the thermal conductivity of ceramic materials to become highly degraded under neutron irradiation. Such degradation can have a great negative impact on the performance of some ceramics, such as those used in reactors where they are frequently bombarded with neutrons. However, a better understanding of the scattering process could help scientists tailor the thermal conductivity of thermoelectric materials to improve their performance.

The way quantized waves of thermal energy, or phonons, bounce off defects (or scatter) in ceramic materials is important because it affects how quickly and evenly heat is transferred through the material. A theoretical understanding of the scattering process could enable materials scientists to manipulate defects in ceramics to tailor their thermal conductivity for specific applications. To date, though, researchers have not been able to experimentally validate a description of the phenomenon of phonon defect scattering in ceramics.

Recently, however, a theoretical approach was developed to quantify the strength of phonon scattering associated with each individual defect in a ceramic sample, such as vacancies, vacancy clusters, anti-site defects, and extended defects (e.g., loops and voids). Lance Snead and Ken Littrell of
ORNL are leading an effort to validate this theoretical treatment through irradiation and characterization of highly pure, crystalline silicon carbide ( $\mathrm{SiC}$ ) samples. These model materials have been irradiated in the flux trap position of HFIR, and the resulting microstructure has been analyzed by high-resolution transmission electron microscopy (TEM) and HFIR's new general-purpose small-angle neutron scattering (SANS) instrument (SANS1).

The experiments show that after neutron irradiation, significant swelling of the sample material occurs, which is attributed to the temperature-dependent formation of interstitials and interstitial clusters. The result is a dramatic reduction in the thermal conductivity of the material. Because the theoretical treatment of phonon transport requires an accurate definition of the types of defects present in the ma- 
terial, their sizes, and their number density, these characteristics were quantified for irradiated $\mathrm{SiC}$ samples. The figure below gives a compilation image of the temperature and dose dependence of the microstructure of the sample as determined using high-resolution TEM. This image clearly indicates that defects larger than $3 \mathrm{~nm}$ include vacancy clusters, Frank loops, and dislocation networks. Although these defects are abundant, they do not come close to accounting for the amount of swelling or degradation in thermal conductivity measured; this indicates that the primary defects responsible for these property changes are less than $3 \mathrm{~nm}$ in size. The most likely candidates are vacancies, small vacancy clusters, or anti-site defects (e.g., a carbon atom on a silicon sub-lattice site).

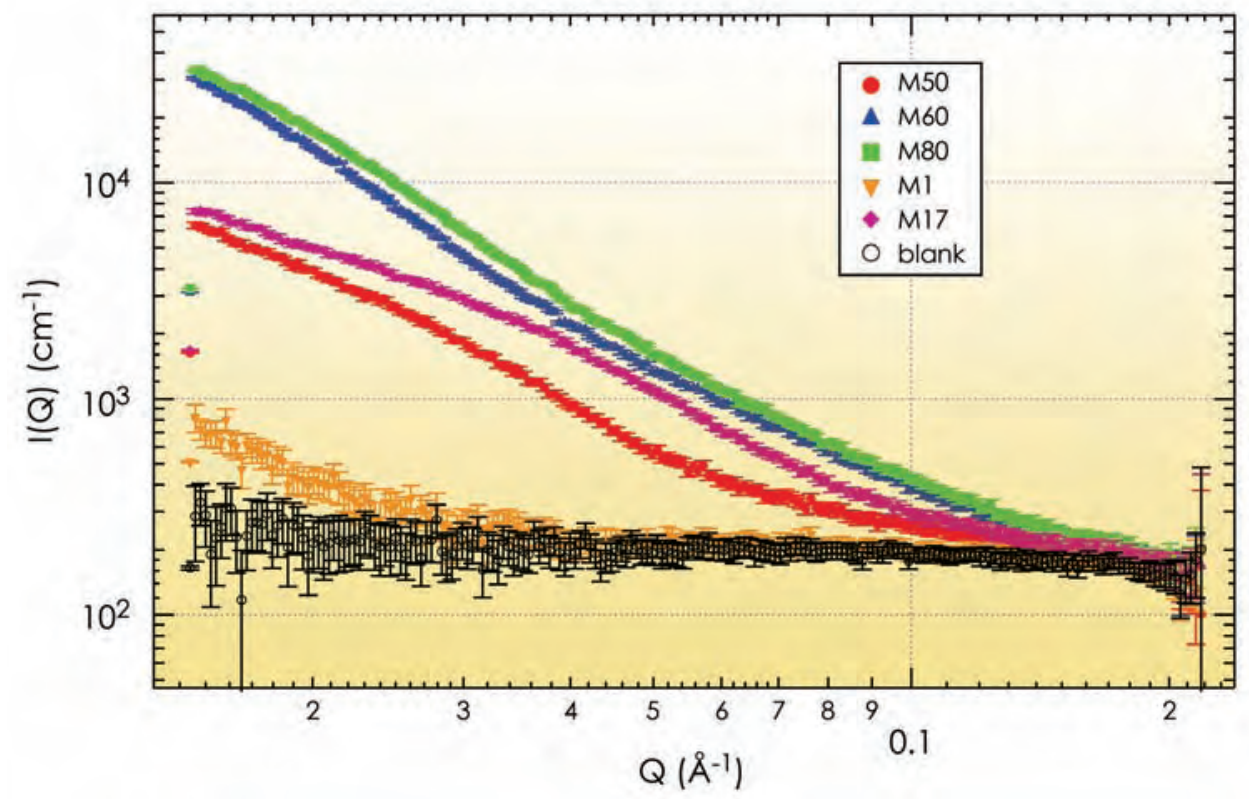

Small-angle scattering data from irradiated SiC samples. These data show structural defects increasing in size as the irradiation dose increases.

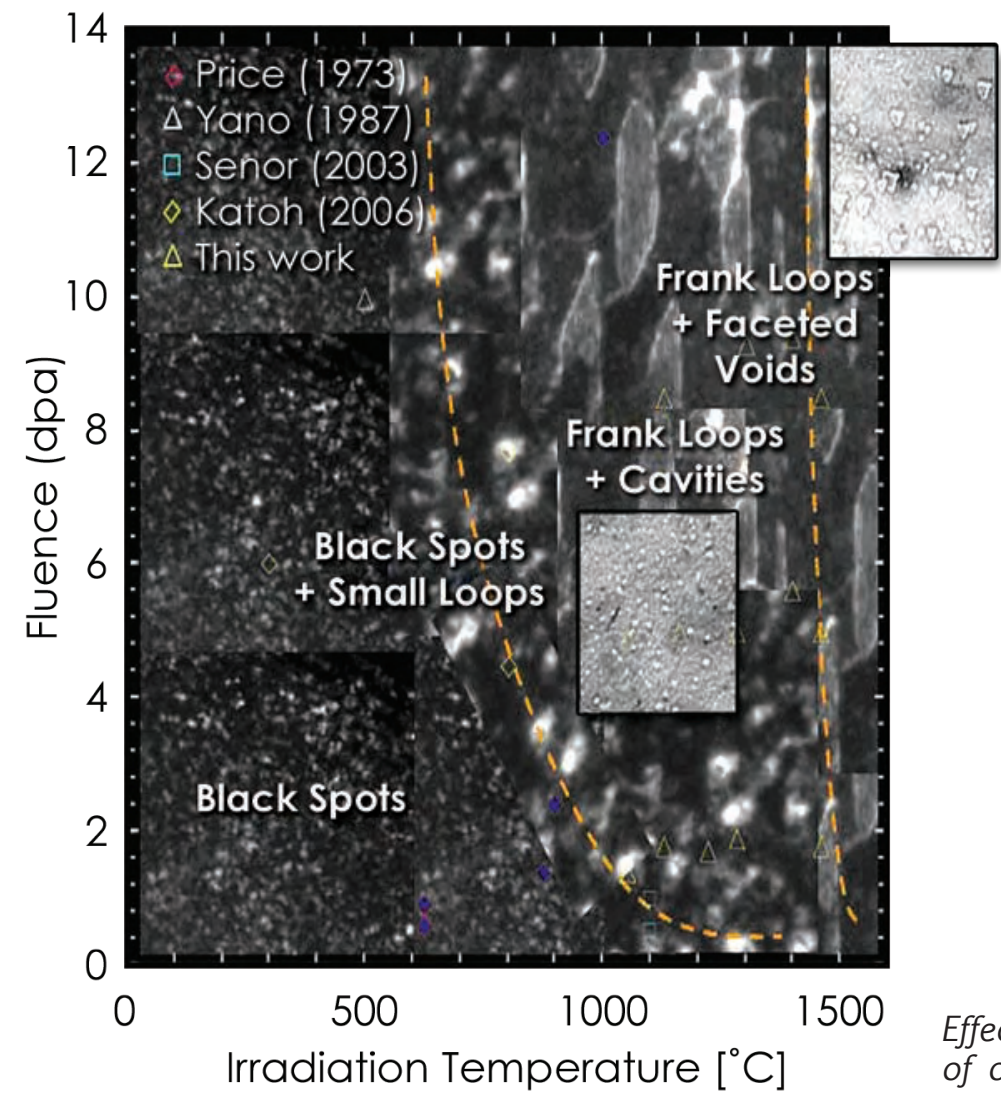

Characterization of the defect structure at the lower limit of TEM resolution is being carried out with SANS1. In this first step, SANS1 is being used to confirm what can be directly observed by TEM; the final objective is characterizing defects currently invisible to TEM. The measured scattering curves are shown above. The sample irradiated to the highest dose at the lowest irradiation temperature (M1, 8 displacements per atom or dpa, $1064^{\circ} \mathrm{C}$,) was essentially indistinguishable from an empty holder at the length scales measured.

However, for a higher irradiation temperature at the same dose $\left(\mathrm{M} 17,8 \mathrm{dpa}, 1267^{\circ} \mathrm{C}\right)$, there are hints of something large at low Q. This becomes even clearer in the sample irradiated near the highest irradiation temperature of this study (M50, $2 \mathrm{dpa}, 1500^{\circ} \mathrm{C}$ ). A modified Guinier analysis indicates the presence of rodlike structures (see page 34 ). This result sup- 

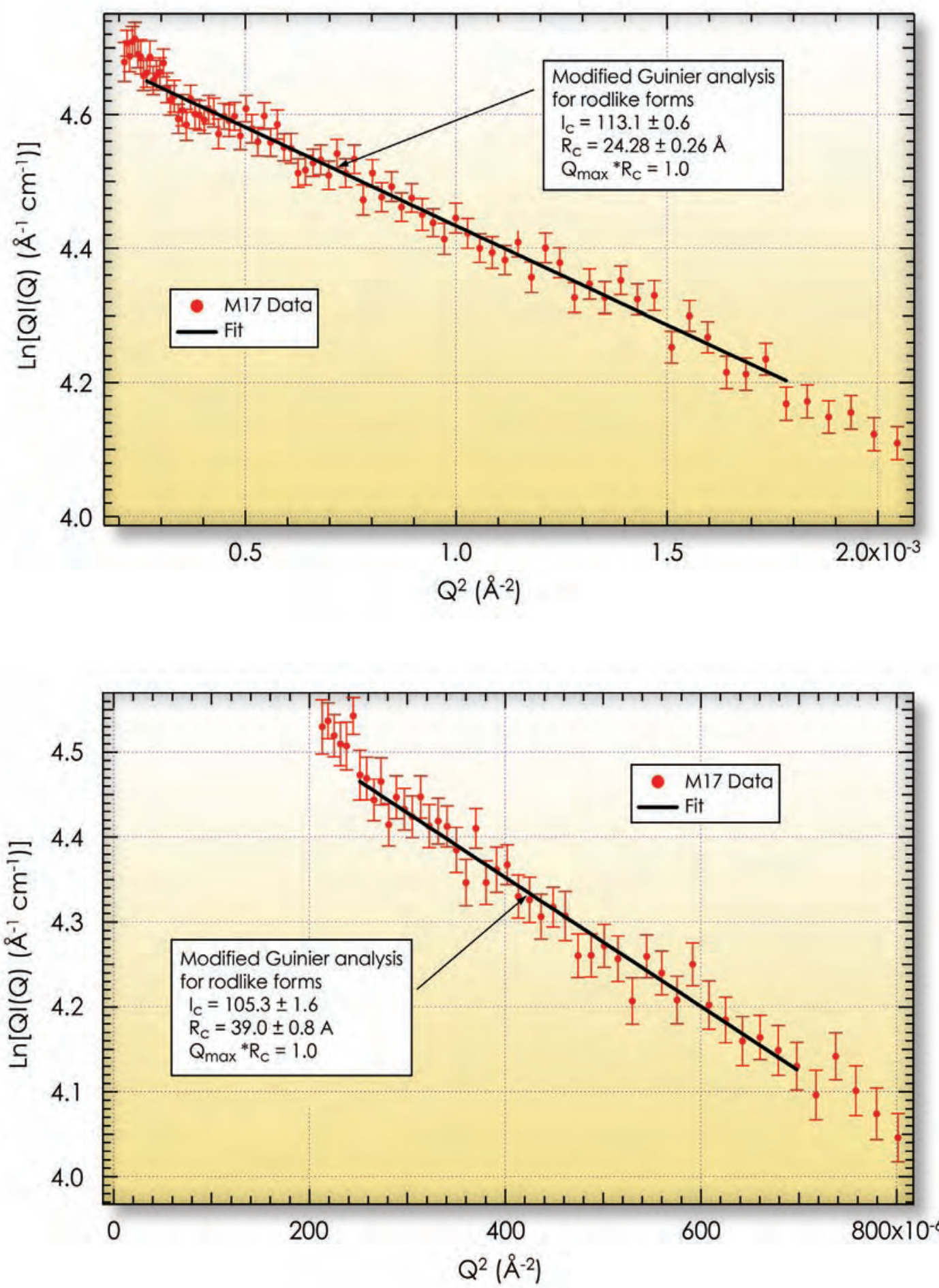

Modified Guinier analysis for rodlike forms showing the clear presence of extended, rodlike structures in the M17 and M50 samples. ports the TEM findings for this microstructure. The M60 and M80 samples (both irradiated at $1500^{\circ} \mathrm{C}$ to 5 and $8 \mathrm{dpa}$, respectively) scatter strongly with a signal characteristic of very large objects, supporting the evidence for decreased density and the growth of tetragonal voids in the observed microstructure.

In this initial work, we have gained confidence that SANS1 can be used to quantify the defects responsible for phonon scattering in ceramic materials, at least at the lower end of resolution for TEM observation. The next hurdle is to apply this technique to those defects we cannot currently image, which is also the scale at which most of the phonon scattering defects exist. With the final description of these small vacancy complexes in irradiated $\mathrm{SiC}$, the phonon scattering from all defects can be accounted for and the general theory for phonon transport in defected ceramics validated.

Contact: Ken Littrell (littrellkc@ornl.gov) 


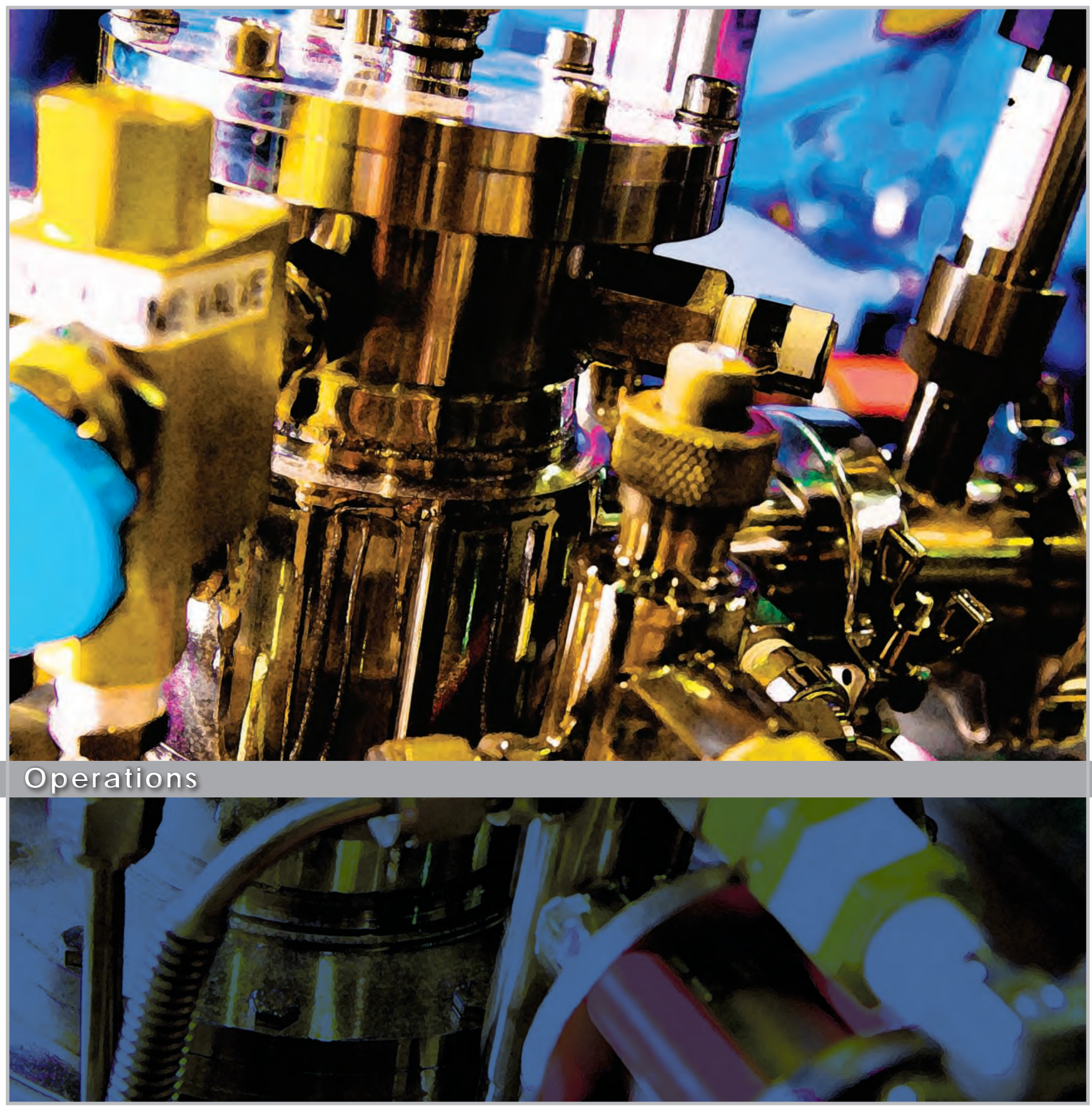


For neutron sciences at ORNL, "operations" was the buzz word for 2007. Although a great deal of design, installation, and testing was and is still taking place, successful operation of HFIR and SNS was the focus. This banner year included reactor, accelerator, and instrument performance that exceeded expectations in many cases. Another step forward was the beginning of integration with other ORNL facilities, expanding the resources readily available to users. Most important, 2007 was a safe year thanks to dedicated staff and effective programs that keep safety at the forefront of all neutron science work.

\section{High Flux Isotope Reactor}

In 2007, HFIR completed the most dramatic transformation in its 40-year history. During a shutdown of more than a year, the facility was refurbished and a number of new instruments were installed, as well as a cold neutron source. The reactor was restarted in mid-May; it attained its full power of $85 \mathrm{MW}$ within a couple of days, and experiments resumed within a week.

Improvements and upgrades to HFIR include an overhaul of the reactor structure for reliable, sustained operation; significant upgrading of the eight thermal-neutron spectrometers in the beam room; new computer system controls; installation of the liquid hydrogen cold source; and a new cold neutron guide hall. The upgraded HFIR will eventually house 15 instruments, including 7 for research using cold neutrons.

The cold source was tested successfully during the first few months of 2007. Testing verified the design assumptions and demonstrated that the cold source would support safe, reliable operation of the reactor. Since the initial startup with the cold source installed, both the reactor and cold source have operated safely and reliably for five fuel cycles.

Completion of all the testing was followed by a highly productive period of reactor operation. From May through December, HFIR operated for 9169.6 MW-d at its 85-MW full-power rating with the exception of a few hours at lower power to perform the HB-4 brightness measurements. This provided valuable neutron scattering instrument commissioning time and 1178 facility operating hours for users. During this time, 72 users performed 35 neutron scattering experiments. In addition to neutron scattering work, HFIR staff performed isotope production, neutron activation analysis, and materials irradiation experiments for a variety of customers. 
An aggressive operating schedule is planned for 2008, with a tentative schedule of 140 operating days. This schedule assumes six operating cycles during the calendar year. Steady-state operation of HFIR will eventually provide neutron beams for eight to ten reactor cycles per year. With regular operation, the next anticipated major shutdown-for a beryllium reflector replacement-will not be necessary until after 2020.

Contact: Mike Farrar (farrarmb@ornl.gov)
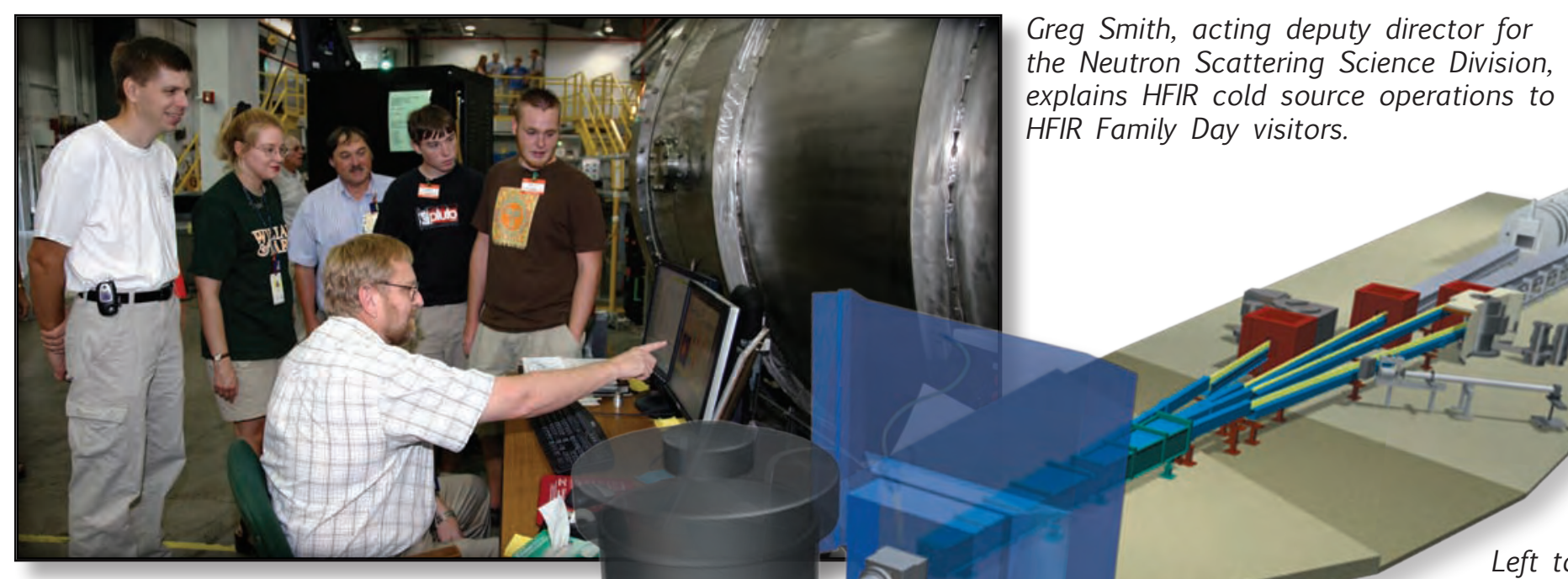

\begin{abstract}
Greg Smith, acting deputy director for explains HFIR cold source operations to HFIR Family Day visitors.
\end{abstract}

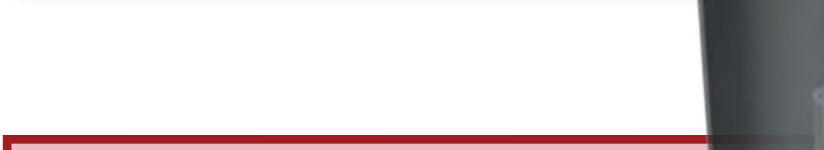

\title{
HFIR Design and Operation
}

The HFIR design, based on the sions: (1) neutron scattering,
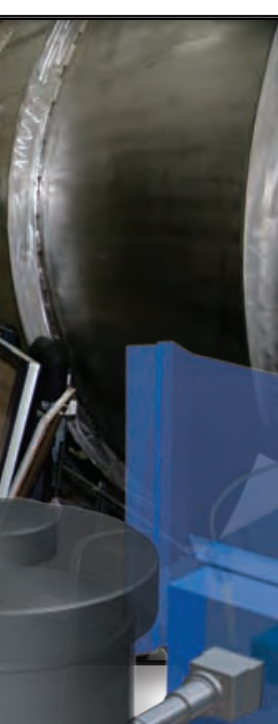
2

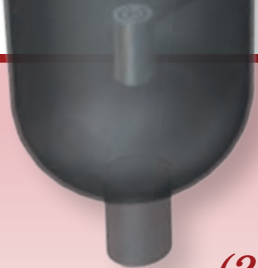

"flux trap" principle, enables it to fulfill four mis(2) isotope production, (3) materials irradiation, and (4) neutron activation. The reactor has a fuel region surrounding an unfueled moderating region or "island." High-energy neutrons are released from the fuel and then cooled and slowed in the island. The design produces a region with a very high $\left(2.0 \times 10^{15}\right.$ neutrons $/ \mathrm{cm}^{2} \bullet$ s $)$ flux of thermal (room-temperature) neutrons at the center of the island.

The neutrons "trapped" in the island are used to produce isotopes for medical, research, and industrial uses. Other neutrons are guided through beam lines into research instruments outside the reactor shielding, where neutron scattering studies are conducted. Holes in the reflector outside the fuel region allow researchers to irradiate samples of materials that are then retrieved and analyzed to determine the effects of the radiation. The beryllium reflector contains numerous experimental facilities with thermal-neutron fluxes of up to $1.0 \times 10^{15}$ neutrons $/ \mathrm{cm}^{2} \bullet$ s. 


\section{Spallation Neutron Source}

This was the first full year of operation for SNS. A positive accelerator readiness review in April permitted an increase in the administrative beam power limit from $100 \mathrm{~kW}$ to $2 \mathrm{MW}$. Since then, power levels, intensity, neutron production, and reliability have all steadily increased. By the end of 2007, SNS had achieved

- Continuous operation at $183 \mathrm{~kW}$

- A record number of protons per pulse: $1.1 \times 10^{14}$

- A $60-\mathrm{Hz}$ beam to target at $\sim 70 \mathrm{~kW}$

- $160 \mathrm{MWh}$ of beam to target

- Accelerator availability of $79 \%$

- 1500 neutron production hours
In regard to instrumentation, the Wide Angular-Range Chopper Spectrometer came online in 2007, joining the already operating Magnetism and Liquids Reflectometers and the Backscattering Spectrometer. The first user experiments were completed in August and September. Eventually SNS will make available to researchers a suite of up to 25 best-in-class instruments, which will allow measurements of greater sensitivity, higher speed, higher resolution, and in more complex sample environments than ever before.

A vibrant and engaged neutron scattering user community is vital to the success and scientific productivity of both HFIR and SNS. The user community was engaged from the beginning of the SNS project in the prioritization and selection of the neutron scattering instrument suite and is now beginning to use the instruments. As SNS completes more of
This graph shows the increase in integrated beam power delivered during FY 2007 versus the commitment from SNS. For the next year, plans are to operate for 4000 hours, reach an operating power of $750 \mathrm{~kW}$, and produce neutrons for 2700 hours. In addition, machine availability is expected to increase to about $83 \%$.

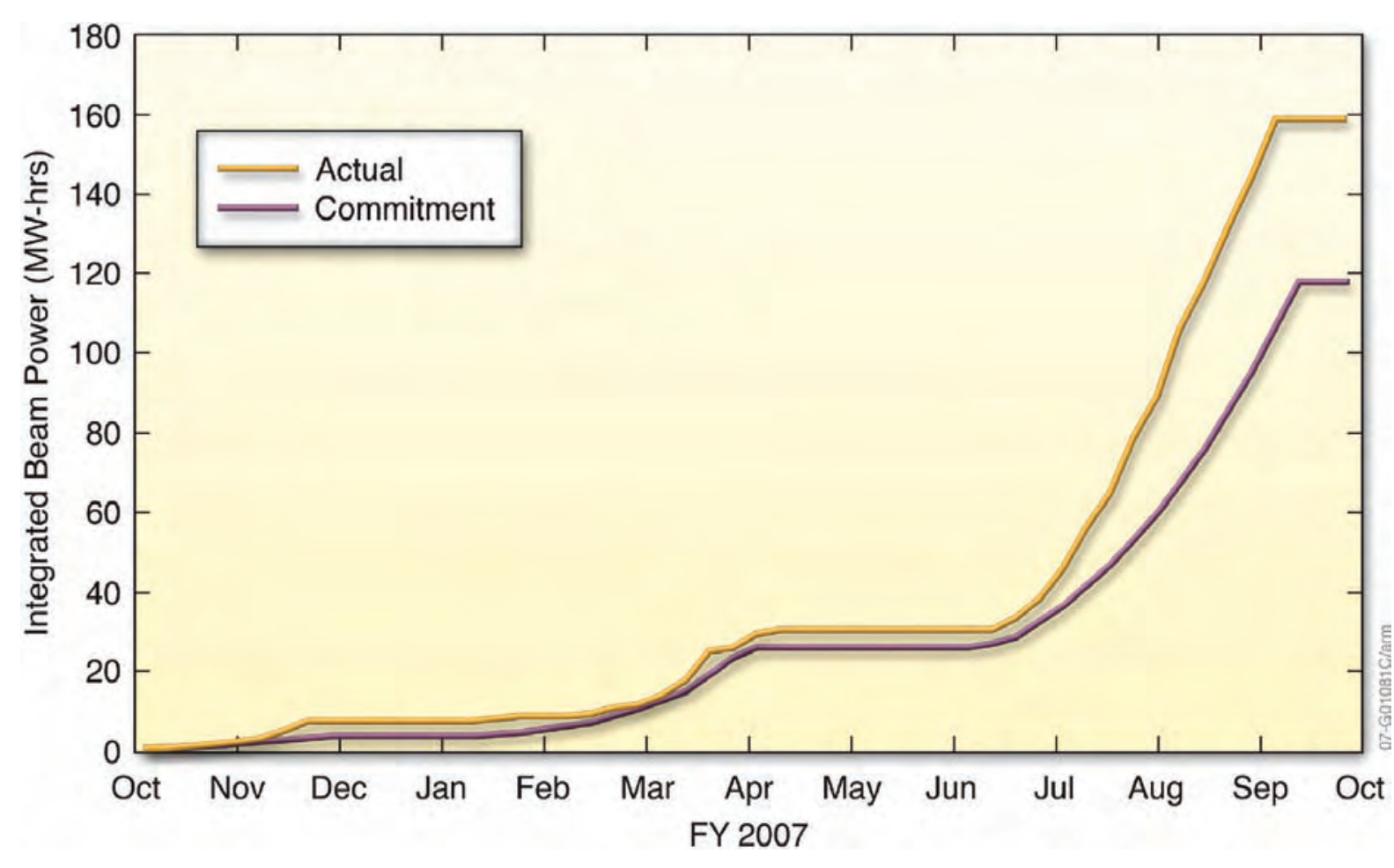

Actual versus committed integrated beam power performance at SNS during FY 2007. 
these instruments and adds more operating hours over the next several years, it is anticipated that
1000 to 2000 researchers per year from all areas of science and industry will use these facilities.

\section{SNS Design and Operation}

The SNS process begins with injecting negatively charged hydrogen ions into a linear accelerator (linac), which accelerates them to very high energies (a billion electron volts, or $1 \mathrm{GeV}$ ). The ions pass through a foil that strips off their electrons and converts the electrons to protons. The protons accumulate in a ring, from which brief (a millionth of a second), powerful pulses of protons are released 60 times a second to strike a target containing liquid mercury. As the protons strike the target, pulses of neutrons are ejected or "spalled" from the mercury nuclei.

The neutrons shooting from the target are too high in energy to be usable as is. They are slowed down, or moderated, by passing them through vessels of water (to produce room-temperature or "thermal" neutrons) or liquid hydrogen at $20 \mathrm{~K}$ (for cold neutrons). The neutrons are then guided through a set of beam lines to specialized instruments that use the neutrons in a wide variety of experiments.

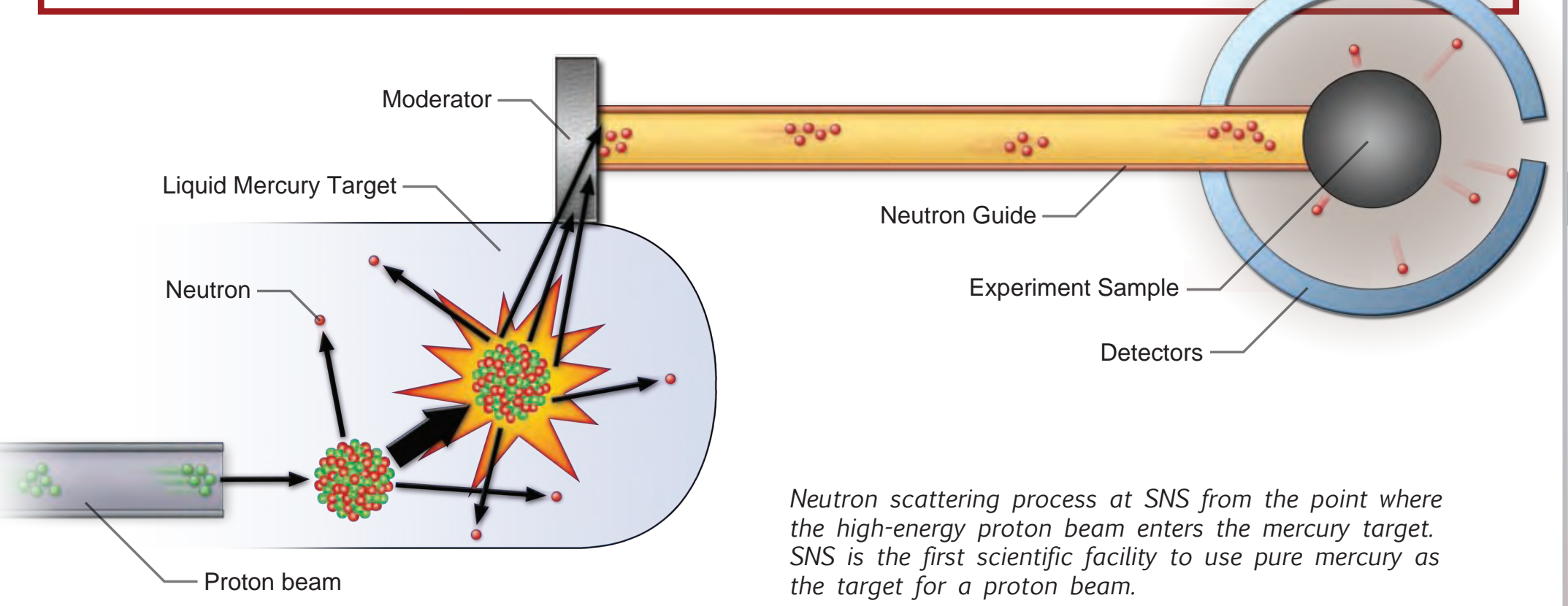




\section{Facility Integration}

Research capabilities at HFIR and SNS are enhanced by the proximity of other ORNL user facilities, most with the same access and training requirements. An important goal for Neutron Sciences is improving integration between the facilities, making it easier for users to access the support they need. Major user facilities at ORNL include

- Center for Structural Molecular Biology (CSMB)

- Center for Nanophase Materials Sciences (CNMS)

- National Center for Computational Sciences (NCCS)

- Shared Research Equipment User Facility (SHaRE)

- High Temperature Materials Laboratory (HTML)

\section{Center for Structural Molecular Biology (www.cnms.ornl.gov)}

CSMB operates the HFIR Bio-SANS instrument, which supports and develops user programs in the neutron

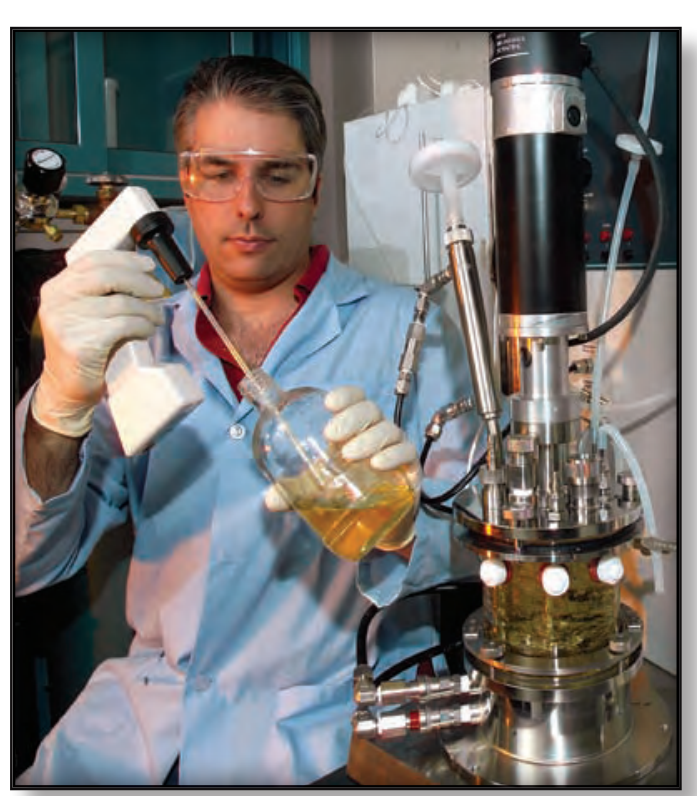

CSMB postdoc Kevin Weiss uses a laboratory scale fermentor to culture organisms in isotopically labeled growth media to produce biomolecules for neutron scattering studies. function. CSMB develops technologies and methodologies for the structural molecular biology research community and develops computational tools to reduce, analyze, model, and interpret SANS data.

\section{Bio-Deuteration Laboratory (www.csmb.ornl.gov/Bio-Deuteration)}

CSMB has established a Bio-Deuteration Laboratory for in vivo production of hydrogen/deuterium-labeled bio-macromolecules for research at HFIR and SNS. The laboratory provides facilities and expertise for cloning, protein expression, purification, and characterization of deuterium-labeled biological macromolecules. Users can design and produce proteins, complexes, and macromolecular assemblies optimized for neutron scattering; and the data can be used to construct biologically meaningful models of protein complexes, assemblies, and hierarchical structures.

Current research efforts at CSMB include modeling the structure of the Putidaredoxin Reductase (Pdr) and Putidaredoxin ( $\mathrm{Pdx}$ ) complex, visualizing morphology changes in biomass during pretreatment for conversion to biofuel, investigating peptides that have the protein context of huntington exon 1 , associated with Huntington's disease, and elucidating the impact of the water-miscible ionic liquid [bmim] Cl on the protein fold in aqueous solutions.

Contact: Dean Myles (mylesda@ornl.gov)

\section{Center for Nanophase Materials Sciences (www.cnms.ornl.gov/)}

CNMS is a research facility for nanoscale science and technology. Housed in an 80,000- $\mathrm{ft}^{2}$ building adjacent to SNS, CNMS allows users access to a complete suite of unique capabilities for studying nanoscale materials and assemblies. CNMS integrates nanoscale science with three other research areas: neutron science at SNS and HFIR; synthesis science facilitated by a new Nanofabrication Research 


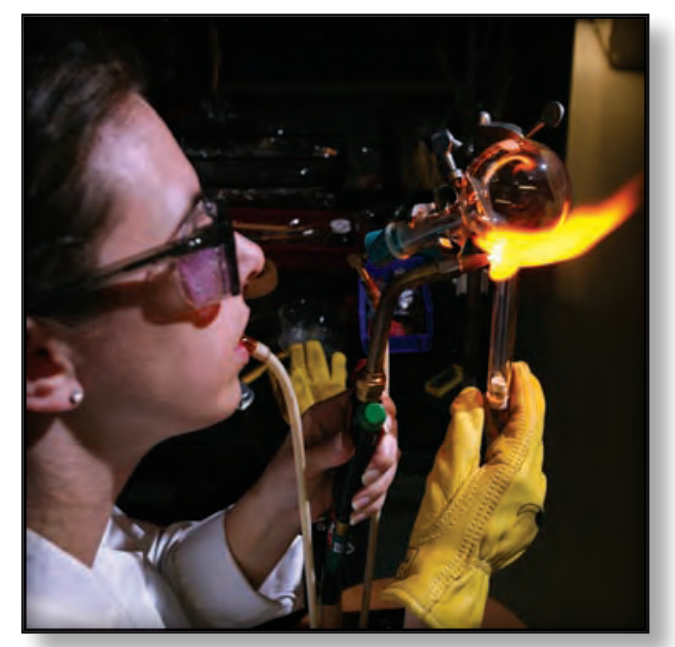

Deanna Pickel, a polymer chemist at CNMS, prepares a glass reactor for an anionic polymerization experiment that requires high purity and high-vacuum conditions to create well-defined materials. Many of these materials are already being incorporated into experiments at ORNL neutron facilities.

Laboratory and other labs; and theory, modeling, and simulation using the Nanomaterials Theory Institute and access to high-performance computers at ORNL's NCCS and the National Energy Research Supercomputing Center at Lawrence Berkeley National Laboratory.

Contact: Linda Horton (hortonll@ornl.gov)

\section{National Center for Computational Sciences (www.nccs.gov)}

NCCS hosts the Cray XT4 "Jaguar" supercomputer, which was capable of more than 119 trillion calculations per second (119 teraflops) at the end of 2007 and was being upgraded to $250+$ teraflops. A petaflops supercomputer, capable of a quadrillion calculations per second, is to be installed in 2008. NCCS is also home to several smaller supercomputers. Allocations for large supercomputing projects (i.e., millions of processor-hours) are awarded through a proposal process that issues a yearly call for proposals. Smaller allocations are occasionally awarded to "director's discretion" projects.

Contact: Jim Hack (jhack@ornl.gov)

\section{Shared Research Equipment User Facility (www.ms.ornl.gov/share)}

SHaRE provides access to a suite of advanced instruments and expert staff scientists for the micrometer-to-nanometer-scale characterization of materials in several focused research areas: transmission and scanning electron microscopy, atom probe tomography, X-ray photoelectron spectrometry, and dual-beam focused ion beam and ultramicrotomy specimen preparation and support. Researchers submit research proposals for review and approval to gain access to SHaRE's characterization facilities. Proposals are accepted at any time.

Contact: Carolyn Wells (wellscb@ornl.gov)

\section{High Temperature Materials Laboratory (www.html.ornl.gov)}

HTML helps solve materials problems that limit the efficiency and reliability of automotive systems. Six user centers are available to researchers. The centers are staffed by experts in the materials sciences and are equipped with instruments that can characterize the structural, chemical, physical, and mechanical properties of materials at the nanoscale and microscale over a wide range of temperatures and pressures. Research capabilities include microstructural analysis; X-ray and neutron diffraction; residual stress analysis; thermophysical properties studies; mechanical characterization; and analysis, thermography, and tribology.

\section{Contact: Edgar Lara-Curzio (laracurzioe@ornl.gov)}

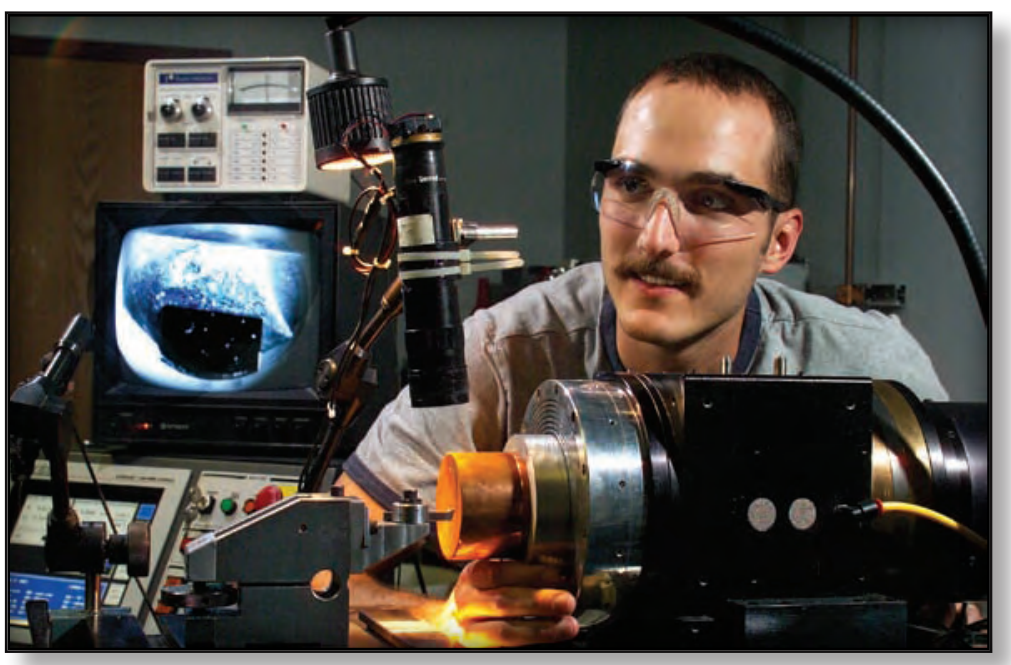

Jason Braden demonstrates use of a diamond tool to turn a concave mirror onto a piece of copper. 
Safety is critical to the success of the Neutron Sciences work at ORNL. Efficient operation and safety are inextricably linked and are an integral part of every individual's performance plan. This total safety awareness led to the formation of the Integrated Safety Management Program, the cornerstone of our operations. Our primary goal is to operate the best neutron facilities in the world. Achieving this goal means involving staff in all levels of work, from planning through post-task analyses, and incorporating the best ideas from those with the most knowledge of the hazards.

The focus on safety at all levels resulted in impressive safety statistics for FY 2007. SNS employees and contractors had zero lost workday injuries in FY 2007, and the rate of injuries resulting in restrictions was only 0.2 per 200,000 hours worked. This rate is below the DOE Office of Science goal of 0.25 injuries per 200,000 hours worked. Neutron Sciences personnel working at HFIR have worked 303,699 hours without a lost workday case (the last case occurred in June 2006).

Our facilities are regulated by DOE requirements for both reactors (HFIR) and accelerators (SNS). These safety-based requirements are clearly identified to establish safe operating envelopes. Work control processes ensure the integrity of systems created to protect staff, the public, and the environment. Staff members strive to reduce or eliminate pollution and waste materials, as well as to conserve energy and other resources.
Even though all of ORNL's neutron facilities operate safely and efficiently, a number of programs are being implemented to move to more in-depth levels of safe operation. Incorporating human factors information into work planning helps identify potential pitfalls before workers begin a task. Managers are trained to identify conditions and requirements that "trap" workers through unclear expectations or conflicting requirements. Through human factors training, managers have the tools they need to clarify directions given to workers and to deal with potential conflicts associated with work activities.

Enhancing interactions with staff in the workplace through the Management Observation Program also increased worker involvement and ownership of the safety programs and increased the efficiency of operations. For example, involving workers in planning activities during the major maintenance periods at SNS reduced the radioactive dose by about $90 \%$ from the levels initially estimated for the work. This task-level planning led to using as-low-as-reasonably-achievable (ALARA) goals even more effectively than for previous jobs and resulted in the use of real-time dose feedback that provided immediate dose information to the workers. This instant-feedback method is now used for maintenance and other tasks and is implemented throughout the entire work control process.

Contact: Frank Kornegay (kornegayfc@ornl.gov) 


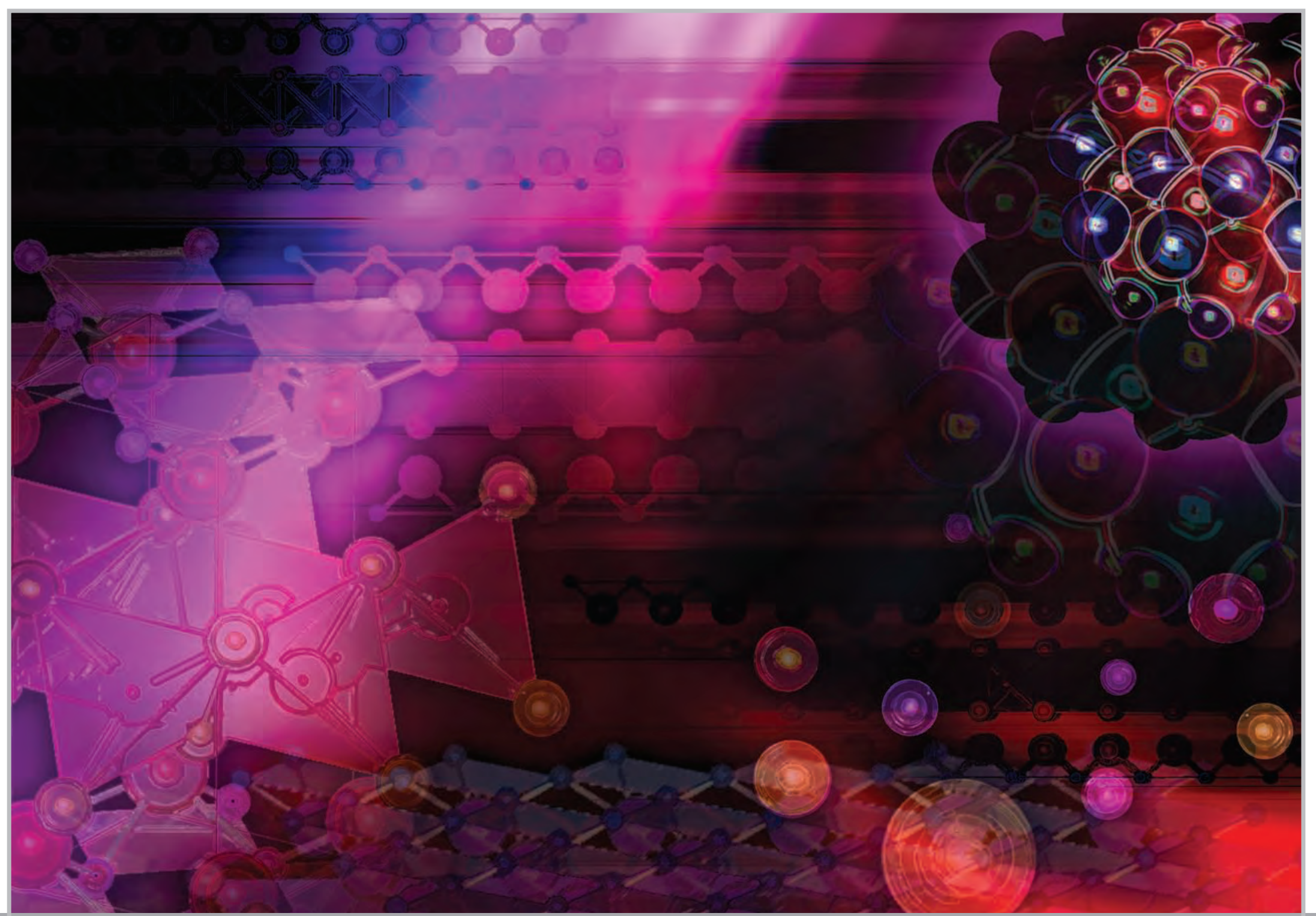

Facility Development 


\section{Instruments}

\section{High Flux Isotope Reactor}

HFIR has six operating instruments available to users (see table below). During 2007, 9 external users performed 16 experiments on the triple-axis spectrometers and 2 experiments on the

Wide-Angle Neutron Diffractometer in support of ORNL Laboratory Directed Research and Development projects.

Commissioning of the Neutron

Residual Stress Mapping Facility 2 was completed, and the facility was able to support six user projects (conducted by both industry- and universitybased researchers). In total, 35 scattering experiments were conducted (out of more than 70 proposals).

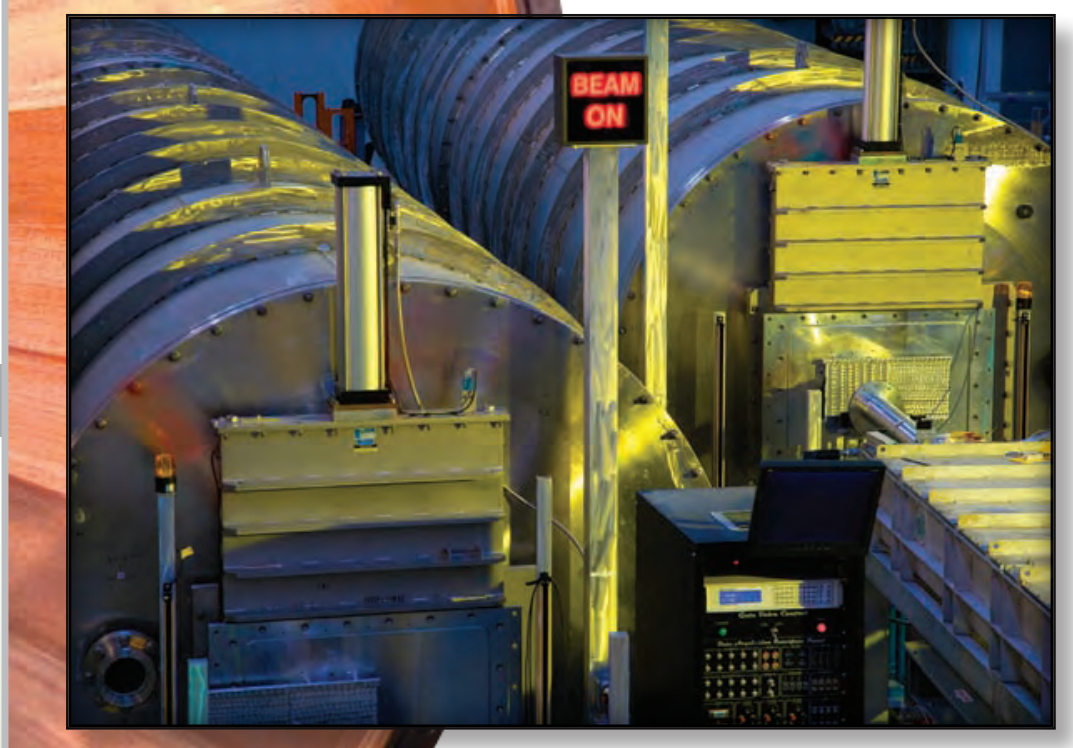

Detector tanks for the new SANS instruments at HFIR. On the left is the tank for the general-purpose, high-resolution instrument; the tank on the right is for the Bio-SANS instrument, which is constructed specifically for biological research.

\section{Small-Angle Neutron Scattering Instruments}

HFIR's new cold neutron source provides beams to two new small-angle neutron scattering (SANS) instruments, the SANS1 for general SANS analysis and a Bio-SANS for biological research. Even though the SANS instruments were still being commissioned during 2007, proposals were accepted and experiments run on both instruments.

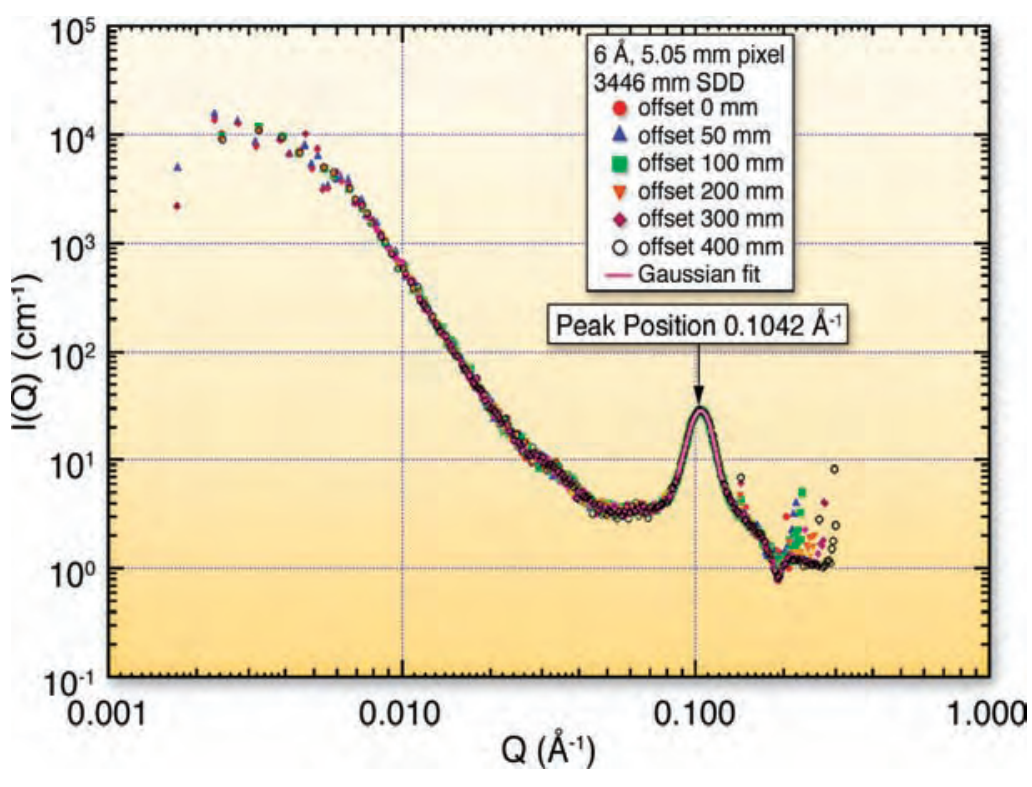

Reduced scattering curve from a standard calibration sample of a polymer blend with diffraction peaks taken from data generated at the Bio-SANS instrument.

HFIR instruments currently in the user program

\begin{tabular}{|l|l|}
\hline Beam line & Instrument \\
\hline HB-1 & Polarized Triple-Axis Spectrometer \\
\hline HB-1A & Fixed-Incident-Energy Triple-Axis Spectrometer \\
\hline HB-2B & NRSF2-Neutron Residual Stress Mapping Facility \\
\hline HB-3 & Triple-Axis Spectrometer \\
\hline CG-2 & $\begin{array}{l}\text { SANS1-Small-Angle Neutron Scattering } \\
\text { Diffractometer }\end{array}$ \\
\hline CG-3 & Bio-SANS-Biological SANS instrument \\
\hline
\end{tabular}




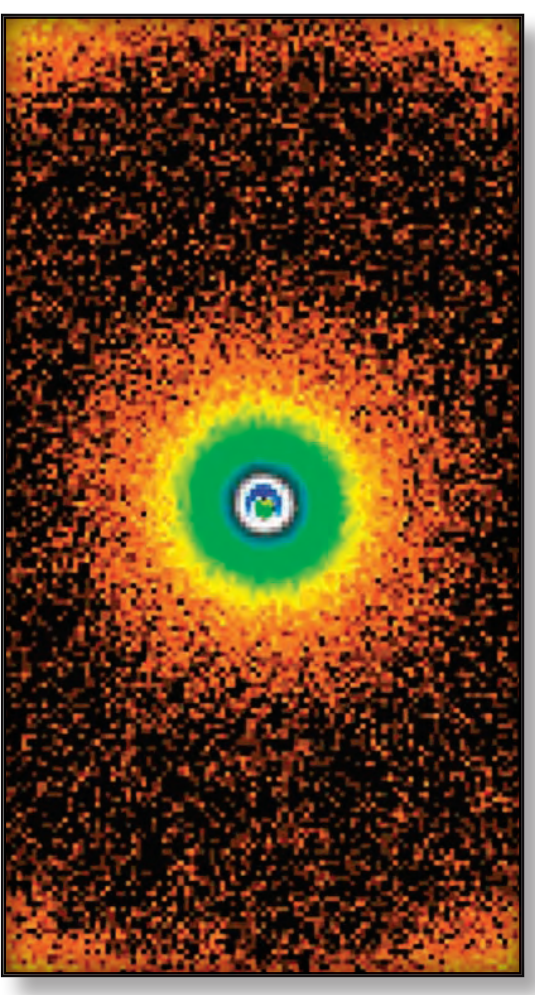

Two-dimensional scattering pattern of a polymer from data taken at the Bio-SANS instrument. Major milestones for instrumentation at HFIR

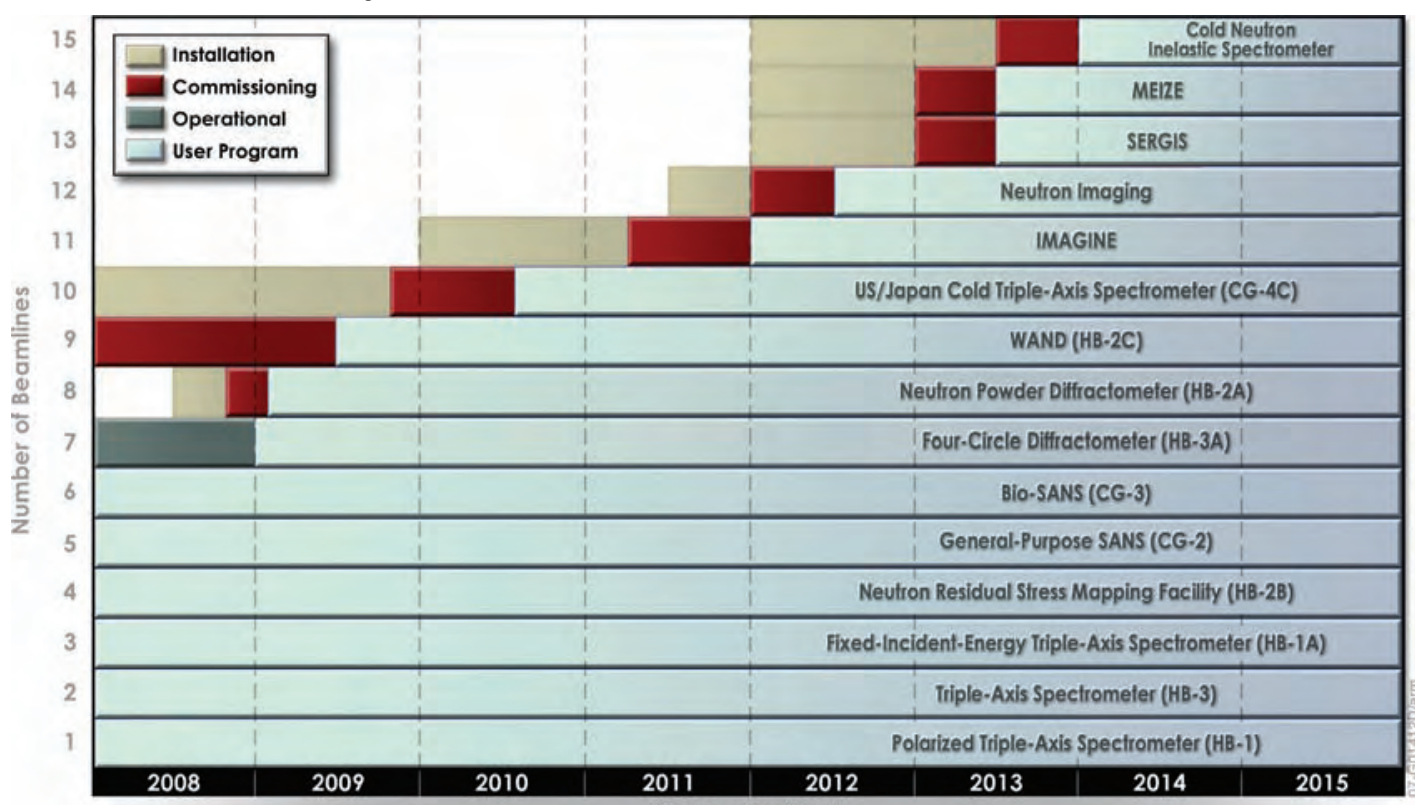

\section{SANS1}

SANS1 is optimized to provide information about structure and interactions in materials on the scale of 5 to $2000 \AA$. It has cold neutron flux on sample and capabilities comparable to those of the best SANS instruments worldwide. Its capabilities include a wide range of neutron wavelengths $(\lambda=5-30 \AA)$, resolution $\delta \lambda / \lambda=9.45 \%$, and a $1-\mathrm{m}^{2}$ area detector with $5 \times 5 \mathrm{~mm}$ pixel resolution with a maximum counting capability of up to $200 \mathrm{kHz}$. The sampleto-detector distance can be varied from 1 to $20 \mathrm{~m}$, and the detector can be offset horizontally by up to $45 \mathrm{~cm}$, allowing a total accessible $\mathrm{Q}$ range from $<0.001$ to $1 \AA^{-1}$. The 2-m sample environment area will accommodate large, special-purpose sample environments such as cryomagnets, furnaces, mechanical load frames, and shear cells. SANS1 is ideal for studies of soft condensed materials (e.g., complex fluids, glassy systems, polymers); hard condensed materials (e.g., metallurgical alloys, nanocomposites, ceramics, catalysts); and magnetic systems (e.g., flux lattices in superconductors, ferrofluids).

\section{Bio-SANS}

Bio-SANS is operated by the Center for Structural Molecular Biology (see "Facility Integration" in the Operations Section) and provides the most advanced capabilities in the world for analysis of biological systems. The instrument provides detailed structural data for bio-materials from 10 to $1000 \AA$ in length, enabling scientists to build a detailed understanding of the internal structures of complex biological systems and study their responses to changing conditions.

Bio-SANS is designed to have a low background to enable studies of weakly scattering systems. The instrument's sample area has a 2-m footprint, making it suitable for sample environments ranging from traditional liquid cells to large, high-field magnets. Its enclosed sample chamber can handle most samples, and it has a temperature-controlled, multiposition sample changer. 
More information about the two SANS instruments is available in the Facts and Figures section.

Four other HFIR instruments are being commissioned or will be commissioned in 2008 and 2009:

- US/Japan Wide-Angle Neutron Diffractometer (WAND), beam line HB-2C

- Four-Circle Diffractometer, beam line HB-3A

- Neutron Powder Diffractometer, beam line HB-2A

- US/Japan Cold Triple-Axis Spectrometer, beam line CG-4

Efforts are also under way to establish instrument projects for each of the five open positions on the HFIR beam lines (one thermal and four cold neutron positions). The plan is to initiate two projects in 2008 and the remaining three in 2009. All open instrument positions are expected to be occupied by 2012. Instrument development teams (IDTs) have been formed for three possible instruments: a quasi-laue diffractometer (IMACINE) for beam line CG-4, a cold triple-axis spectrometer for beam line CG-1, and a neutron imaging instrument. The IDTs have submitted letters of intent for IMAGINE and the cold triple-axis spectrometer to the Neutron Scattering Science Advisory Committee, and both were approved for the submittal of full proposals.

\section{Spallation Neutron Source}

The Backscattering Spectrometer, Liquids Reflectometer, and Magnetism Reflectometer were commissioned in spring 2006 and have been available to a limited number of users since then. (Please see the Science Highlights section for some of the experiments that have been conducted.) All three

SNS instruments currently in the user program

\begin{tabular}{|l|l|}
\hline Beam line & Instrument \\
\hline 2 & Backscattering Spectrometer \\
\hline $4 \mathrm{~A}$ & Magnetism Reflectometer \\
\hline $4 \mathrm{~B}$ & Liquids Relectometer \\
\hline
\end{tabular}

instruments are performing well and are expected to continue to expand in reliability and capability.

SNS instrument development and construction continues at a fast pace. In September, the Wide Angular-Range Chopper Spectrometer (ARCS) at beam line 18 was completed and measured its first neutrons. Commissioning then began, and the first user experiments are expected in 2008. The Spallation Neutrons and Pressure Diffractometer (SNAP) began receiving neutrons in January 2008, and progress is on schedule for six other instruments scheduled for completion and commissioning during 2008:

- EQ-SANS (Extended Q-Range Small-Angle Neutron Scattering Diffractometer), BL-6

- CNCS (Cold Neutron Chopper Spectrometer), BL-5

- POWGEN (Powder Diffractometer), BL-11A

- FNPB (Fundamental Neutron Physics Beam Line), $B L-13$

- SEQUOIA (Fine-Resolution Fermi Chopper Spectrometer), BL-17

- VULCAN (Engineering Materials Diffractometer), BL-7

The Neutron Spin Echo Spectrometer is scheduled for commissioning in 2009.

Two "SNS Instruments-Next Generation" (SING) projects will add nine more instruments to the SNS lineup between 2008 and 2013. SING I-a suite of five best-in-class instruments-is more than $50 \%$ complete. The construction, commissioning, and schedule for the current SNS instrument suite availability is shown at right. 


\section{SING I}

Beam line Instrument

\begin{tabular}{|l|l|}
\hline $1 B$ & Nanoscale-Ordered Materials Diffractometer (NOMAD) \\
\hline 3 & Spallation Neutrons and Pressure Diffractometer (SNAP) \\
\hline 12 & Single-Crystal Diffractometer (TOPAZ) \\
\hline $14 B$ & Hybrid Spectrometer (HYSPEC) \\
\hline 17 & Fine-Resolution Fermi Chopper Spectrometer (SEQUOIA) \\
\hline
\end{tabular}

SING II

Beam line Instrument

\begin{tabular}{l|l}
\hline 1A & Time-of-Flight Ultra-Small-Angle Neutron Scattering
\end{tabular} Instrument (TOF-USANS)

$9 \quad$ Elastic Diffuse Scattering Spectrometer (CORELLI)

\begin{tabular}{lll}
\hline $11 B$ & Macromolecular Neutron Diffractometer (MaNDi) \\
\hline $16 B$ & Chemical Spectrometer (VISION)
\end{tabular}

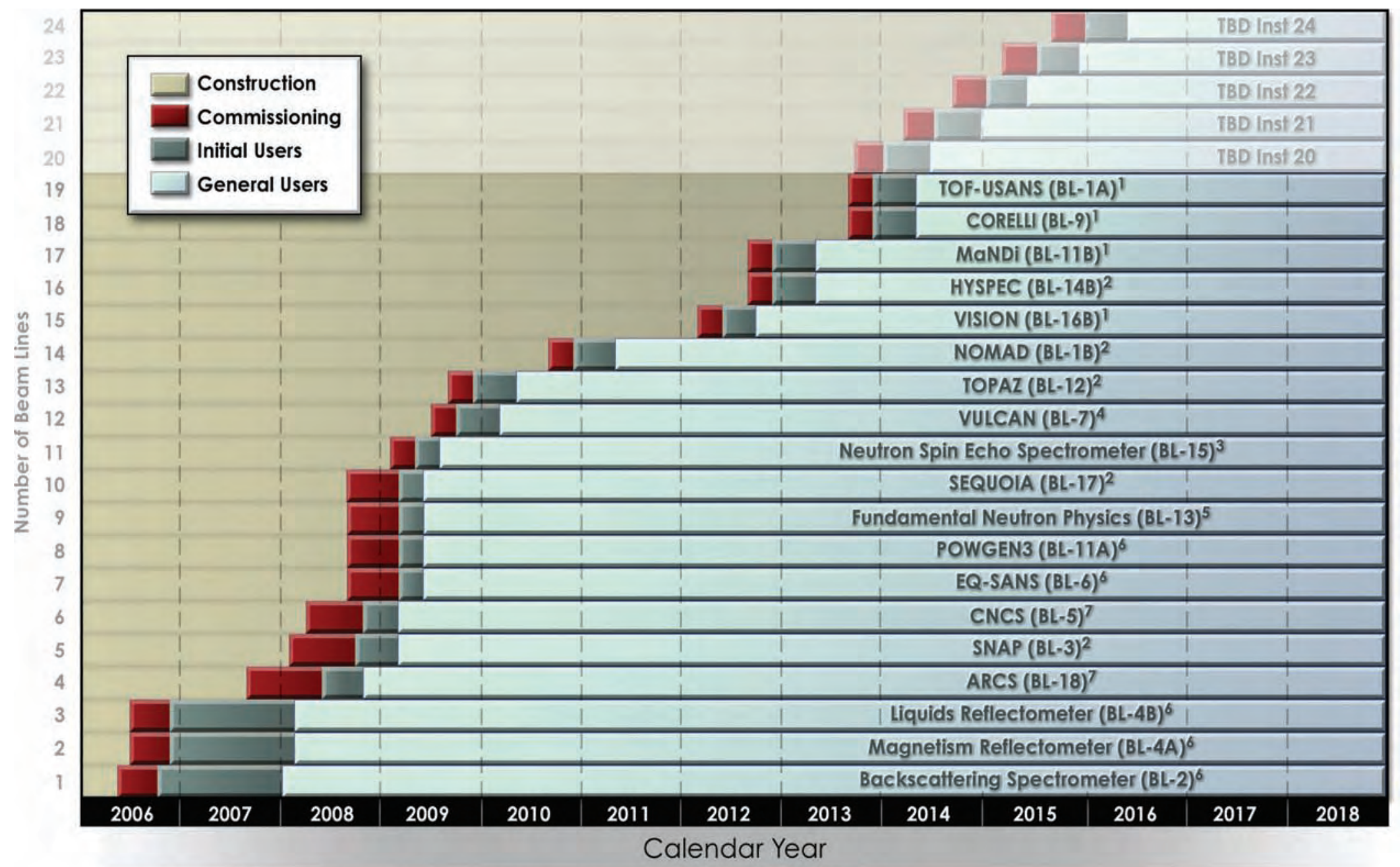

Funding: ' ${ }^{1}$ ING-II; ${ }^{2}$ IING-I; ${ }^{3}$ Jülich; ${ }^{4}$ Canada Fund for Innovation; ${ }^{5}$ DOE-NP; ${ }^{6}$ SNS; ${ }^{7}$ DOE-BES. 


\section{Sample Environment}

The Sample Environment teams at HFIR and SNS joined forces in 2007 to create a single group and a more unified program. The group purchased and commissioned a number of standard, workhorse sample environments to support the user community at the two facilities.

The most exciting Sample Environment projects involved research and development collaborations with scientists using the neutron scattering instruments. One such project opened up a new way to study the science behind materials processing under extreme conditions. ORNL scientists wanted to perform the first in situ study of phase transformation under simultaneous high magnetic field and high temperature. This proof-of-principle experiment required building a high-temperature sample insert to fit inside a magnet on the Wide-Angle Neutron Diffractometer (WAND) at HFIR (see Science Highlights). The new technique was successful, opening the door to greater understanding of the role of magnetic fields in structure changes and phase equilibria at high temperatures.

Collaborations with research teams also led to the development of controlled atmosphere furnaces, gas pressure cells, and a controlled humidity cell that was tested and commissioned on the SNS Liquids Reflectometer during the summer. A $1700^{\circ} \mathrm{C}$ controlled atmosphere reaction (CAR) furnace was tested offline in October. The CAR furnace will be commissioned on the HFIR WAND and will be available for use on other HFIR and SNS instruments. Additional furnace designs are under development. New gas pressure cells were also designed, including a sapphire cell optimized for inelastic measurements on the SNS Backscattering Spectrometer.

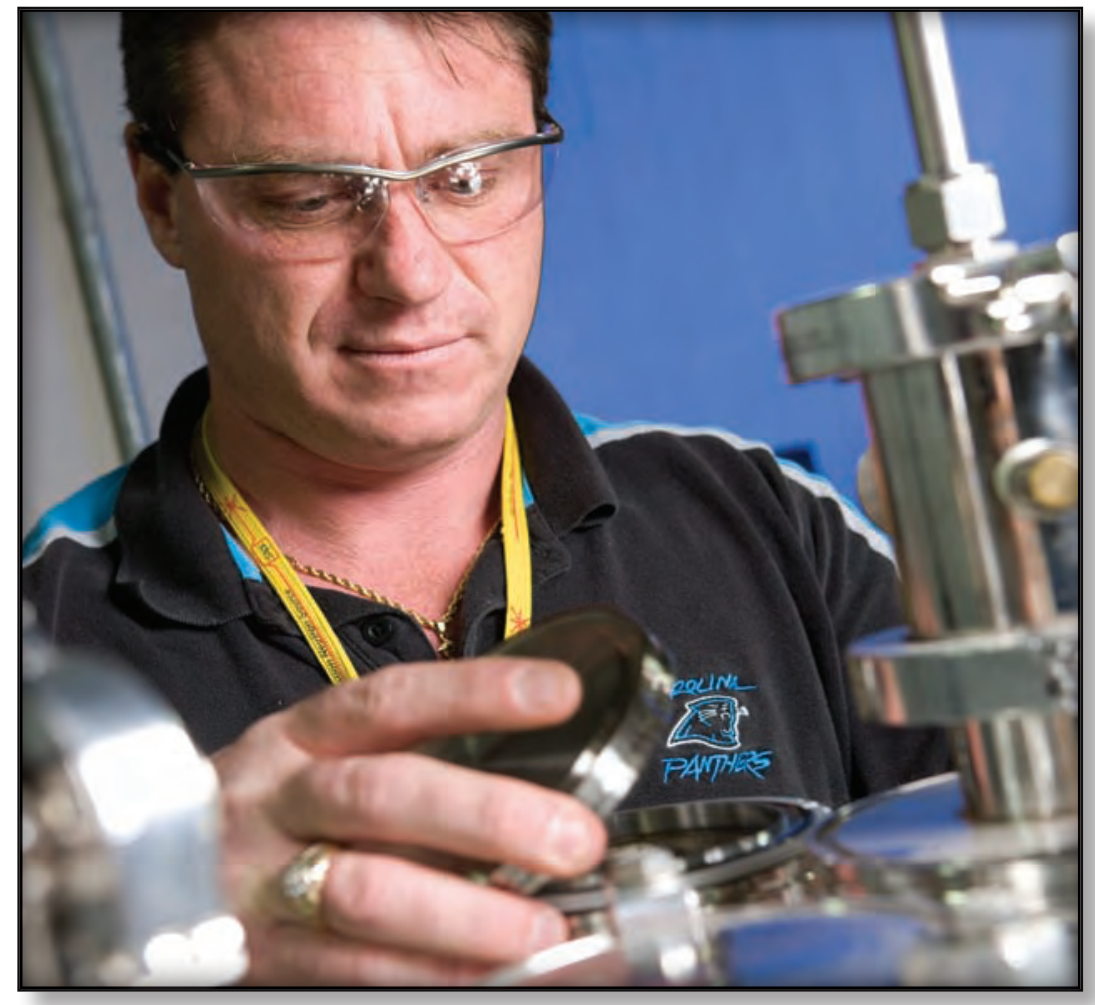

Instrument developer John Wenzel tests engineering changes to improve the efficiency and performance of a top-loading cryostat.
The completion of laboratory automation projects has been a significant boost to the Sample Environment program. The Fast Exchange Refrigerator for Neutron Science (FERNS) was developed to meet the demands of high-throughput powder diffractometers such as POWGEN at SNS. FERNS includes a benchtop encapsulation station for sealing powder samples into vanadium cans, a 24-sample automatic changer module, a sample can identification system, and a cryogenic module that cools the sample below $10 \mathrm{~K}$ within

10 minutes and regulates sample temperature throughout the range of $10 \mathrm{~K}$ to room temperature. FERNS, delivered to SNS in 2006, underwent rigorous testing and upgrades in 2007 to make it a userready system. It is now available as a commercial product. 
The FERNS cryogenic sample changer for handling sample cans (right) was also delivered in 2006 and was tested and upgraded in 2007 to make it user ready. It is also now commercially available. At the other end of the spectrum, the SNS Single-Crystal Diffractometer will be cooling and remotely manipulating saltgrain-size samples using a special system that is under development.

For the SNS Liquids Reflectometer, a system was designed and fabricated to handle sample plates for horizontal scattering geometry. It features an articulating robotic arm and environmentally controlled storage racks.

A project to develop a 16-Tesla actively shielded split-coil vertical field magnet for neutron scattering is progressing on schedule. The analysis phase was completed in April 2007, and the design phase was completed in April 2008. The magnet will be delivered to SNS in 2009. Smaller systems have already arrived: a 5-Tesla actively shielded vertical magnet was commissioned in May 2008, and a 2-Tesla electromagnet and integrated Displex system is operating on the SNS Magnetism Reflectometer.

The Spallation Neutrons and Pressure Diffractometer (SNAP) is a single-crystal instrument that positions very small samples held in a complicated sample environment. To meet the needs of this instrument, the following equipment is being commissioned:

- 8 large-volume Paris-Edinburgh (P-E) presses

- 5 large-volume gas devices

- 15 panoramic high-pressure cells with gem-anvils, a cryo-cooling system capable of cooling the massive P-E press, a graphite furnace heating system for the P-E press, and a laser heating system for the gem-anvil pressure cells.

A list of Sample Environment equipment for each facility is available in the Facts and Figures section.

Contact: Lou Santodonato (santodonatol@ornl.gov)

HFIR: neutrons.ornl.gov/hfir_instrument_systems/ hfir_sample.shtml

SNS: neutrons.ornl.gov/instrument_systems/sample/ 


\section{Detec tor Systems}

The Detector Group is responsible for developing, assembling, calibrating, installing, and commissioning neutron detectors for HFIR and SNS beam lines. Detectors count the number of incoming neutrons, and, more important, they record the position and arrival time (i.e., energy) of every single neutron that is seen by the detectors. Ongoing efforts are being made to count neutrons more efficiently and at finer spatial and temporal resolution to increase the capacity and resolving power of all of the neutron scattering instruments.

Although the Detector Group is beginning to support needs for HFIR instruments, in 2007 most of the development work was for the three operating SNS instruments. The Detector Group focused its efforts on development of three neutron detector systems: linear positionsensitive detector (LPSD) "8-pack"

modules, shifting scintillator detectors, and neutron Anger cameras with position-sensitive photomultiplier tubes. These three new designs, along with traditional multiwire proportional chambers, make up the four detector types used at SNS.

\section{LPSD 8-Pack Modules}

LPSD 8-pack modules, based on GE Reuter-Stokes ${ }^{3} \mathrm{He}$ proportional tubes, were initially developed for the Wide Angular-Range Chopper Spectrometer (ARCS) and have been chosen for several other instruments as well. A 112-tube array has been running on the Backscattering Spectrometer since its commissioning in 2006. The electronics, mounted on each module, include low-noise preamplifiers and a "ROC" board that digitizes the signal, determines position by charge division, and sends the position and time for each neutron to the data acquisition system. The detector bias supply is also mounted on each module. The low-power electronics are designed

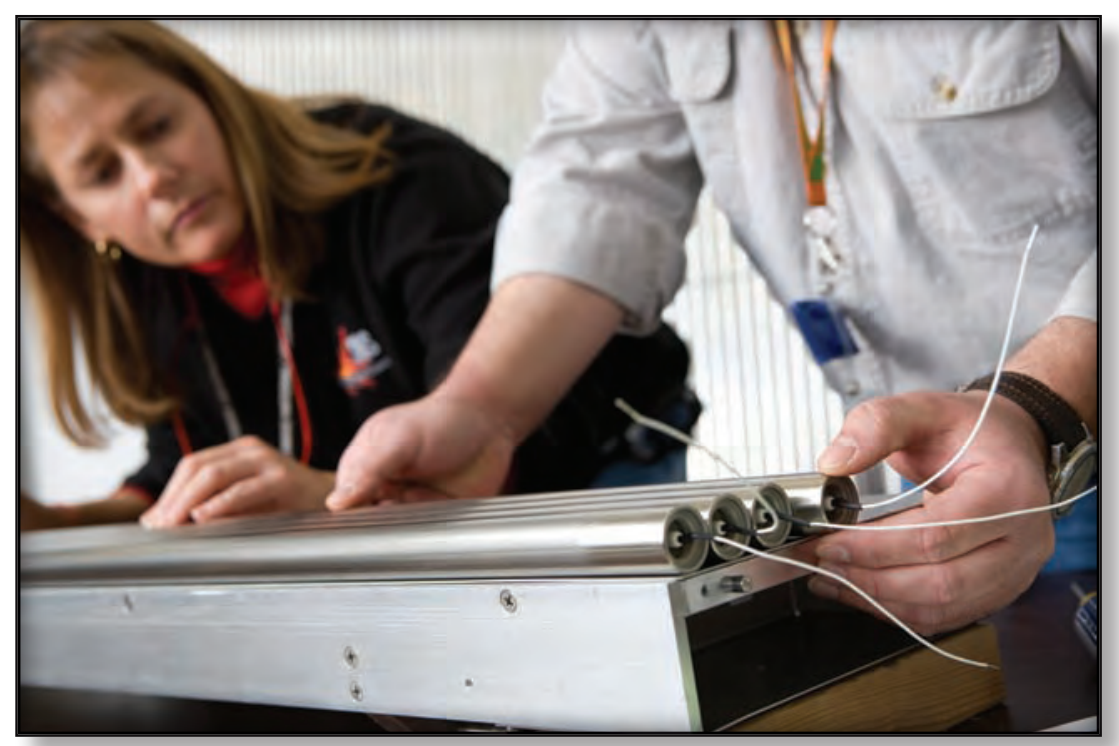

Pam Morrison and Will Reynolds of the SNS Detectors Group install a 2-meter-long LPSD into 8-packs for the Cold Neutron Chopper Spectrometer on beam line 5. for normal operation within the instrument vacuum tank.

One of the highlights this year was development of Pharos, a highly efficient neutron detector array that can operate on solar power and can be located anywhere without support facilities (see the Honors and Awards section for more details).

During 2007, all 115 ARCS modules (920 LPSD tubes, $2.5 \mathrm{~cm}$ in diameter $\times 100 \mathrm{~cm}$ in length) were completed and calibrated. In September, eight modules were used in the ARCS commissioning measurements. The full ARCS array was installed in early November.

LPSD tubes have been acquired and assembly is in progress for three more SNS instruments scheduled for 2008 commissioning, including the Extended Q-Range Small-Angle Neutron Scattering Diffractometer (300 tubes, $0.8 \times 100 \mathrm{~cm}$ ), the Cold Neutron Chopper Spectrometer (660 tubes, $2.5 \times$ $200 \mathrm{~cm}$ ), and the Fine-Resolution Fermi Chopper Spectrometer $(1440$ tubes, $2.5 \times 120 \mathrm{~cm})$. In addition, the LPSD systems will be used on the 
Hybrid Spectrometer, VISION Chemical Spectrometer, Nanoscale-Ordered Materials Diffractometer, and Corelli Diffractometer. All of these instruments are now undergoing design and prototyping. Other laboratories also have expressed interest in the LPSD system.

\section{Shifting Scintillator Detectors}

The shifting scintillator detectors, developed for the POWGEN Powder Diffractometer and the VULCAN Engineering Materials Diffractometer, are now in production for commissioning of these instruments in 2008. These detectors use ${ }^{6} \mathrm{LiF} / \mathrm{ZnS}: \mathrm{Ag}$ scintillators to convert neutrons to blue photons, which are then collected by a grid of wavelength-shifting fibers and transported to an array of photomultiplier tubes for position encoding. The fiber assembly technique has been transferred to a small business, PartTec, Ltd., which is now producing fiber assemblies for SNS. Eight POWGEN and three VULCAN modules have been assembled and will be ready for instrument installation in late 2008.

\section{Neutron Anger Cameras with Position-Sensitive Photomultiplier Tubes}

An all-new neutron Anger camera system was developed for the Spallation Neutrons and Pressure Diffractometer (SNAP) and the Single-Crystal Diffractometer (TOPAZ). The two-dimensional resolution goals, $1.3 \mathrm{~mm}$ for SNAP and $1 \mathrm{~mm}$ for TOPAZ, had not been achieved previously with neutron Anger cameras (or by any large-area, time-of-flightcapable neutron detector).

Each module uses 9 Hamamatsu 8500 positionsensitive photomultiplier tubes (PSPMT), each with 64 elements, in a $3 \times 3$ array behind a single $15 \times 15 \mathrm{~cm}^{2}$ GS20 $6 \mathrm{Li}$ glass scintillator plate. A glass diffuser plate and an innovative parahedral lens are located between the tube and the scintillator. The optics serve to spread the scintillation signal for position determination using Anger logic and to minimize the effects of gaps
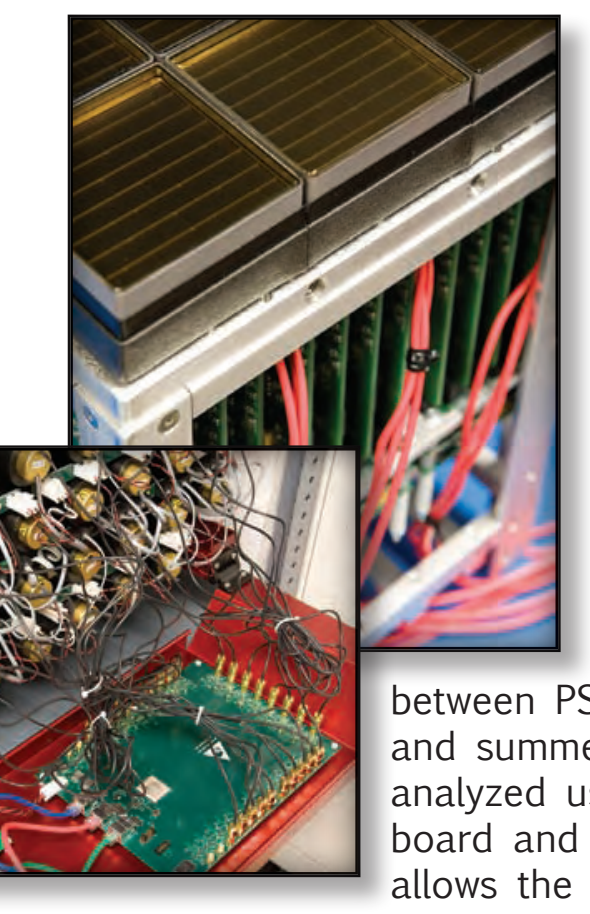
Top right: View inside an Anger camera showing the input windows of the position-sensitive photomultiplier tubes and their preamplifier boards.

Bottom left: Back of a shifting scintillator detector for the VULCAN instrument showing the photomultiplier tubes and the high-speedcomparator readout card, CROC.

between PSPMTs. The preamplified and summed photon signals are analyzed using the "Anger ROC" board and readout software, which allows the module to operate as a single element. Modules assembled and tested for SNAP have achieved the 1.3-mm SNAP resolution requirement; further development is in progress to reach the $1-\mathrm{mm}$ TOPAZ requirement. Additional Anger cameras are planned for the MaNDi Diffractometer. The Anger team achieved a major milestone by installing 18 assembled modules in SNAP in September.

In addition to developing detectors for installation, the Detector Group works to maintain detectors on operating instruments, including the Brookhaven area detectors on the SNS reflectometers. The group is also developing low-efficiency monitor assemblies for the SNS instruments. A new scintillator detector assembly laboratory went into service in 2007, and the group maintains two $35-\mu g{ }^{252} \mathrm{Cf}$ neutron sources for test and calibration, a smaller check source, and the interim HB-2DS Detector Test Station at HFIR. The SNS group is also participating in external development projects on scintillators, scattering detectors, and imaging detectors.

\section{Contact: Ron Cooper (cooperrg@ornl.gov)}

neutrons.ornl.gov/instrument_systems/components/ detectors.shtml 


\section{Data Ac quisition Systems}

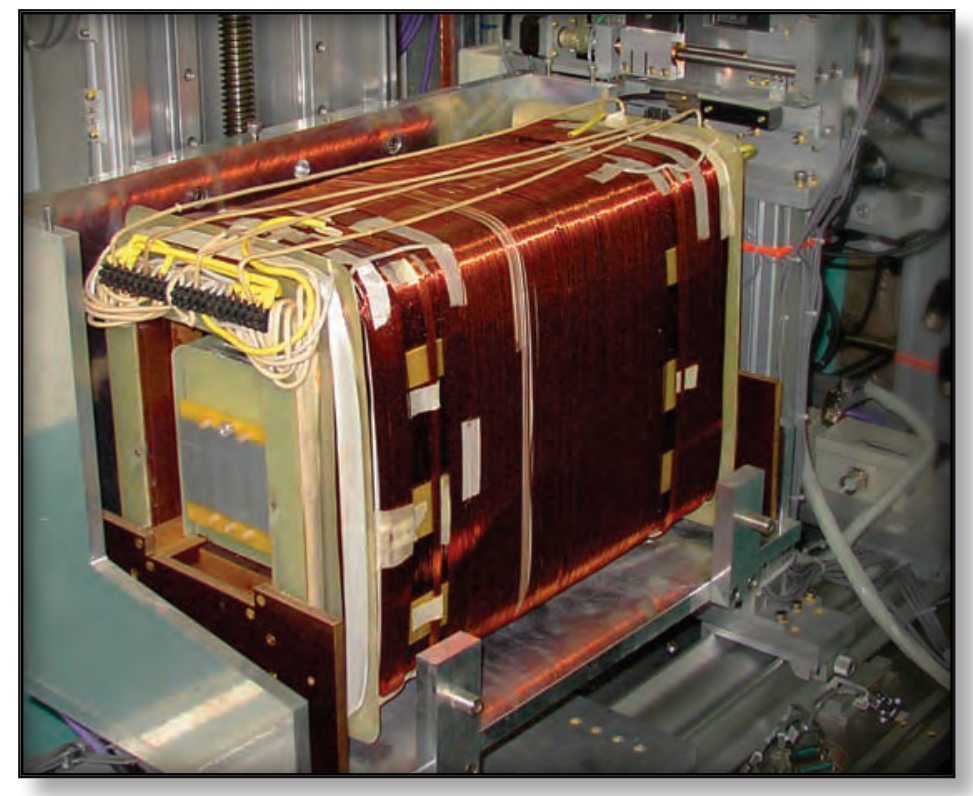

Over the next few years, the data rates and intensities produced at HFIR and SNS are expected to be among the fastest and highest possible. To prepare for that onslaught of information, the Data Acquisition Systems (DAS) Group has been working to develop and test software and electronics to meet the unique data collection and handling requirements of the neutron scattering instruments. Chief among these efforts is development of software that allows real-time control and visualization of instrument operation and neutron scattering data; coordination of hardware interfaces of various subsystems, such as sample environment; and design and assembly of custom electronics for detector systems.

Software development was a major emphasis in 2007, and the power of the Neutron Sciences DAS was demonstrated throughout the year as instruments were restarted and commissioned at both facilities. Software such as $\mathrm{C}++$ library modules and LabView Vls were tested extensively for ease of use and reliability under a variety of operational
The resonance spin flipper at the SNS Magnetism Reflectometer. This system and other magnetic equipment are now operational and controllable via the data acquisition system.

conditions with more than a dozen different users. New software features requested by the instrument scientists, such as region of interest and handling of polarization/analyzer state live views, were added during the commissioning and first user cycles, offering new methods of controlling long experimental sequences.

Additional software developments by the DAS group were key to successful data acquisition and real-time translation. During commissioning of the Wide Angular-Range Chopper Spectrometer at SNS, the DAS successfully provided real-time views of d-spacing while data was collected at a rate of two million events per second. These high data rates allow experiments to be completed in much shorter times, freeing up time for additional experiments. The popular SPICE software, which was developed to control and collect data on the HFIR triple-axis instruments, was expanded and upgraded to run the SANS instruments at HFIR. Automated notification of the data management server allowed real-time translation of non-Nexus files into NeXus format, which allows for easier sharing of data between collaborators. Python software was used as a scripting language to develop custom-control graphical user interfaces for spin flippers and polarizers for the SNS Magnetism Reflectometer. These customized scripts allow for greater flexibility in the control of instruments, while hiding many of the complexities of hardware control. In addition, version control for software development in the DAS Group was successfully migrated from CVS to Subversion, which is now the version control 
standard for both the data analysis and the data acquisition groups.

The adaptability of the software architecture was demonstrated at SNS, where custom user equipment was integrated with DAS control in less than a day. Field gate programmable array code was developed for the Anger readout card and comparator readout card boards using new techniques for position determination in the Anger camera detectors and crossfiber detectors. These innovations allow greater resolution, higher rates, and lower backgrounds for the detector systems.

As part of the buildout of the SNS instrument suite, the DAS Group oversaw the manufacture of about 1,000 large electronic boards designed for a variety of uses, such as position determination and time stamping, cross-

fiber detection, Anger camera detector systems, data concentration, supply of detector bias, optical transmission of detector data, communication to and from detector systems, and optical transmission of digital signals. All of the electronics were designed by the SNS DAS Group and represent a suite of state-of-the-art electronics for large-area, high-rate detector systems. Build kits were coordinated by Neutron Sciences staff and were manufactured by outside vendors.

This screen shows region-of-interest (ROI) capability for live display of data. An ROI can be defined in the two-dimensional display area, which controls what data are used to update other graphical displays of reduced data such as d spacing or energy transfer. das.shtml
Data acquisition needs will continue to grow as more instruments and ancillary equipment come online. In response, the DAS Group continues to work hard developing the best possible new software and improved hardware for data acquisition.

Contact: Rick Riedel (riedelra@ornl.gov)

neutrons.ornl.gov/instrument_systems/components/

Analysis Computer
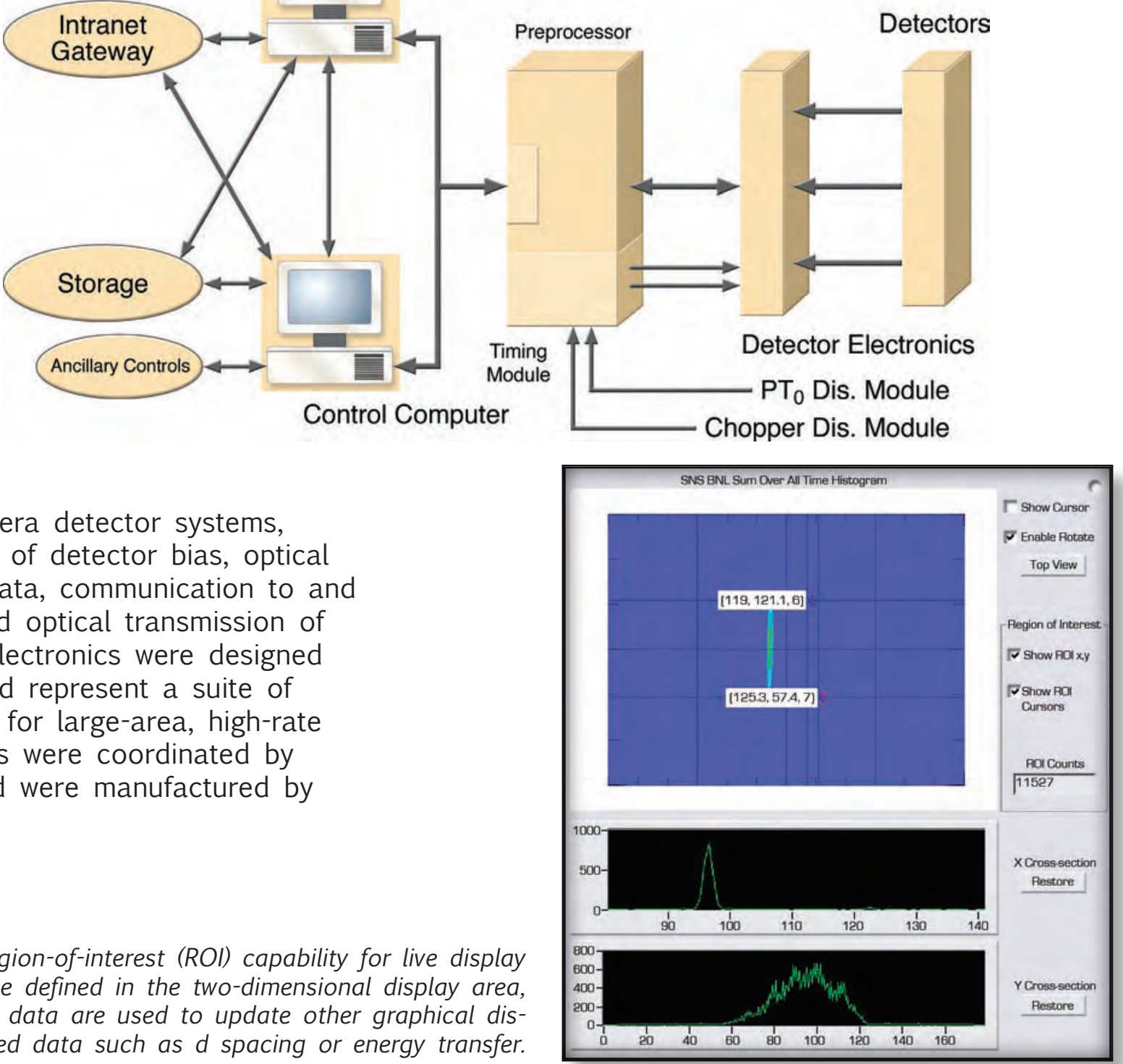


\section{Data Analysis}

The Scientific Computing Group helps researchers transform their experimental data into scientific results. This year marked a transition from developing infrastructure to providing commissioning support for instrument teams and to supporting the first facility users. As a result of these efforts, a framework is in place that automatically flows experimental data from the HFIR and SNS data acquisition system (DAS) into the centralized data management system via a process called "live cataloging."

Experiment data are compiled into NeXus format. As mentioned in the previous DAS section, NeXus files allow for more flexible sharing of data among different systems. NeXus is based on the Hierarchical Data Format (HDF5) supported broadly via commercial data processing applications such as IDL and IgorPro and community packages such as ISAW. A Web-based data access system called the Neutron Sciences Portal (the portal) provides users with ubiquitous access to data. Cataloging the data enables users to search and discover data of interest via the portal, while keeping the data accessible only to the experiment team.

Integrated with the portal are data reduction applications for the SNS Backscattering Spectrometer (BASIS) and the Liquids and Magnetism Reflectometers (the SNS instruments available to users 2007). These same data reduction applications are available both on site and off site via the portal. By (manually) cataloging data sets from both the Lujan Neutron Powder Diffractometer at the Los Alamos Neutron Science Center and the LENS Small-Angle Neutron Scattering instrument at the Indiana University Cyclotron Facility, we've also demonstrated that the data portal concept can be extended. The plan is to support live cataloging for these and additional instruments outside ORNL in the future, providing a centralized location for users to access and process their experiment data.

The portal currently provides access to a number of existing applications developed by the Scientific Computing Group. Applications are developed in

\begin{tabular}{|c|c|c|}
\hline \multicolumn{3}{|c|}{ Applications Available Via the Portal } \\
\hline $\begin{array}{l}\text { Developed by the Neutron } \\
\text { Sciences Scientific } \\
\text { Computing Group }\end{array}$ & $\begin{array}{l}\text { Community } \\
\text { Developed }\end{array}$ & $\begin{array}{l}\text { Commercial and Open Source } \\
\text { (availability might depend on } \\
\text { license availability) }\end{array}$ \\
\hline BASIS data reduction & DAVE & IDL \\
\hline $\begin{array}{l}\text { Liquids Reflectometer and } \\
\text { Magnetics Reflectometer } \\
\text { data reduction }\end{array}$ & EXPGUI & Matlab \\
\hline $\begin{array}{l}\text { Reflectometry data scaling } \\
\text { utility }\end{array}$ & FullProf & SigmaPlot \\
\hline $\begin{array}{l}\text { NeXus file creation utility- } \\
\text { converts event lists into } \\
\text { NeXus files }\end{array}$ & ISAW & Origin \\
\hline \multirow[t]{3}{*}{$\begin{array}{l}\text { Geometry generator utility- } \\
\text { used in conjunction with } \\
\text { data reduction }\end{array}$} & $\begin{array}{r}\text { McStas } \\
\text { (still in } \\
\text { beta test) }\end{array}$ & IgorPro \\
\hline & PDFgui & Python \\
\hline & WinPLOTR & Open Office \\
\hline
\end{tabular}

\begin{tabular}{|l|r|r|r|r|r|}
\hline Instrument & $\begin{array}{l}\text { NeXus } \\
\text { files }\end{array}$ & $\begin{array}{l}\text { Event } \\
\text { file size } \\
\text { (MB) }\end{array}$ & $\begin{array}{l}\text { Histogram } \\
\text { size (MB) }\end{array}$ & $\begin{array}{l}\text { NeXus file } \\
\text { size (MB) }\end{array}$ & $\begin{array}{l}\text { Compression } \\
\text { (\%) }\end{array}$ \\
\hline BASIS & 280 & 73.0 & 703 & 5.80 & 99.2 \\
\hline $\begin{array}{l}\text { Liquids } \\
\text { Reflectometer }\end{array}$ & 2191 & 2.4 & 233 & 6.80 & 97.0 \\
\hline $\begin{array}{l}\text { Magnetism } \\
\text { Reflectometer }\end{array}$ & 1346 & 27.0 & 148 & 7.58 & 95.0 \\
\hline
\end{tabular}

As instruments produce larger and larger histograms, the value of data reduction made available through the portal will continue to grow. 
conjunction with instrument commissioning in close collaboration with the instrument teams. Initially, data reduction applications were the primary focus. These applications can be segmented into two primary components, the graphical user interface (GUI) and the reduction engine. In essence, the $\mathrm{GUl}$ provides a convenient means of interacting with data, setting parameters, and configuring options in order to create command-line execution calls identical to those that could be manually typed on the analysis computer command line. It allows for significant flexibility as to which computers the GUI and reduction engines can be placed on, including installation on separate computers. The GUls used on the instrument analysis computers are also accessible via the portal. Separating the GUI from processing provides flexibility and insight into the requirements for portal-based computing and data management architectures.

Data analysis capability will also be significantly enhanced by the incorporation of software being developed in the neutron scattering community within

Instruments at neutron

facilities produce raw data that flow into the data management system via instrument-associated analysis computers to be prepped, cataloged, and archived. Users have access to data, applications such as data reduction, and computing resources through a portal interface. Via the portal, users can access both data and applications using a Web browser. Behind the scenes, a series of servers transact user requests, locating data and automatically selecting computer resources. Community-produced analysis applications such as PDFgui, ISAW, and DAVE are also made available to users. The portal provides a home area for storing data created by users. the DANSE (Distributed Data Analysis of Neutron Scattering Experiments) project, which is funded by the National Science Foundation. A number of DANSE applications are beginning to make their way into the portal. Leading the way is software developed for diffraction applications; however, the final suite will include small-angle neutron scattering, reflectometry, and inelastic software applications. New and improved DANSE applications will be made accessible via the portal as they become available.

Users can request computer access via https:// portal.sns.gov/accounts/.

\section{Contact: Steve Miller (millersd@ornl.gov)}

neutrons.ornl.gov/instrument_systems/computing/
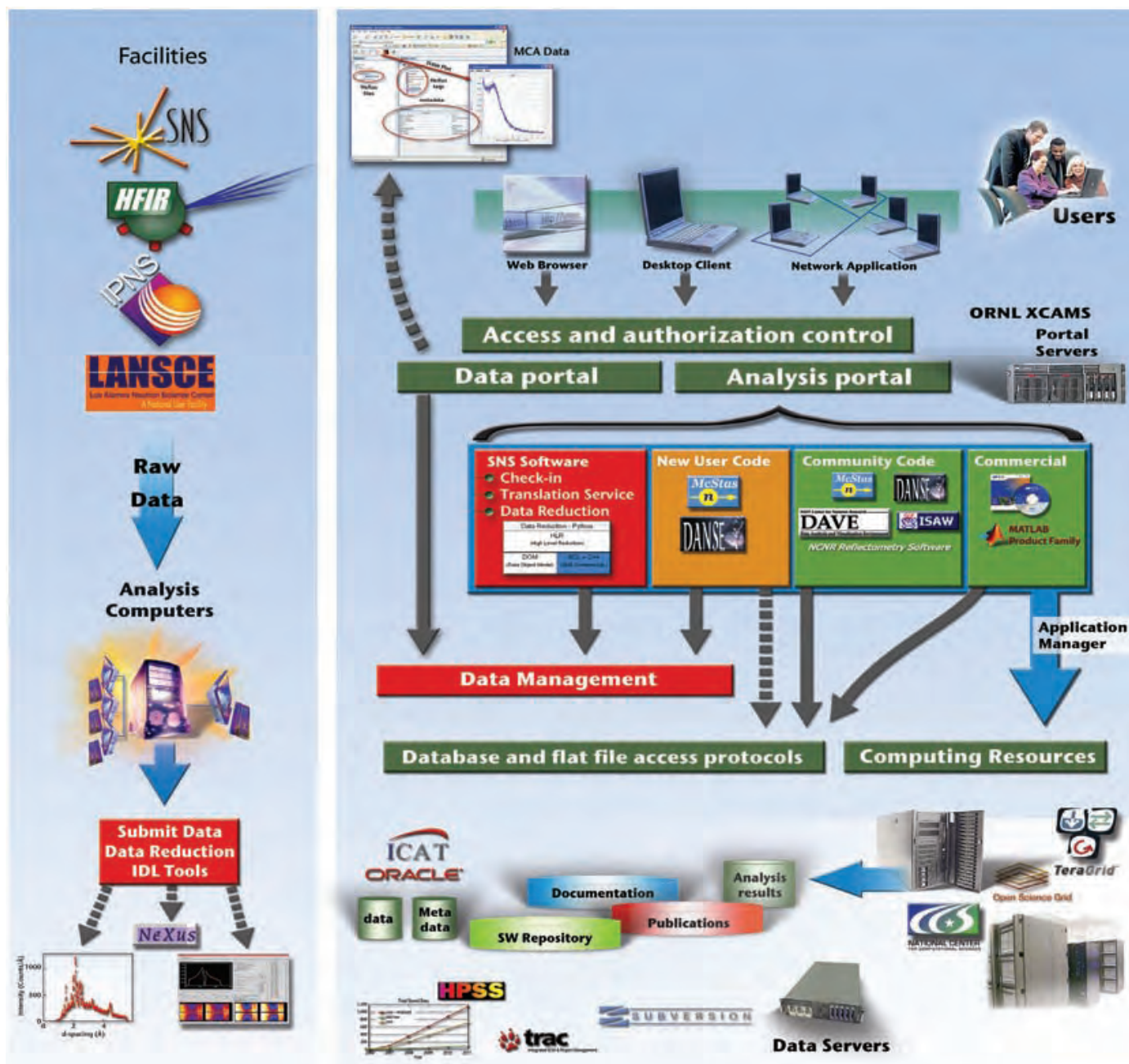


\section{Pola rized Neutron Development}

Polarized neutrons are used in studying magnetic structure and magnetic excitation phenomena in materials. Recently, neutron polarizers and analyzers based on spin-dependent neutron absorption by ${ }^{3} \mathrm{He}$ have become viable for neutron scattering. This type of neutron spin filter can accommodate a neutron beam with a wide bandwidth, large beam cross section, and large angular divergence. There is little if any background caused by small-angle scattering from the spin filter.

SNS staff have been working with the polarized ${ }^{3} \mathrm{He} \mathrm{R} \& \mathrm{D}$ community to develop polarized ${ }^{3} \mathrm{He}$ neutron spin filters for scattering. In a series of experiments carried out at the Single Crystal Diffractometer (SCD) at the Intense Pulsed Neutron Source (IPNS), they developed a compact neutron polarizer that can be installed at an instrument as needed. Improving upon the conventional use of such spin filters, in which the ${ }^{3} \mathrm{He}$ polarization decays over time, the new system maintained a stable non-decaying ${ }^{3} \mathrm{He}$ polarization online by continuously polarizing the ${ }^{3} \mathrm{He}$ for the duration of the experiment.

The SNS team also used the adiabatic fast passage (AFP) technique in nuclear magnetic resonance to flip the ${ }^{3} \mathrm{He}$ polarization with respect to the field, thereby creating a combined neutron polarizer and neutron spin flipper. A ${ }^{3} \mathrm{He}$ cell that reached $67 \%$ polarization at the SCD was used. The polarization of $3-\AA$ neutrons was determined by measuring the spin positive and negative beam intensities downstream of the ${ }^{3} \mathrm{He}$ polarizer. Repeatedly flipping the ${ }^{3} \mathrm{He}$ polarization at an equivalence of one flip every 5 minutes showed no impact on the polarization. In the most recent polarized SCD experiment, the magnetic structure of a single crystal of $\mathrm{Yb}_{14} \mathrm{MnSb}_{11}$ was measured and a previously unknown ferromagnetic structure identified.

After completing these experiments, the SNS team developed a ${ }^{3} \mathrm{He}$ analyzer, constructed at the National Institute of Standards and Technology, for the SNS Magnetism Reflectometer (at left). As in the test system, the instrument incorporated continuous polarizing capability to keep the ${ }^{3} \mathrm{He}$ polarization at its maximum and AFP to flip the ${ }^{3} \mathrm{He}$ polarization for spin positive and spin negative measurements. Commissioning tests for the analyzer are under way.

To meet the future demand for polarized ${ }^{3} \mathrm{He}$ spin filters-especially wide-angle analyzers that cover up to a $120^{\circ}$ span of scattering angles-SNS is developing a ${ }^{3} \mathrm{He}$ production system based on spin exchange optical pumping to polarize ${ }^{3} \mathrm{He}$. A largescale laboratory-based system (above) is being built that can produce a large volume of high-polarization ${ }^{3} \mathrm{He}$ gas and maintain the polarization until an experiment is conducted. It can also be used to fill sealed cells for online spin filter systems. A compact system is being designed for direct use at the SNS Hybrid Spectrometer and potentially at other instruments. 
Polarized neutrons are also used in neutron spin echo (NSE), a technique based on the neutron spin precession in a magnetic field. NSE has conventionally been used to achieve high-energy resolution in neutron scattering, but spin echo scattering angle measurement (SESAME) techniques are being developed to extend the technique to achieving high-angular resolution that cannot otherwise be reached. As illustrated below, parallelogram-shaped magnetic field regions are imposed before and after a sample. Neutrons that are not scattered by the sample find the precession in the two field regions canceled, whereas scattered neutrons acquire a net precession angle. The scattering angle can therefore be determined with high precision by measuring the change of neutron polarization.
The ongoing collaboration on developing SESAME techniques focuses on reaching micron-scale spin-echo lengths and minimizing the amount of materials in the neutron beam. These developments will be applied either to expand the measurement capability of an instrument or on a dedicated stateof-the-art SESAME instrument.

Contact: Hal Lee (leewt@ornl.gov)

In collaboration with Roger Pynn (SNS and Indiana University Cyclotron Facility), we have been developing SESAME techniques for scattering. In 2007, an experiment was conducted at the Asterix polarized neutron reflectometer at the Los Alamos Neutron Scattering Center (LANSCE). The experiment aimed at testing an approach that uses a series of triangular-shape coils to produce parallelogramshape magnetic fields while mitigating the complexity due to the inclined field boundaries. The setup, as shown at right, was tested for spin-echo small-angle neutron scattering measurements where 100-nm polystyrene spheres suspended in $\mathrm{D}_{2} \mathrm{O}$ with volume concentrations of $8.2 \%$ and $10.7 \%$, respectively, were used.

Principle of SESAME. For un-scattered neutrons, the spin precession in the parallelograms cancels, whereas for scattered neutrons, there is a net precession resulting in a change in the polarization. 


\section{Future Initiatives}

\section{SNS Power Upgrade and Second Target Station}

To improve the performance of the SNS neutron source, a power upgrade project is in the works that will double the proton beam power by the end of 2016, making twice as many neutrons available for the SNS neutron scattering science programs. This additional beam power will be achieved by increasing the energy of the protons by $30 \%$ from 1.0 to $1.3 \mathrm{GeV}$ and from raising the beam current by $60 \%$. The project will include an upgrade of the target systems to withstand the higher power. The project is waiting on approval to begin planning and preliminary engineering, and construction is expected to start in 2010.

To provide a second source of neutrons to more instruments, SNS is developing plans and conceptual designs for a second target station. Studies show that this station will improve performance by more than an order of magnitude for broad areas of forefront science and could open totally new areas to exploration. Construction could be finished in 2019.

\section{Contact: Kent Crawford (crawfordrk@ornl.gov)} neutrons.ornl.gov/facilities/proposed_upgrades.shtml

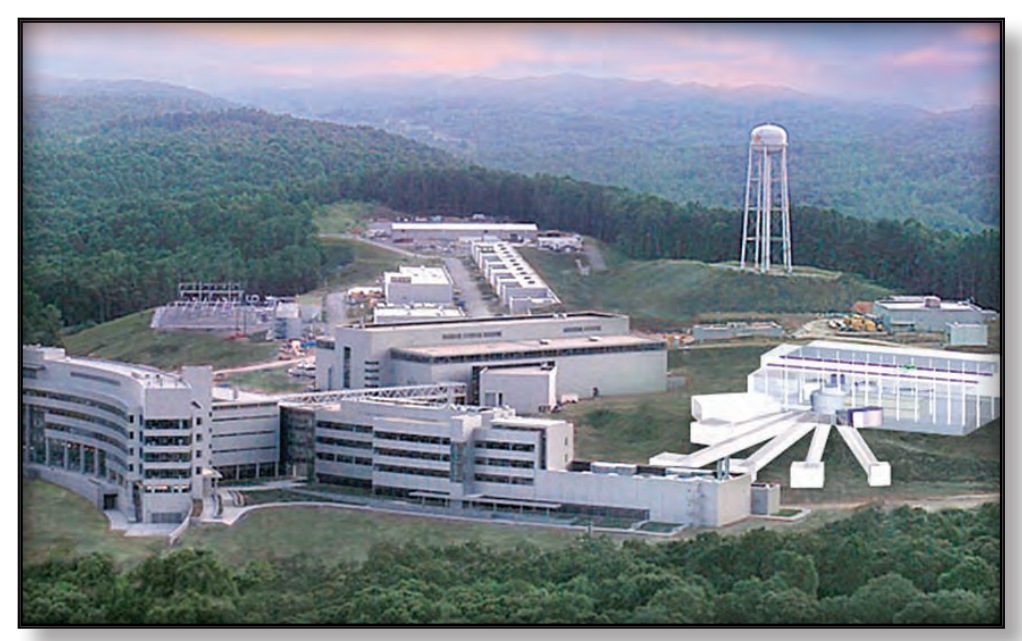

SNS site on Chestnut Ridge. On the right is the projected location of the second target station.

\section{Second Cold Source and Neutron Science Center at HFIR}

As part of DOE's Facilities for the Future: A TwentyYear Outlook plan, HFIR is pursuing a second cold source and guide hall to support nine cold neutron guides with higher brightness than existing guides. In addition, to provide more permanent space and to satisfy future needs, layout and planning have started for the HFIR Neutron Science Center. This center would provide office and lab space and other user support facilities. Decisions to proceed with either or both of these projects are expected about 2012.
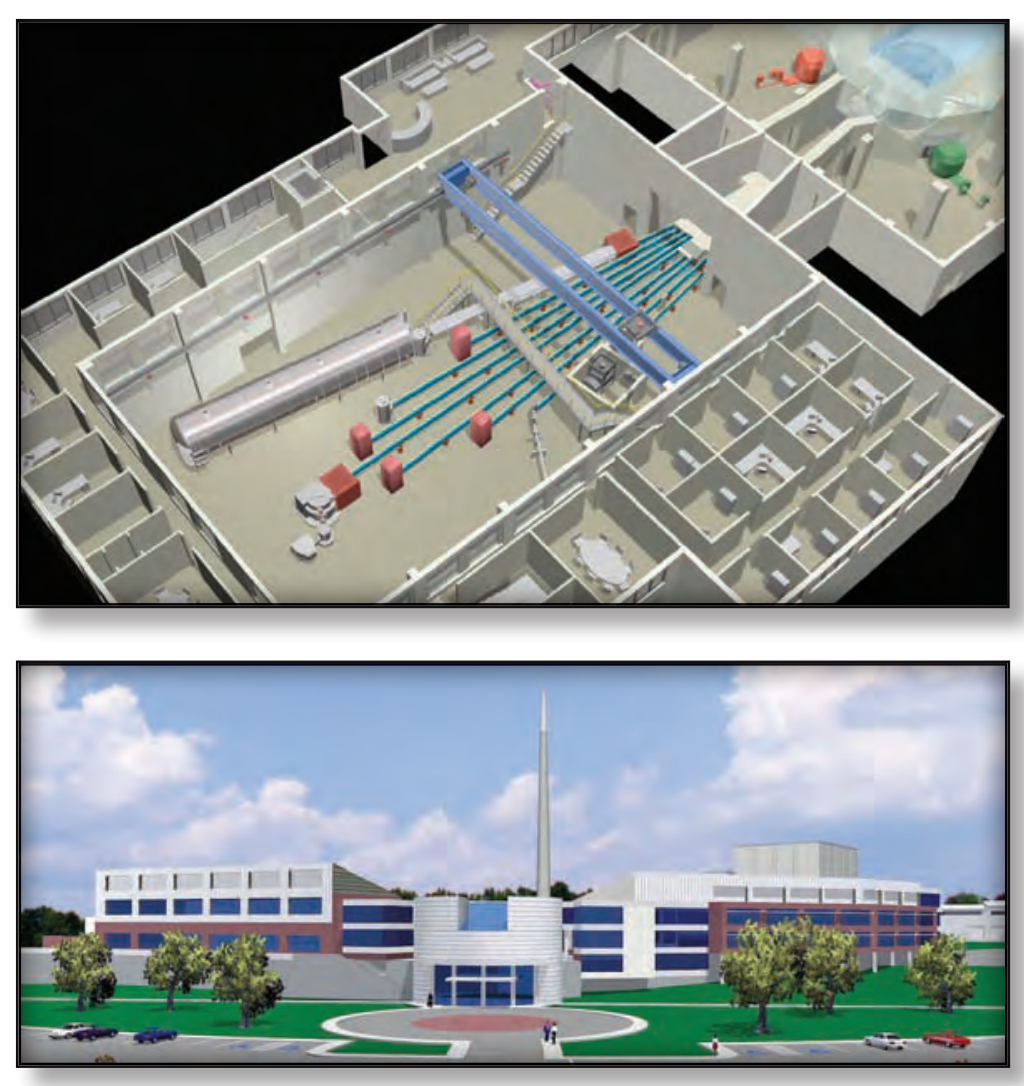

Top image: Rendering of the HFIR cold source and guide hall with nine beam lines. Bottom image: Artist's conception of the proposed HFIR Neutron Science Center. 


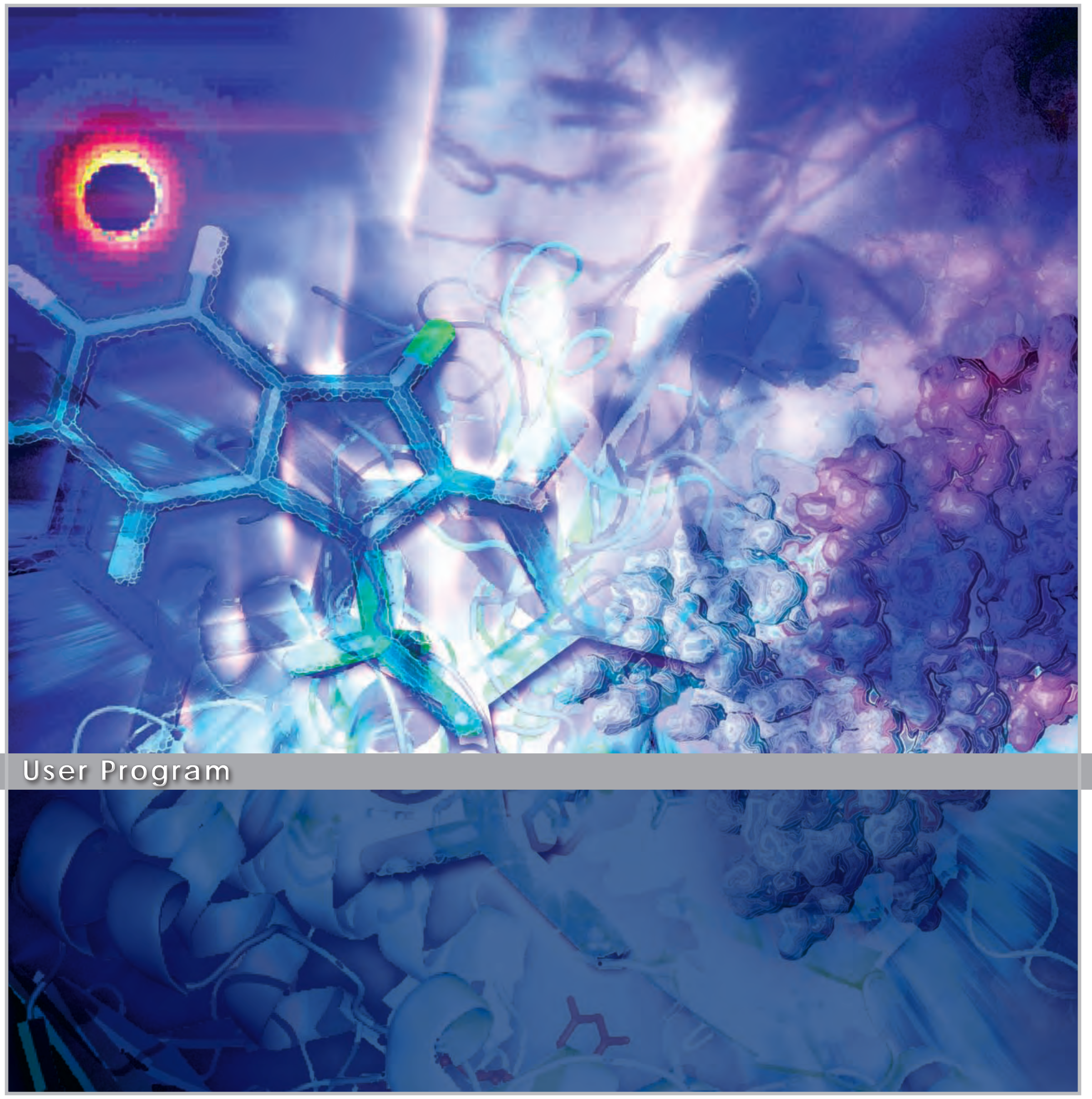




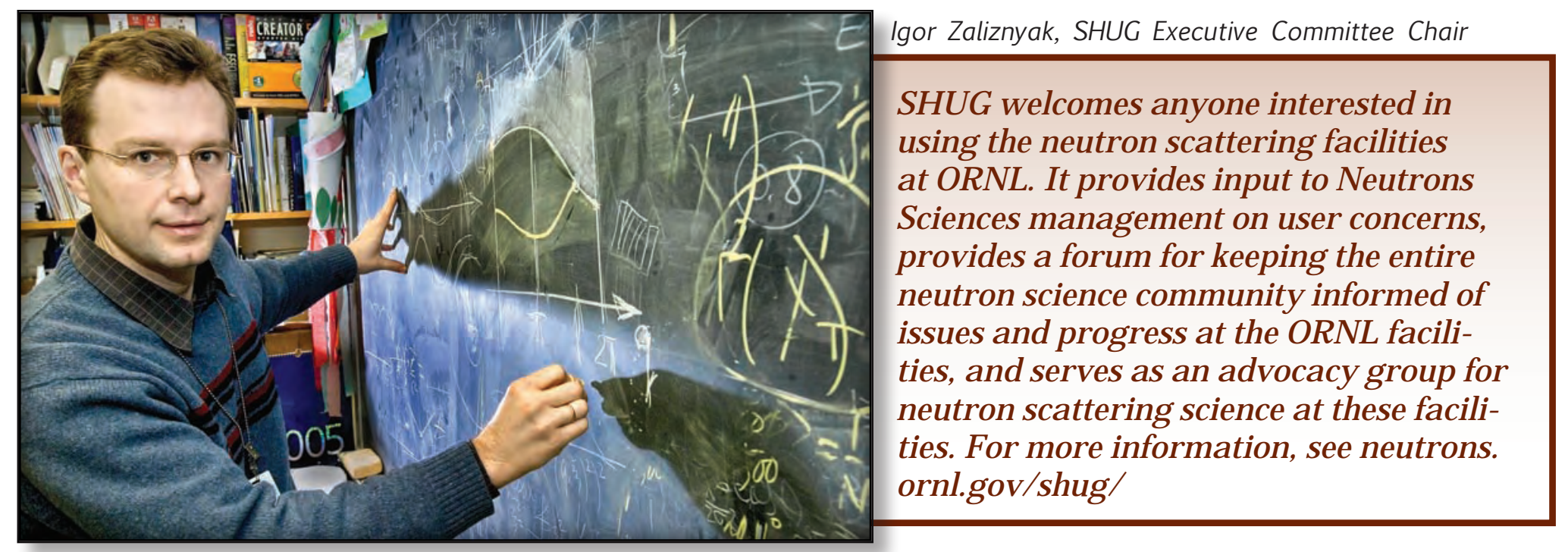

\section{Fellow HFIR and SNS users,}

It is my pleasure to serve as chair of the SNS-HFIR User Group (SHUG) at a time of good news and exciting events. Thanks to dedicated efforts by ORNL staff and many SHUG members, ORNL's neutron facilities are up and running. Users can now take part in the frontier science these facilities make possible.

Although not all instruments are yet online, the emphasis at SNS and HFIR is shifting toward reliable operation and development of the user program. A vibrant, vigorous user program is key to the success of these facilities-success that will ultimately be demonstrated by the quality of the research and the scientific advances that emerge.

Running an efficient user program requires close cooperation and coordination with the user community. The ORNL Neutron Sciences staff are eager to work with users, both by informing us of news and developments and by listening to our concerns and suggestions. The SNS-HFIR user meeting at ORNL on October 8-11 provided a forum for such communication. The scientific agenda presented an overview of scientific issues the neutron community will address using SNS and HFIR, as well as technical challenges the facilities face. On behalf of the meeting organizers and the SHUG Executive Committee, I thank all those who participated.

Development of software tools was mentioned as a top challenge for the facilities, particularly for the new instruments. Another important challenge is developing funding models for user support and education, including travel support for new users. Several such programs have already been established at ORNL, among them an undergraduate summer research program, the Clifford Shull and Instrument Development fellowships, and the Joint Institute for Neutron Sciences.

An important goal for the user program is increasing the size of the user community. Steps toward this goal will include finding new ways to attract students and researchers from universities and industry, as well as working to obtain new funding sources. As a core user group, SHUG must play a central role in community building and educational and outreach activities, expanding the ranks of researchers using neutron tools.

I wish you success with your upcoming experiments at SNS and HFIR.

Igor Zaliznyak, SHUG Executive Committee Chair 


\section{HFIR and SNS: Open to Users}

Within a few years, HFIR and SNS are expected to host more than 1000 users annually. One user program serves both facilities and was developed from experience at HFIR and other national and international user facilities, with the best practices adapted to the environment at ORNL. The goal of the program is to provide world-class user services at these facilities. Current user program activities are focused on three areas: the proposal system, user administration, and outreach and education.

\section{Proposal System}

The user program's most important effort in 2007 was development of the Integrated Proposal Tracking System (IPTS). This Web-based system became available to the user community during the July call for proposals, which resulted in more than 200 submissions. The second call for proposals ended in January 2008. We anticipate at least two annual calls for proposals, each to be announced about two months before the proposal window opens.

The Center for Nanophase Materials Sciences (CNMS), located adjacent to SNS, has a strong interest in materials characterization using neutrons. Because of these close ties and the adaptability of the IPTS to other user facilities, CNMS will also use IPTS for its proposals in the future.

The 2007 effort was just the first stage of IPTS development. Future IPTS enhancements will include expanding the flexibility of processing reviews; initiating scheduling and sample management systems;

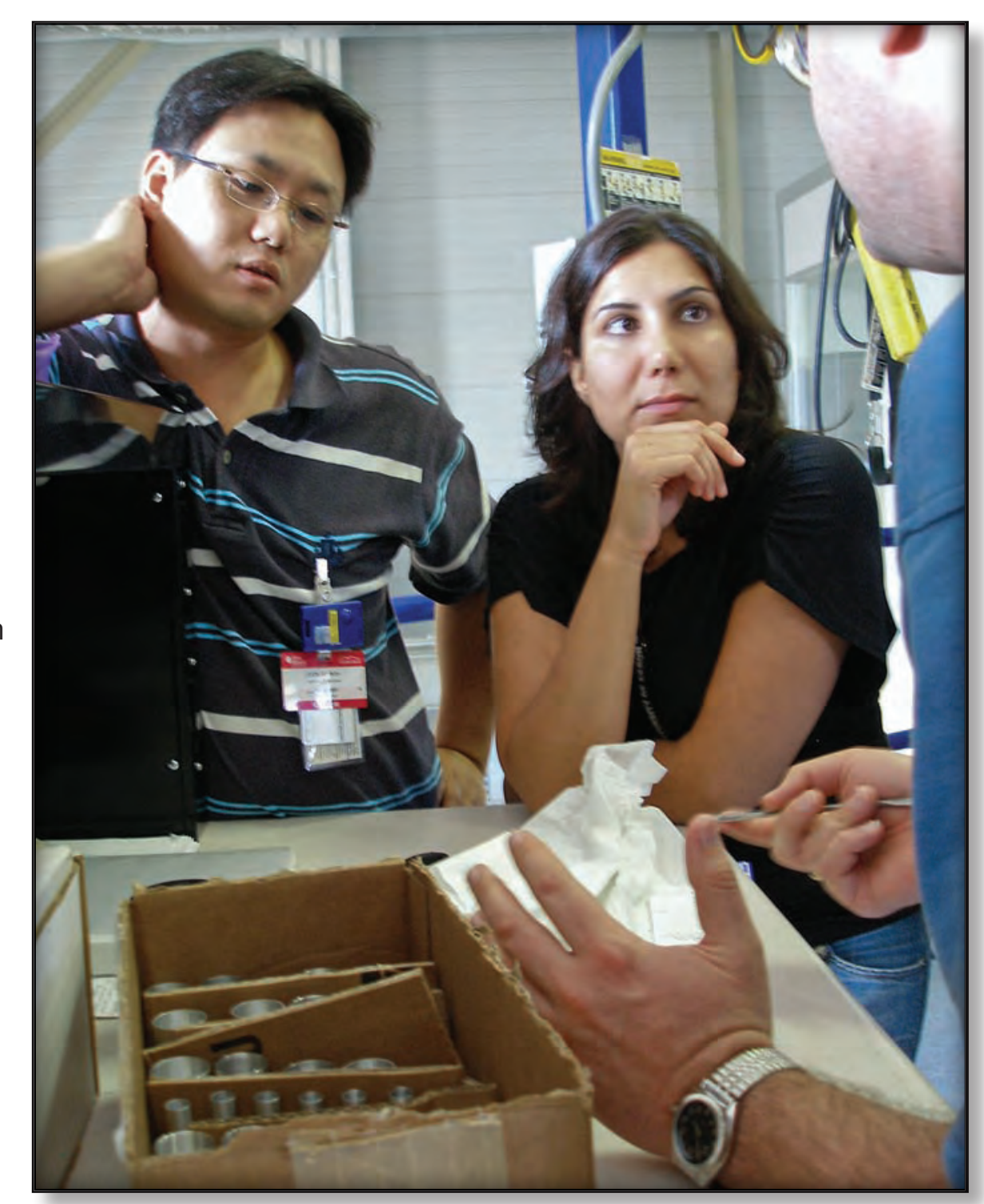

Users Joon Ho Roh and linking to other ORNL systems, including those related to site and facility access, training, and publications.

(University of Maryland) and Sheila Khodadadi (University of Akron) talk with Eugene Mamontov (right), instrument scientist for the SNS Backscattering Spectrometer. Along with two other users from the University of Akron, the team conducted an experiment on the relaxation dynamics of hydrated RNA. 


\section{User Administration}

After proposals are reviewed and beam time is awarded, users prepare to visit ORNL. Protocols are in place for all users to take three Web-based courses, each requiring about an hour, before arriving at ORNL. Completing the courses before coming to ORNL expedites facility access and the completion of required training for which the courses are prerequisites. All users must successfully complete a radiological worker training practicum for neutron scattering users and about 2 to 4 hours of hands-on training specific to the instruments and labs they will be using. Users also receive dosimeters and reference cards with key telephone numbers and safety reference information. Our goal is to have new users ready to begin their experimental work in about a half day. Training is valid for two years, and returning users can receive their badges and dosimeters and begin work immediately if their training is current.
At the end of an experiment, a user completes an online survey; returns the ORNL badge, dosimeter, proximity card, and reference cards; and notifies the user office of any publications resulting from the research.

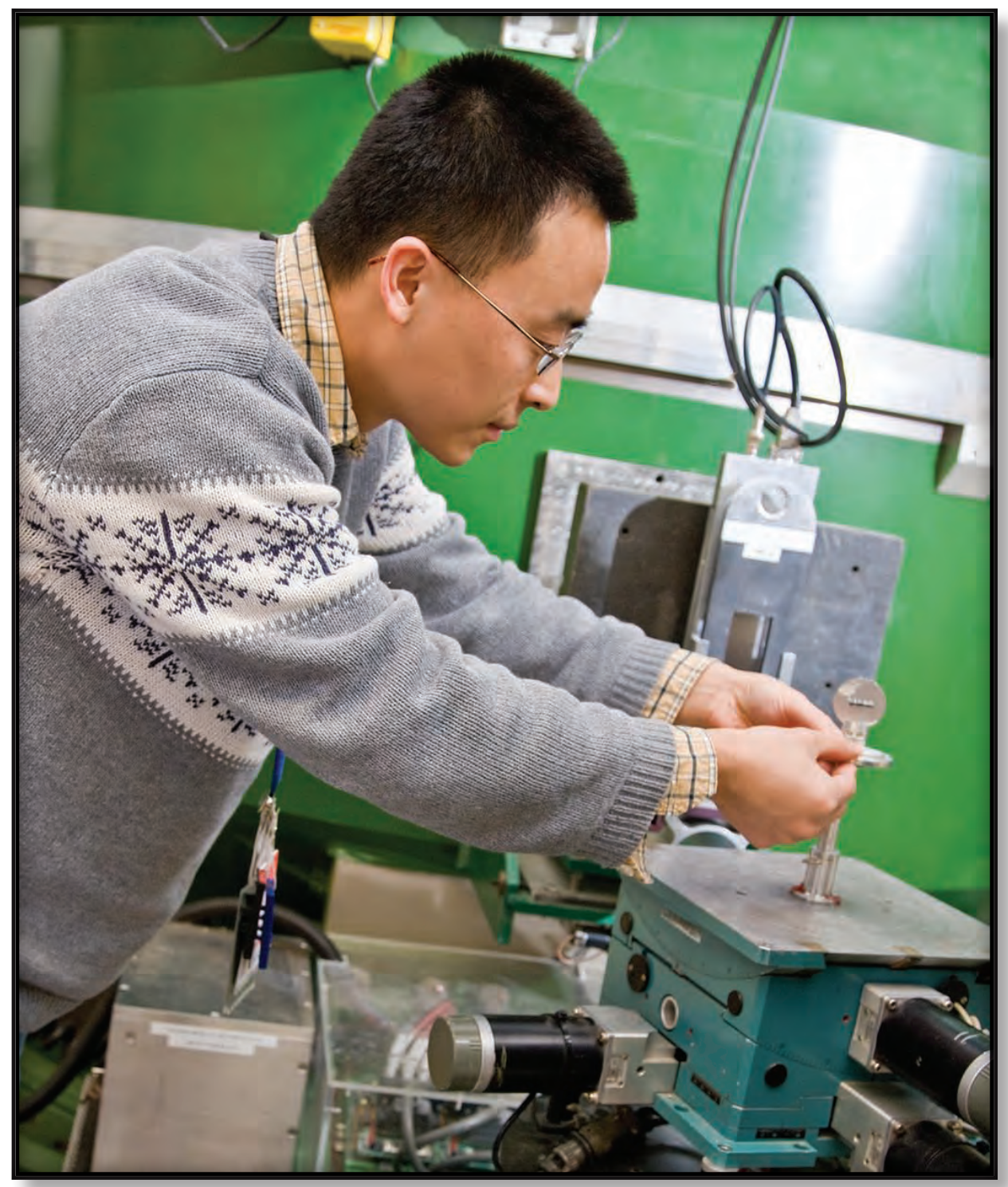

Feng Ye of ORNL works with the HB-3 Triple-Axis Spectrometer at HFIR.

The Neutron Sciences Web site (neutrons.ornl.gov) provides more information about policies, practices, and expectations for users. Information about the Oak Ridge and East Tennessee area and links to other on-site resources are also available.

\section{Outreach and Education}

Outreach and education are necessary not only to develop a user community but also to identify the resources needed to perform cutting-edge science. In response to requests from the user community for additional information, several means of communication have been established. Monthly progress reports are distributed electronically to the 1400 individuals on the $\mathrm{Neu}^{-}$ tron Scattering Science Division mailing list and are 


\begin{tabular}{|l|r|r|}
\hline User Statistics for 2007 & SNS & HFIR \\
\hline Badged Users (total) & 24 & 72 \\
- First-time users & 24 & 43 \\
- Students & 10 & 14 \\
- Postdocs & 4 & 18 \\
\hline Support Sources & & \\
- U.S. Department of Energy (DOE) & 10 & 30 \\
- Office of Basic Energy Sciences & 5 & 13 \\
- DOE other & 3 & 2 \\
- Nat. Department of Defense & 2 & 16 \\
- National Science Foundation & 1 & 8 \\
- Industry & 4 & 4 \\
- Other & 540 & 1178 \\
\hline - Operating Hours Available to Users & & \\
\hline
\end{tabular}

Current and prospective users became acquainted with the research capabilities of the user facilities through presentations, tours, and workshops. Attendees were also introduced to the user proposal process.

Contact: Judy Trimble (trimblejl@ornl.gov) neutrons.ornl.gov/users/

posted on the Neutron Sciences Web site (neutrons. ornl.gov/snsnews/progress_reports.shtml). A general fact sheet about SNS and HFIR is also available on the Web at neutrons.ornl.gov/pubs/fs_hfirsns.pdf. Articles about the ORNL Neutron Sciences have appeared in several technical journals, and two issues of The Neutron Pulse users newsletter were issued by the Neutron Sciences User Office in 2007. Beginning in 2008, The Neutron Pulse will be replaced by the Neutron Sciences annual report.

On October 8-11, the SNS-HFIR User Group helped stage a highly successful ORNL Users Week. The event focused on the scientific resources of four ORNL user facilities funded by the DOE Office of Basic Energy Sciences: the Spallation Neutron Source, High Flux Isotope Reactor, Center for Nanophase Materials Sciences, and Shared Research Equipment Program. Some statistics from the event are shown above.
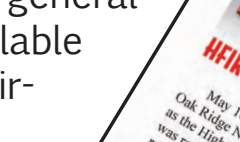
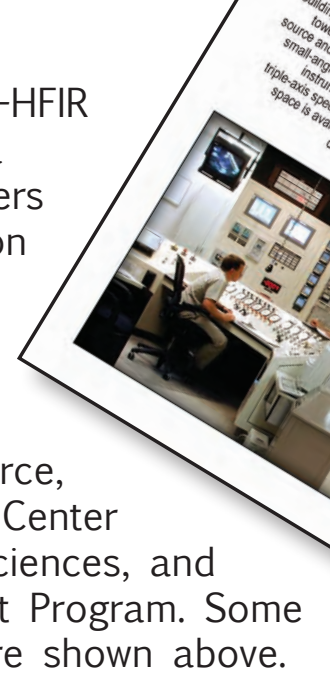

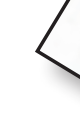

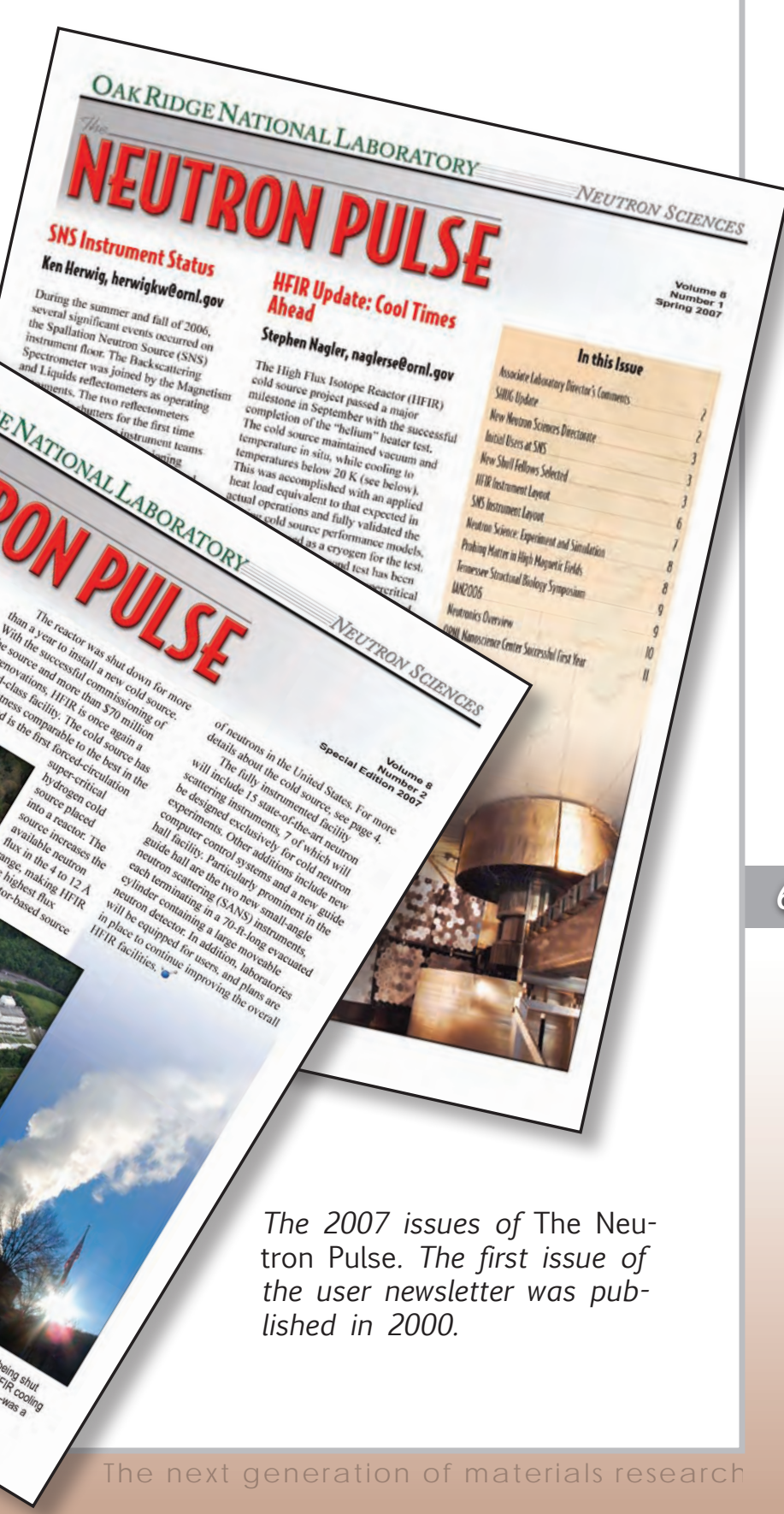


SNS Liquids Reflectometer users Joe Strzalka (left) and Venkata Nagarajan (right) participated in the first measurement of a free liquid surface on the instrument. Both users are from the University of Pennsylvania.

ORNL Users Week Statistics

Number of registrants

Institutions represented:

- Colleges and universities

Regions represented:

- U.S. states and District of Columbia

- Foreign countries

Sessions registered for:

- Nanoscience

- Neutrons

- Combined sessions

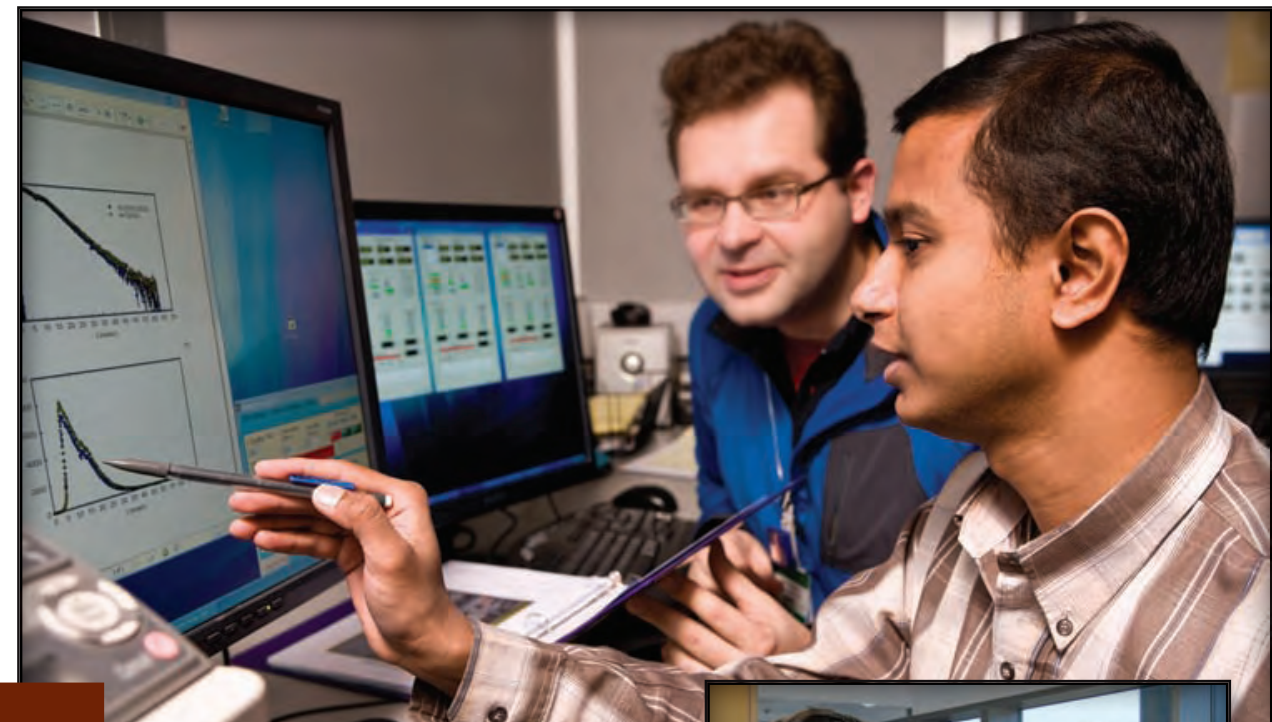

\begin{tabular}{|l|l|}
\hline Registrants for nine tutorial sessions & 200 \\
\hline
\end{tabular}

Attendees at the 2007 ORNL Users Week Workshop.
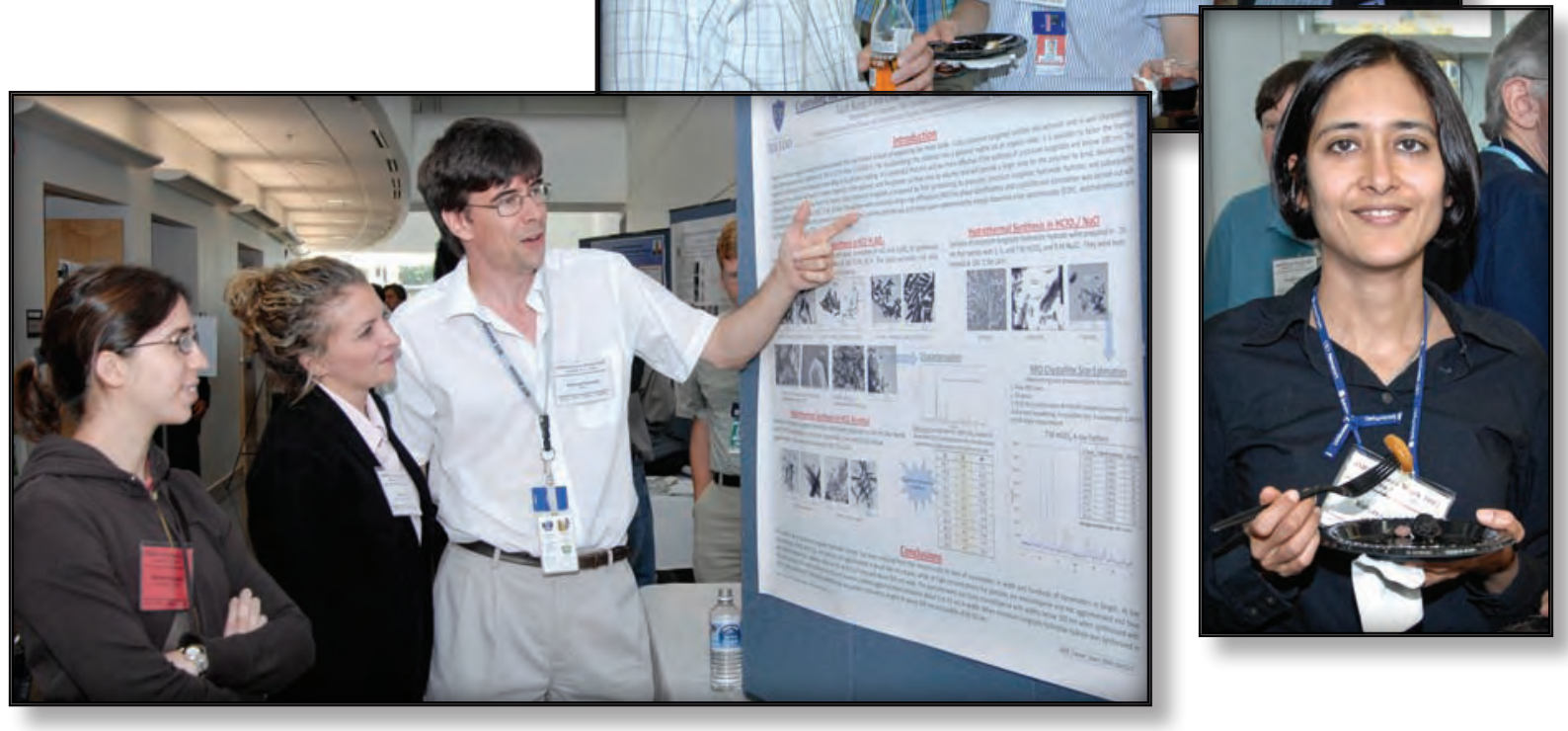


\section{Accessing Beam Time at HFIR and SNS}

Access to Oak Ridge user facilities such as HFIR or SNS is a two-step process:

1. Review and approval of the user's proposal.

2. Signed agreement between the user institution and UT-Battelle, LLC, the managing contractor of ORNL.

ORNL's Neutron Science User Program supports research at HFIR and SNS. General users receive at least $75 \%$ of the beam time allocation for the instruments included in the general user program. Proposals for time on the instruments are submitted electronically through the Integrated Proposal Tracking System (IPTS), which will also be used for the Center for Nanophase Materials Sciences, located adjacent to SNS. This system provides easy, convenient access to all three facilities. Details about IPTS, including policies and guidelines, are available at neutrons.ornl.gov/ users.

When a proposal has been accepted, ORNL's Technology Transfer and Economic Development Office executes a user agreement with

the user institution. This agreement, which can be either proprietary or nonproprietary, stipulates the terms and conditions for the interaction (including disposition of intellectual property). Most user research will be in the public domain and must be disseminated by publication in the open literature; policies for access for proprietary research are listed at the Web site just mentioned.

Each external user must have an ORNL contact who works closely with the principal investigator and

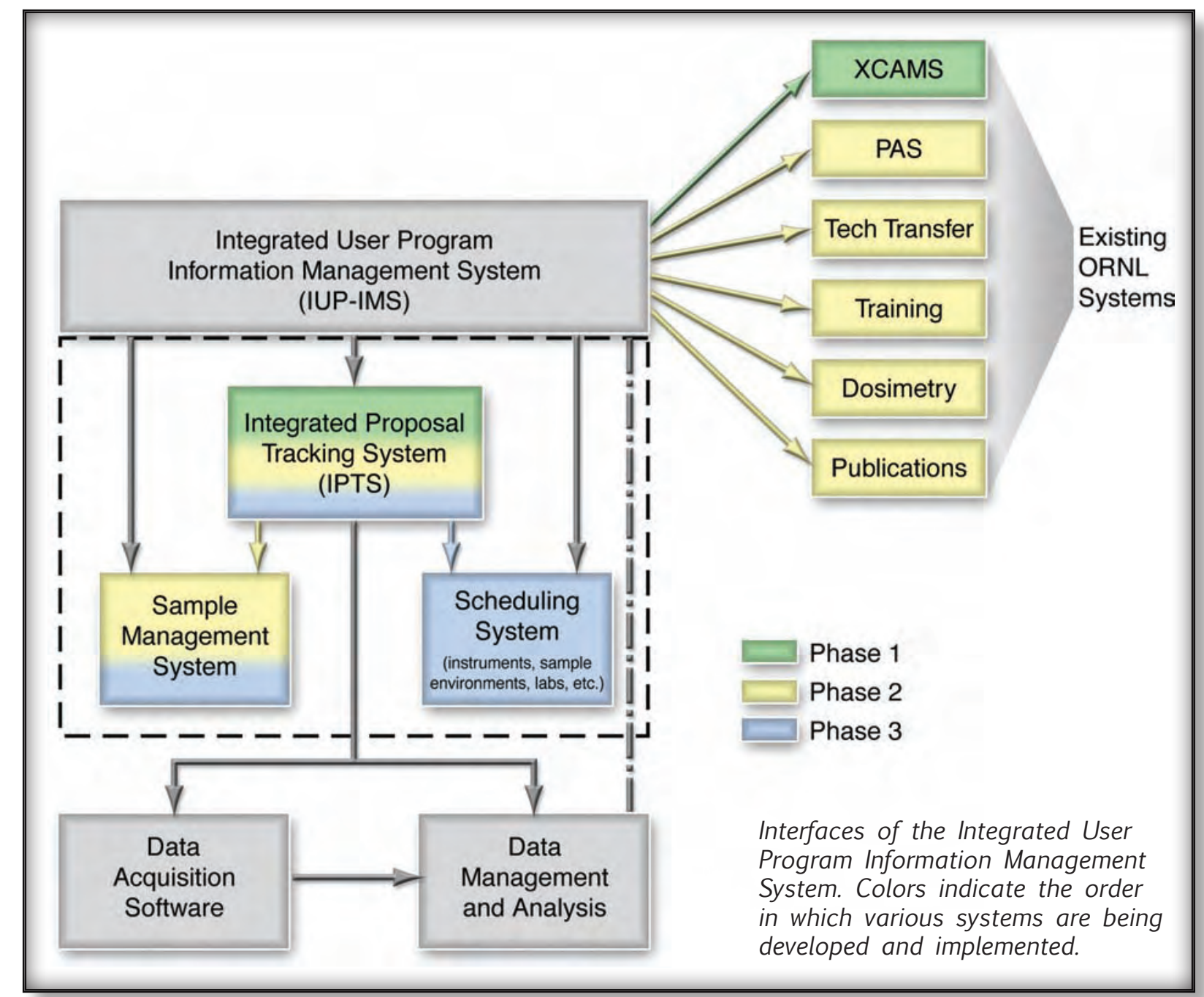


the experiment team to prepare and perform the experiment. Prospective users should examine the appropriate instrument pages (neutrons.ornl.gov/instrument_systems) and contact instrument scientists when developing proposals. Each instrument has a Web site that describes the capabilities and functions of the instrument and identifies the instrument scientist. The instrument scientist can help to confirm the feasibility of a proposed experiment and the effectiveness of the research technique and answer questions about the capabilities of the instrument.

The evaluation criteria used in the peer review procedures for all users are proposed by the International Union of Pure and Applied Physics in its recommendations on the operation of major user facilities (www.iupap.org/ga/ga22/majfacil.html). There are four criteria:

- scientific merit

- technical feasibility

- capability of the experimental group

- availability of the resources required

The goal of HFIR and SNS is to maintain a safe, ecologically sound research environment for users. Facility staff and users shall place the highest priority on protecting the health and ensuring the safety of HFIR and SNS users and visitors, ORNL personnel, and the public and on preventing damage to property and the environment. All reasonable measures will be taken to do so. Facility operations are never given a higher priority than personnel safety.

For additional information about becoming a user at HFIR or SNS, contact the Neutron Scattering Science Division User Office:

neutronuser@ornl.gov 865.241.3675 neutrons.ornl.gov/users.

Mirror guide for the SNS Cold Neutron

Chopper Spectrometer on beam line 5 . 


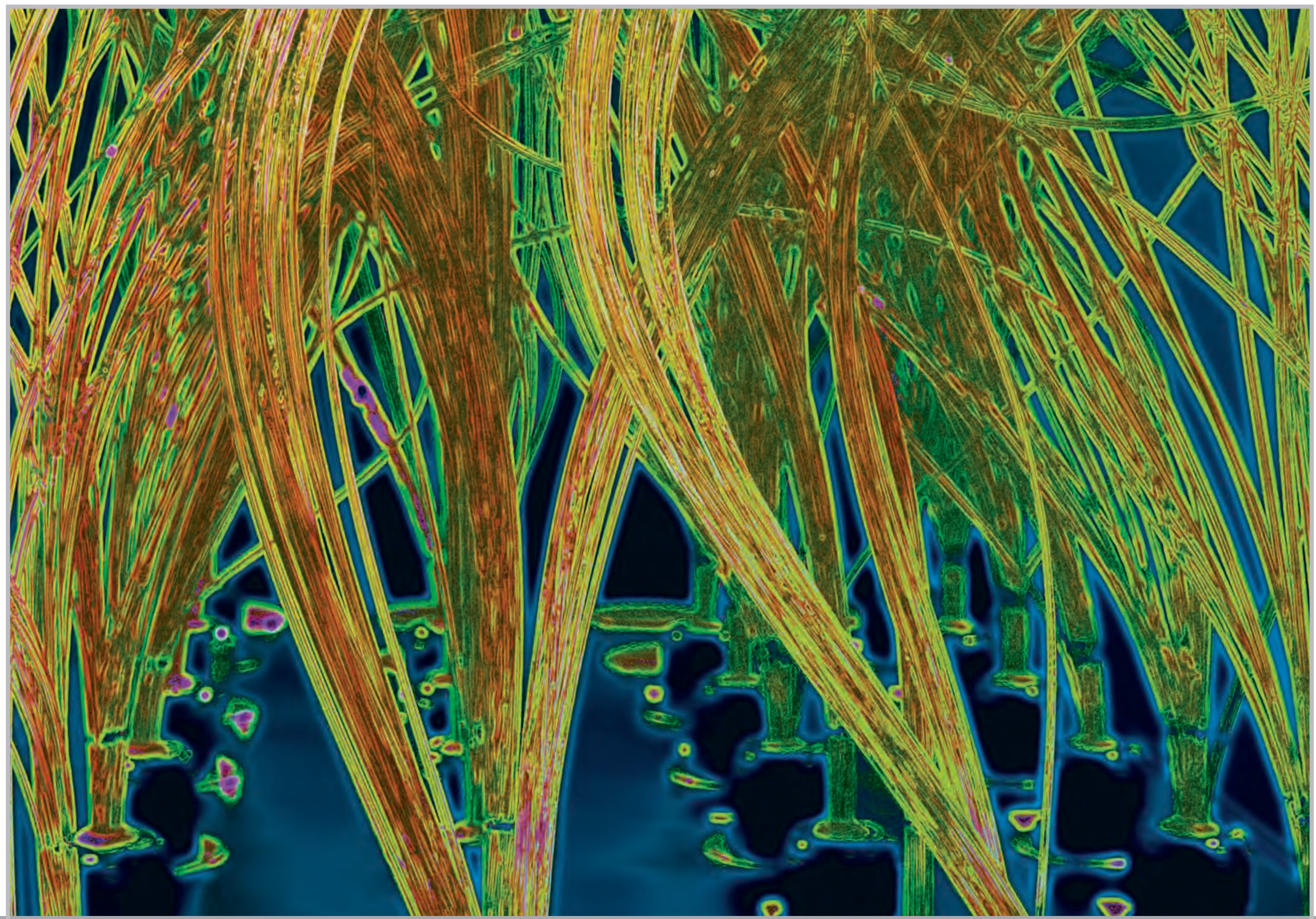

Education and Outreach

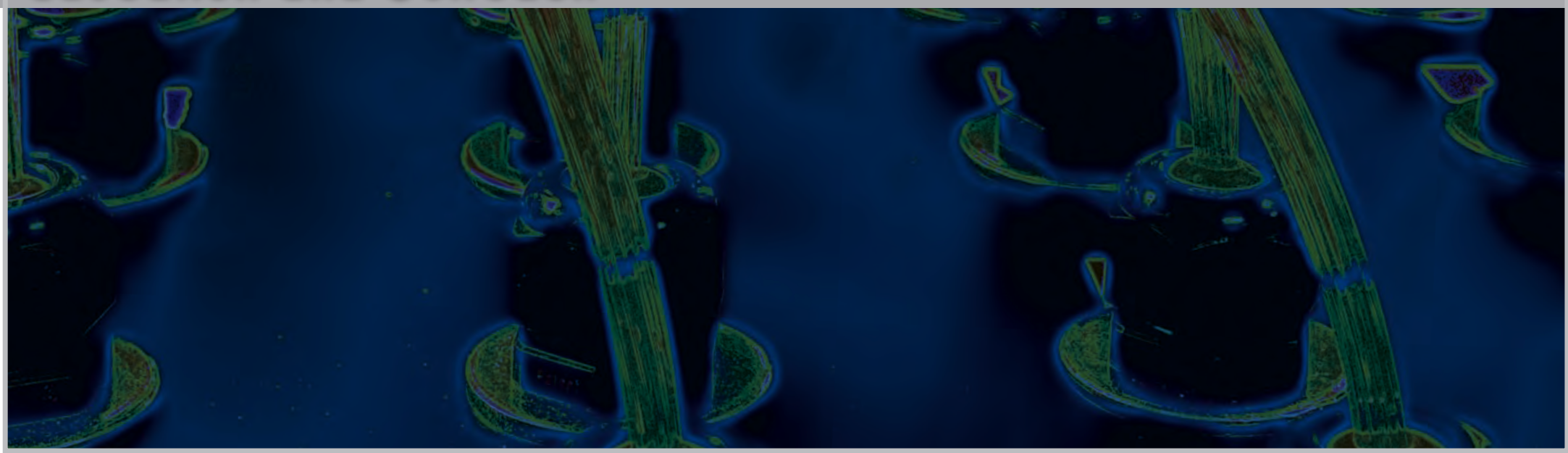




\section{On-Site Research and Educational Opportunities}

One of the priorities of the Neutron Sciences is to educate scientists, students, and the public about the benefits and possibilities of neutron scattering research. Some of the ways we accomplish this include

- Fellowships and sabbatical opportunities for researchers

- Internships for high school and college students

- Meetings and workshops for the scientific community

- The J oint Institute for Neutron Sciences

- Presentations at local universities and public schools

- Presentations at meetings of local community organizations

- Facility tours for the public and special visitors

- Community days at HFIR and SNS that are open to the public

- Outreach materials such as publications, displays, and multimedia

- Neutron Sciences public Web site

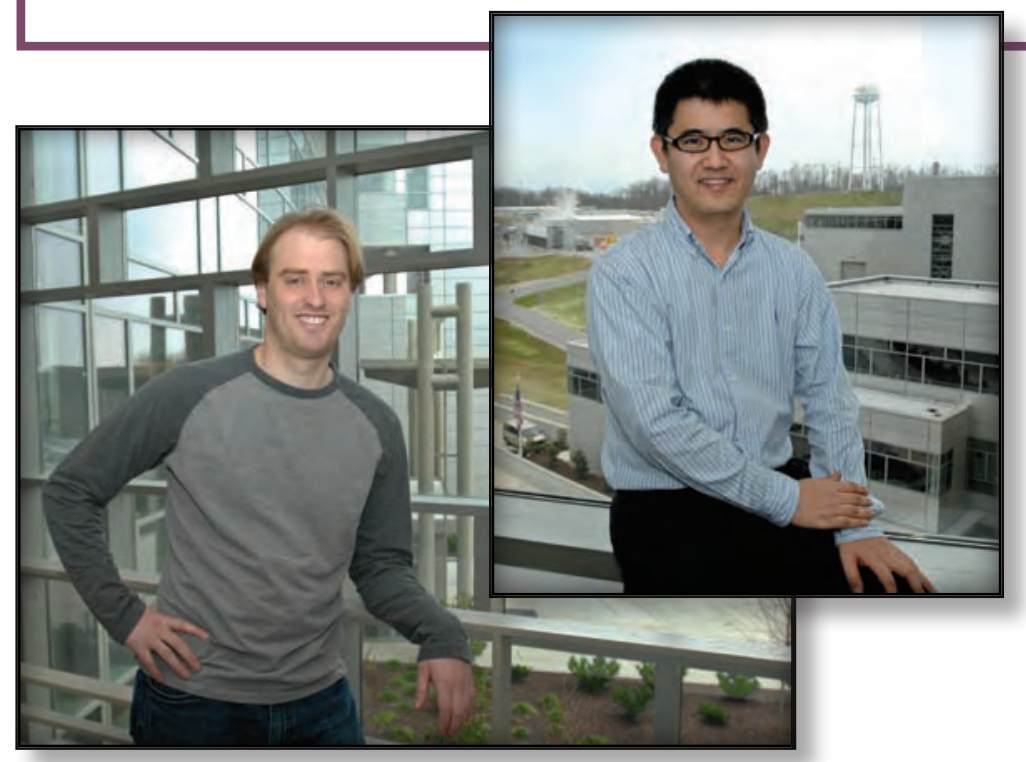

Shull fellows for 2006: Andrew Christianson (left) and WeiRen Chen (right).

Shull fellows for 2007: Christopher Stanley (left) and Sylvia McLain (right).

\section{Fellowships}

Two types of fellowships are funded by the Neutron Scattering Science Division: the Clifford G. Shull Fellowship and the Instrument Development Fellowship.

\section{Clifford G. Shull Fellowship}

The Clifford G. Shull Fellowship was established in 2005, with the first appointments in 2006. Corecipient of the 1994 Nobel Prize in physics, Shull began his work in 1946 at what is now ORNL. He has been called the "Father of Neutron Scattering," and this fellowship was established in recognition of his pioneering work in this field. The goal of this fellowship is to attract new scientific tal-

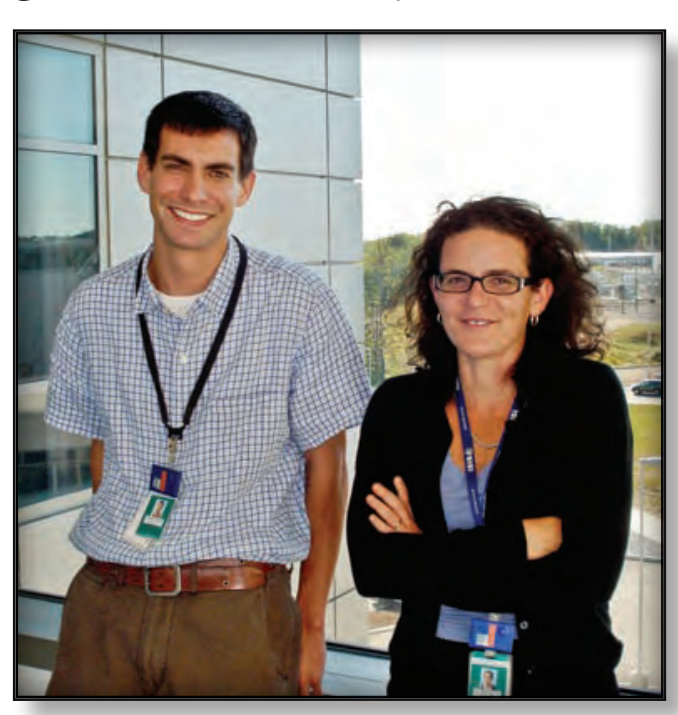
ent to ORNL for the development of its neutron science program. We look for candidates with exceptional ability who are capable of developing innovative research programs and who show the promise of outstanding 
leadership. Appointments are for two years, with the possibility of being renewed for a third.

To date, four Shull fellows have been appointed, two each in 2006 and 2007:

- Andrew Christianson, Colorado State University

- Wei-Ren Chen, Massachusetts Institute of Technology

- Sylvia McLain, University of Oxford and ISIS

- Christopher Stanley, National Institute of Standards and Technology and the National Research Council

\section{Instrument Development Fellowship}

The Instrument Development Fellowship focuses on the development of novel neutron instrumentation and instrument components to be used for neutron science at ORNL or other U.S. neutron centers. The call is directed to scientists within 10 years of their Ph.D. who are located at academic, industrial, or government institutions. This fellowship was established in 2006, and the first appointment was made in 2007 to Thorwald Van Vuure, Institute for Transuranium Elements, Karlsruhe, Germany. Appointments will range from one to three years.

Candidates are evaluated through their proposal submissions. Proposals should contain ideas for novel concepts for neutron instrumentation that will enable unexplored areas of science to be addressed or that will significantly improve current methods in the field. Proposals may describe an entire instrument concept or a major component of an instrument including, but not limited to, detectors, polarization techniques, optical components, analysis software, or source components.

\section{Internships and Postdoctoral Appointments}

Every year the Neutron Sciences Directorate sponsors internships for high school and college students. In 2007, we hosted a record 42 summer students. Some of these students were invited to extend their appointments for longer periods. Applications from each student are reviewed, an interview is conducted, and selected students are assigned to a areas best suited to their paths of study and interest. Each student is assigned a mentor, who is responsible for overseeing the student's work and for ensuring that the student is given opportunities to learn and grow from the experience.

Postdoctoral appointments are also made throughout the year. During the past year, 16 postdoc assignments were made.

\section{Contact: Bob Martin (martinrg@ornl.gov)}

neutrons.ornl.gov/jobs/fellowships.shtml

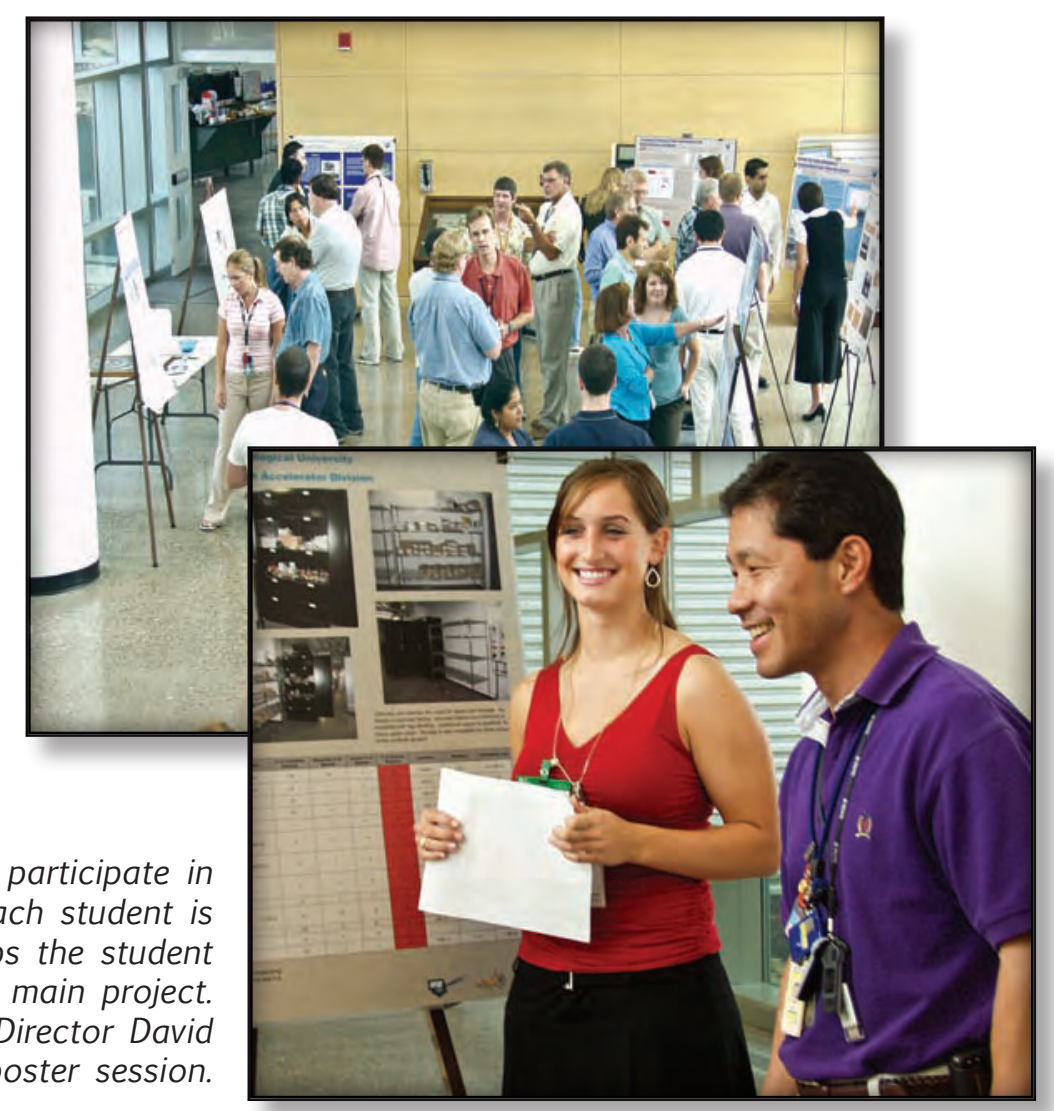

Summer interns sponsored by Neutrons Sciences participate in a poster session during their tenure at ORNL. Each student is assigned a mentor in his or her field, who helps the student develop a poster summarizing the summer's main project. Right: DOE-Oak Ridge Federal Project Director David Arakawa talks with students at the poster session. 


\section{Joint Institute for Neutron Sciences}

The Joint Institute for Neutron Sciences (JINS) promotes and supports research using the HFIR and SNS neutron scattering facilities. JINS was founded by ORNL and the University of Tennessee to serve as an intellectual center for the neutron sciences and as a gateway for users of ORNL's neutron facilities. It is one of four ORNL joint institutes funded by the state of Tennessee.

JINS sponsors fellowships and sabbatical opportunities to draw neutron scientists from all over the world, joint faculty appointments between ORNL and its university partners, and scholarships for graduate students and young faculty members to workshops related to HFIR and SNS programs.

The first researcher selected to visit ORNL on a JINS sabbatical is Julia Chan of the Chemistry Department of Louisiana State University (LSU). Chan will work at SNS in 2008. She will investigate the structures of new materials discovered in her LSU laboratory, including several highly correlated electron systems and cerium and ytterbium intermetallics (powder and single crystals). Neutron diffraction and scattering measurements will be invaluable to Chan's research

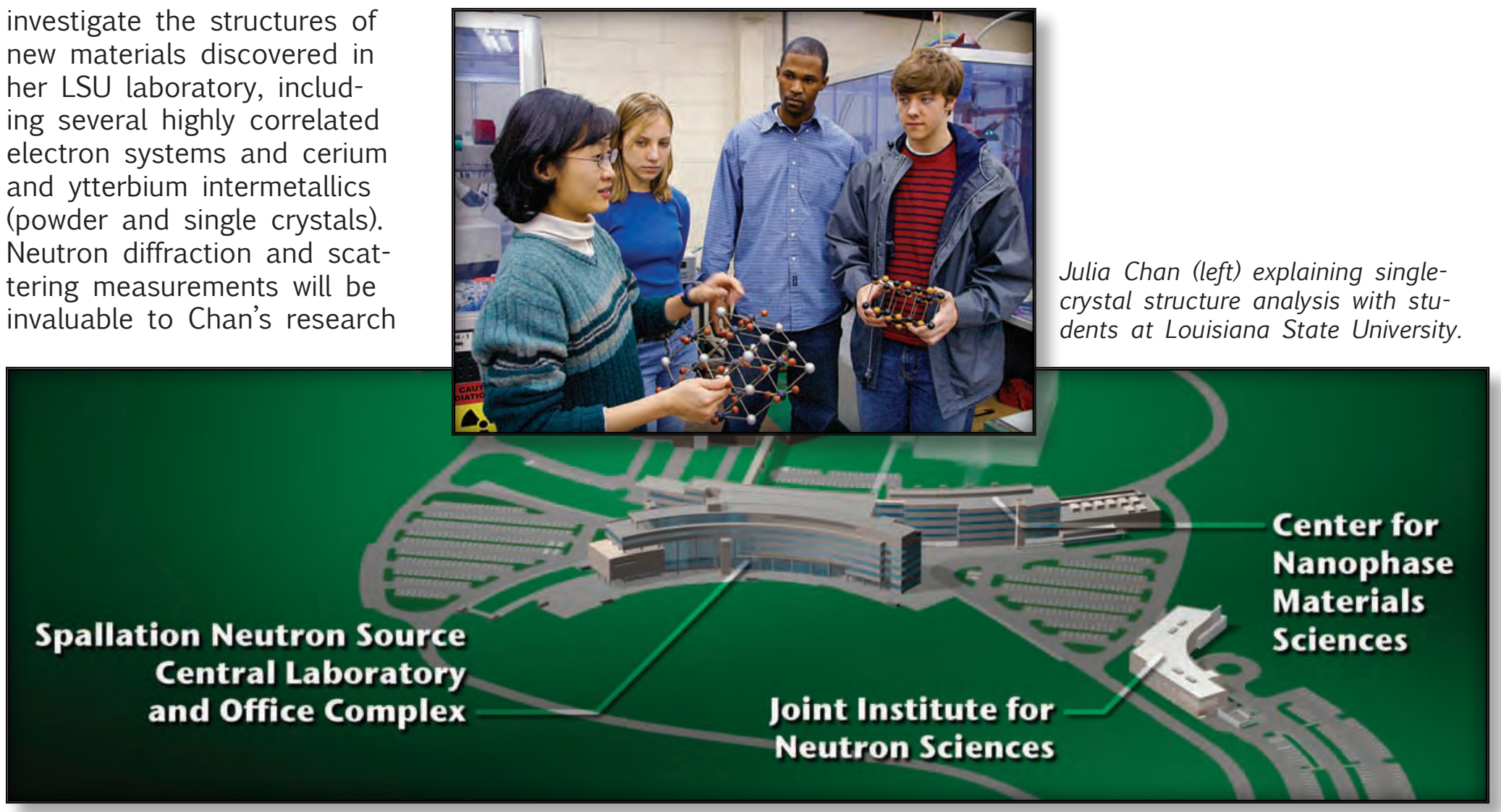

to determine the atomic positions of lighter elements and elements with similar atomic numbers.

During 2007, JINS provided support to visiting scholars to attend these neutron science workshops:

- Educational Symposium on Neutrons for Materials Science and Engineering, April 2007

- Neutron Stress, Texture, and Phase Transformation for Industry, April 2007

- ORNL Users Week, October 2007

Construction of a JINS building near SNS is scheduled for 2008. This image below shows the layout of the JINS building on the Chestnut Ridge site. The facility is expected to be completed in late 2009.

\section{Contact: Al Ekkebus (ekkebusae@ornl.gov)}

neutrons.ornl.gov/jins/ 


\section{Meetings and Workshops}

To fulfill its goal of excellence in science, the Neutron Sciences Directorate aims to attract members of the science and engineering community and develop expertise to effectively use ORNL's neutron facilities. Two ways of accomplishing those goals are outreach efforts and leadership and active participation in the scientific community. The outreach effort includes active participation by Neutron Sciences staff in educational programs for the user community. These include special sessions at conferences or specialized workshops in which the benefits and capabilities of neutron scattering are described for at least one scientific discipline. Community leadership and participation involves staff taking a role in discussing, identifying, and planning a path forward for future research and enabling technologies.

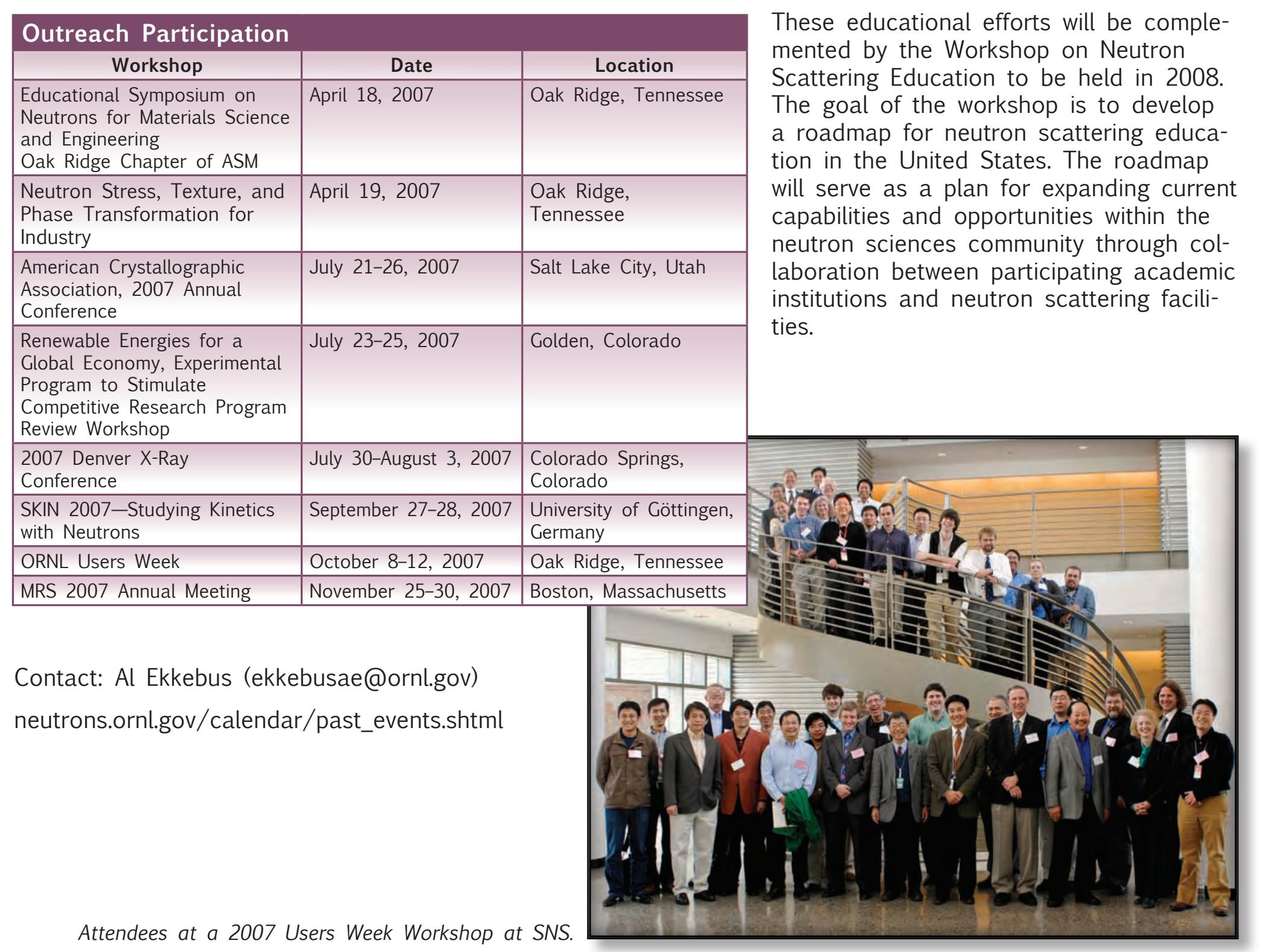




\section{Distinguished Visitors}

HFIR and SNS welcome visitors for tours of their facilities. Distinguished visitors in 2007 included legislators and their staff members, officials of DOE and other federal agencies, Tennessee and local government officials, delegations from other countries, and representatives of other research institutions.

One of the big events for 2007 came in August when U.S. Senator Lamar Alexander and U.S. Congressmen Bart Gordon and Zach Wamp of Tennessee participated in a panel discussion at SNS about the America COMPETES Act. Other panel participants were DOE-Oak Ridge Office Manager Gerald Boyd, Oak Ridge Associated Universities President Ron Townsend, University of Tennessee Executive VicePresident David Milhorn, and Oak Ridge High School teacher Benita Albert. During the event, ORNL Director Thom Mason announced that SNS had officially become the world's most powerful pulsed spallation neutron source when the protons-on-target power passed the 180-kW mark earlier in August.

Contact: Al Ekkebus (ekkebusae@ornl.gov) neutrons.ornl.gov/visitors/

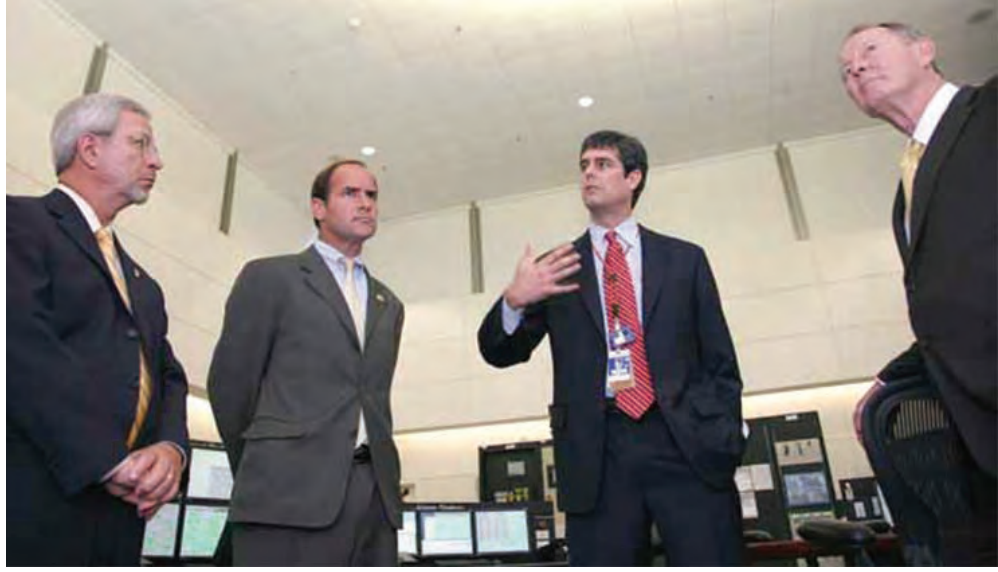

DOE-Oak Ridge Office Manager Gerald Boyd, Congressman Zach Wamp, ORNL Director Thom Mason, and Senator Lamar Alexander during the August 2007 America COMPETES Act and SNS record announcement media event at SNS.

\begin{tabular}{|l|l|}
\hline Neutron Sciences Visitors in 2007 \\
\hline February 21 & $\begin{array}{l}\text { Staff from the office of U.S. Senator } \\
\text { Bob Corker }\end{array}$ \\
\hline March 8 & $\begin{array}{l}\text { Jeff Kupfer, Chief of staff for Energy } \\
\text { Secretary Bodman }\end{array}$ \\
\hline April 5 23 & Ambassador Howard Baker, Jr. \\
\hline April 5 & $\begin{array}{l}\text { Staff from the offices of U.S. } \\
\text { Senators from New Mexico Pete } \\
\text { Dominici and Jeff Bingaman }\end{array}$ \\
\hline May 8-9 & Japan Atomic Energy Agency \\
\hline May 17 & $\begin{array}{l}\text { Tokyo Institute of Technology } \\
\text { the International Thermonuclear } \\
\text { Experimental Reactor project }\end{array}$ \\
\hline June 20 & $\begin{array}{l}\text { National Council of State Legislatures } \\
\text { Advisory Council on Energy }\end{array}$ \\
\hline June 20 & $\begin{array}{l}\text { University of Tennessee Board of } \\
\text { Trustees }\end{array}$ \\
\hline August 29 & British Consulate \\
\hline August 30 & $\begin{array}{l}\text { U.S. Senator Lamar Alexander and } \\
\text { Congressmen Zach Wamp and Bart } \\
\text { Gordon }\end{array}$ \\
\hline September 14 & Oak Ridge Mayor Tom Beehan \\
\hline September 26 & $\begin{array}{l}\text { Nuclear Regulatory Commission } \\
\text { Commissioner Pete Lyons }\end{array}$ \\
\hline September 28 & $\begin{array}{l}\text { University of Tennessee Chancellor } \\
\text { Loren Crabtree }\end{array}$ \\
\hline
\end{tabular}




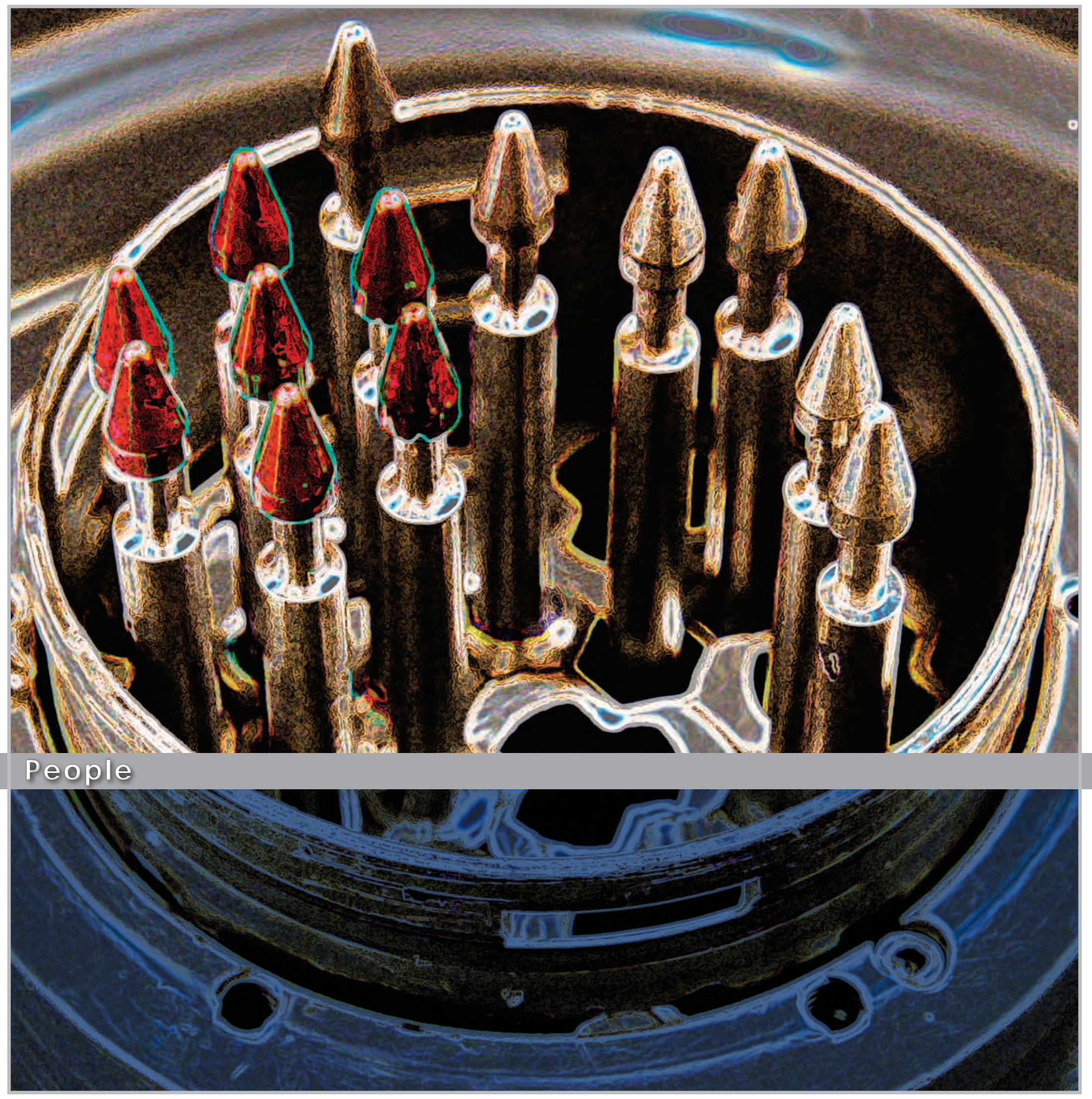




\section{Neutron Sciences Staff}

The ORNL Neutron Sciences Directorate is composed of four divisions, each focused on a specific mission:

- Neutron Scattering Science

- Neutron Facilities Development

- Research Accelerator

- Research Reactors

With a staff of about 600, Neutron Sciences is one of the largest science groups at ORNL. HFIR and SNS personnel work with staff from the Center for Nanophase Materials Sciences, other ORNL research divisions, the Joint Institute for Neutron Sciences, universities, industry, and other research institutes. The goals of these collaborations are to broaden the range and productivity of science programs, promote educational and outreach programs, and ensure the optimum use of ORNL's world-leading neutron facilities.

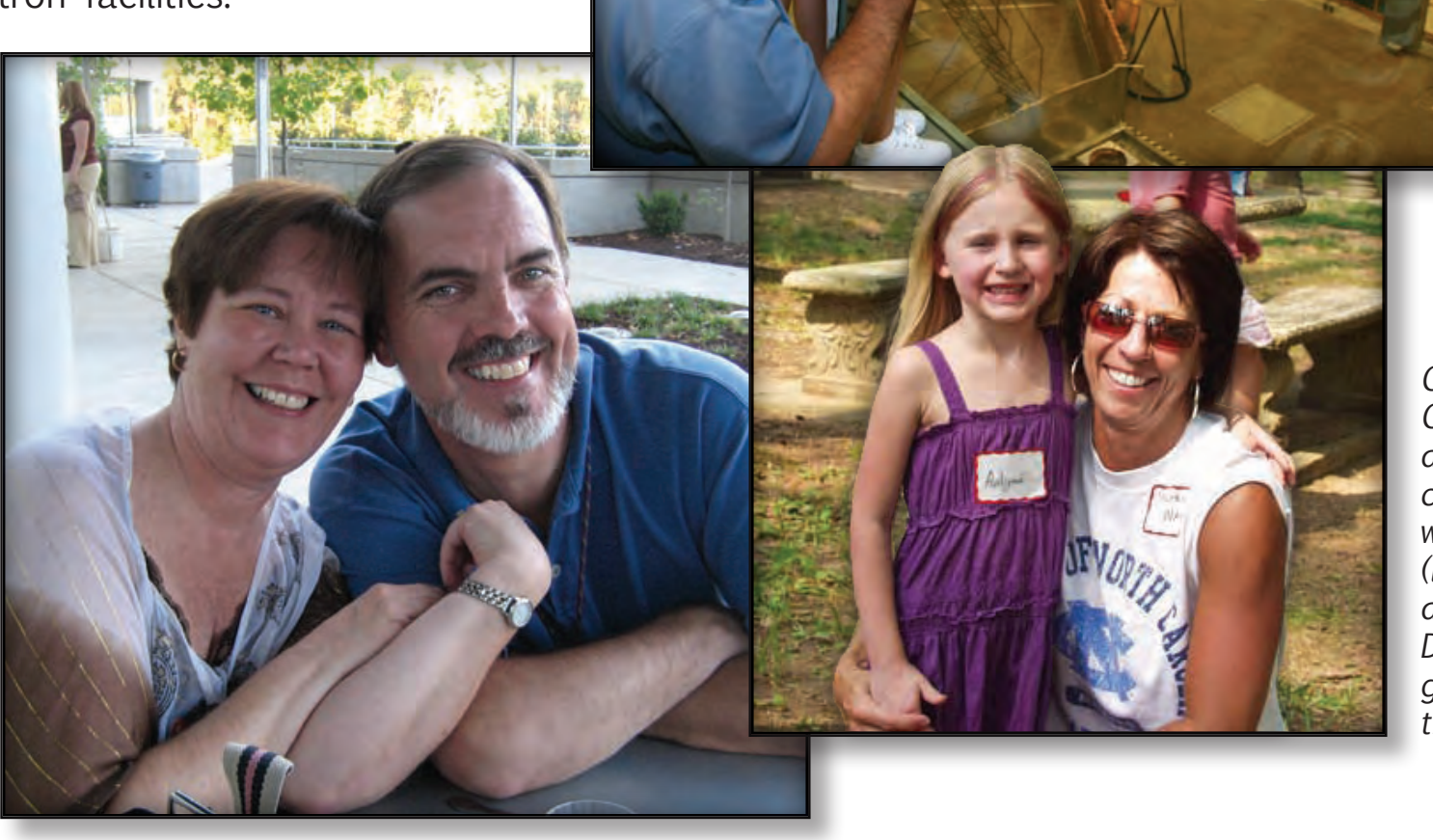

The directorate hired 85 new staff members in 2007 and hosted 42 students throughout the year. The visiting students were associated with programs such as the Oak Ridge Associated Universities Higher Education Research Experiences Program, the DOE/National Science Foundation Faculty-Student Teams program, ORNL's Nuclear Engineering Science Laboratory Synthesis Program, and the DOEOffice of Science Undergraduate Laboratory Internships.

Neutron Sciences staff are actively involved in the community and donate their time, money, and energy to organizations such as the United Way, Habitat for Humanity, and others too numerous to mention. Employees also participate in Lab-sponsored activities such as community day and family day, when staff can invite their families to come visit the HFIR and SNS sites.

Clockwise left to right: Cathy and Bob Cummins at the SNS completion celebration. David Glasgow with his children, Brady (left) and Bailey (right), at the July 21 HFIR Family Day. Melissa Ward and her granddaughter, Aaliyah, at the directorate picnic. 


\section{Awards and Honors}

Neutron Sciences staff received a number of prestigious honors and awards during 2007 from ORNL, the U.S. Department of Energy (DOE), and academic and professional organizations. Several other ORNL staff received awards based on research conducted at Neutron Sciences facilities.
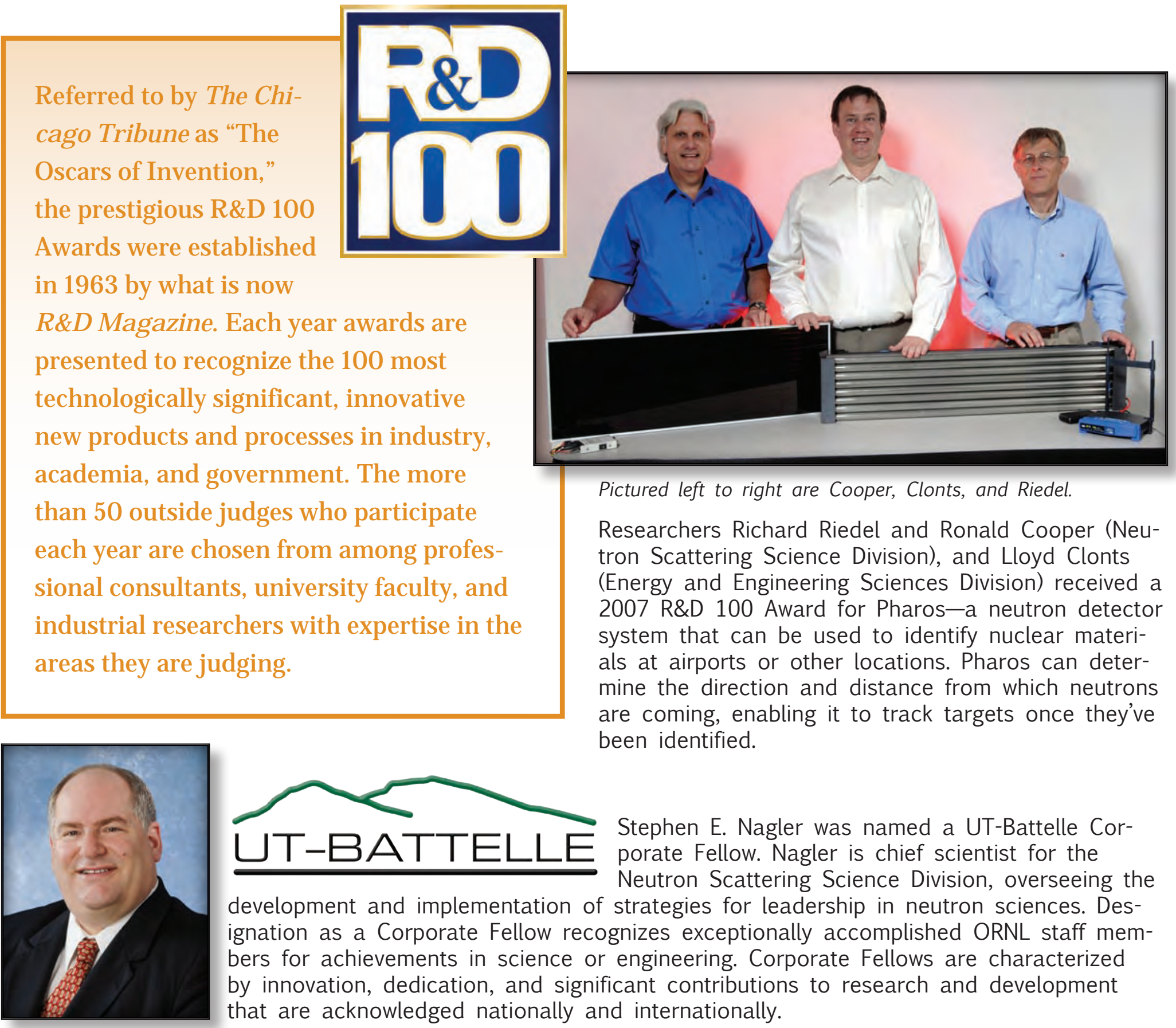

Stephen E. Nagler was named a UT-Battelle Corporate Fellow. Nagler is chief scientist for the Neutron Scattering Science Division, overseeing the development and implementation of strategies for leadership in neutron sciences. Designation as a Corporate Fellow recognizes exceptionally accomplished ORNL staff members for achievements in science or engineering. Corporate Fellows are characterized by innovation, dedication, and significant contributions to research and development that are acknowledged nationally and internationally. 

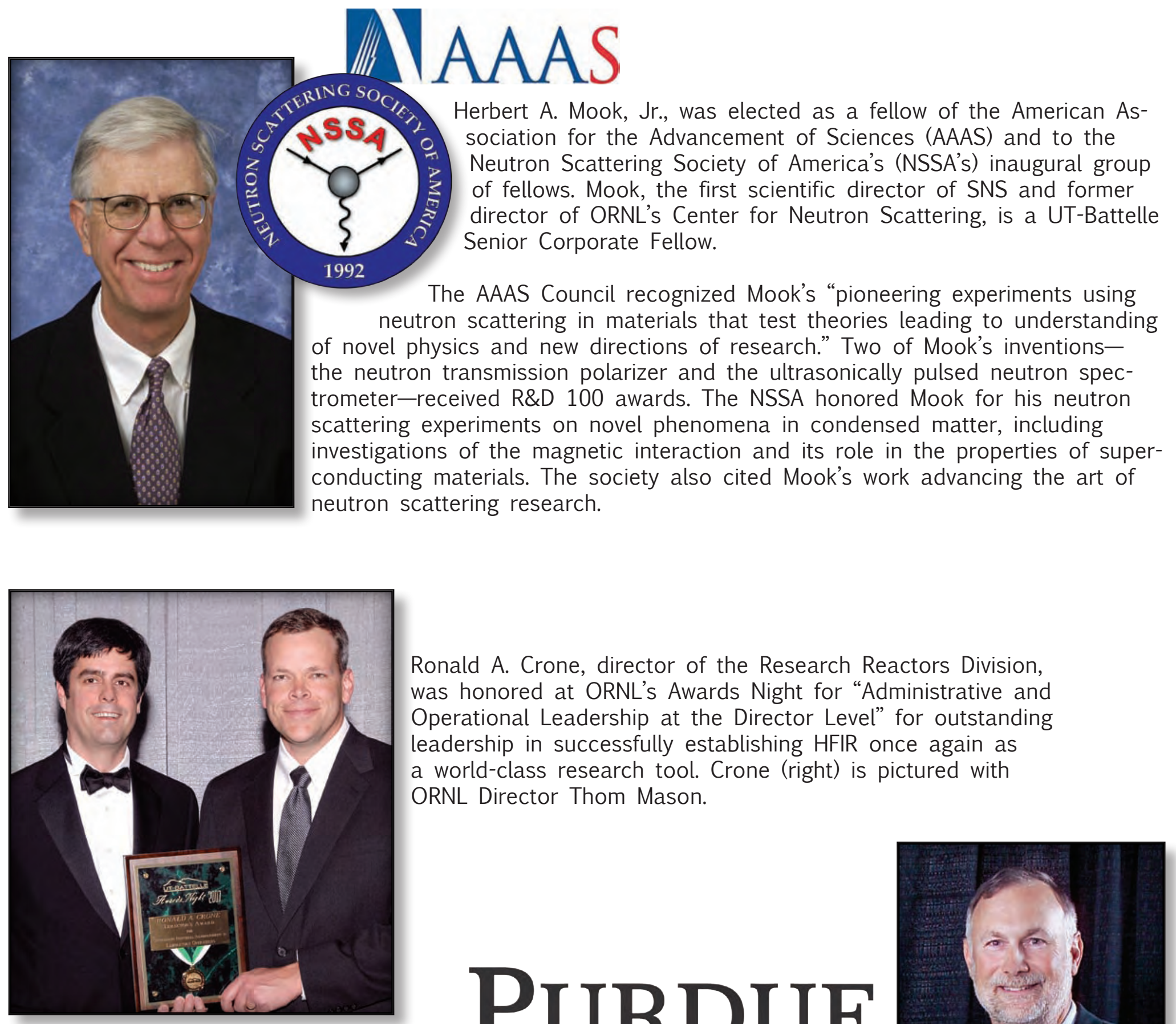

Ronald A. Crone, director of the Research Reactors Division, was honored at ORNL's Awards Night for "Administrative and Operational Leadership at the Director Level" for outstanding leadership in successfully establishing HFIR once again as a world-class research tool. Crone (right) is pictured with ORNL Director Thom Mason.

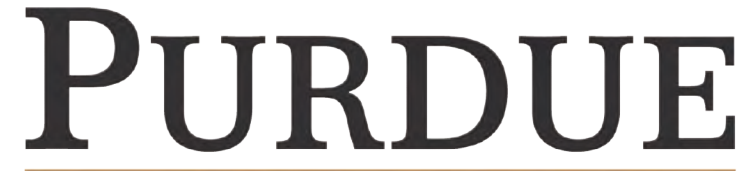

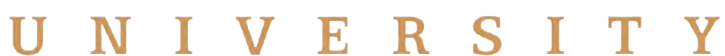

Frank Kornegay, SNS operations manager, was honored by Purdue University's

Department of Earth and Atmospheric Sciences as an outstanding alumnus. Kornegay received his B.S. and M.S. degrees in atmospheric science from Purdue.

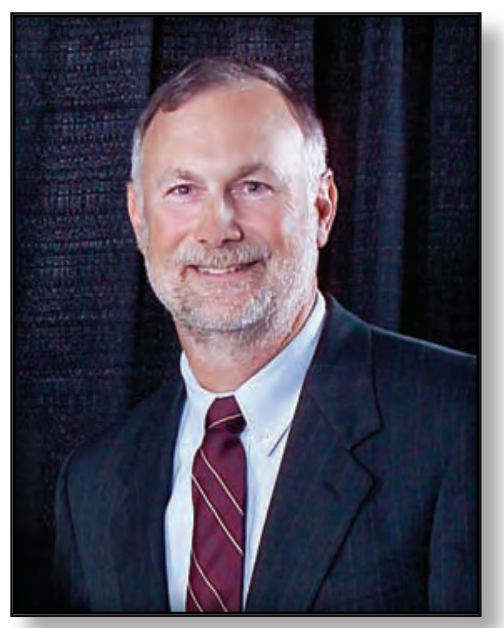




\section{Awards for Research at Neutron Sciences Fa cilities}

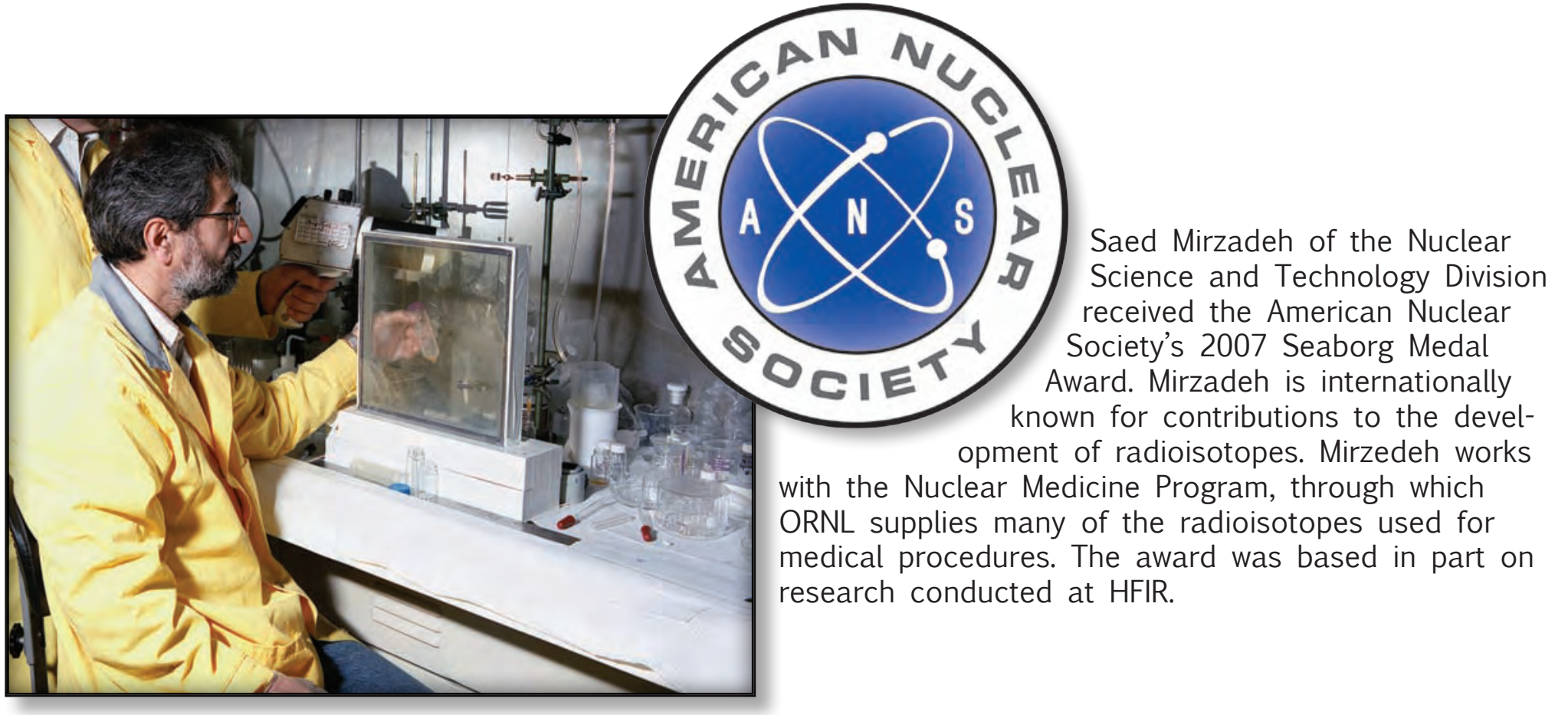

Steven Zinkle, director of the ORNL Materials Science and Technology Division, won DOE's Ernest Orlando Lawrence Award, which honors midcareer scientists and engineers for exceptional contributions in research and development. Zinkle's work has focused on physical metallurgy of structural materials and investigating radiation effects on ceramic materials and metallic alloys for fusion and fission reactors and space reactor systems. The award was based in part on research conducted at HFIR.

Lawrence Award presented to Steve Zinkle by Energy Secretary Samuel Bodman, left, and Undersecretary for Science Raymond Orbach, right.

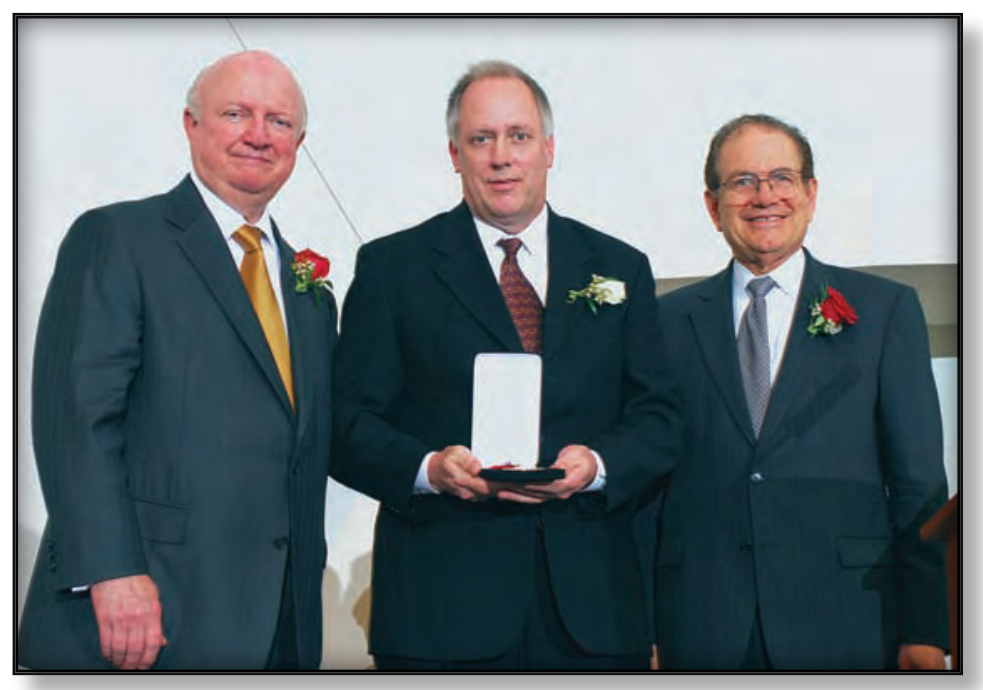




\section{Advisory Committees}

Several review committees and advisory teams provide advice and support to the Neutron Sciences organization. The committees are made up primarily of members of the scientific community outside ORNL, as well as some ORNL staff.

\section{Neutron Sciences Advisory Board}

Chair, Gregory Boebinger, Florida State University

This committee reports to the ORNL director and advises the associate Laboratory director for Neutron Sciences on all aspects of ORNL's neutron facilities. The goal of the committee is to maximize the scientific impact and benefit of these facilities to ORNL, DOE, and the national and international scientific communities. The committee identifies and brings to the attention of Laboratory management any issues the resolution of which is critical to the technical and scientific success of ORNL neutron facilities, including meeting performance, cost, and schedule goals. The committee is made up of members of the scientific communities that are fundamentally involved with HFIR and SNS, as well as individuals with experience managing major science facilities, particularly materials research facilities.

\section{Neutron Scattering Science Advisory Committee}

Chair, Susan Krueger, National Institute of Standards and Technology

This committee reports to the associate Laboratory director for Neutron Sciences and advises the Neutron Scattering Science Division (NSSD) director and the Neutron Facilities Development Division (NFDD) director on the directorate's science programs and instrument development. Primarily, the committee provides advice on the types of instruments required to effectively meet the requirements of a multidisciplinary scientific community. The committee also counsels the NSSD director on outreach programs and interaction with the neutron user community. Committee members consist mainly of members from the scientific community who are experts in the instrumentation at HFIR and SNS, potential users, and managers with experience in the effective operation of user programs.

\section{SNS Accelerator Advisory Committee}

Chair, Gerry Dugan, Cornell University

This committee reports to the associate Laboratory director for Neutron Sciences and advises the Research Accelerator Division (RAD) and NFDD directors on the operations and performance of the SNS accelerator complex. Committee members are appointed by the Neutron Sciences associate Laboratory director in consultation with the RAD and NFDD directors.

\section{Instrument Advisory and Development Teams}

Instrument advisory teams work with the ORNL staff to design and construct instruments funded by ORNL Neutron Sciences. These instruments are made available to the user community through a peer reviewed proposal system. Instrument development teams (IDTs) build, and sometimes operate, instruments funded from other sources. A portion of beam time on these instruments is allotted for the scientific program of the IDT, with the balance available for general users. At least $75 \%$ of the beam time for these instruments is devoted to the general user program. Policies and guidelines regarding instrument development and use are available at neutrons.ornl.gov/users/policies.shtml. 


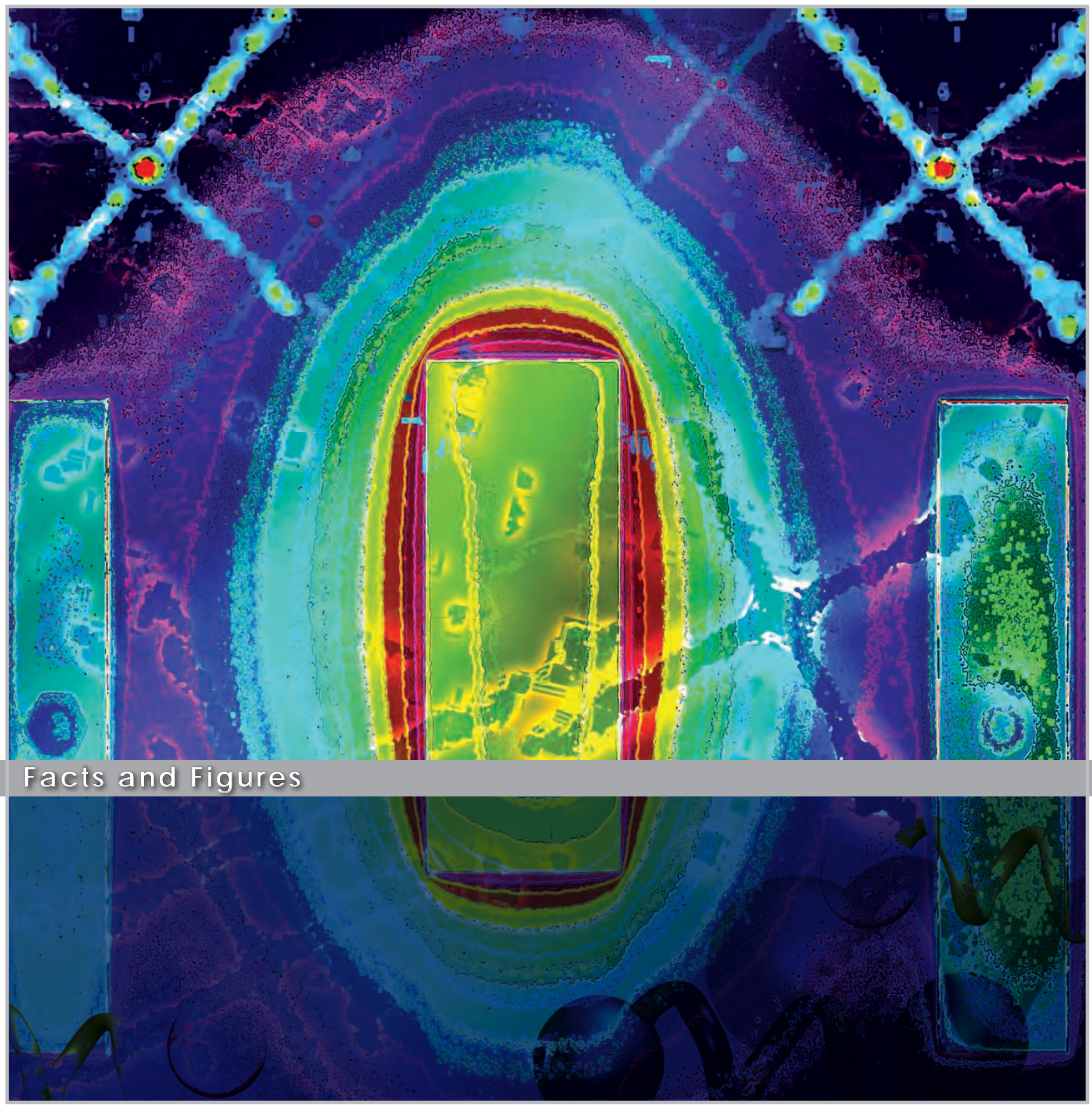




\section{Tec hnic al Pa ra meters-HFIR}

\begin{tabular}{|c|c|}
\hline Type of core & Cylindrical annulus, flux trap \\
\hline Type of fuel elements & $\begin{array}{l}\text { Cylindrical annuli (2); } \\
\text { Involute 6061-Al fuel plates } \\
\text { assembled in 6061-Al side plates }\end{array}$ \\
\hline Number of plates (inner element) & 171 \\
\hline Number of plates (outer element) & 369 \\
\hline Fuel plate thickness & 0.050 in. \\
\hline Fuel plate spacing (coolant channel) & 0.050 in. \\
\hline Fuel plate length & 24 in. \\
\hline Length of active fuel & 20 in. \\
\hline Inner fuel element (inside diameter) & 5.067 in. \\
\hline Inner fuel element (outer diameter) & 10.590 in. \\
\hline Outer fuel element (inside diameter) & $11.250 \mathrm{in.}$ \\
\hline Outer fuel element (outer diameter) & 17.134 in. \\
\hline Active fuel volume & $50.59 \mathrm{~L}$ \\
\hline Heat transfer surface area & $428.8 \mathrm{ft}^{2}$ \\
\hline \multicolumn{2}{|l|}{ Reactor Core Materials } \\
\hline Fuel & $\begin{array}{l}\mathrm{U}_{3} \mathrm{O}_{8}\left(93 \% \mathrm{U}_{235}\right) \text { dispersed in } \\
\text { aluminum }\end{array}$ \\
\hline $\begin{array}{l}\text { Total fuel loading } \\
\text { - Inner fuel element fuel loading } \\
\text { - Outer fuel element fuel loading }\end{array}$ & $\begin{array}{l}9.4 \mathrm{~kg} \\
2.6 \mathrm{~kg} \\
6.8 \mathrm{~kg}\end{array}$ \\
\hline $\begin{array}{l}\text { Burnable poison (inner element only) } \\
\text { - Inner fuel element poison loading }\end{array}$ & $\begin{array}{l}\mathrm{B}_{4} \mathrm{C} \text { dispersed in aluminum } \\
2.8 \mathrm{~g}\end{array}$ \\
\hline Reflector & Beryllium \\
\hline Moderator & $\mathrm{H}_{2} \mathrm{O}$ \\
\hline
\end{tabular}

\begin{tabular}{|c|c|}
\hline Rated power level & $85 \mathrm{MW}$ thermal \\
\hline Average reactor power density & $1.64 \mathrm{MW} / \mathrm{L}$ \\
\hline \multicolumn{2}{|l|}{ Typical Operating Cycle } \\
\hline Normal operation & Steady-state, $85 \mathrm{MW}$ thermal \\
\hline Length (dependent on core loading) & $22-25$ days \\
\hline \multicolumn{2}{|c|}{ Maximum Unperturbed Thermal Flux Density in Reflector (Beam Tube Sour } \\
\hline Beginning of cycle & $9.35 \mathrm{E}+14 \mathrm{n} / \mathrm{cm}^{2} \mathrm{~s}$ \\
\hline End of cycle & $1.36 \mathrm{E}+15 \mathrm{n} / \mathrm{cm}^{2} \mathrm{~s}$ \\
\hline \multicolumn{2}{|c|}{ Unperturbed Thermal Flux Density at Reflector Outer Diameter } \\
\hline Beginning of cycle & $1.19 \mathrm{E}+14 \mathrm{n} / \mathrm{cm}^{2} \mathrm{~s}$ \\
\hline End of cycle & $1.45 \mathrm{E}+14 \mathrm{n} / \mathrm{cm}^{2} \mathrm{~s}$ \\
\hline \multicolumn{2}{|l|}{ Peak Thermal Flux Density } \\
\hline Measured thermal flux in target region & $2.5 \mathrm{E}+15 \mathrm{n} / \mathrm{cm}^{2} \mathrm{~s}$ \\
\hline \multicolumn{2}{|l|}{ Reactor Coolant Parameters } \\
\hline Coolant/moderator & $\mathrm{H}_{2} \mathrm{O}$ \\
\hline Inlet temperature & $120^{\circ}$ \\
\hline Outlet temperature & $156^{\circ}$ \\
\hline Fuel coolant volumetric flow rate & $13,000 \mathrm{gal} / \mathrm{min}$ \\
\hline Total coolant volumetric flow rate & $16,000 \mathrm{gal} / \mathrm{min}$ \\
\hline Inlet pressure & 468 psig \\
\hline Fuel clad surface temperature & $327^{\circ}$ \\
\hline Average heat flux & $0.66 \mathrm{E}+05 \mathrm{BTU} / \mathrm{h} \mathrm{ft}^{2}$ \\
\hline Hot spot heat flux & $2.15 \mathrm{E}+06 \mathrm{BTU} / \mathrm{h} \mathrm{ft}^{2}$ \\
\hline
\end{tabular}

NEUTRON BEAM ALLOCATION

Horizontal Beam Tube HB-1: Thermal Neutron Beam-Tangential to Core

\begin{tabular}{l|l} 
- HB-1 & Triple-Axis Spectrometer \\
HB-1A & Fixed-Incident-Energy Triple-Axis Spectrometer
\end{tabular}

Horizontal Beam Tube HB-2: Thermal Neutron Beam-Radial to Core

- HB-2A $\quad$ Neutron Powder Diffractometer (under development)

- HB-1A $\quad$ Neutron Residual Stress Mapping Facility

- $\mathrm{HB}-2 \mathrm{C}$ US/Japan Wide-Angle Neutron Diffractometer (WAND)

- HB-2D Future development

Horizontal Beam Tube HB-3: Thermal Neutron Beam-Tangential to Core

\begin{tabular}{l|l} 
: HB-3 & Triple-Axis Spectrometer \\
HB-3A & Four-Circle Diffractometer \\
\hline
\end{tabular}

Horizontal Beam Tube HB-4: Thermal Neutron Beam-Tangential to Core

\begin{tabular}{|l|l|}
\hline CG-1 & Future development \\
CG-2 & Small-Angle Neutron Scattering Diffractometer (SANS1) \\
$:$ CG-3 & Small-Angle Neutron Scattering Instrument (Bio-SANS) \\
CG CG-4B & Future development \\
$:$ CG-4C & Future development \\
- CG-4D & US/Japan Cold Neutron Triple-Axis Spectrometer (under development) \\
\hline
\end{tabular}




\begin{tabular}{|c|c|c|c|c|c|c|c|c|}
\hline $\begin{array}{l}\text { SE } \\
\text { Description }\end{array}$ & $\begin{array}{l}\text { Temperature } \\
\text { Range (K) }\end{array}$ & $\begin{array}{l}\text { Bore } \\
\text { Size }\end{array}$ & $\begin{array}{l}\text { Interface } \\
\text { Connec- } \\
\text { tions }\end{array}$ & $\begin{array}{l}\text { Distance } \\
\text { from } \\
\text { Interface to } \\
\text { Beam Center }\end{array}$ & $\begin{array}{l}\text { Stick Distance } \\
\text { to Beam } \\
\text { Center }\end{array}$ & $\begin{array}{l}\text { Special Features/ } \\
\text { Comments }\end{array}$ & $\begin{array}{l}\text { SE Team } \\
\text { Comments }\end{array}$ & $\begin{array}{l}\text { Helium Fill } \\
\text { and } \\
\text { Hold Time } \\
\text { Estimates }\end{array}$ \\
\hline $\begin{array}{l}\text { High-temp } \\
\text { displex-1AF }\end{array}$ & $5-800$ & $\mathrm{~N} / \mathrm{A}$ & 0.25-in. hole & 2 in. & $\mathrm{N} / \mathrm{A}$ & & & \\
\hline Displex-1A & $11-300$ & $\mathrm{~N} / \mathrm{A}$ & $\begin{array}{l}1 / 4-28 \\
\text { Female }\end{array}$ & 2.325 in. & $\mathrm{N} / \mathrm{A}$ & $\begin{array}{l}\text { For use with } \\
\text { standard sample can }\end{array}$ & & \\
\hline Displex-A & $4-300$ & N/A & $\begin{array}{l}1 / 4-28 \\
\text { Female }\end{array}$ & 2.325 in. & $\mathrm{N} / \mathrm{A}$ & & & \\
\hline Displex-B & $6.5-300$ & $\mathrm{~N} / \mathrm{A}$ & $\begin{array}{l}1 / 4-28 \\
\text { Female }\end{array}$ & 2.325 in. & $\mathrm{N} / \mathrm{A}$ & & & \\
\hline Displex-H & $8-00$ & $\mathrm{~N} / \mathrm{A}$ & $\begin{array}{l}1 / 4-28 \\
\text { Female }\end{array}$ & 2.325 in. & $\mathrm{N} / \mathrm{A}$ & $\begin{array}{l}\text { Optional saphirre } \\
\text { window for SANS }\end{array}$ & & \\
\hline Displex-I & $8-300$ & N/A & $\begin{array}{l}1 / 4-28 \\
\text { Female }\end{array}$ & 2.325 in. & $\mathrm{N} / \mathrm{A}$ & $\begin{array}{l}\text { Turbo- } 1 \text { hour RT } \\
\text { to base temp }\end{array}$ & & \\
\hline Displex-M & $14-300$ & $\mathrm{~N} / \mathrm{A}$ & $\begin{array}{l}1 / 4-28 \\
\text { Female }\end{array}$ & 2.325 in. & $\mathrm{N} / \mathrm{A}$ & $\begin{array}{l}\text { High capacity for } \\
\text { use with high- } \\
\text { pressure cells }\end{array}$ & & \\
\hline Omniplex-O & $5.5-300$ & $50 \mathrm{~mm}$ & $\begin{array}{l}1 / 4-28 \\
\text { Female }\end{array}$ & $\begin{array}{l}1.5 \text { in. } w / \\
+/-2 \text { in. adj. }\end{array}$ & $19-7 / 8$ in. & Top-loading displex & & \\
\hline Omniplex-O2 & $4.8-300$ & $50 \mathrm{~mm}$ & $\begin{array}{l}1 / 4-28 \\
\text { Female }\end{array}$ & $\begin{array}{l}1.5 \text { in. } w / \\
+/-2 \text { in. adj. }\end{array}$ & $19-7 / 8$ in. & Top-loading displex & & \\
\hline $\begin{array}{l}\text { 4.5-Tesla } \\
\text { horizontal field } \\
\text { magnet }\end{array}$ & $1.8-300$ & $40 \mathrm{~mm}$ & M6 Male & $\begin{array}{l}2.325 \text { in./59 } \\
\mathrm{mm}\end{array}$ & $\begin{array}{l}44.325 \text { in./ } / 1125 \\
\mathrm{~mm}\end{array}$ & $\begin{array}{l}\text { Access for SANS use } \\
\text { only }\end{array}$ & & $\begin{array}{l}\text { Fill }=225 \mathrm{~L} / \\
6 \text { days at field }\end{array}$ \\
\hline $\begin{array}{l}\text { 5-Tesla vertical } \\
\text { field magnet }\end{array}$ & $2-300$ & $50 \mathrm{~mm}$ & Custom & $\begin{array}{l}1.97 \text { in./50 } \\
\mathrm{mm}\end{array}$ & $\begin{array}{l}33.75 \text { in./857 } \\
m m+/-15 \mathrm{~mm}\end{array}$ & $\begin{array}{l}\text { WAND }{ }^{a} \text { mount } \\
\text { capable }\end{array}$ & $\begin{array}{l}\text { Sample well } \\
\text { depth }=35- \\
7 / 16 / 40 \mathrm{~mm} \text { be- } \\
\text { low beam center }\end{array}$ & $\begin{array}{l}\text { Fill }=60 \mathrm{~L} / 1 \\
\text { day at field }\end{array}$ \\
\hline $\begin{array}{l}\text { 7-Tesla vertical } \\
\text { field magnet }\end{array}$ & $2-300$ & $25 \mathrm{~mm}$ & M6 Male & $\begin{array}{l}\text { Nominal } 1.5 \\
\text { in. }\end{array}$ & 46 in. & $\begin{array}{l}\text { Field limited to } 5.5 \mathrm{~T} \\
\text { at } \mathrm{HB}-1 \mathrm{~A}\end{array}$ & & $\begin{array}{l}\text { Fill }=125 \mathrm{~L} / \\
6 \text { days at field }\end{array}$ \\
\hline $\begin{array}{l}\text { Helium cryostat- } \\
\text { Variox } 1\end{array}$ & $1.5-300$ & $50 \mathrm{~mm}$ & M8 Female & $\begin{array}{l}\text { Nominal } 1.5 \\
\text { in. }\end{array}$ & 46 in. & & & \\
\hline $\begin{array}{l}\text { Helium cryostat- } \\
\text { old blue }\end{array}$ & Variable & $\mathrm{N} / \mathrm{A}$ & Custom & $\mathrm{N} / \mathrm{A}$ & $\mathrm{N} / \mathrm{A}$ & $\begin{array}{l}\text { For use with high- } \\
\text { pressure cells }\end{array}$ & & \\
\hline
\end{tabular}

${ }^{a}$ US/Japan Wide-Angle Neutron Diffractometer. 


\section{Technic al Pa ra meters-SNS}

\section{PRIMARY PARAMETERS}

\begin{tabular}{|l|l|}
\hline Proton beam power on target & $1.4 \mathrm{MW}$ \\
\hline Proton beam kinetic energy on target & $1.0 \mathrm{GeV}$ \\
\hline Average beam current on target & $1.4 \mathrm{~mA}$ \\
\hline Pulse repetition rate & $60 \mathrm{~Hz}$ \\
\hline Protons per pulse on target & $1.5 \times 10^{14}$ protons \\
\hline Charge per pulse on target & $24 \mu \mathrm{c}$ \\
\hline Energy per pulse on target & $24 \mathrm{~kJ}$ \\
\hline Proton pulse length on target & $695 \mathrm{~ns}$ \\
\hline lon type (Front-end, Linac ${ }^{a}$, HEBT ${ }^{b}$ & $\mathrm{H}$ minus \\
\hline Average linac macropulse H- current & $26 \mathrm{~mA}$ \\
\hline Linac beam macropulse duty factor & $6 \%$ \\
\hline Front-end length & $7.5 \mathrm{~m}$ \\
\hline Linac length & $331 \mathrm{~m}$ \\
\hline HEBT length & $170 \mathrm{~m}$ \\
\hline Ring circumference & $248 \mathrm{~m}$ \\
\hline RTBT length & $150 \mathrm{~m}$ \\
\hline lon type (Ring, RTBT, Target) & Proton \\
\hline Ring filling time & $1.0 \mathrm{~ms}$ \\
\hline Ring revolution frequency & $1.058 \mathrm{MHz}$ \\
\hline Number of injected turns & 1060 \\
\hline Ring filling fraction & $68 \%$ \\
\hline Ring extraction beam gap & $250 \mathrm{~ns}$ \\
\hline Maximum uncontrolled beam loss & $1 \mathrm{~W} / \mathrm{m}$ \\
\hline Target material & $\mathrm{Hg}$ \\
\hline Number of ambient/cold moderators & $1 / 3$ \\
\hline Number of neutron beam shutters & 18 \\
\hline Initial number of instruments & 5 \\
\hline
\end{tabular}

Linear accelerator.

'High-energy beam transport (system).

Ring-to-target beam transport (system)

\begin{tabular}{|c|c|c|c|}
\hline Beam & Position $^{a}$ & Moderator & Instrument \\
\hline $1 \mathrm{~A}$ & & & \\
\hline $1 A$ & 10 & Hydrogen decoupled & $\begin{array}{l}\text { lime-of-Hight Ultra-Small-Angle Neutron Scattering } \\
\text { Instrument (TOF-USANS) }\end{array}$ \\
\hline 1B & TU & Hydrogen decoupled & $\begin{array}{l}\text { Nanoscale-Ordered Materials Diffractometer } \\
\text { (NOMAD) }\end{array}$ \\
\hline S2 & TU & Hydrogen decoupled & Backscattering Spectrometer (BASIS) \\
\hline 3 & TU & Hydrogen decoupled & $\begin{array}{l}\text { Spallation Neutrons and Pressure Diffractometer } \\
\text { (SNAP) }\end{array}$ \\
\hline $4 \mathrm{~A}$ & TD & Hydrogen coupled & Magnetism Reflectometer \\
\hline 4B & TD & Hydrogen coupled & Liquids Reflectometer \\
\hline 5 & TD & Hydrogen coupled & Cold Neutron Chopper Spectrometer (CNCS) \\
\hline 6 & TD & Hydrogen coupled & $\begin{array}{l}\text { Extended Q-Range Small-Angle Neutron Scattering } \\
\text { Diffractometer (EQ-SANS) }\end{array}$ \\
\hline 7 & BU & Water & Engineering Materials Diffractometer (VULCAN) \\
\hline $8 \mathrm{~A}$ & BU & Water & \\
\hline $8 \mathrm{~B}$ & $\mathrm{BU}$ & Water & \\
\hline 9 & BU & Water & Elastic Diffuse Scattering Spectrometer (CORELLI) \\
\hline 10 & TU & Hydrogen decoupled & \\
\hline $11 \mathrm{~A}$ & TU & Hydrogen decoupled & Powder Diffractometer (POWGEN) \\
\hline $11 \mathrm{~B}$ & TU & Hydrogen decoupled & Macromolecular Diffractometer (MaNDi) \\
\hline 12 & TU & Hydrogen decoupled & Single-Crystal Diffractometer (TOPAZ) \\
\hline 13 & $\mathrm{BD}$ & Hydrogen coupled & Fundamental Neutron Physics Beam Line \\
\hline $14 \mathrm{~A}$ & BD & Hydrogen coupled & \\
\hline $14 \mathrm{~B}$ & BD & Hydrogen coupled & Hybrid Spectrometer (HYSPEC) \\
\hline 15 & BD & Hydrogen coupled & Neutron Spin Echo Spectrometer (NSE) \\
\hline $16 \mathrm{~A}$ & BU & Water & Chemical Spectrometer (VISION) \\
\hline $16 \mathrm{~B}$ & BU & Water & \\
\hline 17 & BU & Water & $\begin{array}{l}\text { Fine-Resolution Fermi Chopper Spectrometer } \\
\text { (SEQUOIA) }\end{array}$ \\
\hline 18 & BU & Water & Wide Angular-Range Chopper Spectrometer (ARCS) \\
\hline
\end{tabular}

${ }^{a} \mathrm{~T}=$ Top, $\mathrm{U}=$ Upstream, $\mathrm{D}=$ Downstream, $\mathrm{B}=$ Bottom 


\begin{tabular}{|c|c|c|c|c|}
\hline Equipment ID & Description & $\begin{array}{l}\text { Temperature Range } \\
\text { (K) }\end{array}$ & $\begin{array}{l}\text { Sample Space } \\
\text { Diameter }\end{array}$ & Status \\
\hline CRYO 01 & Janis helium cryostat & $2-600$ & $58 \mathrm{~mm}$ & Operational \\
\hline CRYO 02 & $\begin{array}{l}\text { Janis "SuperTran" CF } \\
\text { cryostat }\end{array}$ & $4-300$ & $60 \mathrm{~mm}$ & Operational \\
\hline CRYO 03 & AS orange cryostat & $2-300$ & 70 mm & Operational \\
\hline CCR 03 & FERNS $^{a}$ auto changer & $7-300$ & $\begin{array}{l}\text { Has own vanadium } \\
\text { cans: } 4,6,8 \mathrm{~mm}\end{array}$ & POWGEN ${ }^{b}$ dedicated \\
\hline CCR 04 & $\begin{array}{l}\text { Sumitomo bottom } \\
\text { load with warm stage }\end{array}$ & $7-400$ & $55 \mathrm{~mm}$ & Operational \\
\hline CCR 05 & $\begin{array}{l}\text { Top load "Split Head" } \\
\text { CCR }^{c}\end{array}$ & $10-300$ & $47 \mathrm{~mm}$ & available Dec. 08 \\
\hline CCR 06 & High-temp top loader & $10-500$ & 70 mm & Operational \\
\hline CCR 07 & $\mathrm{ARCS}^{d}$ goniometer & $10-300$ & $>100$ mm & ARCS dedicated \\
\hline CCR 08 & $\begin{array}{l}\text { Bottom load JT- } \\
\text { displex }\end{array}$ & $2-300$ & $70 \mathrm{~mm}$ & Operational \\
\hline CCR 09 & $\begin{array}{l}\text { Top loading CCR and } \\
1-\mathrm{K} \text { pot }\end{array}$ & $1.5-300$ & $50 \mathrm{~mm}$ & available Sept. 08 \\
\hline CCR 10 & $\mathrm{CNCS}^{e}$ custom rig & $4-300$ & TBD & Under development \\
\hline HOT 01 & ILL $L^{f}$ vacuum furnace & $300-1900$ & $50 \mathrm{~mm}$ & Operational \\
\hline ULT 01 & $\mathrm{He}^{3}$ insert & $0.3-300$ & $30 \mathrm{~mm}$ & Operational \\
\hline ULT 02 & $\begin{array}{l}\text { Dilution insert for } \\
\text { MAC } 01\end{array}$ & $0.03-0.4$ & $30 \mathrm{~mm}$ & available Sept. 08 \\
\hline ULT 03 & $\begin{array}{l}\text { Cryogen-free } \mathrm{He}^{3} \\
\text { system }\end{array}$ & $0.3-320$ & 100 mm & available Sept. 08 \\
\hline MAG 01 & $\begin{array}{l}\text { 5-T vertical field } \\
\text { actively shielded }\end{array}$ & $\begin{array}{l}\text { 2-300 } \\
\text { (compatible with } \\
\text { ULT-02) }\end{array}$ & & Operational \\
\hline MAG 02 & $\begin{array}{l}16-T \text { vertical field } \\
\text { actively shielded }\end{array}$ & $2-300$ & & available Dec. 09 \\
\hline MAG 03 & $\begin{array}{l}2-T \text { vertical field/ } \\
\text { rotating displex }\end{array}$ & $5-300$ & $\begin{array}{l}\text { Special sample holder } \\
\text { (contact SE team) }\end{array}$ & $\begin{array}{l}\text { Magnetism } \\
\text { reflectometer dedicated }\end{array}$ \\
\hline HIP 01 & $\begin{array}{l}\text { 1-kBar TiZr gas } \\
\text { pressure cell }\end{array}$ & $2-600$ & & available May 08 \\
\hline HIP 02 & 2-kBar sapphire cell & $\begin{array}{l}\text { To } 670 \\
\text { with dedicated } \\
\text { furnace }\end{array}$ & & available June 08 \\
\hline HIP 03 & $\begin{array}{l}\text { 100-Bar gas pressure } \\
\text { stick }\end{array}$ & $\begin{array}{l}2 \text { to } 500 \\
\text { (with CCR) }\end{array}$ & & available Sept. 08 \\
\hline $\begin{array}{l}\text { Anvil pressure } \\
\text { cells }\end{array}$ & \multicolumn{4}{|c|}{ Consult SE team for details } \\
\hline
\end{tabular}

${ }^{a}$ Fast Exchange Refrigerator for Neutron Science.

bPowder Diffractometer.

${ }^{c}$ Closed cycle refrigerator.

'Wide Angular-Range Chopper Spectometer.

${ }^{e}$ Cold Neutron Chopper Spectometer.

flnstitut Laue-Langevin. 


\section{Conceptual Drawing ${ }_{S N S}$}

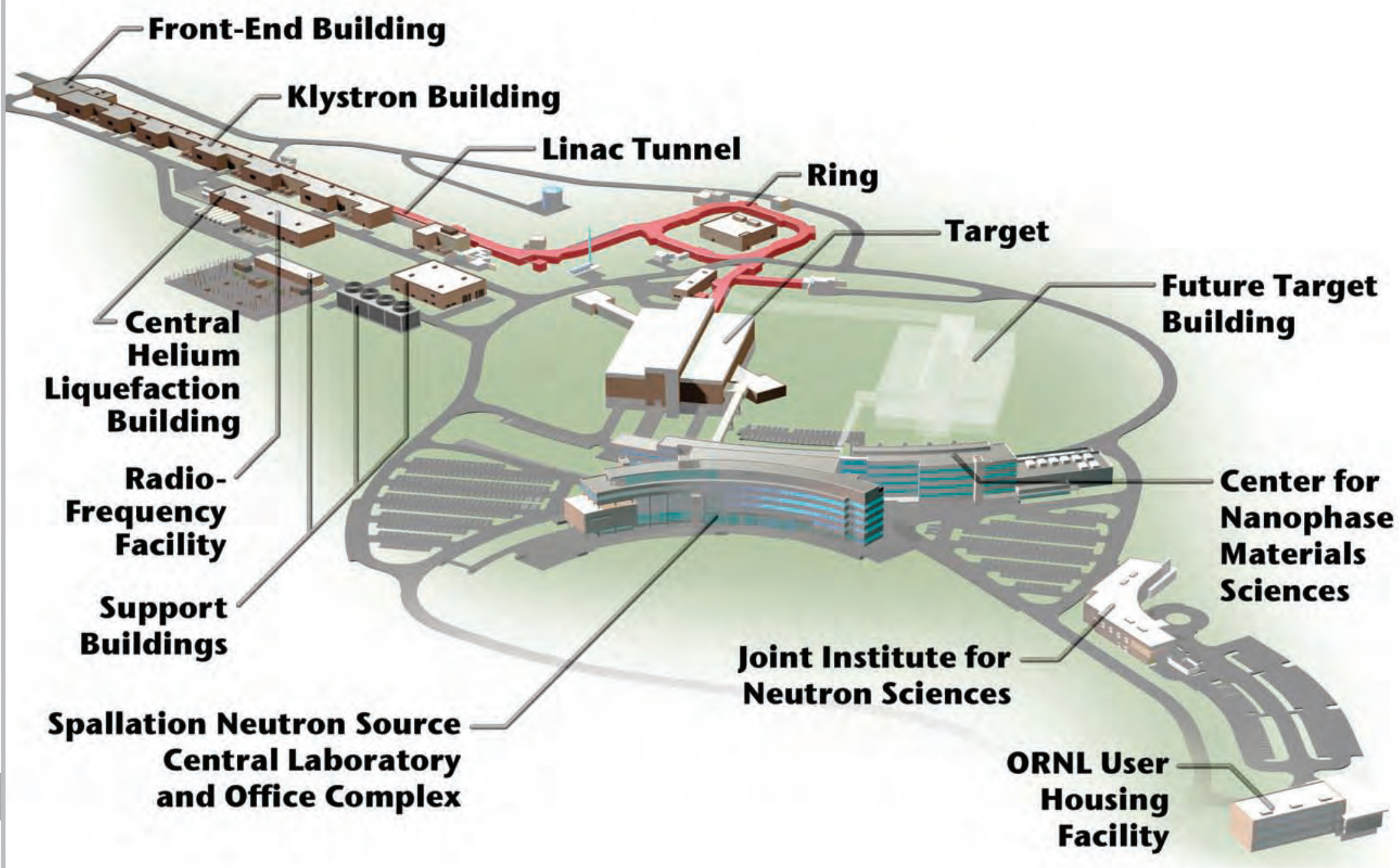




\section{Instrument La youts}

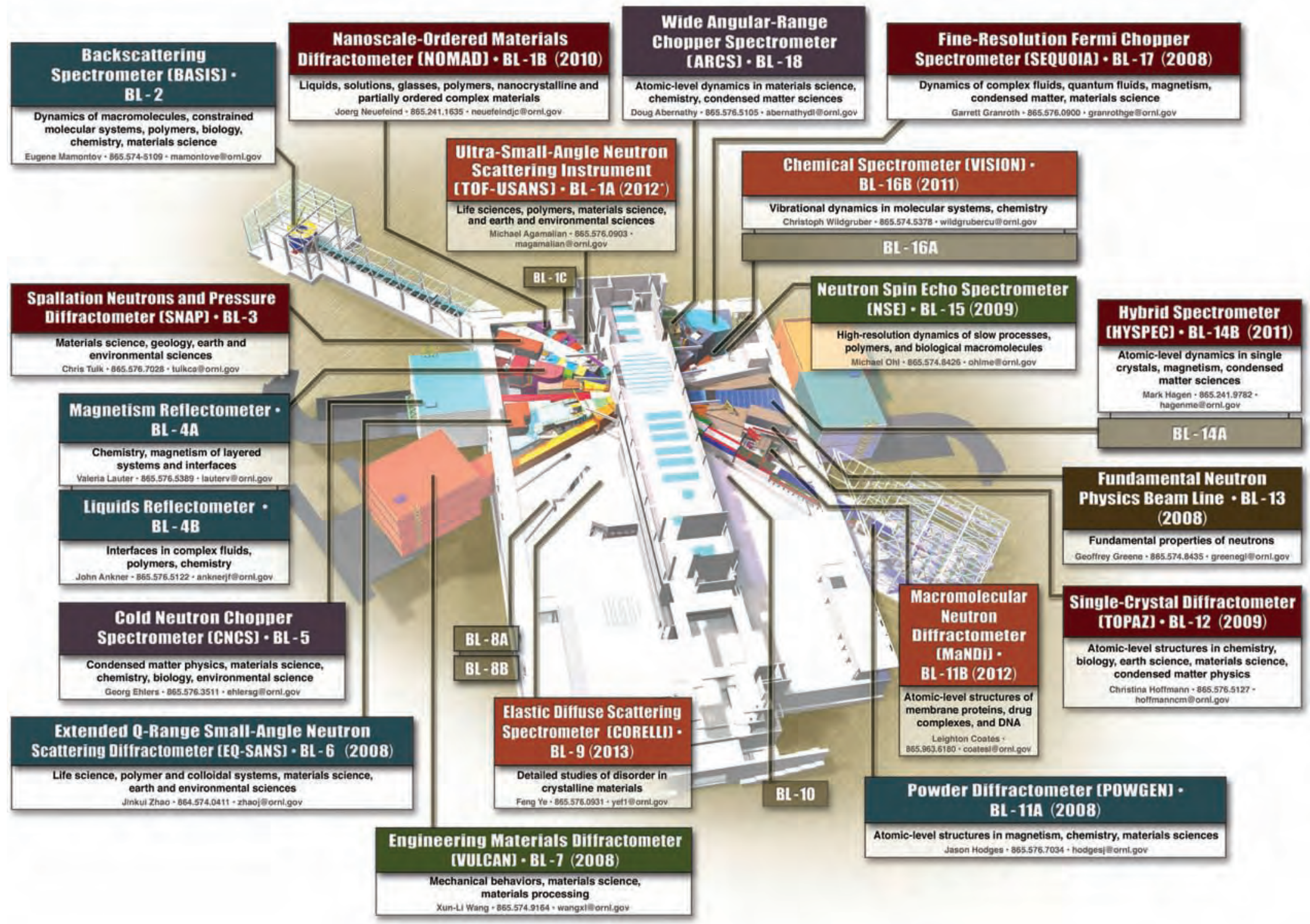

* Scheduled commissioning date

\begin{tabular}{|c|c|c|}
\hline \multicolumn{3}{|c|}{ LEGEND } \\
\hline SNS TPC & | SINGI & | SING II \\
\hline DOE Grant & DOE NP & Non U.S. \\
\hline
\end{tabular}




\section{Instrument La youts}

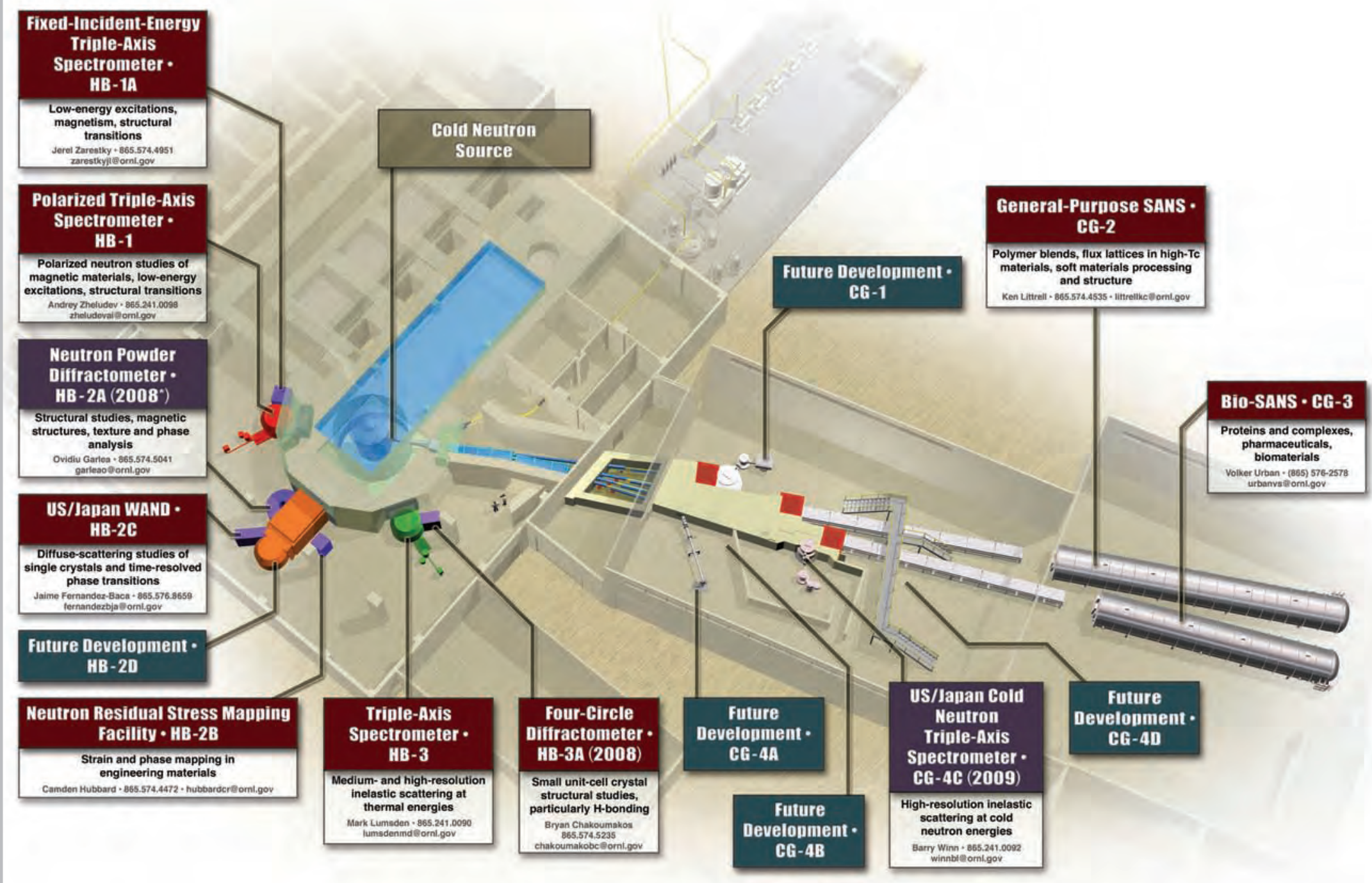

* Date shown is the scheduled commissioning date. 


\section{INGTRUMENT} EC-

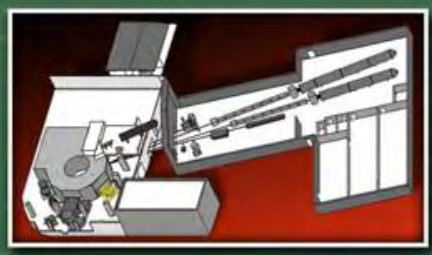

\section{GENERAL-PURPISE SANS}

\section{SMALL-ANGLE NEUTREN}

SCATTERING DIFFRACTIMETER

The general-purpose SANS diffractometer is optimized for providing information about structure and interactions in materials in the size range of $0.5-200 \mathrm{~nm}$. It will have cold neutron flux on sample and capabilities comparable to those of the best SANS instruments worldwide, including a wide range of neutron wavelengths $\lambda 5-30 \AA$, resolution $\delta \lambda \lambda \lambda 9.45 \%$, and a $1-\mathrm{m}^{2}$

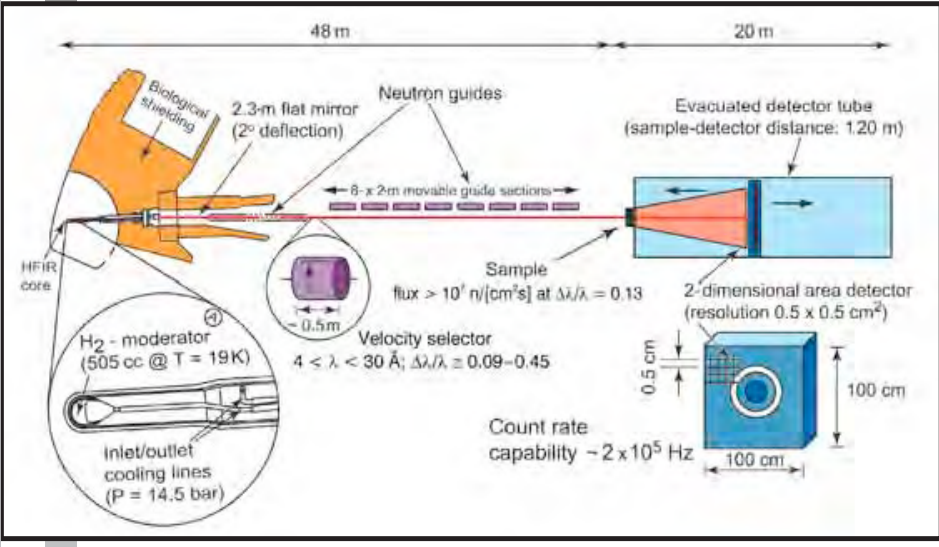
area detector with $5-\times 5-\mathrm{mm}^{2}$ pixel resolution with a maximum counting capability of up to $200 \mathrm{kHz}$. The sample-to-detector distance can be varied from 1 to $20 \mathrm{~m}$, and the detector can be offset horizontally by up to $45 \mathrm{~cm}$, allowing a total accessible $\mathrm{Q}$ range of from $<0.001$ to $1 \AA^{-1}$. The 2-m sample environment area will accommodate large, specialpurpose sample environments such as cryomagnets, furnaces, mechanical load frames, and shear cells.

\section{APPLICATIONS}

- Soft condensed matter: molecular self-assembly and interactions in complex fluids; intermediate order in glassy systems, polymer solutions, gels and blends, colloids, micelles, and microemulsions

- Hard condensed matter: phase separation, grain growth, and orientation in metallurgical alloys, nanocomposites, advanced ceramics, and porous catalytic and adsorbent materials

- Magnetic systems: flux lattices in superconductors, ferrofluids, and the relationship between structural and magnetic domains and ordering

\section{FIR MIRE INFIRMATION, CONTACT}

Instrument Scientist: Ken Littrell, littrellkc@ornl.gov, 865.574.4535

Instrument Scientist: Yuri Melnichenko, melnichenkoy@ornl.gov, 865.576.7746

Scientific Associate: Katherine Atchley, atchleykm@ornl.gov, 865.574.3989

http://neutrons.ornl.gov/hfir_instrument_systems/CG-2.shtml

\section{SPECIFICATIONS}

\begin{tabular}{|c|c|}
\hline Beam spectrum & Cold \\
\hline Monochromator & $\begin{array}{l}\text { Helical slot } \\
\text { selector }\end{array}$ \\
\hline $\begin{array}{r}\text { Incident } \\
\text { wavelength }\end{array}$ & $4<\lambda<30 \AA$ \\
\hline Resolution range & $\Delta \lambda / \lambda 0.09-0.45 \%$ \\
\hline Collimation & $\begin{array}{l}\text { Eight removable } \\
\text { guide sections, } \\
\text { each } 4 \times 4 \mathrm{~cm}^{2} \\
\text { and } 2 \mathrm{~m} \text { long; } \\
2 \text {-m open area } \\
\text { at sample stage } \\
\text { to mount auto- } \\
\text { matic changers, } \\
\text { furnaces, mag- } \\
\text { nets, cryostats, } \\
\text { pressure cells, } \\
\text { etc. }\end{array}$ \\
\hline $\begin{array}{r}\text { Q range }\left(\AA^{-1}\right) \\
1.5-\mathrm{m} \\
\text { collimation }\end{array}$ & $\begin{array}{l}0.038<Q< \\
1.0 \AA^{-1}(5 \AA) ; \\
0.019<Q< \\
0.50 \AA^{-1}(10 \AA)\end{array}$ \\
\hline 20-m collimation & $\begin{array}{l}0.004<Q< \\
0.074 \AA^{-1}(5 \AA) \\
0.002<Q< \\
0.037 \AA^{-1}(10 \AA)\end{array}$ \\
\hline $\begin{array}{r}\text { Sample-detector } \\
\text { distances }\end{array}$ & $1<\mathrm{D}<20 \mathrm{~m}$ \\
\hline Detector & $\begin{array}{l}\text { 2-D }\left({ }^{3} \mathrm{He}\right) \text { po- } \\
\text { sition-sensitive } \\
\text { detector with } \\
1-\mathrm{m}^{2} \text { active area } \\
\text { and } 5.1 \times 5.1 \\
\mathrm{~mm}^{2} \text { pixels }\end{array}$ \\
\hline $\begin{array}{r}\text { Max counting } \\
\text { rate }\end{array}$ & $200 \mathrm{kHz}$ \\
\hline
\end{tabular}

Status: Operational

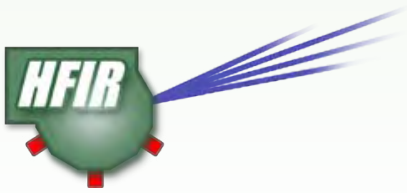

May 2008 


\section{INGTRUMENT}

狊 HIGH FLUX ISTTOPE REAGTOR

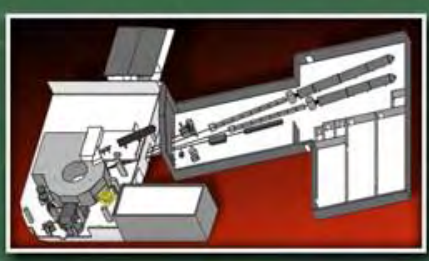

\section{BID-SANS - BIDLgGICAL SMALL-ANELE NEUTRON SCATTERING INGTRUMENT}

Bio-SANS was designed and optimized for analysis of the structure, function, and for Structural Molecular Biology (CSMB) at Oak Ridge National Laboratory. The Bio-

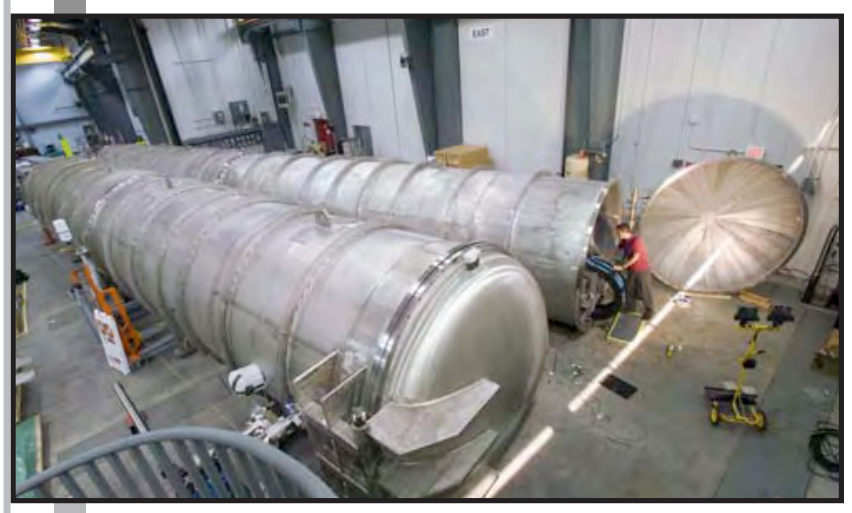

SANS instrument is supported by additional CSMB capabilities that include development of advanced computational tools for neutron analysis and modeling, as well as biophysical characterization and $\mathrm{X}$-ray scattering infrastructure. A dedicated biological sample preparation laboratory is located adjacent to the instrument.

Detector tanks for the new SANS instruments at HFIR The Bio-SANS detector is on the right.

\section{APRLICATIONS}

- Bio-macromolecules and their assemblies

- Protein complexes

- Protein/DNA complexes

$\square$ Lipids

- Viruses

- Carbohydrates

- Biomimetic and bio-inspired systems
- Hierarchical biological structures

- Gels

- Vesicles

- Microemulsions

- Membrane diffraction
- Fibers and fibrils dynamics of complex biological systems. Bio-SANS is the cornerstone of the Center

SPECIFICATIONS

\begin{tabular}{|r|l|}
\hline Wavelength & $6<\lambda<30 \AA$ \\
\hline $\begin{array}{r}\text { Wavelength } \\
\text { resolution }\end{array}$ & $\begin{array}{l}\Delta \lambda / \lambda= \\
12-45 \%\end{array}$ \\
\hline $\mathrm{Q}$ range & $0.002-1 \AA^{-1}$ \\
\hline $\begin{array}{r}\text { Sample- } \\
\text { to-detector } \\
\text { distance }\end{array}$ & $1-15 \mathrm{~m}$ \\
\hline Detector & $2-\mathrm{D}{ }^{3} \mathrm{He}$ \\
\hline Detector size & $1 \times 1 \mathrm{~m}$ \\
\hline $\begin{array}{r}\text { Detector } \\
\text { resolution/ } \\
\text { pixel size }\end{array}$ & $5.1 \times 5.1 \mathrm{~mm}^{2}$ \\
\hline $\begin{array}{r}\text { Max count } \\
\text { rate }\end{array}$ & $200 \mathrm{kHz}$ \\
\hline
\end{tabular}

\section{CENTER CAPABILITIES}

\begin{tabular}{|l|}
\hline X-ray scattering \\
\hline Light scattering \\
\hline Computational tools \\
\hline Bio-support lab \\
\hline Protein production + analysis \\
\hline Bio-deuteration lab \\
\hline Status: Operational
\end{tabular}

\section{USER ACCESS}

Bio-SANS is operated as a user facility and is sponsored by DOE's Office of Biological and Environmental Research. The instrument is managed under the CSMB User Program. For information about the CSMB rapid access proposal process, go to www.csmb.ornl.gov.

\section{FIR MORE INFIRMATION, CONTACT}

Instrument Scientist: Volker Urban, urbanvs@ornl.gov, 865.576.2578

Instrument Scientist: William Heller, hellerwt@ornl.gov, 865.241.5694

Center Director: Dean Myles, mylesda@ornl.gov, 865.574.5662

http://neutrons.ornl.gov/hfir_instrument_systems/factsheet_pdf/Instrument_cg3.pdf
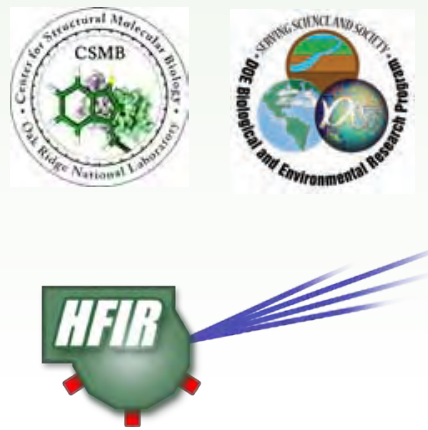

May 2008 


\section{INGTRUMENT} 狊 HIGH FLUX ISGTOPE REAGTOR

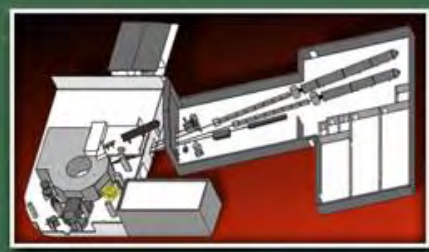

\section{US/JAPAN CRLD NEUTRᄆN TRIPLE-AXIS SPECTRDMETER}

The US/Japan Cold Neutron Triple-Axis Spectrometer is a conventional triple-axis spectrometer with variable incident energy and variable monochromator-sample and sample-analyzer distances. The cold guide 4 bender and guide hall shielding reduce

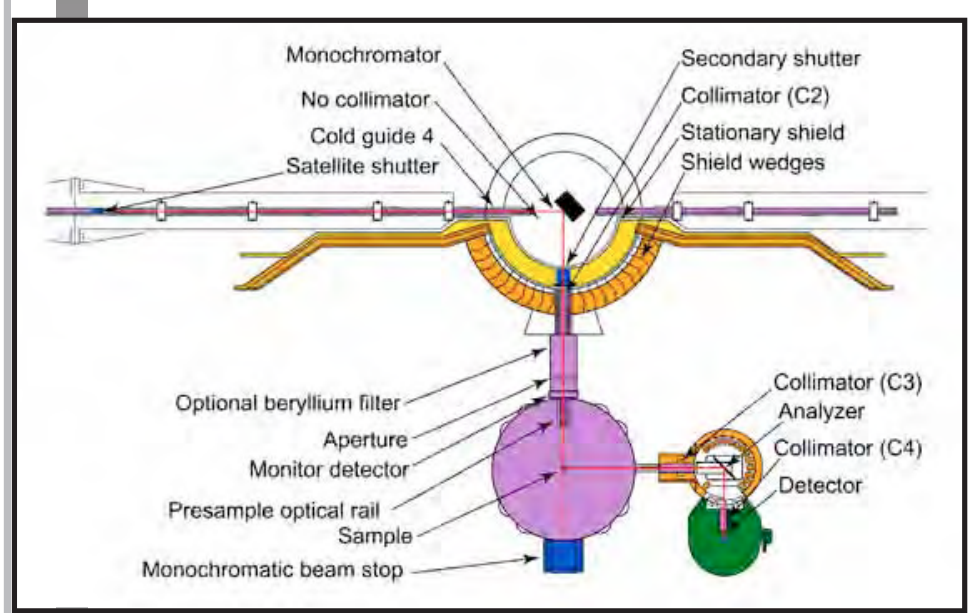

background levels at

CG-4C, and the 15-cm-tall guide profile is well exploited by CG-4C's vertically focusing monochromator (PG 002). To enhance accommodation of strong magnetic fields at the sample position and to simplify future polarization analysis, the amount of ferromagnetic material has been minimized in the construction of this instrument.

CG-4C is a collaboration of the Neutron Scattering Science Division at Oak Ridge National Laboratory, the Neutron Scattering Group at Brookhaven National Laboratory, and the Neutron Science Laboratory, Institute for Solid State Physics, at the University of Tokyo.

\section{APPLICATIONS}

- High-resolution measurement of low-energy excitations with high signal-to-noise ratios due to the low background

- Studies of magnetic phenomena, exploiting the energy range that matches achievable applied field at sample

\section{SPECIFICATIONS}

\begin{tabular}{|c|c|}
\hline $\begin{array}{r}\text { Incident } \\
\text { energy range } \\
(P G \text { 002) }\end{array}$ & 2-20 meV \\
\hline $\begin{array}{r}\text { Final energy } \\
\text { range } \\
(P G ~ 002)\end{array}$ & $>2.8 \mathrm{meV}$ \\
\hline $\begin{array}{r}\text { Sample } \\
\text { scatter } \\
\text { angular range }\end{array}$ & $\begin{array}{l}\text { Geometry } \\
\text { dependent } \\
\left(<160^{\circ}\right)\end{array}$ \\
\hline $\begin{array}{r}\text { Collimation } \\
\text { before mono- } \\
\text { chromator }\end{array}$ & $\begin{array}{l}\text { Guide } \\
\text { dependent } \\
\left(40^{\prime} \text { at } 2 \text { meV, }\right. \\
20 \text { ' at } 20 \\
\text { meV) }\end{array}$ \\
\hline $\begin{array}{r}\text { Collimation } \\
\text { after mono- } \\
\text { chromator }\end{array}$ & $\begin{array}{l}10^{\prime}, 20^{\prime}, 40^{\prime}, \\
80^{\prime}\end{array}$ \\
\hline
\end{tabular}

Status:

To be commissioned in 2008

FIR MURE INFIRMATION, CINTACT

Principal Investigator: Steve Shapiro, shapiro@bnl.gov, 631.344.3822

Principal Investigator: Hideki Yoshizawa, yoshi@issp.u-tokyo.ac.jp Instrument Scientist: Barry Winn, bwinn@bnl.gov, 865.241.0092 http://neutrons.ornl.gov/hfir_instrument_systems/CG-4C.shtml

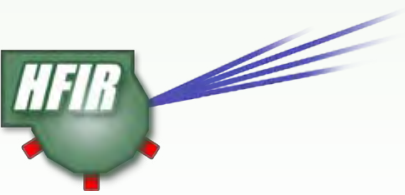

May 2008 


\section{INGTRUMENT}

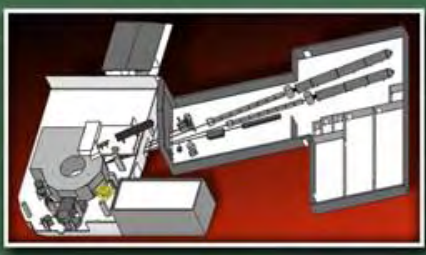

\section{TRIPLE-AXIG GPECTRDMETER}

The HB-1 Triple-Axis Spectrometer is designed primarily for the study of excitations in crystalline solids at intermediate energies. Thanks to the vertical beam focusing and the

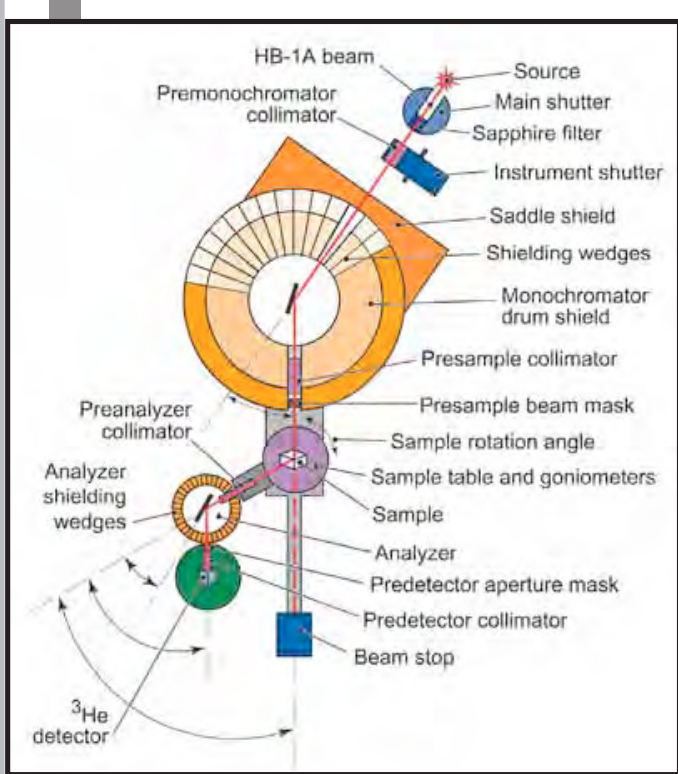
very high time-averaged flux at HFIR, its geometry is optimal for investigating small samples and weak scattering in specific areas of energy-momentum space. The sample goniometers and a full software implementation of the three-dimensional sample orientation matrix allow measurements outside the traditional single-scattering plane. The unique capability of HB-1 is the polarized configuration for studies of excitations, phase transitions, structures, and density distributions in magnetic materials.

\section{APPLICATIONS}

The following are some of the scientific applications for which the Triple-Axis Spectrometer is particularly well suited.

- Spin waves in ordered magnetic materials

- Exotic excitations in low-dimensional, molecular, itinerate, and other "quantum" magnets

- Spin and lattice excitations in high- $\mathrm{T}_{\mathrm{C}}$ superconductivity, colossal magnetoresistance materials, and multiferroic systems

- Spin density distributions in magnetic compounds

- Phonon dispersion curves in alloys and phonon-driven phase transitions

\section{FIR MIRE INFGRMATION, CONTACT}

Instrument Scientist: Andrey Zheludev, zheludevai@ornl.gov, 865.241.0098 http://neutrons.ornl.gov/hfir_instrument_systems/HB-1.shtml

\section{SPECIFICATIONS}

\begin{tabular}{|c|c|}
\hline Beam spectrum & Thermal \\
\hline \multirow[t]{2}{*}{$\begin{array}{r}\text { Monochro- } \\
\text { mators }\end{array}$} & $\begin{array}{l}\text { Unpolarized } \\
\text { PG(002) }\end{array}$ \\
\hline & $\begin{array}{l}\text { Polarized (not } \\
\text { currently avail- } \\
\text { able) }\end{array}$ \\
\hline \multirow[t]{2}{*}{ Analyzers } & $\begin{array}{l}\text { Unpolarized } \\
\text { PG(002), } \\
\mathrm{Be}(101), \\
\mathrm{Be}(002) \\
\text { horizontally fo- } \\
\text { cused PG(002) }\end{array}$ \\
\hline & $\begin{array}{l}\text { Polarized (not } \\
\text { currently avail- } \\
\text { able) }\end{array}$ \\
\hline $\begin{array}{r}\text { Monochromator } \\
\text { angle }\end{array}$ & 18 to $75^{\circ}$ \\
\hline Sample angles & 0 to $360^{\circ}$ \\
\hline $\begin{array}{r}\text { Scattering } \\
\text { angle }\end{array}$ & -90 to $140^{\circ}$ \\
\hline Analyzer angles & -40 to $140^{\circ}$ \\
\hline \multirow[t]{4}{*}{$\begin{array}{r}\text { Collimations } \\
\text { (FWHM) }\end{array}$} & $\begin{array}{l}\text { C1: } 0.25,0.5 \\
0.8^{\circ}\end{array}$ \\
\hline & $\begin{array}{l}\text { C2: } 0.166 \text {, } \\
0.333,0.666 \text {, } \\
1,1.333^{\circ}\end{array}$ \\
\hline & $\begin{array}{l}\text { C3: } 0.166 \text {, } \\
0.333,0.666 \text {, } \\
1,1.333^{\circ}\end{array}$ \\
\hline & $\begin{array}{l}\text { C4: } 0.333 \text {, } \\
0.666 .1,2^{\circ}\end{array}$ \\
\hline
\end{tabular}

Status: Operational

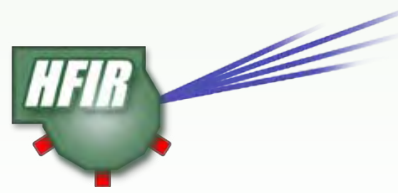

May 2008 


\section{INGTRUMENT}

\section{FIXED-INCIDENT-ENERGY TRIPLE-AXIS SPECTRIMETER}

The Fixed-Incident-Energy (14.6 meV) Triple-Axis Spectrometer uses a double pyrolitic graphite monochromator system. The first monochromator is vertically focused, and the second can be

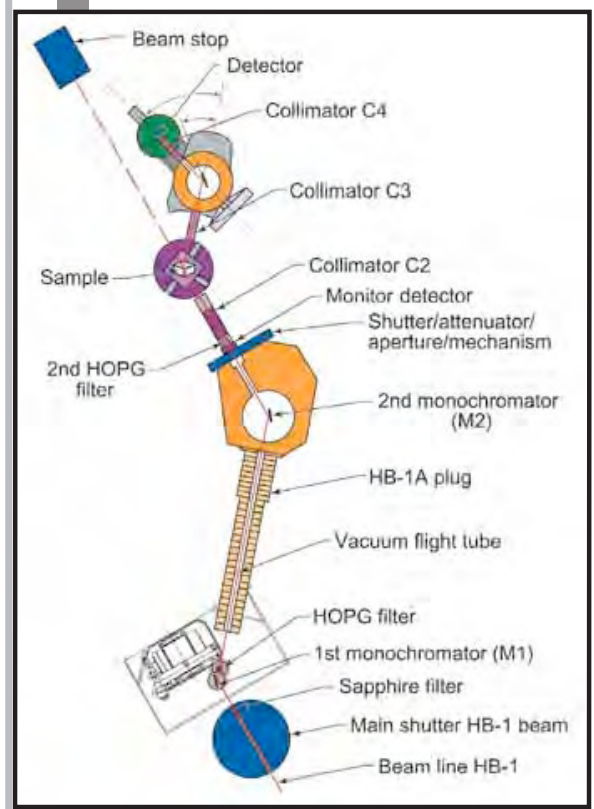

either a vertically or doubly focused unit. Two highly oriented pyrolytic graphic filters (HOPG), one after each monochromator, are used to reduce $\lambda / 2$ contamination. These filters, together with the double monochromator system, provide HB-1A with an exceptionally clean beam in terms of higher-order contamination neutrons: $\mathrm{I}_{\lambda / 2} \approx 10^{-4} \times \mathrm{I}_{\lambda}$. This spectometer also has one of the most intense beams at this energy at the HFIR, as well as a very low $\gamma$ and fast neutron background. Typical energy resolution is $\sim 1 \mathrm{meV}$, but, using the beryllium analyzer, the energy resolution width can be reduced to $\sim 0.5 \mathrm{meV}$.

HB-1A development and operation is a collaborative effort of the Oak Ridge National Laboratory and Ames Laboratory neutron scattering groups.

\section{APPLICATIONS}

- Excitation spectra to $\sim 35 \mathrm{meV}$ using neutron energy gain and low-lying excitations, $1-9 \mathrm{meV}$, using neutron energy loss

- Elastic studies on crystallographic and magnetic structures and transitions in a Q range of 0.2 to $4.9 \AA^{-1}$

- Elastic studies and excitations in thin films and other small-volume samples where high flux and very low higher-order contamination of the beam are critical

Recent experiments on this instrument include measurement of phonon dispersion curves in martensitic, shape-memory, and magnetostrictive alloys; crystallographic and magnetic structure determinations in giant magnetocaloric, magnetoresistive, and intermetallic alloys; magnetic structures and spin-density waves in thin films; magnetism in low-dimensional systems; and spin waves and magnetic structures in magnetoelectric materials.

FIR MIRE INFGRMATILN, CONTACT

Instrument Scientist: Jerel Zarestky, zarestkyjl@ornl.gov, 865.574.4951 http://neutrons.ornl.gov/hfir_instrument_systems/HB-1A.shtml

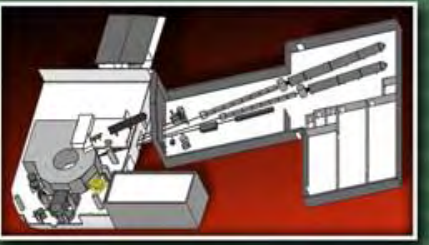

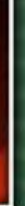

SPECIFICATIDNS

\begin{tabular}{|c|c|}
\hline Beam spectrum & Thermal \\
\hline $\begin{array}{r}\text { Monochro- } \\
\text { mator }\end{array}$ & $\begin{array}{l}\mathrm{PG}(002) \text { double } \\
\text { crystal }\end{array}$ \\
\hline $\begin{array}{l}\text { Monochro- } \\
\text { mator angle }\end{array}$ & $\begin{array}{l}2 \Theta_{\mathrm{M}}=41.3^{\circ} E_{i}= \\
14.6 \mathrm{meV}\end{array}$ \\
\hline Analyzers & $\begin{array}{l}\mathrm{PG}(002) \mathrm{Be}(101) \\
\mathrm{Be}(002) \mathrm{Si}(111) \\
\mathrm{Ge}(111)\end{array}$ \\
\hline Sample angles & $0^{\circ}<\mathrm{s} 1<360^{\circ}$ \\
\hline Scattering angle & $-5^{\circ}<\mathrm{s} 2<135^{\circ}$ \\
\hline Analyzer angles & $-60^{\circ}<\mathrm{a} 2<120^{\circ}$ \\
\hline $\begin{array}{r}\text { Collimations } \\
\text { (FWHM) }\end{array}$ & $\begin{array}{l}\text { C1: open (48' } \\
\text { effective) } \\
\text { C2: open (40' } \\
\text { effective) (30', } \\
\text { 20', 10') } \\
\text { C3: 40', 30', } \\
20^{\prime}, 10^{\prime} \text { (sample } \\
\text { analyzer) } \\
\text { C4: } 34^{\prime}, 68 \text { ', } \\
\text { 136' (analyzer- } \\
\text { detector) }\end{array}$ \\
\hline Beam size & $\begin{array}{l}40 \times 150 \mathrm{~mm} \\
\max \end{array}$ \\
\hline Filters & $\begin{array}{l}\text { Sapphire pre- } \\
\text { monochro- } \\
\text { mator-1 } \\
\text { 2-HOPG; after } \\
\mathrm{M}-1 \text { and } \mathrm{M}-2 \\
\left(\mathrm{I}_{\lambda / 2} \approx 10^{-4} \mathrm{I}_{\lambda}\right)\end{array}$ \\
\hline Flux at sample & $\begin{array}{l}\sim 2 \times 10^{7} \mathrm{n} / \\
\mathrm{cm}^{2} / \mathrm{s} \text { (est.) }\end{array}$ \\
\hline Momentum range & $\begin{array}{l}0.2 \text { to } 4.9 \AA^{-1} \\
\text { (elastic configura- } \\
\text { tion) }\end{array}$ \\
\hline Energy transfer & $\begin{array}{l}\sim-35 \mathrm{meV} \text { to } \\
\sim+11 \mathrm{meV} \text { at } \\
\mathrm{q}=3 \AA^{-1}\end{array}$ \\
\hline
\end{tabular}

Status: Operational

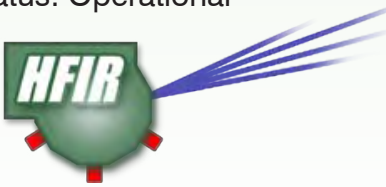

May 2008 


\section{INGTRUMENT} 高 HIGH FLUX ISGTOPE REAETOR

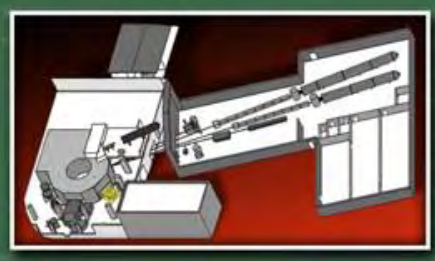

\section{NEUTREN PUWDER DIFFRACTIMETER}

The Neutron Powder Diffractometer has a Debye-Scherrer geometry. The detector bank has $44{ }^{3} \mathrm{He}$ tubes, each with 6' Soller collimators. A germanium wafer-stack monochromator is vertically focusing and provides one of three principal wavelengths, depending on which

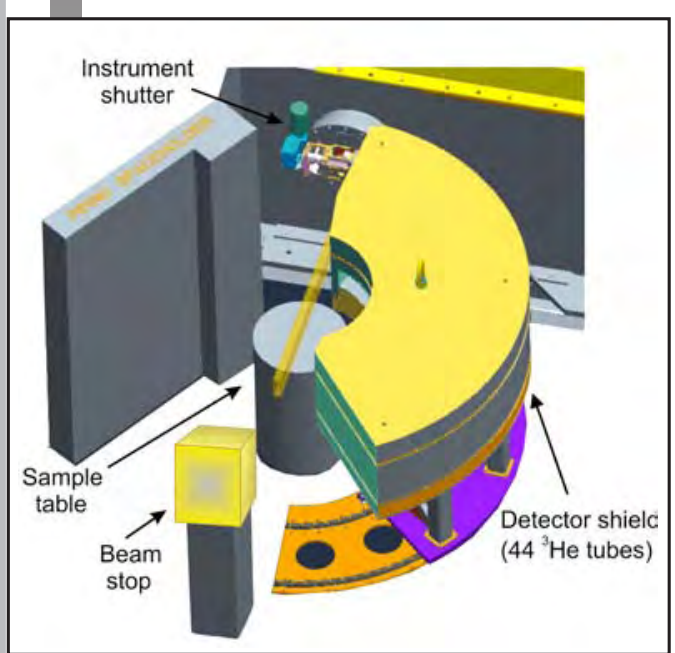
reflection is in the diffracting condition: (113) $2.41 \AA$, (115) $1.54 \AA$, and (117) $1.12 \AA$. The takeoff angle from the monochromator is fixed at $90^{\circ}$, and the minimum peak full width at half maximum (FWHM) is $0.2^{\circ}$. There are two choices of premonochromator collimation $\left(\alpha_{1}=12^{\prime}\right.$ or open $)$ and three choices of presample collimation $\left(\alpha_{2}=16^{\prime}, 21^{\prime}\right.$, or $\left.31^{\prime}\right)$ that allow the operation of the instrument in high-resolution or highintensity modes.

\section{APPLICATIONS}

The HB-2A Neutron Powder Diffractometer is a workhorse instrument used to conduct crystal structural and magnetic structural studies of powdered and ceramic samples, particularly as a function of intensive conditions ( $\mathrm{T}, \mathrm{P}, \mathrm{H}$, etc.). Technologically important materials amenable to study by neutron powder diffraction include (but are not limited to) catalysts, ionic conductors, superconductors, alloys, intermetallic compounds, ceramics, cements, colossal magnetoresistance perovskites, magnets, minerals, waste forms, H-storage, thermoelectrics, zeolites, and pharmaceuticals. Powder diffraction data collected on this instrument are ideally suited for the Rietveld method. In addition to traditional crystal structural refinements, studies of phase transitions, thermal expansion, quantitative analysis, residual stress, and ab initio structure solution can be undertaken from the powder data. A full range of ancillary sample environments can be used, including cryofurnaces (4-800 K), furnaces (to $1800 \mathrm{~K}$ ), cryostats (to $0.3 \mathrm{~K}$ ), and cryomagnets (to $7 \mathrm{~T}$ ).

\section{FIR MORE INFLRMATION, CONTACT}

Instrument Scientist: Ovidiu Garlea, garleao@ornl.gov, 865.574.5041

http://neutrons.ornl.gov/hfir_instrument_systems/HB-2A.shtml

\section{SPECIFICATIONS}

\begin{tabular}{|c|c|}
\hline $\begin{array}{r}\text { Beam } \\
\text { spectrum }\end{array}$ & Thermal \\
\hline $\begin{array}{r}\text { Monochro- } \\
\text { mator }\end{array}$ & $\begin{array}{l}\text { Vertically } \\
\text { focusing Ge } \\
\text { (115) } 20\end{array}$ \\
\hline $\begin{array}{l}\text { Monochro- } \\
\text { mator angle }\end{array}$ & $2 \Theta_{\mathrm{m}}=90^{\circ}$ \\
\hline Wavelengths & $\begin{array}{r}\lambda=1.54 \AA(115) \\
2.41 \AA(113) \\
1.12 \AA(117)\end{array}$ \\
\hline $\begin{array}{r}\text { Sample } \\
\text { angles }\end{array}$ & $0^{\circ}<\omega<360^{\circ}$ \\
\hline $\begin{array}{r}\text { Scattering } \\
\text { angle }\end{array}$ & $\begin{array}{l}-5^{\circ}<2 \Theta< \\
165^{\circ}\end{array}$ \\
\hline $\begin{array}{r}\text { Collimations } \\
\text { (FWHM) }\end{array}$ & $\begin{array}{l}\alpha_{1}=12^{\prime} \text { or open } \\
\alpha_{2}=16^{\prime}, 21^{\prime}, \\
\text { or } 31^{\prime}\end{array}$ \\
\hline $\begin{array}{r}\text { Detector } \\
\text { bank }\end{array}$ & $\begin{array}{l}44{ }^{3} \mathrm{He} \text { detec- } \\
\text { tors }\end{array}$ \\
\hline Beam size & $\begin{array}{l}25 \times 25 \mathrm{~mm}^{2} \\
\text { at sample } \\
\text { position }\end{array}$ \\
\hline Resolution & $2 \times 10^{-3} \Delta d / d$ \\
\hline
\end{tabular}

Status:

To be commissioned in 2008

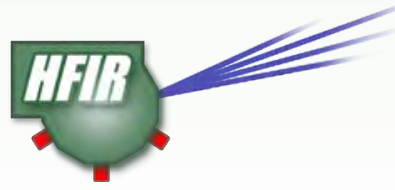

May 2008 


\section{INSTRUMENT}

\section{NRGFZ - NEUTRQN REgIDUAL STREgS MAPPING FACILITY}

NRSF2 at the HFIR HB-2B beam port is optimized for strain measurement and determination of residual stress in engineering materials. The large-specimen "XYZ" instrument is designed for spatial scanning of strains at depths from submillimeters to

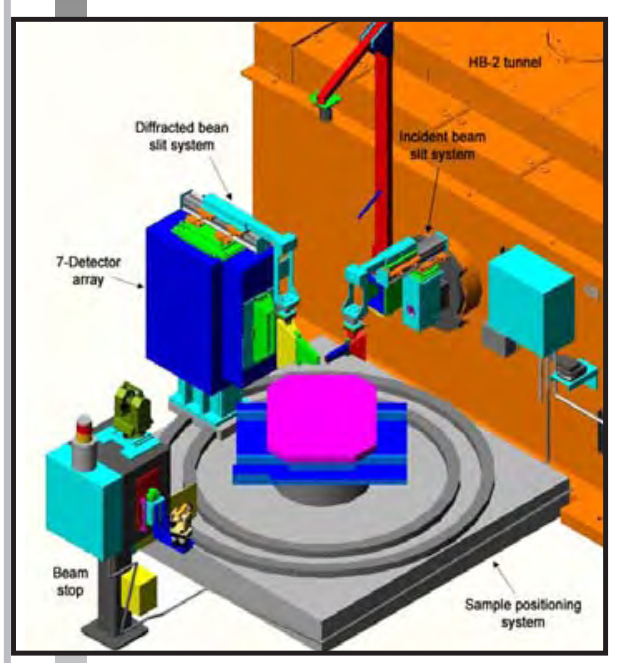
centimeters. The sample orienter can be used to determine the stress tensor and texture mapping and to study strains in large-grained materials and single crystals. The high flux and detector coverage allow real-time, in situ studies or high-resolution mapping. Ancillary equipment available for use at NRSF2 includes a 2,267-kg uniaxial (tension or compression) load frame, a Huber Eulerian cradle, high-temperature furnaces (vacuum or air), and a 5-T superconducting magnet with an induction furnace insert. Custom-built sample environment systems can be installed on the XYZ sample positioning system.

\section{APPLICATIONS}

The penetrating power of neutrons is useful in mapping residual stresses in engineering materials. Examples of applications include residual stress maps of welds, heat-treated samples, forgings, extrusions, bearings and races, fasteners, and composites. Neutron diffraction studies of materials under applied stress reveal phase- and grain-level knowledge of deformation processes, which is fundamental for developing finite-element method and self-consistent field models of materials behavior. Also characterized are strains in functional materials, such as piezoelectrics under the influence of electrical fields, shape memory alloys, and hydrogen storage materials.

\section{USER ACCESS}

NRSF2 is operated as a user facility sponsored by DOE's Office of FreedomCAR and Vehicle Technologies. The NRSF2 instrument is managed under the High Temperature Materials Laboratory (HTML) User Program. Information about the HTML rapid access proposal process can be obtained from http://html.ornl.gov.

\section{FIR MORE INFIRMATION, CONTACT}

Instrument Scientist: Camden Hubbard, hubbardcr@ornl.gov, 865.574.4472 http://neutrons.ornl.gov/hfir_instrument_systems/HB-2B.shtml

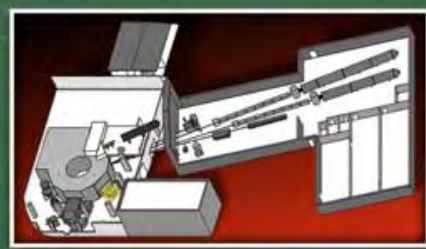

SPECIFICATIONS

\begin{tabular}{|c|c|}
\hline Beam spectrum & Thermal \\
\hline Monochromator & $\begin{array}{l}\text { Stacked Si wafers } \\
\text { with vertical and } \\
\text { horizontal focusing }\end{array}$ \\
\hline $\begin{array}{r}\text { Monochromator } \\
\text { takeoff angle }\end{array}$ & $\begin{array}{l}88^{\circ} \text { (fixed), } \lambda= \\
1.452 \AA \text { (Si } 511) ; \\
1.540 \AA \text { (Si 422); } \\
1.731 \AA \text { (Si 331); } \\
1.886 \AA \text { (Si 400); } \\
2.275 \AA \text { (Si 311); } \\
2.667 \AA \text { (Si 220) }\end{array}$ \\
\hline Flux on sample & $\begin{array}{l}3 \times 10^{7} \mathrm{n} / \mathrm{cm}^{2} / \mathrm{s} \\
\text { (Si } 331 \text { and } \mathrm{Si} 400)\end{array}$ \\
\hline $\begin{array}{r}\text { Detector angle } \\
\text { range }\end{array}$ & $70-100^{\circ}$ optimal \\
\hline Detection system & $\begin{array}{l}7 \text { linear position- } \\
\text { sensitive detectors }\end{array}$ \\
\hline $\begin{array}{l}\text { Position- } \\
\text { sensitive } \\
\text { detector } \\
\text { coverage }\end{array}$ & $\begin{array}{l}5^{\circ} 2 \Theta \\
\pm 17^{\circ} \text { out of plane }\end{array}$ \\
\hline $\begin{array}{r}\text { Sample } \\
\text { positioner }\end{array}$ & $\begin{array}{l}\Omega \pm 180^{\circ} \\
X \pm 200 \mathrm{~mm} \\
Y \pm 100 \mathrm{~mm}\end{array}$ \\
\hline $\begin{array}{r}\text { Z elevator } \\
\text { Z translation }\end{array}$ & $\begin{array}{l}\mathrm{Z} \pm 100 \mathrm{~mm}, 500 \mathrm{Kg} \\
\mathrm{Z} \pm 200 \mathrm{~mm}, 50 \mathrm{Kg}\end{array}$ \\
\hline $\begin{array}{r}\text { Nominal gage } \\
\text { volume }\end{array}$ & $\begin{array}{l}\text { Width: } 0.3-5 \mathrm{~mm} \text {; } \\
\text { Height: } 0.3-20 \mathrm{~mm}\end{array}$ \\
\hline $\begin{array}{r}\text { Peak location } \\
\text { precision }\end{array}$ & $0.003^{\circ} 2 \Theta$ \\
\hline $\begin{array}{r}\text { Sample } \\
\text { environments }\end{array}$ & $\begin{array}{l}\text { - Load frame for ten- } \\
\text { sion and compres- } \\
\text { sion }(2,267-\mathrm{kg}) \\
\text { - Huber Eulerian } \\
\text { cradle for tensor } \\
\text { and texture } \\
\text { - Vacuum and } \\
\text { environmental } \\
\text { furnaces } \\
\text {-5-T superconduct- } \\
\text { ing magnet with } \\
\text { induction heater }\end{array}$ \\
\hline \multicolumn{2}{|c|}{ Status: Operational } \\
\hline
\end{tabular}




\section{INGTRUMENT} $\mathrm{HB}-\mathrm{ZE}$

岁 HIGH FLUX ISTTOPE REAGTOR

\section{WAND - US/JAPAN WIDE-ANGLE NEUTRDN DIFFRACTDMETER}

The US/Japan WAND at the HFIR HB-2C beam tube was designed to provide two specialized data-collection capabilities: (1) fast measurements of medium-resolution powder-diffraction patterns and (2) measurements of diffuse scattering in single crystals using flat-cone geometry. For these purposes, this instrument is equipped with a curved, one-dimensional ${ }^{3} \mathrm{He}$ positionsensitive detector covering $125^{\circ}$ of the scattering angle with the focal distance of $71 \mathrm{~cm}$.

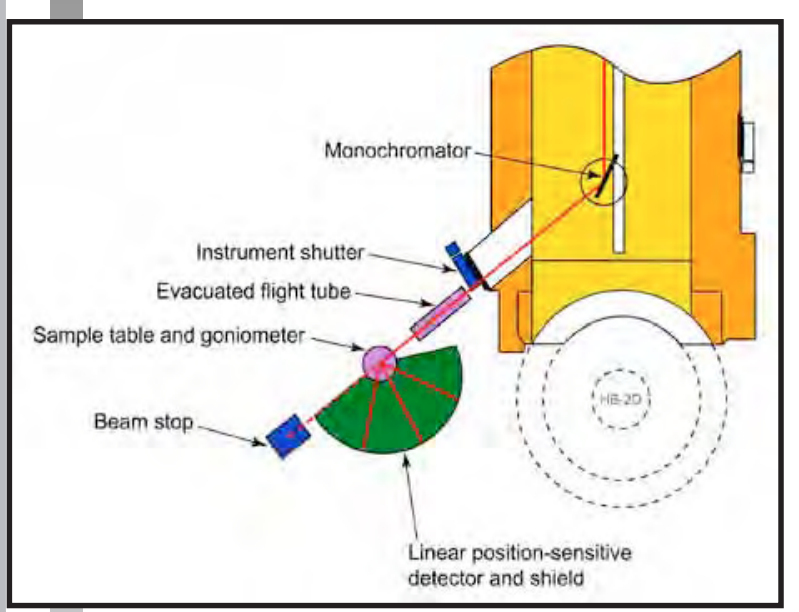

The sample and detector can be tilted in the flat-cone geometry mode. These features enable measurement of single-crystal diffraction patterns in a short time over a wide range of the reciprocal space, as well as performance of timeresolved experiments for structural transformations having short time constants. The WAND detector (ORDELA 1410N) is a multianode type (624 anodes and a $0.2^{\circ}$ pitch) ${ }^{3} \mathrm{He}$ gas counter specially designed for this instrument. This detector has an intrinsic angular resolution of $0.25^{\circ}$ and a maximum counting rate per anode of $10^{5}$ counts/s.

\section{APPLICATIONS}

WAND is ideal for the study of time-resolved phenomena and for the study of diffuse scattering in single crystals. Research performed at WAND includes studies of the growth of ferroelectric ice-XI, hole and charge ordering in colossal magnetoresistance materials, and studies of magnetic structures and correlations in low-dimensional magnetic systems and other magnetic materials.

WAND is operated in collaboration with the Japan Atomic Energy Research Institute under the US/Japan Cooperative Program on Neutron Scattering Research.

\section{FIR MURE INFIRMATION, CONTACT}

Instrument Scientist: Jaime Fernandez-Baca, fernandezbja@ornl.gov, 865.576.8659

http://neutrons.ornl.gov/hfir_instrument_systems/HB-2C.shtml

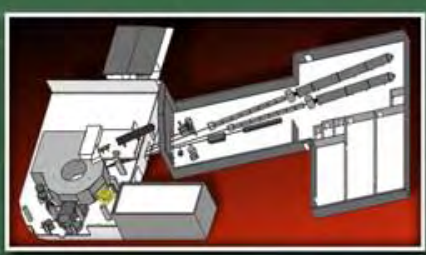

\begin{tabular}{|r|l|}
\hline $\begin{array}{r}\text { Beam } \\
\text { spectrum }\end{array}$ & Thermal \\
\hline $\begin{array}{r}\text { Monochro- } \\
\text { mator }\end{array}$ & $\begin{array}{l}\text { Vertically fo- } \\
\text { cused Ge(113). } \\
\text { Ge(115) is also } \\
\text { available to pro- } \\
\text { vide } \lambda=0.95 \AA\end{array}$ \\
\hline $\begin{array}{r}\text { Monochro- } \\
\text { mator angle }\end{array}$ & $2 \Theta_{\mathrm{M}}=52.0^{\circ}$ \\
\hline Wavelength & $\lambda=1.5 \AA$ \\
\hline $\begin{array}{r}\text { Scattering } \\
\text { angles }\end{array}$ & $10^{\circ}<2 \Theta<$ \\
$135^{\circ}$
\end{tabular}

Status: Operational

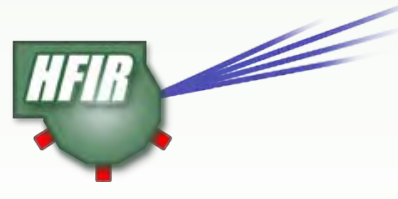

May 2008 


\section{INSTRUMENT}

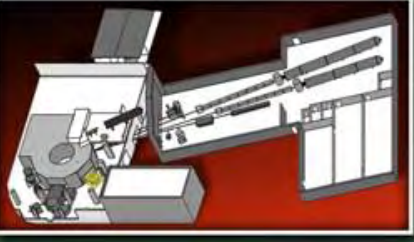

\section{TRIPLE-AXIS SPECTRDMETER}

HB-3 is a high-flux thermal neutron three-axis spectrometer designed for inelastic measurements on single crystals over a wide range of energy and momentum transfers. Although the energy and momentum range for measurements is quite large at HB-3, the instrument is the ideal location for performing experiments at high-energy transfers (up to

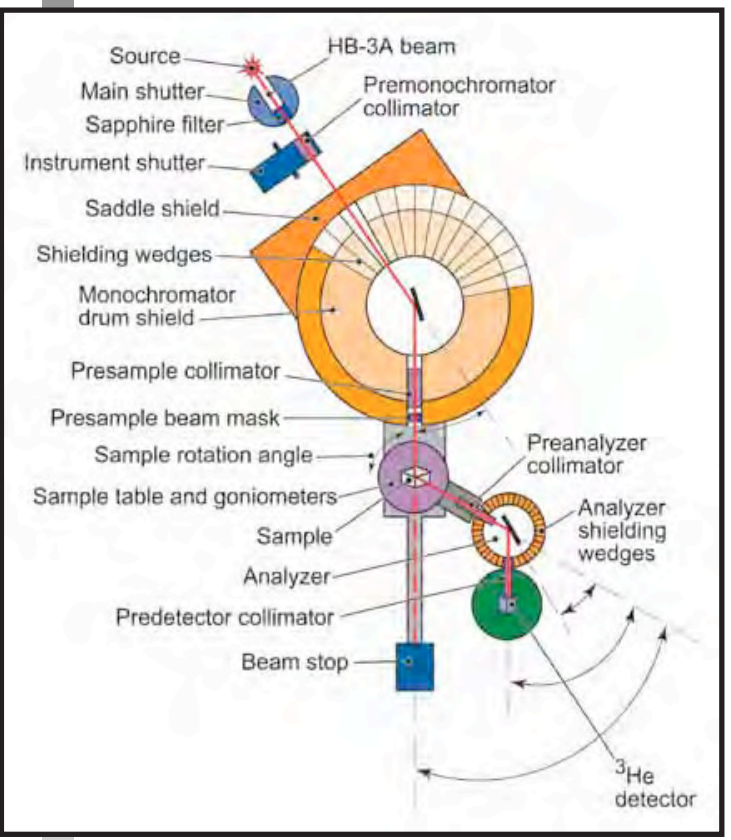
about $100 \mathrm{meV}$ ). This is due to a combination of its location directly at the end of the beam tube and the availability of a beryllium monochromator. The HB-3 monchromator provides three crystal choices (PG 002, Be 002, and Si 111) with variable vertical focus. This focus is calibrated to maintain the smallest beam size at the sample position, thus optimizing incident neutron flux as the incident energy varies. Of the three monochromators, pyrolitic graphite provides the highest neutron intensity as a result of its very high neutron reflectivity. The high-quality beryllium monochromator allows measurements with good energy resolution at higher energy transfers, whereas the silicon 111 monochromator has the advantage of an absent second-order reflection, providing a higher order contamination-free beam.

\section{APPLICATIONS}

The availability of three different monochromator crystals makes HB-3 an extremely versatile instrument for studies of excitations in materials with energies ranging from 2 to $100 \mathrm{meV}$. Typical applications include spin and lattice dynamics in high-temperature superconductors and related compounds; low-dimensional magnetic model systems; magnetic excitations and phonons in colossal magnetoresistive materials, multiferroics, and ruthenates; and spin waves in magnetically ordered materials. The high incident neutron flux makes HB-3 well suited to studying samples that have a small volume or weak scattering characteristics.

FIR MLRE INFIRMATION, CONTACT

Instrument Scientist: Mark Lumsden, lumsdenmd@ornl.gov, 865.241.0090 http://neutrons.ornl.gov/hfir_instrument_systems/HB-3.shtml
SPECIFICATIONS

\begin{tabular}{|c|c|}
\hline $\begin{array}{r}\text { Beam } \\
\text { spectrum }\end{array}$ & Thermal \\
\hline $\begin{array}{r}\text { Monochro- } \\
\text { mators }\end{array}$ & $\begin{array}{l}P G(002), \\
\mathrm{Be}(002), \\
\text { Si }(111)\end{array}$ \\
\hline Analyzer & PG (002) \\
\hline $\begin{array}{l}\text { Monochro- } \\
\text { mator angle }\end{array}$ & $12-88^{\circ}$ \\
\hline Sample angle & $-180-180^{\circ}$ \\
\hline $\begin{array}{r}\text { Scattering } \\
\text { angle }\end{array}$ & Up to $115^{\circ}$ \\
\hline $\begin{array}{r}\text { Analyzer } \\
\text { angle }\end{array}$ & $-120-120^{\circ}$ \\
\hline \multirow[t]{4}{*}{$\begin{array}{r}\text { Collimations } \\
\text { (FWHM) }\end{array}$} & $\begin{array}{l}\text { Premono- } \\
\text { chromator: } \\
15^{\prime}, 30^{\prime}, 48^{\prime}\end{array}$ \\
\hline & $\begin{array}{l}\text { Monochro- } \\
\text { mator - } \\
\text { sample: } 20^{\prime} \text {, } \\
40^{\prime}, 60^{\prime}\end{array}$ \\
\hline & $\begin{array}{l}\text { Sample - } \\
\text { analyzer: } 20^{\prime} \text {, } \\
40^{\prime}, 60^{\prime}, 80^{\prime}\end{array}$ \\
\hline & $\begin{array}{l}\text { Analyzer - } \\
\text { detector: } 70^{\prime} \text {, } \\
120^{\prime}, 240^{\prime}\end{array}$ \\
\hline
\end{tabular}

Status: Operational

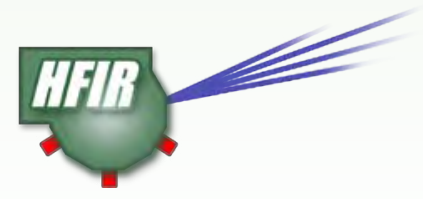

May 2008 


\section{INGTRUMENT} HE- $\mathrm{HA}$

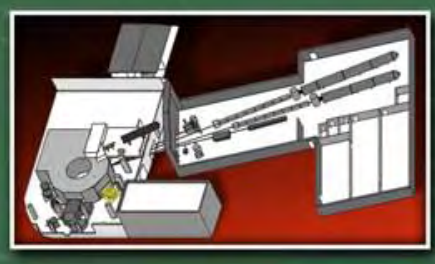

\section{FUUR-CIRELE DIFFRACTDMETER}

The Four-Circle Diffractometer goniometer has a full $\chi$ circle with a 10-K closed-cycle helium refrigerator. The detector is ${ }^{3} \mathrm{He}$ with a 7 -anode array in a honeycomb pattern. The upper $2 \Theta$ limit is $100^{\circ}$. A multilayer-[110]-wafer silicon monochromator with the reflection from planes of the $\langle 011>$ zone ensures sharp diffraction peaks in specified ranges of detector angles by control of the horizontal radius of curvature. Any plane from the $<011>$ zone can be set

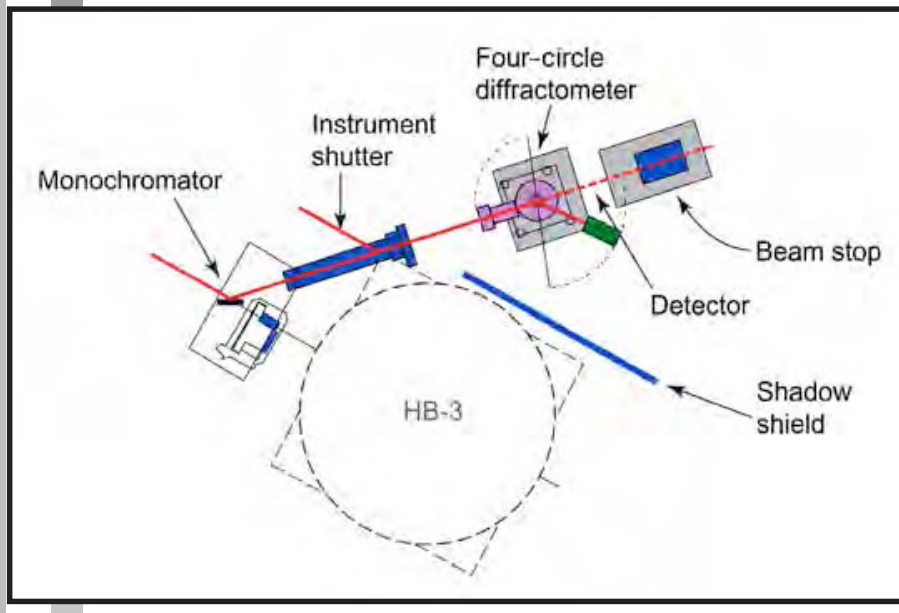
in Bragg position, but only the (155), (133), (022) with (044), and (111) with (333) reflections are of practical interest. For the fixed monochromator angle of $48^{\circ}$, these reflections provide principal incident wavelengths of $0.618,1.01$, 1.56 , and $2.55 \AA$, respectively. A PCbased LabView system provides userfriendly diffractometer control and data acquisition. The beam size is $5 \times 5 \mathrm{~mm}^{2}$, and the minimum crystal size is $1 \mathrm{~mm}^{3}$. The maximum crystal dimension is about $4 \mathrm{~mm}$. The flux on the sample is estimated to be greater than $5 \times 10^{6} \mathrm{n} / \mathrm{cm}^{2} / \mathrm{s}$.

\section{APPLICATIONS}

This instrument is suitable for a wide range of small-unit-cell crystallography studies, from structure refinement and solution to charge and nuclear density mapping. Problems from chemistry, physics, materials science, and mineralogy have been addressed. Specific areas of study include hydrogen bonding and weak interactions, organometallics, supramolecular chemistry and crystal engineering, metal hydrides, charge density, pharmaceuticals, and magnetic structures. More general solid-state physics problems in magnetism, diffuse scattering, and ordering phenomena can also be addressed.

FIR MQRE INFGRMATION, CQNTACT

Instrument Scientist: Bryan Chakoumakos, chakoumakobc@ornl.gov, 865.574.5235 http://neutrons.ornl.gov/hfir_instrument_systems/HB-3A.shtml

\section{SPECIFICATILNS}

\begin{tabular}{|c|c|}
\hline $\begin{array}{r}\text { Beam } \\
\text { spectrum }\end{array}$ & Thermal \\
\hline $\begin{array}{r}\text { Monochro- } \\
\text { mators }\end{array}$ & $\begin{array}{l}\text { Vertically } \\
\text { focusing } \\
\text { silicon }\end{array}$ \\
\hline $\begin{array}{l}\text { Monochro- } \\
\text { mator angle }\end{array}$ & $48^{\circ}$ \\
\hline $\begin{array}{l}\text { Incident } \\
\text { wavelength }\end{array}$ & $\begin{array}{l}0.618 \AA(155), \\
1.01 \AA \text { (133), } \\
1.56 \AA \text { (022), } \\
2.55 \AA \text { (111) }\end{array}$ \\
\hline Goniometer & $\begin{array}{l}\text { Huber, full chi } \\
\text { circle, with } 10 \\
\text { K CCR }\end{array}$ \\
\hline $\begin{array}{r}\text { Scattering } \\
\text { angle }\end{array}$ & $\begin{array}{l}-110^{\circ}<2 \theta< \\
-110^{\circ}\end{array}$ \\
\hline Detector & $\begin{array}{l}7 \text { anode }{ }^{3} \mathrm{He} \\
\text { (honeycomb } \\
\text { pattern) }\end{array}$ \\
\hline $\begin{array}{l}\text { Crystal size } \\
\text { requirement }\end{array}$ & $>1 \mathrm{~mm}^{3}$ \\
\hline Unit-cell size & $<15,000 \AA^{3}$ \\
\hline $\begin{array}{l}\text { Flux at } \\
\text { sample }\end{array}$ & $\begin{array}{l}>5 \times 10^{6} \mathrm{n} \\
\mathrm{cm}^{-1} \mathrm{~s}^{-1} \text { (est.) }\end{array}$ \\
\hline
\end{tabular}

Status:

To be commissioned in 2008

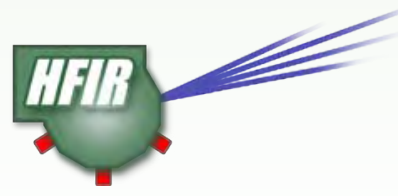

May 2008 


\section{INGTRUMENT}

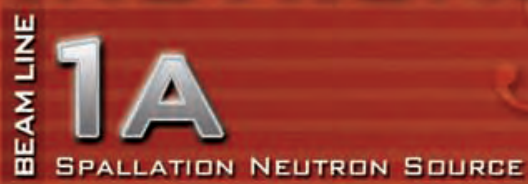

\section{TロF-USANS - TIME-IF-FLIGHT ULTRA-SMALL-ANELE NEUTRIN SCATTERING INSTRUMENT}

The TOF-USANS instrument is designed for the study of hierarchical structures in natural and man-made materials. It can be considered an advanced version of the classical BonseHart Double-Crystal Diffractometer (DCD), which, in contrast with its single-wavelength reactor-based analog, will operate with the discrete multiwavelength spectrum of Bragg reflections. The optical scheme of the TOF-USANS instrument is similar to that of the conventional Bonse-Hart DCD; however, the pulsed nature of SNS offers an opportunity to separate the orders of Bragg reflection in time space using the time-of-flight technique. Thus, the

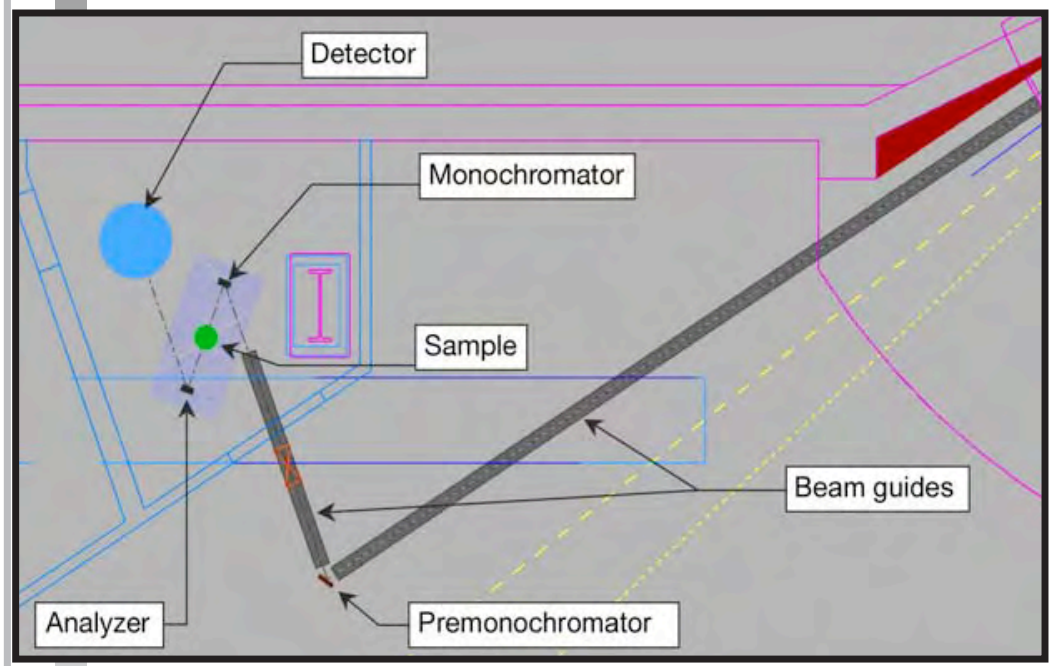
concept of the TOF-USANS technique allows optimization of the neutron flux and the $\mathrm{Q}$ resolution, following the principles of dynamical diffraction theory.

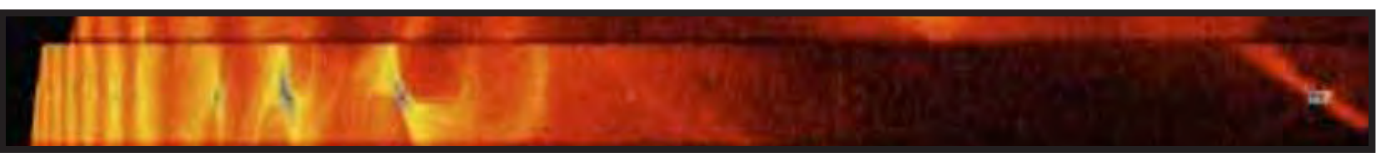

\section{SPECIFICATIONS}

\begin{tabular}{|r|l|}
\hline Moderator & $\begin{array}{l}\text { Decoupled } \\
\text { poisoned } \\
\text { hydrogen }\end{array}$ \\
\hline $\begin{array}{r}\text { Source } \\
\text { detector } \\
\text { distance }\end{array}$ & $25 \mathrm{~m}$ \\
\hline $\begin{array}{r}\text { Focusing } \\
\text { premono- } \\
\text { chromator }\end{array}$ & $\begin{array}{l}\text { Bent sapphire } \\
(1120) \text { crystal }\end{array}$ \\
\hline $\begin{array}{r}\text { Monochro- } \\
\text { mator and } \\
\text { analyzer }\end{array}$ & $\begin{array}{l}\text { Si }(220) \\
\text { channel-cut, } \\
\text { triple-bounce } \\
\text { crystals }\end{array}$ \\
\hline Bragg angle & $70^{\circ}$ \\
\hline Wavelength & $\begin{array}{l}7 \text { Bragg } \\
\text { reflections at } \\
\text { spectrum } \\
\end{array}$ \\
& $\begin{array}{l}0.6,1.8,1.2, \\
0.9 .72,0.6, \\
0.51 \AA\end{array}$ \\
\hline Q range & $\begin{array}{l}210^{-6} \AA^{-1}<\mathrm{Q} \\
<510^{-3} \AA\end{array}$ \\
\hline
\end{tabular}

Status:

To be commissioned in 2013

Discrete multiwavelength spectrum created by a family of Bragg reflections.

FIR MIRE INFIRMATION, CONTACT

Instrument Scientist: Michael Agamalian, magamalian@ornl.gov, 865.576.0903

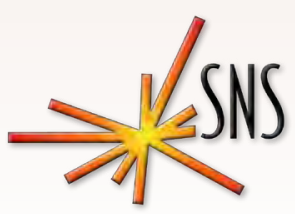

May 2008 


\section{INSTRUMENT}
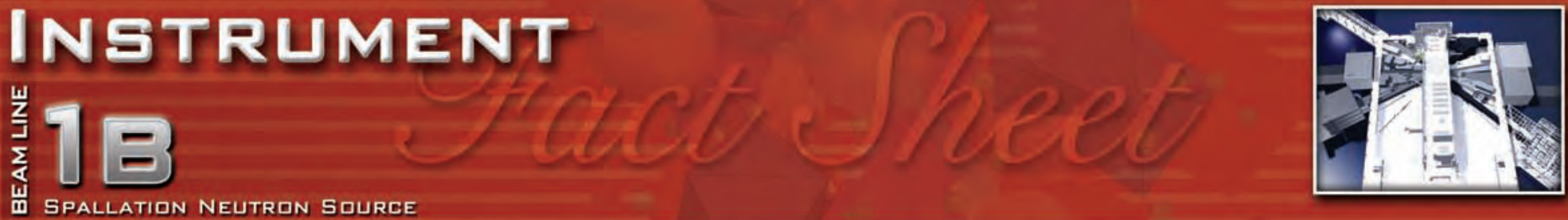

\section{NDMAD - NANDSCALE- DRDEREd MATERIALS DIFFRACTIMETER}

NOMAD is a high-flux, medium-resolution diffractometer that uses a large bandwidth of neutron energies and extensive detector coverage to carry out structural determinations of local order in crystalline and amorphous materials. The instrument enables studies of

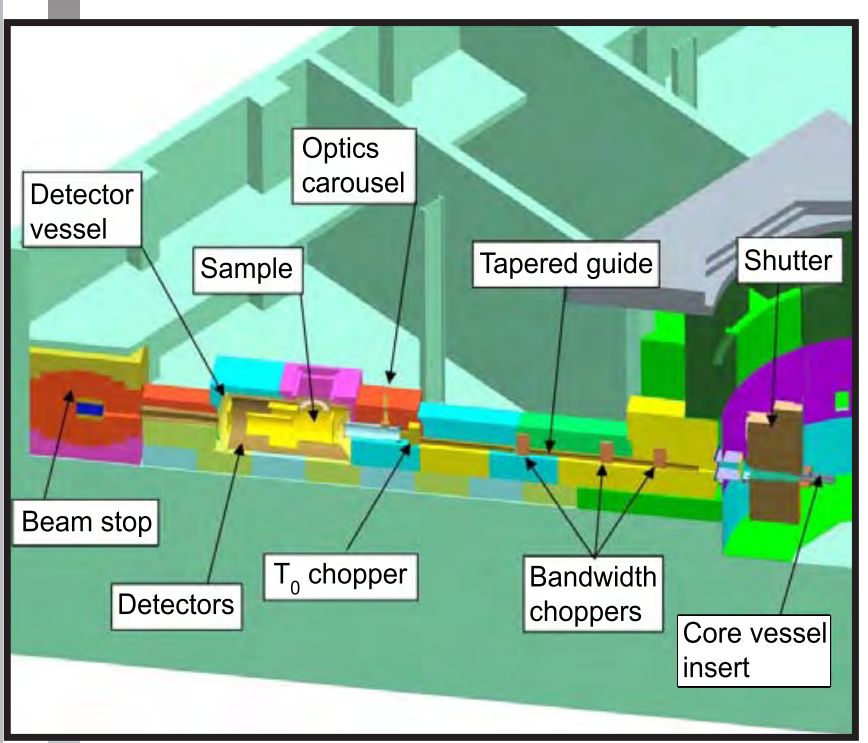

large variety of samples, ranging from liquids and solutions, glasses, and nanocrystalline materials to long-rangeordered crystals. The enhanced neutron flux at SNS, coupled with the advanced neutron optics and detector features, allows for unprecedented access to highresolution pair distribution functions, small-contrast isotope substitution experiments, small sample sizes, and parametric studies.

\section{APPLICATIONS}

- Environmental (e.g., solvent) effects on and direction of nanoscale structure formation

- In situ structural changes in nanoscale oxide catalysts used in automobile catalytic converters

- Structure of hydrogen storage materials under in situ conditions

- Transient structures of materials under extreme conditions (e.g., at high temperature or high pressure under the influence of transient fields or in metastable states)

\section{FIR MIRE INFIRMATION, CONTACT}

Instrument Scientist: Jörg Neuefeind, neuefeindjc@ornl.gov, 865.241.1635 http://neutrons.ornl.gov/instrument_systems/beamline_01b_nomad

\section{SPECIFICATIONS}

\begin{tabular}{|c|c|}
\hline Moderator & $\begin{array}{l}\text { Decoupled } \\
\text { poisoned } \\
\text { supercritical } \\
\text { hydrogen }\end{array}$ \\
\hline $\begin{array}{r}\text { Moderator- } \\
\text { to-sample } \\
\text { distance }\end{array}$ & $19.5 \mathrm{~m}$ \\
\hline $\begin{array}{r}\text { Sample- } \\
\text { to-detector } \\
\text { distance }\end{array}$ & $0.5-3 \mathrm{~m}$ \\
\hline $\begin{array}{r}\text { Wavelength } \\
\text { range }\end{array}$ & $0.1-3 \AA$ \\
\hline $\begin{array}{r}\text { Momentum } \\
\text { transfer } \\
\text { range }\end{array}$ & $0.04-100 \AA^{-1}$ \\
\hline $\begin{array}{r}\text { Detector } \\
\text { angular } \\
\text { range }\end{array}$ & $\begin{array}{l}1-175^{\circ} \\
\text { scattering } \\
\text { angle }\end{array}$ \\
\hline $\begin{array}{r}\text { Detector } \\
\text { coverage }\end{array}$ & $\sim 10.5 \mathrm{sr}$ \\
\hline $\begin{array}{l}\text { Flux on } \\
\text { sample }\end{array}$ & $\begin{array}{l}\sim 1 \times 10^{8} \\
\text { neutrons } \mathrm{cm}^{-2} \\
\mathrm{sec}^{-1}\end{array}$ \\
\hline
\end{tabular}

Status:

To be commissioned in 2010

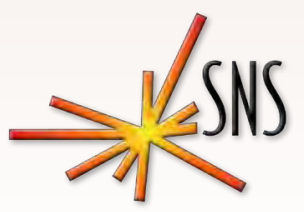

May 2008 


\section{INGTRUMENT}
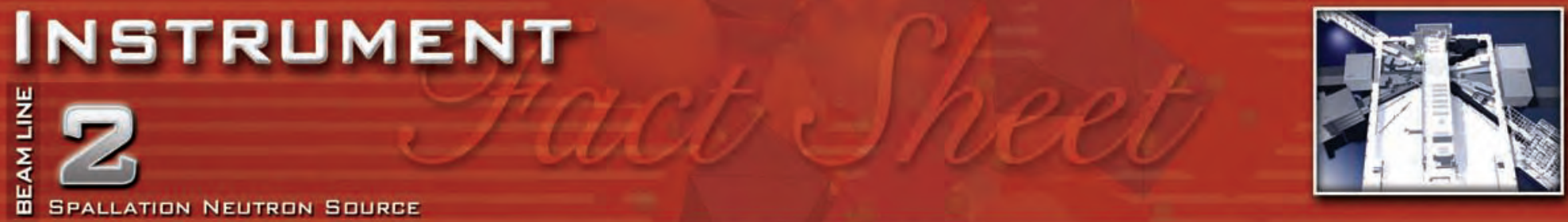

\section{BASIS - BACKSCATTERING SPECTRDMETER}

BASIS is designed to provide extremely high-energy resolution near the elastic peak, enabling studies of the diffusive dynamics of molecules on the atomic length scale (quasi-elastic neutron scattering). This instrument features very high flux and a dynamic range in energy transfer that

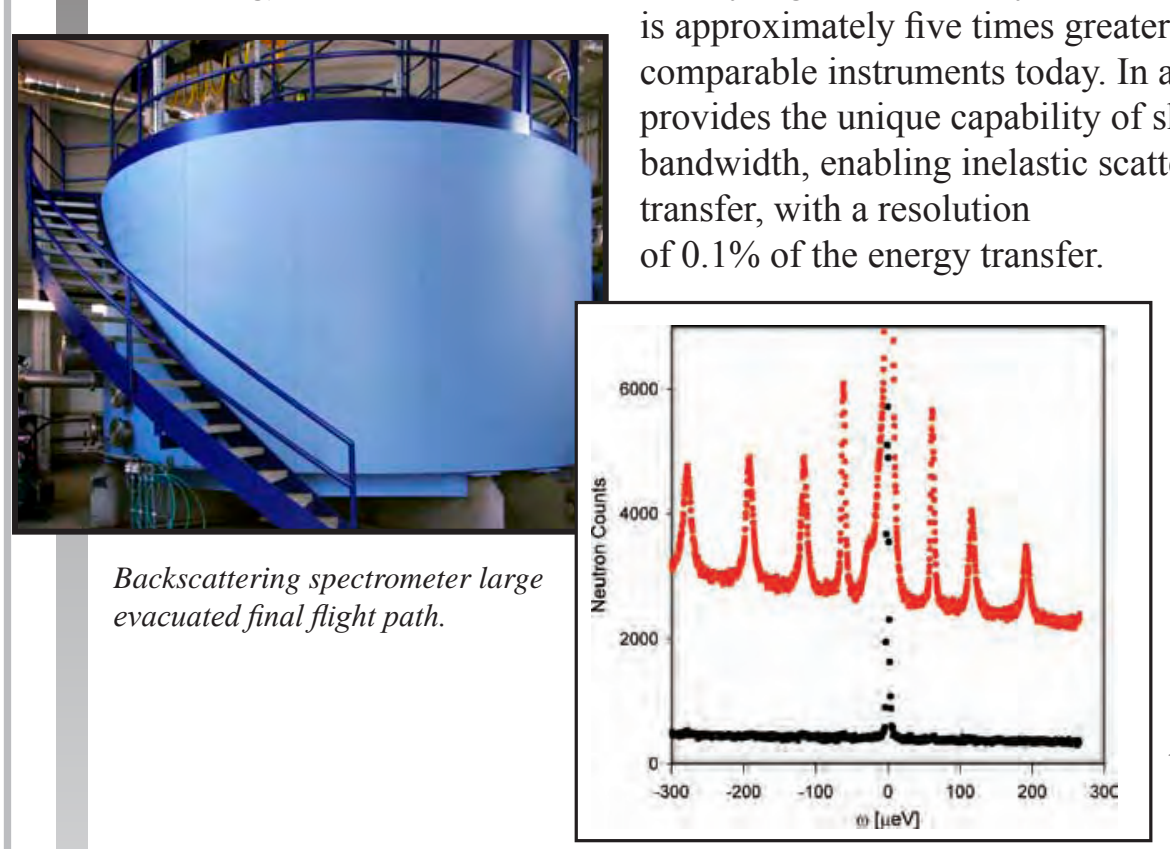

Measurement of the quantum tunneling peaks in 4-methyl pyridine $\mathrm{N}$-oxide ( $\mathrm{N}$-oxy gamma-picoline, $\left.\mathrm{C}_{6} \mathrm{H}_{7} \mathrm{NO}\right)$ at $4 \mathrm{~K}$.

\section{APPLICATIONS}

BASIS can be used to probe dynamic processes in various systems on the pico- to nanosecond time scale. It is well suited for probing diffusive and relaxational motions but can also be effectively used for studying some types of collective excitations in condensed matter. Applicable fields of study include, but are not limited to, biology, polymers, small molecules, complex fluids, magnetism, and materials science.

\section{SPECIFICATIONS}

\begin{tabular}{|c|c|}
\hline \multicolumn{2}{|c|}{ Si 111} \\
\hline $\begin{array}{l}\text { Elastic } \\
\text { energy }\end{array}$ & $2.08 \mathrm{meV}$ \\
\hline Bandwidth & $\pm 250 \mu \mathrm{eV}$ \\
\hline $\begin{array}{r}\text { Resolution } \\
\text { (elastic) }\end{array}$ & $3.5 \mu \mathrm{eV}$ \\
\hline $\begin{array}{l}\text { Q range } \\
\text { (elastic) }\end{array}$ & $\begin{array}{l}0.2 \AA^{-1}<Q< \\
2.0 \AA^{-1}\end{array}$ \\
\hline Solid angle & $\begin{array}{l}1.2 \mathrm{sr} \\
2.4 \mathrm{sr} \\
\text { (upgrade) }\end{array}$ \\
\hline \multicolumn{2}{|c|}{ Si 311 (upgrade) } \\
\hline $\begin{array}{l}\text { Elastic } \\
\text { energy }\end{array}$ & $7.64 \mathrm{meV}$ \\
\hline Bandwidth & $\pm 1700 \mu \mathrm{eV}$ \\
\hline $\begin{array}{r}\text { Resolution } \\
\text { (elastic) }\end{array}$ & $10 \mu \mathrm{eV}$ \\
\hline $\begin{array}{l}\text { Q range } \\
\text { (elastic) }\end{array}$ & $\begin{array}{l}0.38 \AA^{-1}<Q< \\
3.8 \AA^{-1}\end{array}$ \\
\hline Solid angle & $1.2 \mathrm{sr}$ \\
\hline
\end{tabular}

Status: Operational

FLR MORE INFIRMATION, CONTACT

Instrument Scientist: Eugene Mamontov, mamontove@ornl.gov, 865.574.5109

Instrument Scientist: Michaela Zamponi, zamponimm@ornl.gov, 865.576.5119

Scientific Associate: Stephanie Hammons, hammonsse@ornl.gov, 865.300.8100

http://neutrons.ornl.gov/instrument_systems/beamline_02_basis

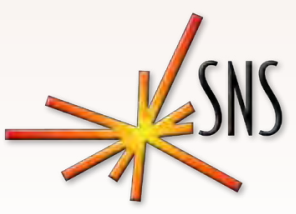

May 2008 


\section{INSTRUMENT}
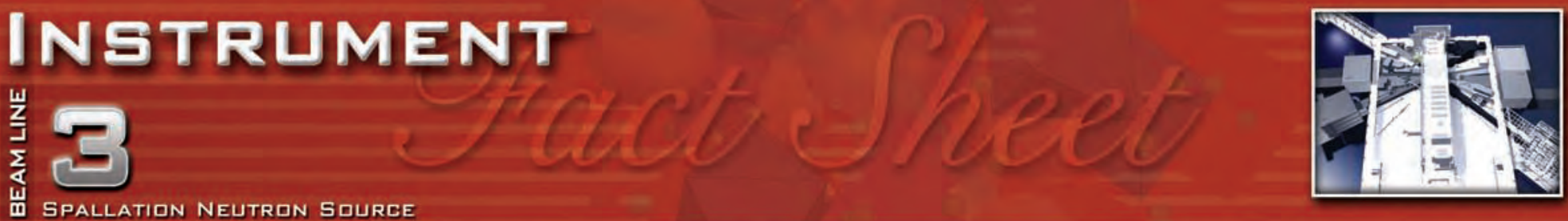

\section{SNAP - SPALLATION NEUTRINS AND PRESSURE DIFFRACTIMETER}

The SNAP Diffractometer allows studies of a variety of powdered and single-crystal samples under extreme conditions of pressure and temperature. The increased neutron flux, coupled with large-volume pressuring cells using large synthetic single-crystal opposed anvils, allows significant advances in the pressure range accessible to neutron diffraction. The pressure goal is 50 to $100 \mathrm{GPa}$ on an $\sim 1-\mathrm{mm}^{3}$ sample on a routine basis. In addition, recent advances in next-

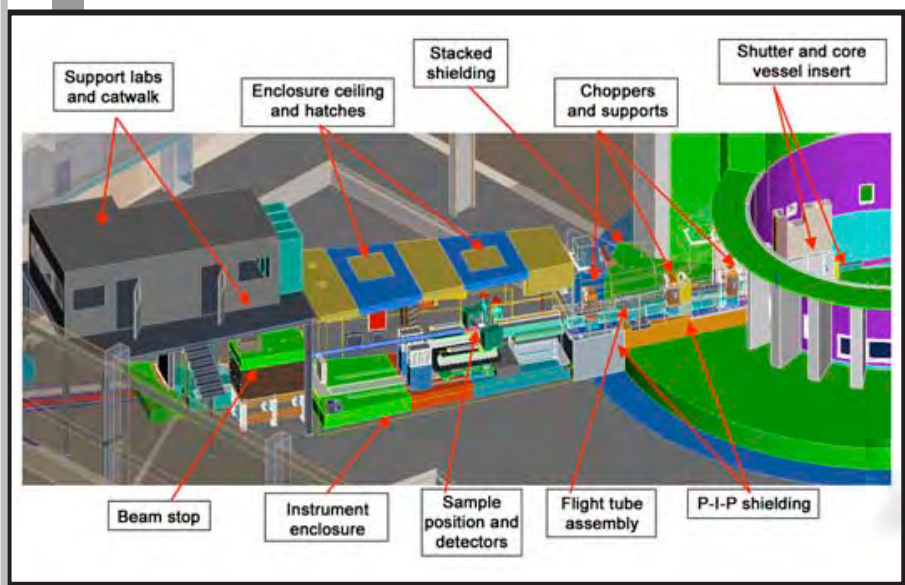
generation detectors will allow the incident beam-focusing optics, pressure chamber, and detector array to be highly integrated, providing a highly flexible facility for materials studies under extreme conditions.

\section{APPLICATIONS}

SNAP offers new opportunities for scientific studies involving the following:

- Hydrogen under extreme conditions

- Elastic anisotropy of $\varepsilon$-iron at Earth core conditions

- Real-time in situ monitoring of "real rocks" as an analogue to the down-going slab in the subduction context

- Planetary ices - structure and strength of ices under pressure

- Silicate melts - glasses at high pressure and temperature and the dynamical changes occurring during heating and pressurization

- Strength and rheology of materials and the relationship to brittle and ductile failure, including stress release as a function of time

- Structural changes accompanying transitions in Fullerenes and their derivatives

- Hydrogen bonding in organic and inorganic systems as a function of pressure and temperature, including liquids

\section{FIR MURE INFIRMATIGN, CLNTACT}

Instrument Scientist: Chris Tulk, tulkca@ornl.gov, 865.576.7028

Scientific Associate: Jamie Molaison, molaisonjj@ornl.gov, 865.206.0478

http://neutrons.ornl.gov/instrument_systems/snap.shtml

\section{SPECIFICATIONS}

\begin{tabular}{|r|l|}
\hline Moderator & $\begin{array}{l}\text { Decoupled } \\
\text { poisoned } \\
\text { supercritical } \\
\text { hydrogen }\end{array}$ \\
\hline $\begin{array}{r}\text { Source- } \\
\text { to-sample } \\
\text { distance }\end{array}$ & $15 \mathrm{~m}$ \\
\hline $\begin{array}{r}\text { Sample- } \\
\text { to-detector } \\
\text { distance }\end{array}$ & $50 \mathrm{~cm}$ \\
\hline $\begin{array}{r}\text { Angular } \\
\text { coverage }\end{array}$ & $\begin{array}{l}381-42^{\circ} \backslash \\
981-50^{\circ} \\
\text { horizontal } \\
\pm 340 \text { vertical }\end{array}$ \\
\hline $\begin{array}{r}\text { Wavelength range } \\
\text { (bandwidth) }\end{array}$ \\
\hline Frame 1 & $0.5-3.65 \AA$ \\
\hline Frame 2 & $3.7-6.5 \AA$ \\
\hline Pressure & $\begin{array}{l}\text { From } \\
\text { ambient } \\
\text { range } \\
\text { pressure to } \\
>50 \mathrm{GPa} \\
(500 \mathrm{kbar})\end{array}$ \\
\hline $\begin{array}{r}\text { Focused } \\
\text { beam size }\end{array}$ & $\begin{array}{l}\text { From } 1 \mathrm{~cm} \text { to } \\
<100 \mu \mathrm{m}\end{array}$ \\
\hline
\end{tabular}

Status: Operational

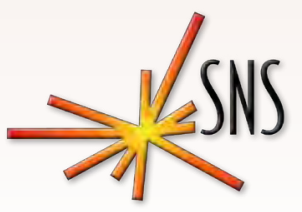

May 2008 


\section{INSTRUMENT}
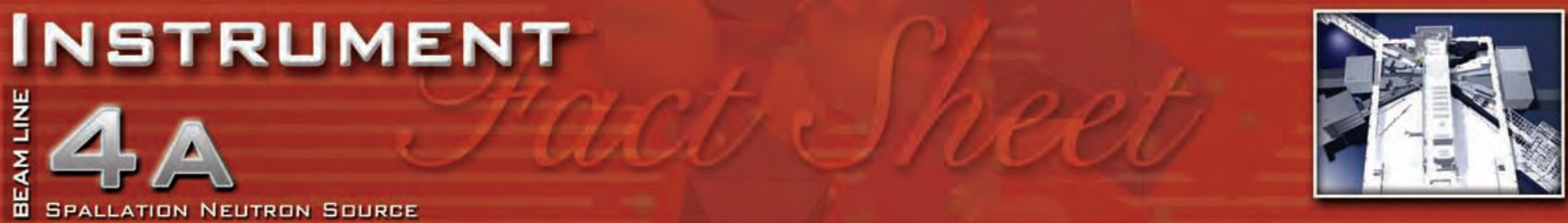

\section{MAGNETISM REFLECTIMETER}

The Magnetism Reflectometer is designed for reflectometry and high-angle diffraction studies of magnetic thin films, superlattices, and surfaces. The combination of the high-power SNS and the use of advanced neutron optics allows for off-specular diffraction studies of in-plane structures. Today, even at the world's most advanced neutron sources, such experiments are extremely difficult to perform. The availability of polarized neutrons and polarization analysis suggests that

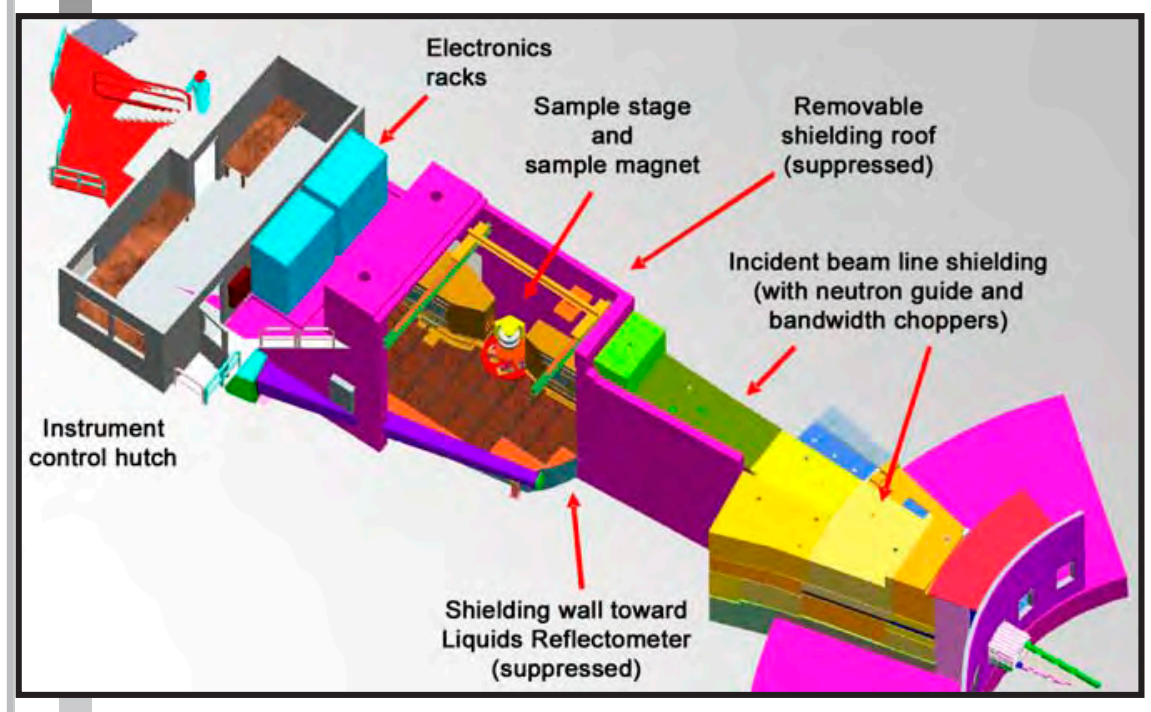

\section{APPLICATIONS}

The Magnetism Reflectometer is applicable primarily to studies with thin magnetic films, an increasingly important area of solid-state physics. Experiments could also benefit engineering, metallurgy, or biological problems. Instrument capabilities allow, for example, studies of magnetic recording media and magnetic sensors, as well as depth-dependent studies of structural/ magnetic nanoparticles or domains. The instrument's unique capabilities provide for multilengthscale experiments, and it has sufficient beam intensity for detailed structural/magnetic phasediagram determinations. In situ studies on ultrathin films in an ultrahigh-vacuum environment are planned as a future upgrade capability. this instrument can also be used for specific studies of nonmagnetic thin-film samples. Examples of the latter include contrast variation, incoherent background reduction, and phase determination for direct inversion of reflectivity data into real-space scattering-length density profiles.

\section{FIR MURE INFIRMATILN, CONTACT}

Instrument Scientist: Valeria Lauter, lauterv@ornl.gov, 865.576.5389

Scientific Associate: Richard J. Goyette Jr., goyetterj@ornl.gov, 865.241.9991

http://neutrons.ornl.gov/instrument_systems/beamline_04a_mr

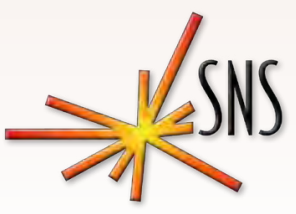

May 2008 


\section{INSTRUMENT}

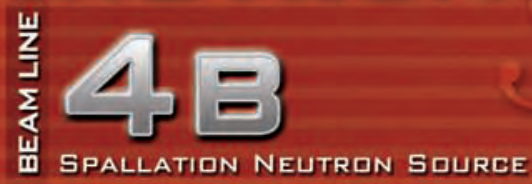

\section{LIQUIDS REFLECTIMETER}

The Liquids Reflectometer features a horizontal sample geometry and thus can accommodate air/liquid surfaces in addition to air/solid and liquid/solid interfaces. Active vibration isolation minimizes capillary-wave production by the external environment. Data rates and Q range

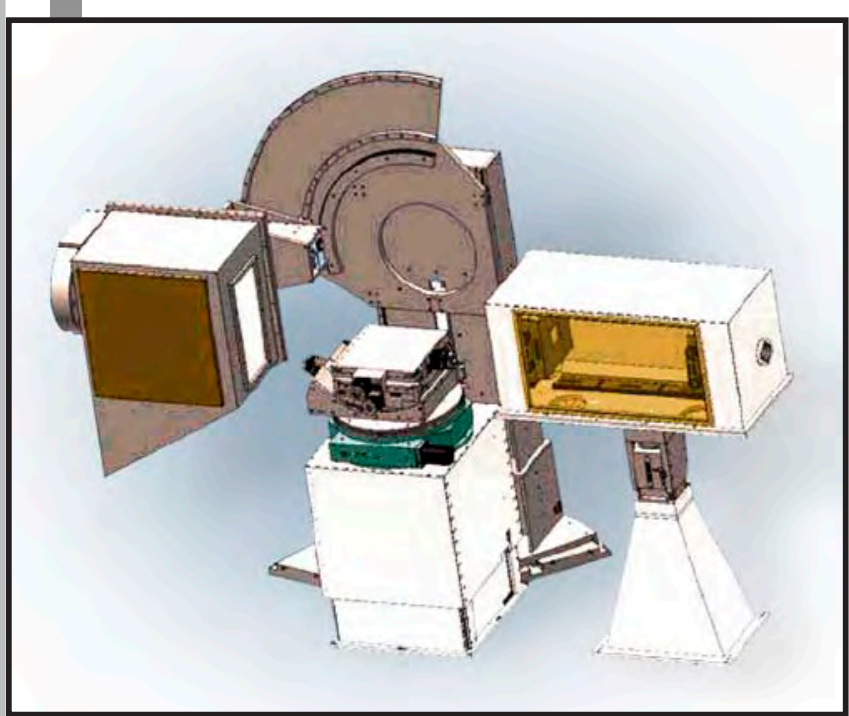

covered at a single scattering angle setting will be sufficiently high to permit "realtime" kinetic studies on many systems. Time-resolved experiments include investigations of chemical kinetics, solidstate reactions, phase transitions, and chemical reactions in general.

Liquids Reflectometer goniostat

\section{APPLICATIONS}

The Liquids Reflectometer is useful for a wide range of science. Current areas of interest include biomaterials, polymers, and chemistry involving thin layers of surfactants or other materials on the surfaces of liquids, such as cell-membrane analogs. These systems provide a flexible platform to study structure-property relationships at the boundary between hard and soft matter, with applications in biomimetics, bio-sensing, and bio-compatible films; hydrogen storage and fuel cells; and polymers.

FIR MLRE INFIRMATILN, CLNTACT

Instrument Scientist: John Ankner, anknerjf@ornl.gov, 865.576.5122

Instrument Scientist: Jim Browning, browningjf@ornl.gov, 865.241.3905

Scientific Associate: Candice Halbert, halbertce@ornl.gov, 865.574.9255

http://neutrons.ornl.gov/instrument_systems/beamline_04b_lr

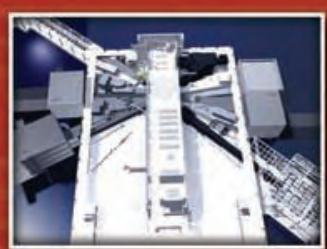

SPECIFICATIONS

\begin{tabular}{|c|c|}
\hline $\begin{array}{l}\text { Source- } \\
\text { to-sample } \\
\text { distance }\end{array}$ & $13.6 \mathrm{~m}$ \\
\hline $\begin{array}{r}\text { Sample- } \\
\text { to-detector } \\
\text { distance }\end{array}$ & $1.5 \mathrm{~m}$ \\
\hline $\begin{array}{r}\text { Detector } \\
\text { size }\end{array}$ & $20 \times 20 \mathrm{~cm}^{2}$ \\
\hline $\begin{array}{l}\text { Detector } \\
\text { resolution }\end{array}$ & $1.3 \times 1.3 \mathrm{~mm}^{2}$ \\
\hline Moderator & $\begin{array}{l}\text { Coupled } \\
\text { supercritical } \\
\text { hydrogen }\end{array}$ \\
\hline Bandwidth & $\Delta \lambda=3.5 \AA$ \\
\hline $\begin{array}{r}\text { Wavelength } \\
\text { range }\end{array}$ & $\begin{array}{l}2.5 \AA<\lambda< \\
17.5 \AA\end{array}$ \\
\hline $\begin{array}{r}\text { Q range (air/ } \\
\text { liquid) }\end{array}$ & $\begin{array}{l}0 \AA^{-1}<Q< \\
0.5 \AA^{-1}\end{array}$ \\
\hline $\begin{array}{r}\text { Q range (air/ } \\
\text { solid) }\end{array}$ & $\begin{array}{l}0 \AA^{-1}<Q< \\
1.5 \AA^{-1}\end{array}$ \\
\hline $\begin{array}{l}\text { Minimum } \\
\text { reflectivity }\end{array}$ & $1 \times 10^{-7}$ \\
\hline
\end{tabular}

Status: Operational

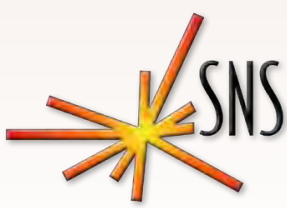

May 2008 


\section{INGTRUMENT}
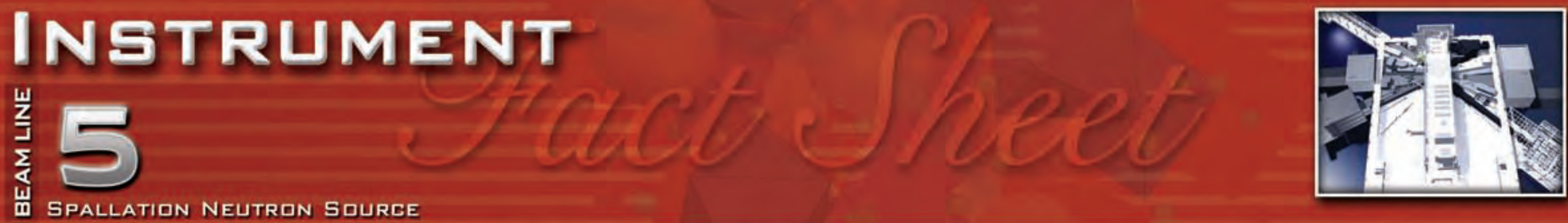

\section{CNES - CDLD NEUTRON CHOPPER SPECTRDMETER}

CNCS is a high-resolution, direct-geometry, multichopper inelastic spectrometer designed to provide flexibility in choice of energy resolution and to perform best at low-incident energies $(2-50 \mathrm{meV})$. Although the initial detector coverage around the sample is $1 \mathrm{sr}$, a later upgrade

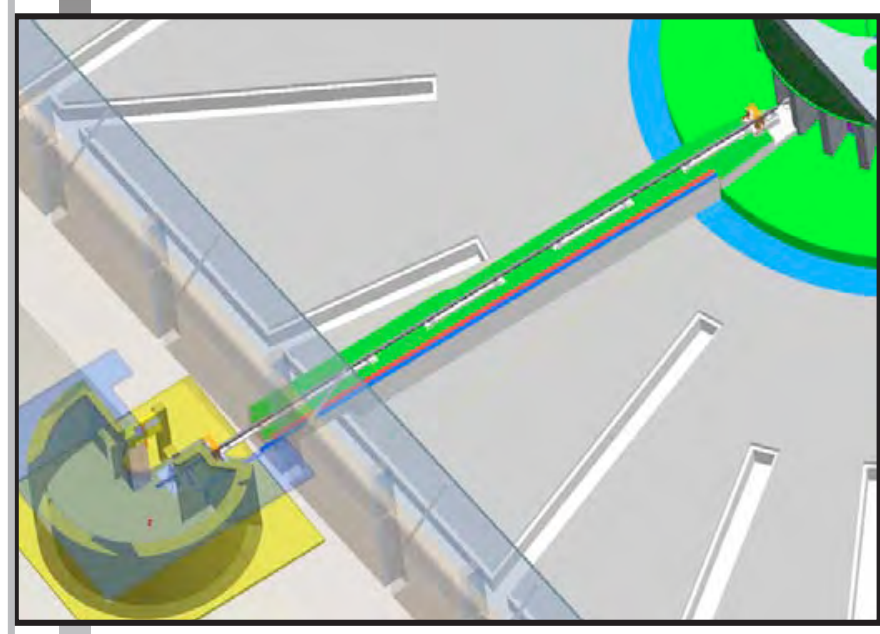

Engineering design of the CNCS beam line from the target monolith to the instrument satellite building.

\section{APPLICATIONS}

CNCS is applicable primarily to studies in the following:

- Complex fluids: dilute protein solutions, biological gels, selective absorption of molecules on surfaces

- Dynamics in confined geometries

- Magnetism: low-dimensional systems; non-Fermi liquids; frustrated, disordered, or molecular magnets

\section{FIR MLRE INFIRMATION, CINTACT}

Instrument Scientist: Georg Ehlers, ehlersg@ornl.gov, 865.576.3511

Scientific Associate: Jennifer Niedziela, niedzielaj1@ornl.gov, 413.478.1621

http://neutrons.ornl.gov/instrument_systems/beamline_05_cncs

\section{SPECIFICATIONS}

\begin{tabular}{|r|l|}
\hline $\begin{array}{r}\text { Source- } \\
\text { to-sample } \\
\text { distance }\end{array}$ & $36.2 \mathrm{~m}$ \\
\hline $\begin{array}{r}\text { Sample- } \\
\text { to-detector } \\
\text { distance }\end{array}$ & $3.5 \mathrm{~m}$ \\
\hline $\begin{array}{r}\text { Angular } \\
\text { coverage }\end{array}$ & $\begin{array}{l}-90 \ldots+140^{\circ} \\
\text { horizontally } \\
\pm 25^{\circ} \text { vertically }\end{array}$ \\
\hline $\begin{array}{r}\text { Energy } \\
\text { resolution }\end{array}$ & $10-500 \mu \mathrm{eV}$ \\
\hline $\begin{array}{r}\text { Incident } \\
\text { energy } \\
\text { range }\end{array}$ & $2-50 \mathrm{meV}$ \\
\hline $\begin{array}{r}\text { Momentum } \\
\text { transfer } \\
\text { range }\end{array}$ & $0.05-10 \AA^{-1}$ \\
\hline
\end{tabular}

Status:

To be commissioned in 2008
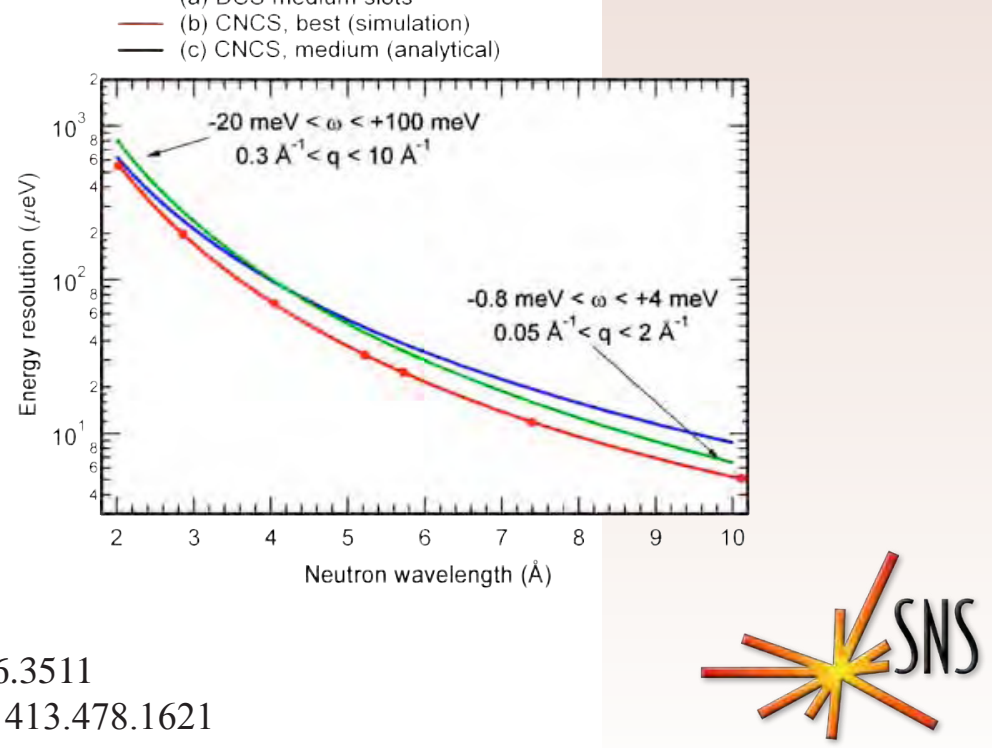

May 2008 


\section{INSTRUMENT}
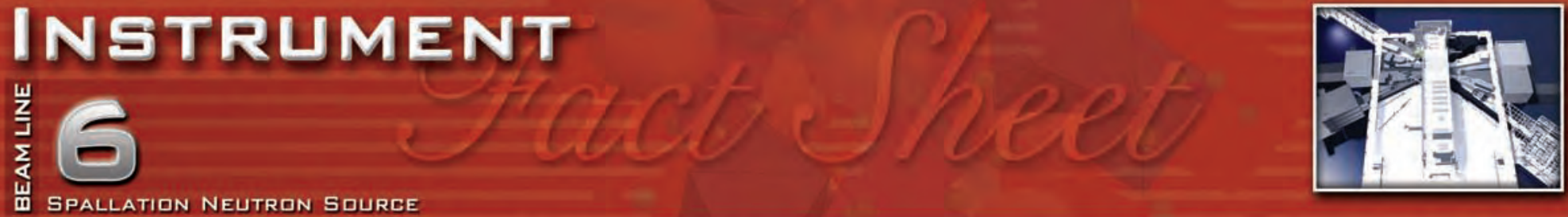

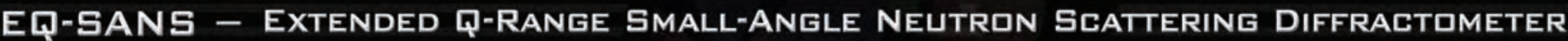

The EQ-SANS Diffractometer is designed to study noncrystalline, nanosized materials in solid, liquid, or gas forms such as polymers, proteins in solution, and micelles. EQ-SANS has very high

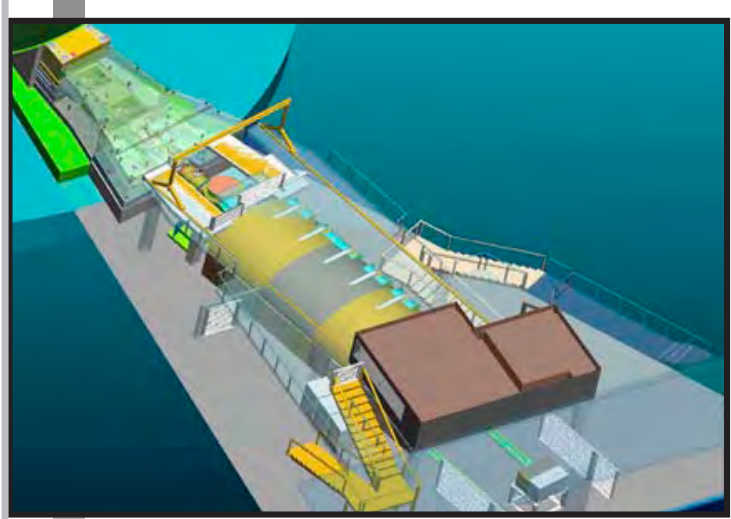
intensity and wavelength resolution. It also has a wide Q coverage, allowing simultaneous data collection in both low-and high-Q regions. Scattering from nanomaterials is concentrated mostly in a forward direction, or small angles. These scattering data yield information about the size and shape of the nanoparticles. Applications include the study of polymers, better detergents and soaps from improved micelles, proteins for better drug design, and materials of interest to the oil industry.

\section{APPLICATIONS}

The unique capabilities of the EQ-SANS offer new opportunities for scientific studies in the following: Life science

- Solution structures of proteins, DNA, and other biological molecules and molecular complexes

- Protein-protein and protein-ligand interactions, kinase regulation

- Protein-membrane interaction

Polymer and colloidal systems

- Block copolymers and dendrimers

- Micelles, aerosols, and emulsions

- Polyelectrolytes and electric double-layer and ion distribution at solid-liquid interfaces

Materials science

- Simultaneous study of domain and crystalline structures

- Crystallization and precipitation

- Nanoparticles

Earth and environmental sciences

- Pore structure in soil

- Absorption of contaminants by soil

- Fractal structure of rocks

\section{FIR MIRE INFIRMATION, CINTACT}

Instrument Scientist: J. K. Zhao, zhaoj@ornl.gov, 865.574.0411

http://neutrons.ornl.gov/instrument_systems/beamline_06_eqsans

\section{SPECIFICATIONS}

\begin{tabular}{|r|l|}
\hline $\begin{array}{r}\text { Source- } \\
\text { to-sample } \\
\text { distance }\end{array}$ & $14 \mathrm{~m}$ \\
\hline Bandwidth & $3-4.3 \AA$ \\
\hline Moderator & $\begin{array}{l}\text { Coupled } \\
\text { supercritical } \\
\text { hydrogen }\end{array}$ \\
\hline $\begin{array}{r}\text { Integrated } \\
\text { flux on } \\
\text { sample }\end{array}$ & $\begin{array}{l}\sim 10^{7}-10^{9} \mathrm{n} / \\
\mathrm{cm}^{2} / \mathrm{s}\end{array}$ \\
\hline $\mathrm{Q}$ range & $\begin{array}{l}0.004 \AA^{-1}<\mathrm{Q} \\
<10 \AA^{-1}\end{array}$ \\
\hline
\end{tabular}

\begin{tabular}{|r|l|}
\hline \multicolumn{2}{|c|}{ Low-Angle Detector } \\
\hline $\begin{array}{r}\text { Sample- } \\
\text { to-detector } \\
\text { distance }\end{array}$ & $1-8 \mathrm{~m}$ \\
\hline $\begin{array}{r}\text { Detector } \\
\text { size }\end{array}$ & $1 \times 1 \mathrm{~m}$ \\
\hline $\begin{array}{r}\text { Detector } \\
\text { resolution }\end{array}$ & $8 \mathrm{~mm}$ \\
\hline
\end{tabular}

\begin{tabular}{|r|l|}
\hline \multicolumn{2}{|c|}{ High-Angle Detector } \\
\hline $\begin{array}{r}\text { Sample- } \\
\text { to-detector } \\
\text { distance }\end{array}$ & $1 \mathrm{~m}$ \\
\hline $\begin{array}{r}\text { Angular } \\
\text { roverage }\end{array}$ & $\sim 35-150^{\circ}$ \\
\hline $\begin{array}{r}\text { Detector } \\
\text { resolution }\end{array}$ & $8 \mathrm{~mm}$ \\
\hline
\end{tabular}

Status:

To be commissioned in 2008

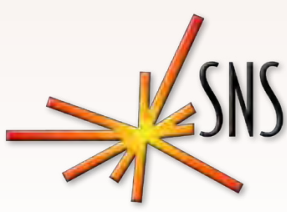

May 2008 


\section{INGTRUMENT}

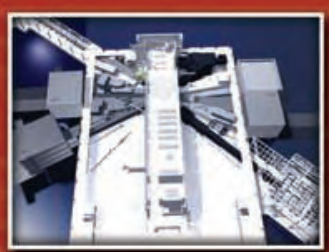

\section{VULCAN - ENGINEERING MATERIALS DIFFRACTIMETER}

VULCAN helps users understand a broad range of engineering and materials science problems. Characteristics of the instrument include stress mapping of engineering components with a $1-\mathrm{mm}^{3}$ sampling volume, in situ loading with 10 to 20 reflections, and real-time studies of the kinetics of materials on subsecond time scales. The basic design allows users to determine

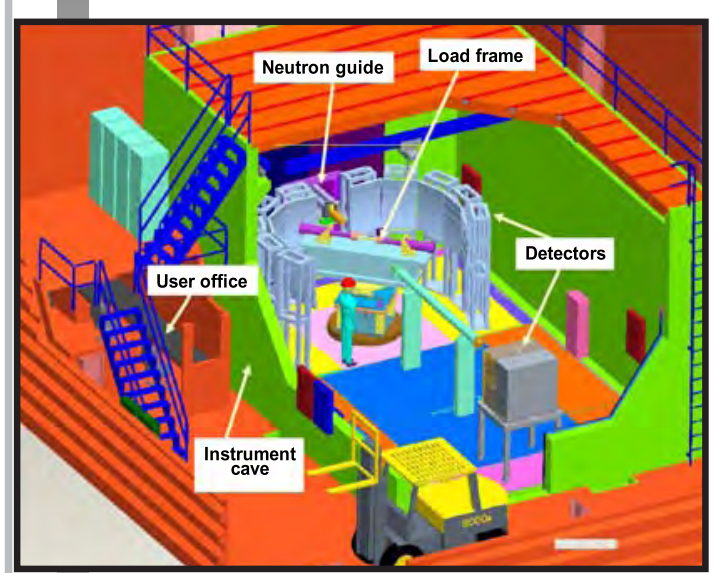

stress distribution in engineering components and to understand more about the deformation of materials under multiaxial loading. VULCAN can help scientists and engineers test the reliability of structural components and better understand how materials deform. The flux on sample will reach $1 \times 10^{8}$ neutrons $/ \mathrm{cm}^{2} / \mathrm{s}$, providing a high intensity for fast kinetic studies. The instrument team plans to have a small-angle detector to allow users to conduct simultaneous measurements of small-angle scattering, thereby enabling studies of the evolution of material structures at multiple-length scales.

\section{APPLICATIDNS}

VULCAN is designed to tackle a variety of problems in materials science and engineering, ranging from determining residual stress in engineering components to understanding the fundamental aspects of materials behaviors during processing and use. Although it is difficult to predict the kinds of new science that will be enabled by instruments like VULCAN, some research areas that VULCAN could benefit include the following:

- In situ studies of materials behavior during processing: temperature distribution, texture changes, stress development, precipitation

- In situ loading studies at high or cryogenic temperatures: fatigue damage, deformation in nanostructured materials, creep behaviors, piezoelectric and shape-memory alloys

- Residual stress and microstructure changes in surface-engineered materials

- Deformation in amorphous materials

- Phase transformation kinetics

FOR MORE INFORMATION, CONTACT

Instrument Scientist: Xun-Li Wang, wangxl@ornl.gov, 865.574.9164

Scientific Associate: Harley Skorpenske, skorpenskehd@ornl.gov, 865.228.8460

http://neutrons.ornl.gov/instrument_systems/beamline_07_vulcan

\section{SPECIFICATIDNS}

\begin{tabular}{|c|c|}
\hline Moderator & $\begin{array}{l}\text { Decoupled } \\
\text { poisoned } \\
\text { water }\end{array}$ \\
\hline $\begin{array}{r}\text { Source- } \\
\text { to-sample } \\
\text { distance }\end{array}$ & $43.5 \mathrm{~m}$ \\
\hline $\begin{array}{r}\text { Sample- } \\
\text { to-detector } \\
\text { distance }\end{array}$ & $1.5-2 \mathrm{~m}$ \\
\hline $\begin{array}{r}\text { Detector } \\
\text { angular } \\
\text { coverage }\end{array}$ & $\begin{array}{l}60^{\circ}<2 \theta< \\
150^{\circ}\end{array}$ \\
\hline $\begin{array}{l}\text { Wavelength } \\
\text { bandwidth }\end{array}$ & $\sim 1.3 \AA$ \\
\hline Resolution & $\begin{array}{l}0.2 \% \text { in high- } \\
\text { resolution } \\
\text { mode }\end{array}$ \\
\hline $\begin{array}{r}\text { Flux on } \\
\text { sample } \\
\left(\mathrm{n} / \mathrm{s} / \mathrm{cm}^{2}\right)\end{array}$ & 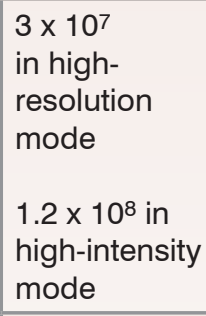 \\
\hline $\begin{array}{l}\text { Gauge } \\
\text { volume }\end{array}$ & $\begin{array}{l}\text { 3D strain } \\
\text { mapping: } \\
1 \mathrm{~mm}^{3} \\
\\
\text { 1D strain } \\
\text { mapping: } \\
0.1 \mathrm{~mm} \\
\end{array}$ \\
\hline SANS Q range & $0.01-0.2\left(\AA^{-1}\right)$ \\
\hline $\begin{array}{l}\text { Status: } \\
\text { To be commissi }\end{array}$ & ioned in 2008 \\
\hline
\end{tabular}




\section{INGTRUMENT}
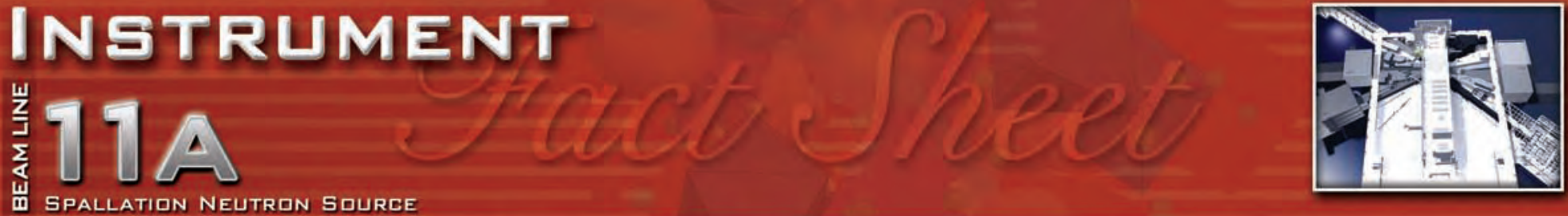

\section{PUWGEN - PQWDER DIFFRACTIMETER}

POWGEN is designed to study polycrystalline materials. This versatile diffractometer enables users to collect typical Rietveld statistics in $\sim 20$ minutes from a $0.6-\mathrm{cm}^{3}$ sample with $<0.1 \%$ resolution at short d-spacings and $<1 \%$ resolution for nearly all d-spacings of interest.

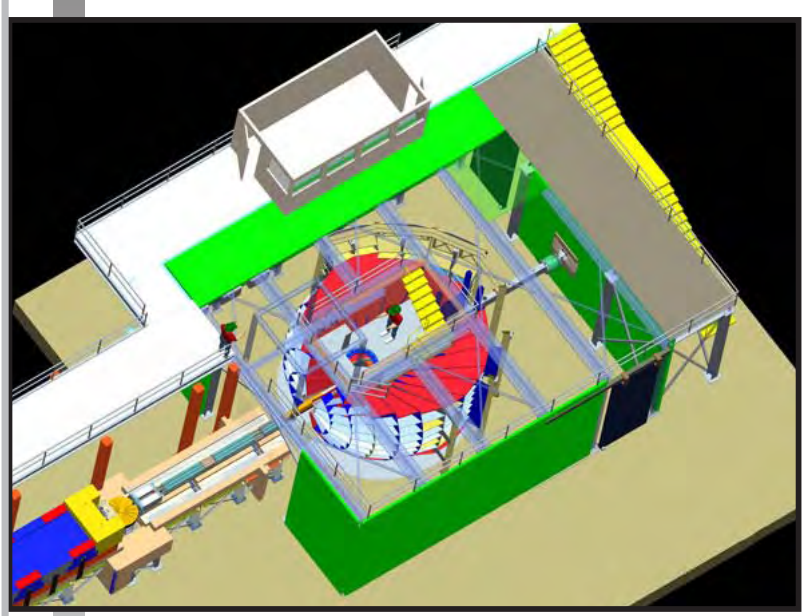
Adjustment of the phase of the bandwidth choppers in this instrument also allows collection of diffraction data for d-spacings as large as $66 \AA$. Because of the third-generation conceptual design of POWGEN, users can choose the wavelengths for data collection and have complete freedom in selecting the subset of data to be included in analysis. These alternatives allow greater flexibility than most existing neutron diffractometers. In addition, this standard tool provides faster and higher precision than other diffractometers in the United States.

Secondary flight path for the Powder Diffractometer. The sample is $60 \mathrm{~m}$ from the moderator, necessitating a satellite building outside the Target Building for the secondary flight path.

\section{APPLICATIONS}

Scientific studies at this instrument encompass a wide range of novel materials. These include, but are not limited to, structural studies of magnetic materials such as high-Tc superconductors, metal-insulator phase transitions, charge and orbital ordering transitions, and molecular magnets Additional possibilities include nonmagnetic materials such as Zeolite and aluminophosphate frameworks; metals and semiconductors; dielectrics, ferroelectrics, and thermoelectrics; and ab initio structure solutions of polycrystalline materials such as pharmaceutical compounds. In addition, POWGEN is capable of acquiring refineable data sets in rapid data collection mode, making it an ideal instrument for parametric studies and time-resolved in situ studies of the electrochemistry of catalysts, ceramic membranes, hydrogen storage materials, and charging and discharging of battery materials.

\section{FIR MARE INFIRMATION, CONTACT}

Instrument Scientist: Jason Hodges, hodgesj@ornl.gov, 865.576.7034

Instrument Scientist: Ashfia Huq, huqa@ornl.gov, 865.574.7923

Scientific Associate: Luke Heroux, herouxla@ornl.gov, 865.241.8673

$\mathrm{http}$ //neutrons.ornl.gov/instrument_systems/beamline_11a_powgen

\section{SPECIFICATIONS}

\begin{tabular}{|r|l|}
\hline Moderator & $\begin{array}{l}\text { Decoupled } \\
\text { poisoned } \\
\text { supercritical } \\
\text { hydrogen }\end{array}$ \\
\hline $\begin{array}{r}\text { Source- } \\
\text { to-sample } \\
\text { distance }\end{array}$ & $60 \mathrm{~m}$ \\
\hline $\begin{array}{r}\text { Sample- } \\
\text { to-detector } \\
\text { distance }\end{array}$ & $1-6 \mathrm{~m}$ \\
\hline $\begin{array}{r}\text { Detector } \\
\text { angular }\end{array}$ & $6<2 \theta<170^{\circ}$ \\
coverage & \\
\hline $\begin{array}{r}\text { Wavelength } \\
\text { bandwidth }\end{array}$ & $\sim 1 \AA$ \\
\hline $\begin{array}{r}\text { Frame } 1 \\
0.3 \AA<\mathrm{d}< \\
10 \AA\end{array}$ \\
\hline Frame 6 & $3 \AA<\mathrm{d}<66 \AA$ \\
\hline $\begin{array}{r}\text { Resolution } \\
0.001<\Delta \mathrm{d} / \mathrm{d} \\
<0.016\end{array}$ \\
\hline $\begin{array}{r}\text { Resolution } \\
\text { at } 90^{\circ}\end{array}$ & $\Delta \mathrm{d} / \mathrm{d}=0.0015$ \\
\hline
\end{tabular}

Status:

To be commissioned in 2008

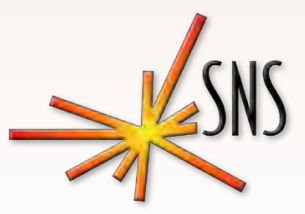

May 2008 


\section{INGTRUMENT}
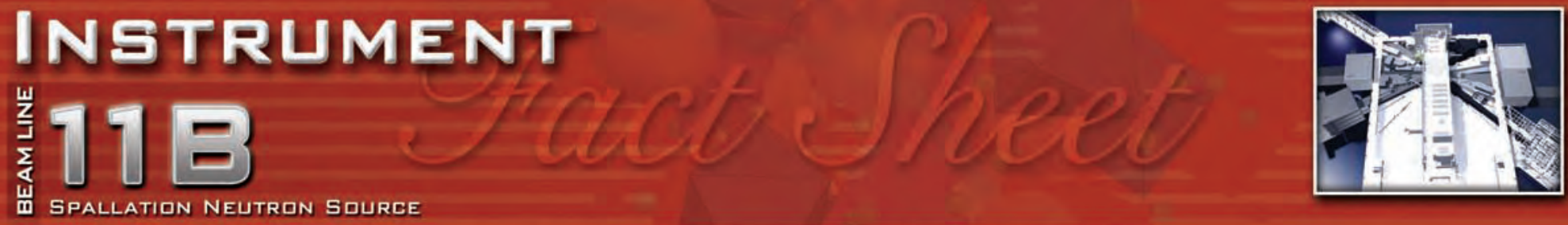

\section{MANDI - MACRIMULECULAR NEUTRIN DiffRACTIMETER}

MaNDi allows the study of single crystals and is optimized for rapid data collection from large macromolecular structures. MaNDi will achieve 1.5- $\AA$ resolution from crystal volumes between 0.1 and $1.0 \mathrm{~mm}^{3}$, with lattice repeats on the order of $150 \AA$. With larger crystals $\left(>1 \mathrm{~mm}^{3}\right)$, it will be possible to obtain useful data in the resolution range of 2.0 to $2.5 \AA$ for unit-cell repeats of up

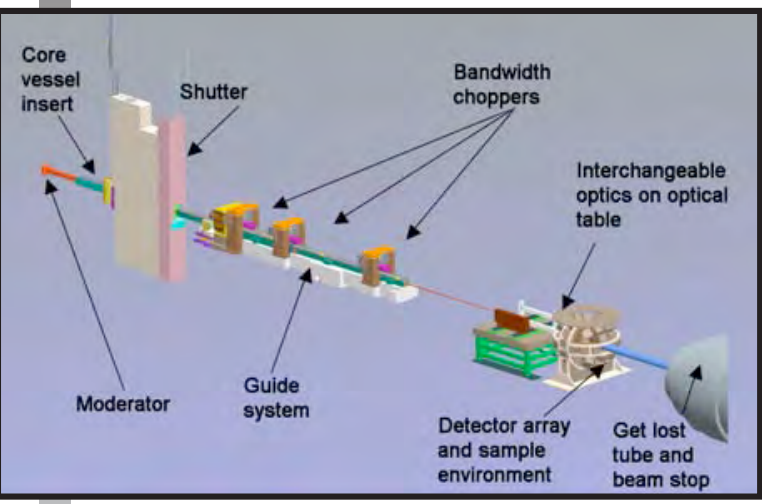

The detector design follows a modular approach. A spherical detector mount will be constructed to accommodate the appropriate number of individual modules of two-dimensional, time-sensitive detectors with front face dimensions of $150 \times 150 \mathrm{~mm}$, leaving openings for the sample orienter/ environment (top) and the incident and exiting direct neutron beam (horizontal plane). The spatial resolution of the detector is $1 \mathrm{~mm}$, with a minimal sensitivity to gamma rays, hence preserving the signal-to-noise ratio of the Bragg peaks. The efficiency of this type of detector using a 1.5-mm-thick scintillator is $78 \%$ for neutrons with a wavelength of $1 \AA$. An increase in neutron wavelength is coupled with an increase in detection efficiency.

Precision mounting will place the $0.1-\mathrm{mm}^{3}$ crystals within the neutron beam, and the samplepositioning system will allow translation and rotation in $\mathrm{x}, \mathrm{y}$, and $\mathrm{z}$ to precisely align the sample. These operations will be remotely controlled and motor driven by a user-friendly graphical user interface.

\section{APPLICATIONS}

MaNDi offers radical new opportunities for scientific studies involving the following:

- Protein studies to provide better drug molecules for the treatment of cancer and HIV

- Studies of enzyme mechanisms to accelerate important industrial reactions

- Mechanisms used by plants to convert light into energy

FIR MLRE INFORMATILN, CONTACT

Instrument Scientist: Leighton Coates, coatesl@ornl.gov, 865.241.3427

http://neutrons.ornl.gov/instrument_systems/beamline_11b_mandi

\section{SPECIFICATIONS}

\begin{tabular}{|r|l|}
\hline Moderator & $\begin{array}{l}\text { Decoupled } \\
\text { hydrogen }\end{array}$ \\
\hline $\begin{array}{r}\text { Source- } \\
\text { to-sample } \\
\text { distance }\end{array}$ & $24 \mathrm{~m}$ \\
\hline $\begin{array}{r}\text { Sample- } \\
\text { to-detector } \\
\text { distance }\end{array}$ & $0.5 \mathrm{~m}$ \\
\hline $\begin{array}{r}\text { Initial angular } \\
\text { detector }\end{array}$ & $4 \mathrm{sr}$ \\
coverage & \\
\hline $\begin{array}{r}\text { Optional } \\
\text { angular } \\
\text { detector }\end{array}$ & $9 \mathrm{sr}$ \\
coverage & \\
\hline $\begin{array}{r}\text { Detector } \\
\text { pixel size }\end{array}$ & $6.2 \times 10^{-6} \mathrm{sr}$ \\
\hline $\begin{aligned} \text { Detector } \\
\text { angles }\end{aligned}$ & $0-180^{\circ}$ \\
\hline $\begin{array}{r}\text { Wavelength } \\
\text { bandwidth }\end{array}$ & $2.69 \AA$ \\
\hline Frame 1 & $1.5-4.2 \AA$ \\
\hline Resolution & $1.5 \%$ \\
\hline Sample size & $0.1 \mathrm{~mm}{ }^{3}$ \\
\hline Divergence & $4.0-9.8 \mathrm{mrad}$ \\
\hline
\end{tabular}

\section{Status:}

To be commissioned in 2012

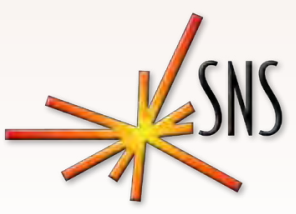

May 2008 


\section{INSTRUMENT}
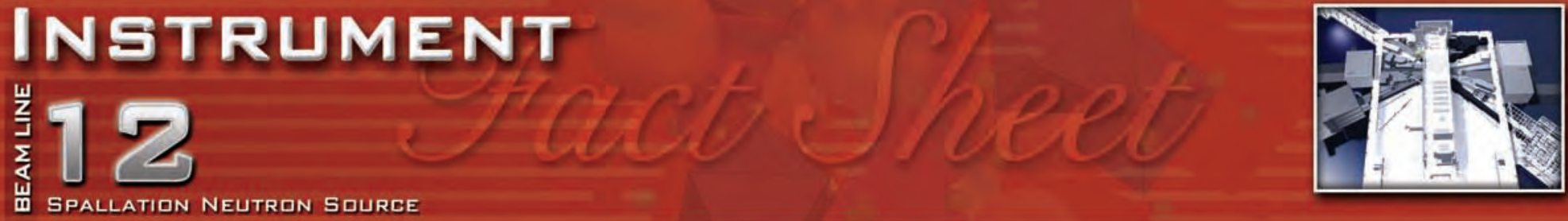

\section{TDPAZ - SINGLE-CRYSTAL DIFFRACTIMETER}

The TOPAZ Single-Crystal Diffractometer (SCD) is designed to perform elastic scattering experiments under controlled environmental conditions to probe material structures and responses. Use of the same single-crystal sample for X-ray and neutron diffraction was the

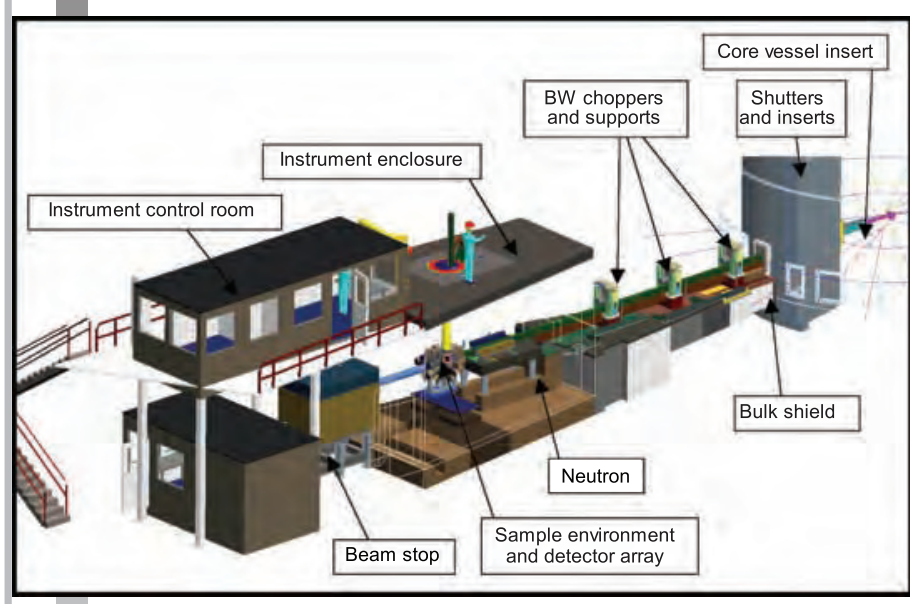

guiding design principle of TOPAZ, a versatile and variable-environment SCD for neutron scattering. Data are collected on samples of between 0.001 and $0.1 \mathrm{~mm}^{3}$, and expected average unit cell sizes are around $50 \AA^{3}$ for compounds of moderate complexity. The goal for TOPAZ is the capability to collect data in a matter of hours rather than days. Materials investigated include functional materials of the high-Tc superconductor perovskite family; magnetic superstructures in perovskites and spinels; the molecular basis of future high-density, three-

dimensional storage materials; and catalytic precursors, metalhydrides, and organometallics. Options to polarize the neutron beam for magnetic scattering experiments are included, as well as the ability to record Bragg intensities and diffuse scattering at cryogenic and elevated temperatures. A polarized incident neutron beam and magnetic field option on the sample help scientists decipher complex and directional magnetism and magnetic transitions.

\section{APPLICATIONS}

TOPAZ can address problems and greatly expand the range of materials explored in chemistry, earth sciences, materials science and engineering, solid-state physics, and biology. It can also assist in studies of therapeutics and medical compounds, such as aspirin and paracetamol, to show differences in hydrogen locations and bonding, helping scientists better understand a material's individual effectiveness.

\section{FLR MLRE INFIRMATION, CLNTACT}

Instrument Scientist: Christina Hoffmann, hoffmanncm@ornl.gov, 865.576.5127

Scientific Associate: Matthew Frost, frostmj@ornl.gov, 865.576.2033

http://neutrons.ornl.gov/instrument_systems/beamline_12_topaz

\section{SPECIFICATIONS}

\begin{tabular}{|r|l|}
\hline Moderator & $\begin{array}{l}\text { Decoupled } \\
\text { poisoned } \\
\text { hydrogen }\end{array}$ \\
\hline $\begin{array}{r}\text { Source- } \\
\text { to-sample } \\
\text { distance }\end{array}$ & $18 \mathrm{~m}$ \\
\hline $\begin{array}{r}\text { Sample- } \\
\text { to-detector } \\
\text { distance, } \\
\text { evacuated }\end{array}$ & $39-45 \mathrm{~cm}$ \\
\hline $\begin{array}{r}\text { Sample- } \\
\text { to-detector }\end{array}$ & $39-45 \mathrm{~cm}$, \\
distance in air & \\
\hline $\begin{array}{r}\text { Initial angular } \\
\text { detector }\end{array}$ & $4 \mathrm{sr}$ \\
coverage & \\
\hline $\begin{array}{r}\text { Optional } \\
\text { angular } \\
\text { detector }\end{array}$ & $9 \mathrm{sr}$ \\
coverage & \\
\hline $\begin{array}{r}\text { Detector pixel } \\
\text { size }\end{array}$ & $6.2 \times 10^{-6} \mathrm{sr}$ \\
$(1 \mathrm{~mm})$
\end{tabular}

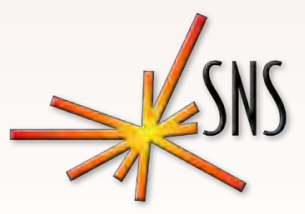

May 2008 


\section{INGTRUMENT}
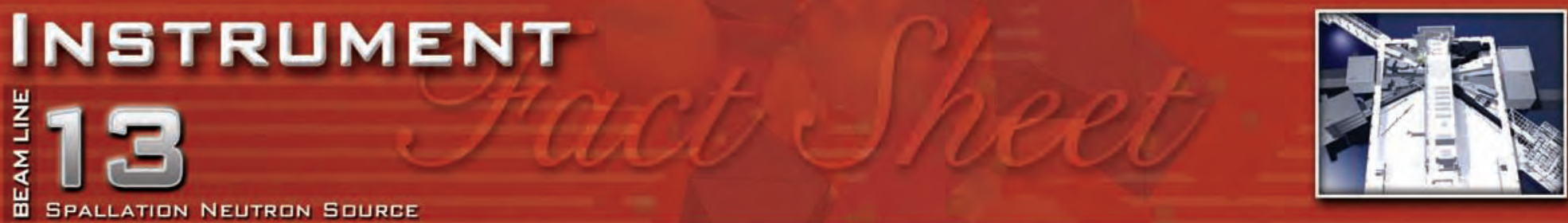

\section{FNPB - FUNDAMENTAL NEUTRON PHYSICS BEAM LINE}

The FNPB provides neutron beams for a variety of experiments in nuclear and particle physics. This facility is designed to accommodate two classes of experiments: (1) cold neutron experiments that require intense, broad-spectrum beams and (2) ultracold neutron experiments in which neutrons of $\sim 1 \mathrm{meV}$ are "down-converted" to near zero energy in superfluid liquid helium. Experiments at the FNPB include precise measurements of the parameters that describe neutron beta decay, studies of the weak interaction between quarks, and a search for a non-zero neutron electric dipole moment. Each of the experiments at the FNPB requires the development, construction, and installation of major pieces of experimental equipment, and each experiment could take beams for periods of several months to a few years.

\section{APPLICATILNS}

The FNPB is designed to address questions of interest in cosmology, nuclear and particle physics, and astrophysics. Among the questions that will be addressed are the origin of the light elements (big bang nuclear synthesis), the source of the cosmic matter-antimatter asymmetry, and the origin of parity violation.

\section{SPECIFICATIONS}

\begin{tabular}{|r|l|}
\hline \multicolumn{2}{|c|}{ Cold Neutron Beam Line } \\
\hline $\begin{array}{r}\text { Supermirror } \\
\text { guide }\end{array}$ & $\begin{array}{l}\text { Curved, } \\
\mathrm{m}=3.6\end{array}$ \\
\hline Beam area & $100 \times 120 \mathrm{~mm}$ \\
\hline Choppers & $\begin{array}{l}4 \text { frame over- } \\
\text { lap }\end{array}$ \\
\hline $\begin{array}{r}\text { Peak } \\
\text { wavelength }\end{array}$ & $3.5 \AA$ \\
\hline
\end{tabular}

\begin{tabular}{|c|}
\hline $\begin{array}{c}\text { Independent secondary } \\
\text { shutter }\end{array}$ \\
\hline $\begin{array}{c}\text { Floor pit for superconducting } \\
\text { magnet }\end{array}$ \\
\hline
\end{tabular}

\begin{tabular}{|r|l|}
\hline \multicolumn{2}{|c|}{$\begin{array}{r}\text { Ultracold Neutron Beam } \\
\text { Line }\end{array}$} \\
\hline Guide & 33 m ballistic \\
\hline Wavelength & $8.9 \AA$ \\
\hline $\begin{array}{r}\text { Monochro- } \\
\text { mator }\end{array}$ & $\begin{array}{l}\text { Double- } \\
\text { crystal alkalai } \\
\text { intercalated } \\
\text { graphite }\end{array}$ \\
\hline
\end{tabular}

External building experimental area

\section{Status:}

To be commissioned in 2008

$$
\begin{aligned}
& \text { Design model of the FNPB } \\
& \text { guide system showing the curved } \\
& \text { cold beam with four frame } \\
& \text { overlap choppers, as well as the } \\
& \text { monochromator housing and the } \\
& \text { ballistic ultracold neutron guide. } \\
& \text { The cold guide and choppers } \\
& \text { share a common vacuum to } \\
& \text { reduce window losses. }
\end{aligned}
$$

\section{FIR MIRE INFIRMATION, CLNTACT}

Project Manager: Geoff Greene, greenegl@ornl.gov, 865.574.8435 http://neutrons.ornl.gov/instrument_systems/beamline_13_fnpb

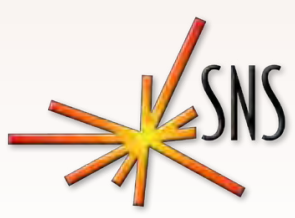

May 2008 


\section{INSTRUMENT}

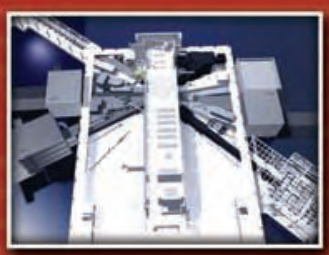

\section{HYSPEC - HYBRID SPECTRDMETER}

HYSPEC is a high-intensity, direct-geometry instrument optimized for measurement of excitations in small single-crystal specimens. The incident neutron beam is monochromated using a Fermi chopper with short, straight blades and is then focused onto the sample using Bragg scattering optics. Neutrons are detected in a bank of position-sensitive detector tubes that

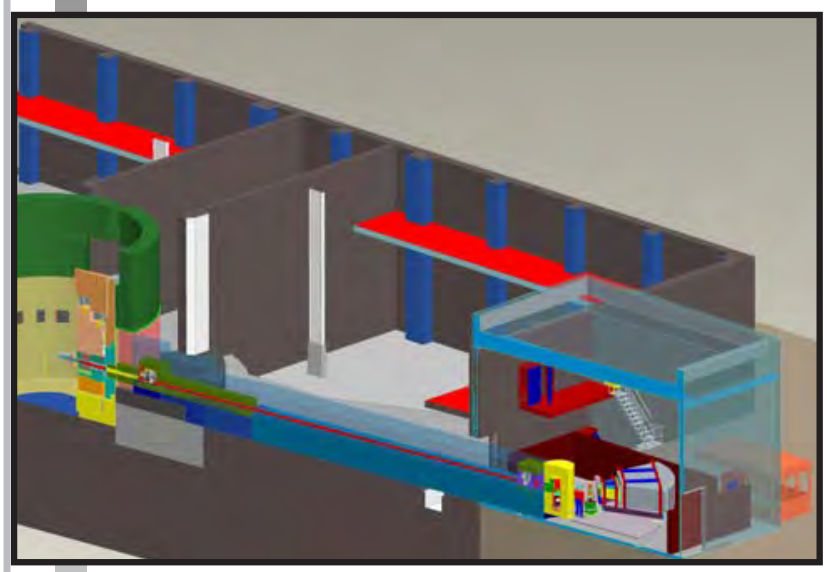
can be positioned over a wide range of scattering angles about the sample axis. This combination of Fermi chopper and Bragg focusing optics, plus a position-sensitive detector bank, leads to a highly flexible instrument in which the energy and wave vector resolution can be independently varied by nearly an order of magnitude. Either full or partial neutron polarization analysis can be deployed on HYSPEC. This is accomplished by using a Heusler crystal array to polarize the incident beam and either a ${ }^{3} \mathrm{He}$ spin filter or supermirror wide-angle polarization analyzers for the scattered beam.

\section{APPLICATIONS}

HYSPEC is applicable primarily to studies in the following:

- Superconductors

- Strongly correlated electron materials

- Ferroelectrics

- Lattice and magnetic dynamics

- Phase transitions

- Quantum critical points

- Complex phases in intermetallic compounds

- Frustrated magnets

- Low-dimensional magnetic excitations

- Transition metal oxides

- Spin and lattice dynamics in nanostructures

\section{FIR MIRE INFIRMATION, CINTACT}

Instrument Scientist: Mark Hagen, hagenme@ornl.gov, 865.241.9782 http://neutrons.ornl.gov/instrument_systems/hyspec.shtml

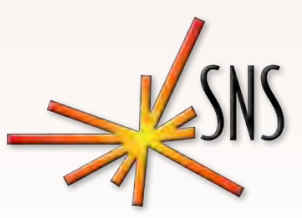

May 2008 


\section{INSTRUMENT}
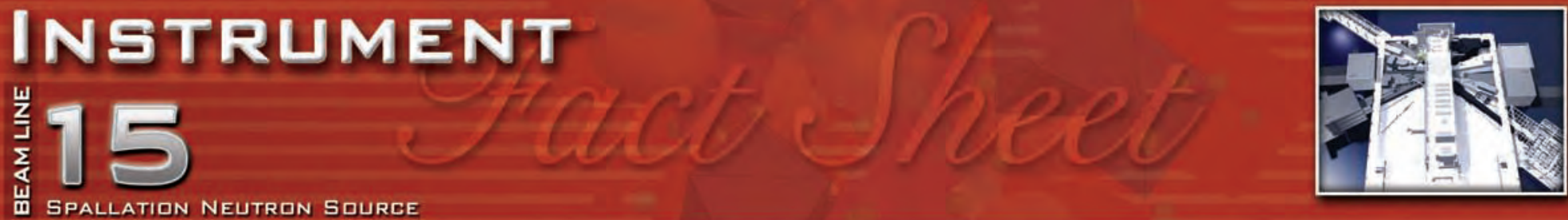

\section{NGE - NEUTRDN SPIN ECH口 SPECTRDMETER}

NSE is the best spectrometer of its class in both resolution and dynamical range. Exploiting superconducting technology and developing novel field correction elements, the maximum achievable Fourier time will be extended to at least $1 \mu$ s. Using wavelengths of $0.25<\lambda / \mathrm{nm}<$ 2.0 , an unprecedented dynamical range of six decades from $1 \mathrm{ps}<\tau$ to $\tau<1 \mu$ s can be achieved. The design of the spectrometer takes advantage of recent progress in neutron optics and polarizing supermirror microbenders, resulting in considerable gains in polarized neutron flux

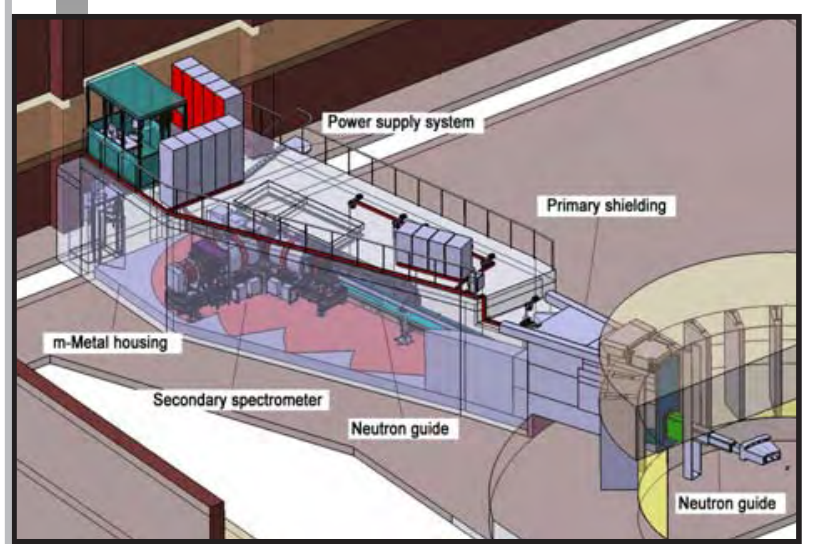
over a wide wavelength range. Performance is also extended by a position-sensitive, two-dimensional detector with a broad detection region. As a result, the effective data rate will gain an additional factor of 5 in addition to the estimated time-averaged sample flux of $10^{7} \mathrm{n} / \mathrm{cm}^{2} \mathrm{~s}$ around $\lambda=1 \mathrm{~nm}$. This yields the highest available data accumulation rate. In addition, the wavelength distribution width at any time is well below $0.5 \%$, causing the resolution in momentum transfer to increase significantly compared with reactor instruments with $10 \%$ or more wavelength distribution width.

\section{APPLICATIONS}

Although the NSE spectrometer is designed primarily for soft-matter research, its capabilities also make it useful for all fields of modern condensed matter and materials science. This instrument is especially suited for analyzing slow dynamical processes and thereby unraveling molecular motions and mobilities at nanoscopic and mesoscopic levels. This feature is highly relevant to soft-matter problems in research on the molecular rheology of polymer melts, related phenomena in networks and rubbers, interface fluctuations in complex fluids and polyelectrolytes, and transport in polymeric electrolytes and gel systems. NSE could also aid studies in biophysics and magnetism.

FIR MURE INFIRMATION, CONTACT

Instrument Scientist: Michael Ohl, ohlme@ornl.gov, 865.574.8426

http://neutrons.ornl.gov/instrument_systems/nse.shtml

\section{SPECIFICATIONS}

\begin{tabular}{|r|l|}
\hline Moderator & $\begin{array}{l}\text { Cold-coupled } \\
\text { hydrogen }\end{array}$ \\
\hline Neutron guide & $\begin{array}{l}58 \mathrm{Ni} \text { coated, } \\
h \times b\end{array} \times 8 \mathrm{~cm}^{2}$, \\
& $\mathrm{m}=1.2$ \\
\hline Wavelength & $\begin{array}{l}\text { Chopper system } \\
\text { consisting of } \\
\text { four choppers } \\
\text { and selecting } \\
\text { a wave length } \\
\text { band up to } \\
3.66 \AA\end{array}$ \\
\hline & $2 \AA<\lambda<20 \AA$ \\
\hline
\end{tabular}

\begin{tabular}{|c|c|}
\hline $\begin{array}{r}\text { Accessible } \\
\text { wavelength } \\
\text { frame }\end{array}$ & $2 \AA<\lambda<20 \AA$ \\
\hline $\begin{array}{r}\text { Declination } \\
\text { angle }\end{array}$ & $3.5^{\circ}$ \\
\hline $\begin{array}{r}\text { Maximum } \\
\text { scattering angle }\end{array}$ & $\cong 80^{\circ}$ \\
\hline Q range & $0.0025-3.6 \AA^{-1}$ \\
\hline $\begin{array}{r}\text { Maximum field } \\
\text { integral }\end{array}$ & $\mathrm{J}=1.8 \mathrm{Tm}$ \\
\hline Dynamic range & $1 \mathrm{ps}<\tau<1 \mu \mathrm{s}$ \\
\hline $\begin{array}{r}\text { Typical sample } \\
\text { size }\end{array}$ & $30 \times 30 \mathrm{~mm}$ \\
\hline Analyzer & $\begin{array}{l}\mathrm{m}=3 \text { rotatable } \\
\text { supermirror }\end{array}$ \\
\hline Detector & $\begin{array}{l}\text { 3He counter } \\
(300 \times 300 \\
\left.\mathrm{mm}^{2}\right)\end{array}$ \\
\hline $\begin{array}{r}\text { Typical } \\
\text { scanning } \\
\text { time with } 10 \% \\
\text { scatterer }\end{array}$ & $\begin{array}{l}5 \text { hours/ } \\
\text { spectrum }\end{array}$ \\
\hline
\end{tabular}

Status:

To be commissioned in 2009

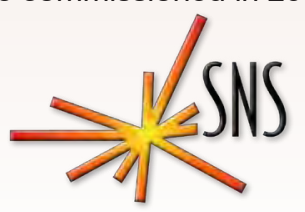

May 2008 


\section{INSTRUMENT}
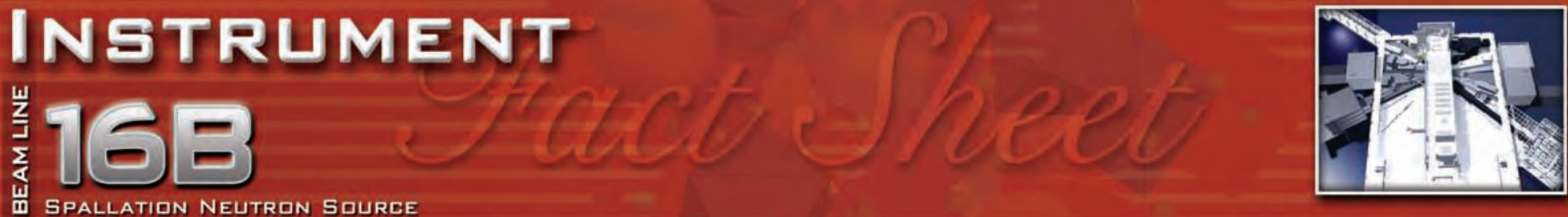

\section{VISIDN - CHEMICAL SPECTRDMETER}

VISION is best thought of as the neutron analogue of an infrared-Raman spectrometer. It is optimized to characterize molecular vibrations in a wide range of crystalline and disordered materials over a broad energy range ( $<5$ to $>500 \mathrm{meV}$ ), while simultaneously recording structural changes using diffraction detectors in the backscattering position and at $90^{\circ}$. This inverted-geometry instrument offers enhanced performance by coupling a white beam of

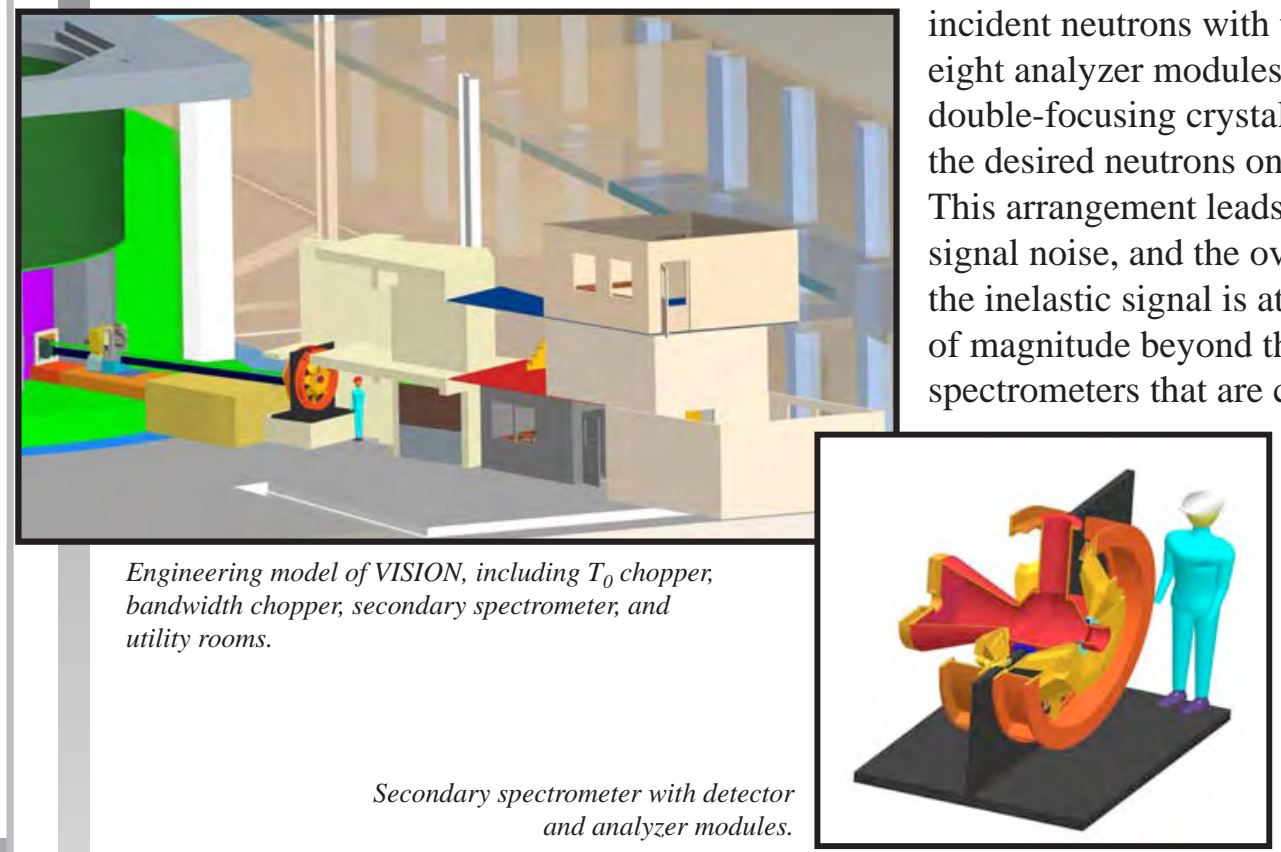
and analyzer modules.

\section{APPLICATIONS}

Leading-edge studies involving scientific disciplines such as nanotechnology, catalysis, biochemistry, geochemistry, and condensed/soft-matter science will all benefit from the enhanced performance and properties of VISION.

\section{FIR MURE INFIRMATILN CONTACT}

Principal Investigator: John Larese, jzl@utk.edu, 865.974.3141

Instrument Scientist: Christoph Wildgruber, wildgrubercu@ornl.gov, 865.574.5378

http://neutrons.ornl.gov/instrument_systems/beamline_16b_vision

\section{SPECIFICATIONS}

\begin{tabular}{|c|c|}
\hline Moderator & $\begin{array}{l}\text { Decoupled } \\
\text { ambient } \\
\text { water }\end{array}$ \\
\hline $\begin{array}{r}\text { Source-to-T } 0 \\
\text { chopper distance }\end{array}$ & $7 \mathrm{~m}$ \\
\hline $\begin{array}{r}\mathrm{T}_{0} \text { chopper-to- } \\
\text { sample distance } \\
\text { (primary flight } \\
\text { path) }\end{array}$ & $17 \mathrm{~m}$ \\
\hline $\begin{array}{r}\text { Sample-to- } \\
\text { detector distance } \\
\text { (secondary flight } \\
\text { path) }\end{array}$ & $0.7 \mathrm{~m}$ \\
\hline $\begin{array}{r}\text { Incident energy } \\
\text { range }\end{array}$ & 3.5-500 meV \\
\hline $\begin{array}{r}\text { Analyzer Bragg } \\
\text { angle }\end{array}$ & $45^{\circ}$ \\
\hline $\begin{array}{r}\text { Total analyzer } \\
\text { area (in } 14 \\
\text { identical units) }\end{array}$ & $0.5 \mathrm{~m}^{2}$ \\
\hline Energy resolution & $\begin{array}{l}\text { Exceeds } 1.5 \% \\
(>5 \mathrm{meV}) \\
-5 \% \\
(<5 \mathrm{meV})\end{array}$ \\
\hline Elastic line width & $90 \mathrm{meV}$ \\
\hline $\begin{array}{r}\text { Annular } \\
\text { diffraction } \\
\text { detector }\end{array}$ & $1.3-14 \AA^{-1}$ \\
\hline $\begin{array}{r}\text { Backscattering } \\
\text { diffraction } \\
\text { detector }\end{array}$ & $1.5-30 \AA^{-1}$ \\
\hline delta-d/d & 0.001 \\
\hline
\end{tabular}

Status:

To be commissioned in 2012

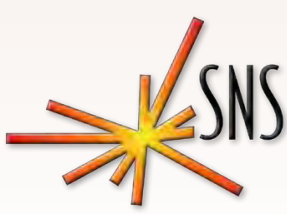

May 2008 


\section{INGTRUMENT}
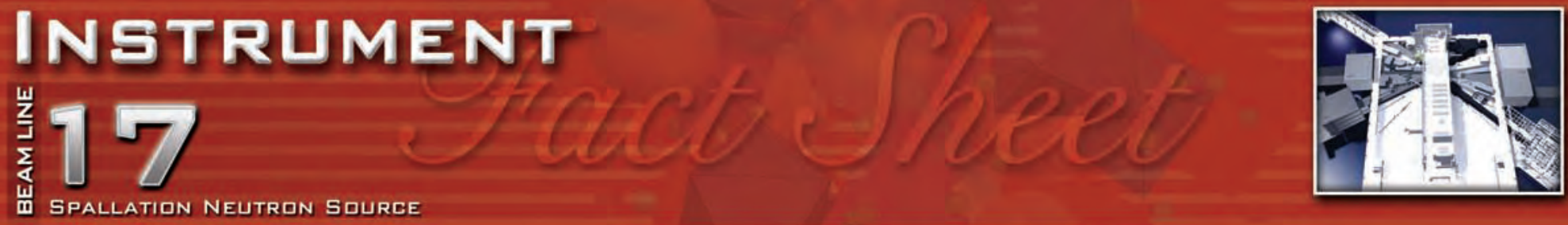

\section{SEQU⿴IA - FINE-RESLLUTION FERMI CHOPPER SPECTRDMETER}

SEQUOIA is a fine-resolution Fermi chopper spectrometer optimized to provide a high neutron flux at the sample and fine energy resolution. The spectrometer is capable of selecting neutrons with incident energies from a few hundredths of an electron volt to a couple of electron volts and thus can study excitations over this wide energy scale. An elliptically shaped supermirror

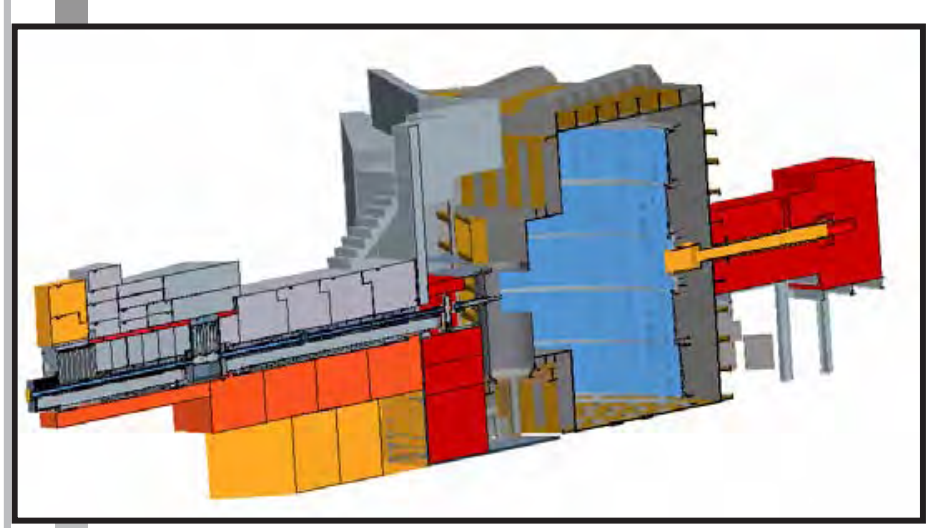
guide in the incident flight path boosts the performance at the lower end of this range. The sample and detector vacuum chambers provide a window-free final flight path and incorporate a large gate valve to allow rapid sample changeout. A new $\mathrm{T}_{0}$ neutron chopper is being developed not only to block the prompt radiation from the source but also to eliminate unwanted neutrons from the incident beam line. SEQUOIA can help scientists understand excitations in many materials, for example, magnetic materials, novel oxides, and high-temperature superconductors. SEQUOIA is a collaboration between Oak Ridge National Laboratory and the Canadian Institute for Neutron Scattering.

\section{APPLICATIONS}

With its capability to acquire data quickly and relate them to three-dimensional momentum transfers, SEQUOIA allows new studies of single crystals and novel systems such as the following:

- High-temperature superconductivity: spin dynamics in superconductors and precursor compounds, incommensurate spin fluctuations at varying doping levels

- Model magnetic systems, such as one-dimensional spin chains and spin ladders, and crossover effects from one- to three-dimensional magnetism

- Excitations in quantum fluids, quantum critical phenomena, and non-Fermi liquid systems

- High-resolution crystal field spectroscopy reaching into the 1-eV range

- Coupling of electronic and spin systems in correlated-electron materials

- Colossal magnetoresistive materials

\section{FIR MIRE INFIRMATION, CONTACT}

Instrument Scientist: Garrett Granroth, granrothge@ornl.gov, 865.576.0900

Scientific Associate: Todd Sherline, sherlinete@ornl.gov, 865.773.3157

http://neutrons.ornl.gov/instrument_systems/hrcs.shtml

\section{SPECIFICATIONS}

\begin{tabular}{|r|l|}
\hline Moderator & $\begin{array}{l}\text { Decoupled } \\
\text { ambient water }\end{array}$ \\
\hline $\begin{array}{r}\text { Source- } \\
\text { to-Fermi } \\
\text { chopper } \\
\text { distance }\end{array}$ & $18 \mathrm{~m}$ \\
\hline $\begin{array}{r}\text { Chopper- } \\
\text { to-sample } \\
\text { distance }\end{array}$ & $2.0 \mathrm{~m}$ \\
\hline $\begin{array}{r}\text { Sample- } \\
\text { to-detector } \\
\text { distance }\end{array}$ & $5.5-6.3 \mathrm{~m}$ \\
cylindrical \\
\hline $\begin{array}{r}\text { Incident } \\
\text { eneometry }\end{array}$ & $10-2000 \mathrm{meV}$ \\
\hline $\begin{array}{r}\text { Resolution } \\
\text { (elastic) }\end{array}$ & $1-5 \% \mathrm{E}_{\mathrm{i}}$ \\
\hline $\begin{array}{r}\text { Vertical } \\
\text { detector } \\
\text { coverage }\end{array}$ & $-30-30^{\circ}$ \\
\hline $\begin{array}{r}\text { Horizontal } \\
\text { detector } \\
\text { coverage }\end{array}$ & \\
\hline $\begin{array}{r}\text { Minimum } \\
\text { detector } \\
\text { angle }\end{array}$ & \\
\hline & $30-60^{\circ}$ \\
\hline
\end{tabular}

Status:

To be commissioned in 2008

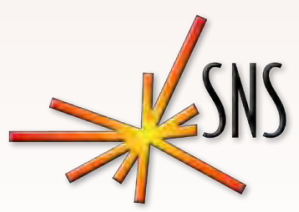

May 2008 


\section{INSTRUMENT}
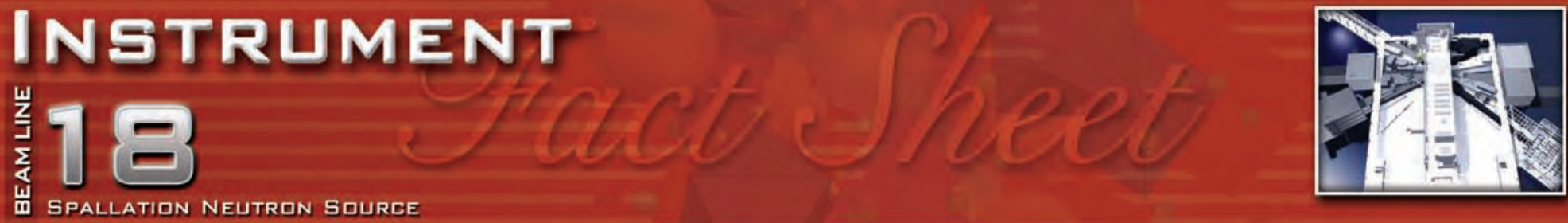

\section{ARES - WIDE ANGULAR-RANGE CHOPPER SPECTRDMETER}

ARCS is optimized to provide a high neutron flux at the sample and a large solid angle of detector coverage. This spectrometer is capable of selecting incident energies over the full energy spectrum

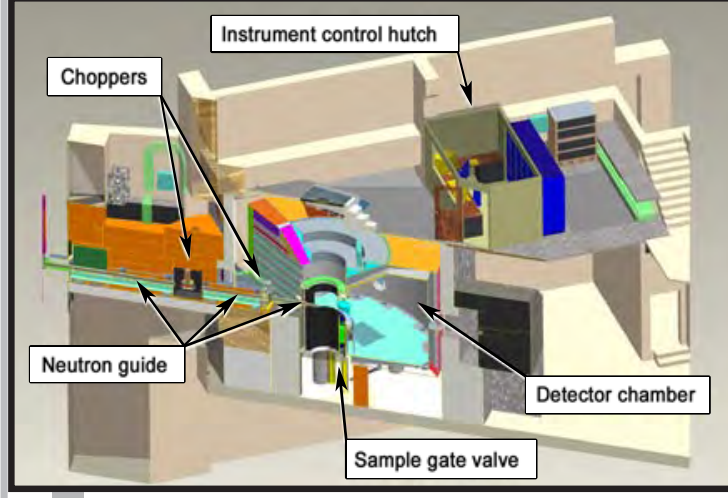

Cutaway view of the engineering model of the ARCS instrument showing the incident beam line components, sample and detector chamber, and control area.

\section{APPLICATIONS}

Compared with current instruments, the increased sensitivity of ARCS offers new opportunities for scientific studies in the following:

Lattice Dynamics

- Entropy and the effects of vibrational modes on stability and phase transitions of solids

- Excitations in disordered materials; effects of nanoscale features on vibrational entropy and thermodynamic stability

- Equations-of-state from the measured phonon density-of-states versus temperature and pressure

- Phonons in correlated-electron materials; coupling of lattice and electronic degrees of freedom in high-Tc, heavy-fermion, and mixed-valence materials

Magnetic Dynamics

- High-temperature superconductivity—spin dynamics in superconductors and precursor compounds and crystal field spectroscopy

- Low-dimensional systems; one-dimensional quantum magnets and low-dimensional conductors

- Magnetism in actinide materials; heavy-fermion magnetism and superconductivity

Chemical Physics

- Deep inelastic neutron scattering studies of hydrogen

\section{FUR MIRE INFIRMATION, CQNTACT}

Instrument Scientist: Doug Abernathy, abernathydl@ornl.gov, 865.576.5105

Instrument Scientist: Matthew B. Stone, stonemb@ornl.gov, 865.241.0483

Scientific Associate: Mark Loguillo, loguillomj@ornl.gov, 865.235.9000

http://neutrons.ornl.gov/instrument_systems/beamline_18_arcs

\section{SPECIFICATIONS}

\begin{tabular}{|r|l|}
\hline Moderator & $\begin{array}{l}\text { Decoupled } \\
\text { ambient water }\end{array}$ \\
\hline $\begin{array}{r}\text { Source- } \\
\text { to-Fermi } \\
\text { chopper } \\
\text { distance }\end{array}$ & $11.6 \mathrm{~m}$ \\
\hline $\begin{array}{r}\text { Chopper- } \\
\text { to-sample } \\
\text { distance }\end{array}$ & $2.0 \mathrm{~m}$ \\
\hline $\begin{array}{r}\text { Sample- } \\
\text { to-detector } \\
\text { distance }\end{array}$ & 3.0 to $3.4 \mathrm{~m}$ \\
cylindrical \\
geometry \\
Incident & $10-1500 \mathrm{meV}$ \\
\hline energy range & \\
\hline $\begin{array}{r}\text { Resolution } \\
\text { (elastic) }\end{array}$ & $2-5 \% \mathrm{E}_{\mathrm{i}}$ \\
\hline $\begin{array}{r}\text { Detector } \\
\text { coverage }\end{array}$ & $-28-135^{\circ}$ \\
horizontal & \\
\hline $\begin{array}{r}\text { Detector } \\
\text { coverage } \\
\text { vertical }\end{array}$ & $-27-26^{\circ}$ \\
\hline $\begin{array}{r}\text { Minimum } \\
\text { detector } \\
\text { angle }\end{array}$ & \\
\hline $3^{\circ}$ \\
\hline Opental
\end{tabular}

Status: Operational

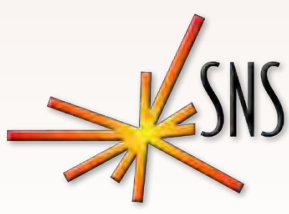

May 2008 


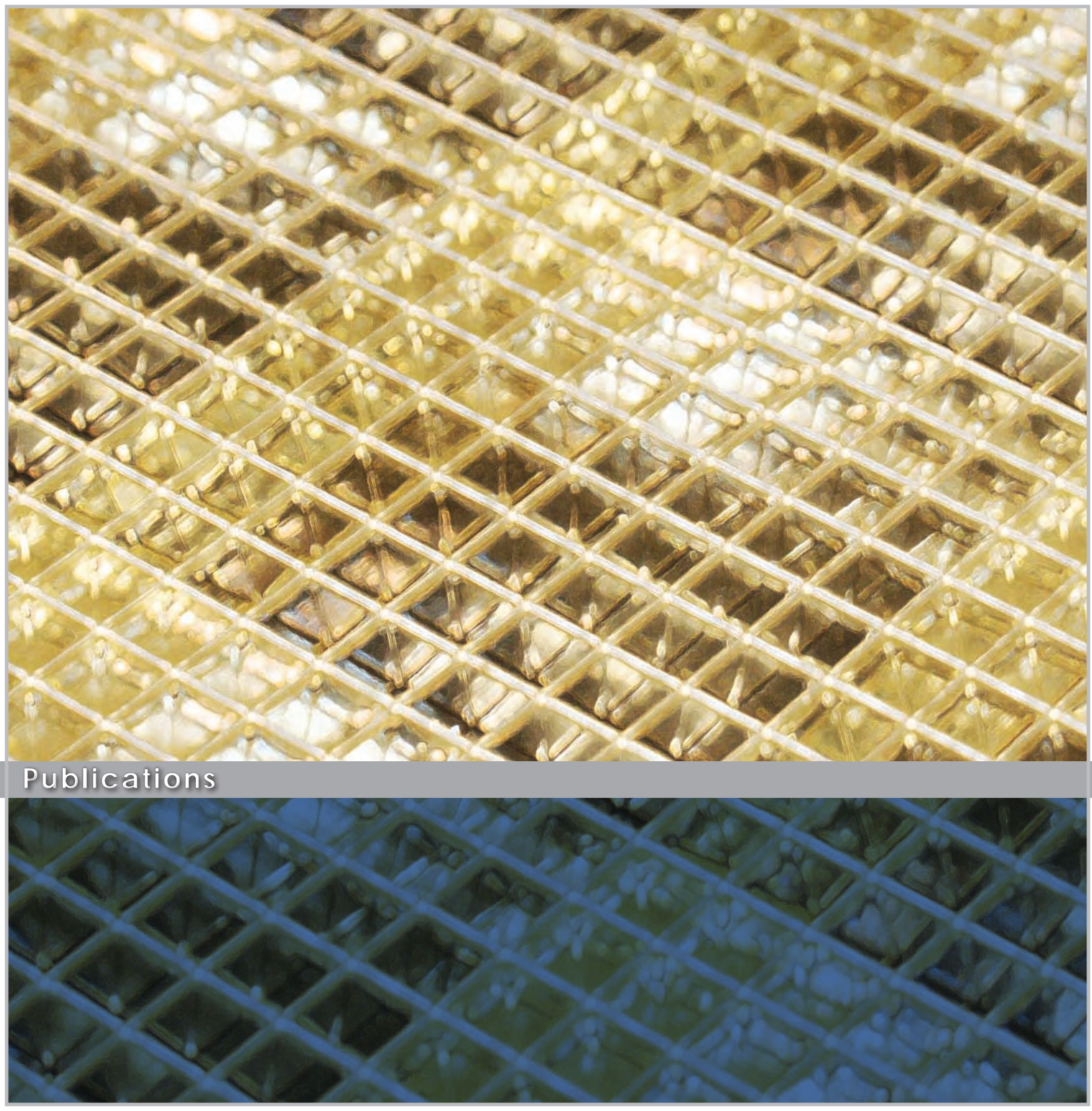




\section{The following publications document the results of studies enabled at least in part by use of} SNS and HFIR during 2007.

R. Alarcon, "Fundamental physics with cold and ultracold neutrons," Revista Mexicana De Fisica 53, 125-127 (February 2007).

M. Ando, M. Li, H. Tanigawa, M. L. Grossbeck, S. Kim, T. Sa wai, K. Shiba, Y. Kohno, and A. Kohyama, "C reep behavior of reduced activation ferritic/martensitic steels irradiated at 573 and $773 \mathrm{~K}$ up to 5 dpa," J ournal of Nuclear Materials 367, 122-126 (August 2007).

M. Ando, H. Tanigawa, K. Shiba, S. Jitsukawa, Y. Kohno, A. Kohyarna, M. Li, and R. E. Stoller, "Irradiation c reep behavior of reduced activation ferritic/martensitic steel irradiated in HFIR," J ournal of the Japan Institute of Metals 71, 559-562 (J uly 2007).

H. N. Bordallo, D. N. Argyriou, M. Barthes, W. Kalceff, S. Rols, K. W. Herwig, C. Fehr, F. J uranyi, and T. Seydel, "Hydrogen in N-methylacetamide: Positions and dynamics of the hydrogen atoms using neutron scattering," J ournal of Physical Chemistry B 111, 7725-7734 (J uly 2007).

M. D. Brown, B. M. Law, S. Satija, W. A. Hamilton, E. Watkins, J. H. J. Cho, a nd J. Majewski, "Comparison of critical adsorption scaling functions obtained from neutron reflectometry a nd ellip so metry," J ournal of Chemic al Physics 126 (Ma y 2007).

T. D. Burchell and L. L. Snead, "The effect of neutron irradiation damage on the properties of grade NBG-10 graphite," J ournal of Nuclear Materials 371, 18-27 (September 2007).

J. T. Busby, K. J. Leonard, and S. J. Zinkle, "Radiation-damage in molybdenum-rhenium alloys for space reactor a p plic ations," J ournal of Nuclear Materials 366, 388-406 (J uly 2007).

T. S. Byun, "Dose dependence of true stress parameters in irradiated bcc, fcc, and hcp metals," J ournal of Nuclear Material 361(2-3), 239-247, (April 2007).

B. C. Chakoumakos, R. Custelcean, T. Kamlyama, K. Oikawa, B. C. Sales, and M. D. Lumsden, "Structural modulation in $\mathrm{K}_{2} \mathrm{~V}_{3} \mathrm{O}$ 8," J ournal of Solid State Chemistry 180, 812-817 (March 2007 ).

W. R. Chen, L. Porcar, Y. Liu, P. D. Butler, and L. J. Magid, “Small a ngle neutron sc attering studies of the counterion effects on the molecular conformation and structure of charged g4 PAMAM dendrimers in aqueous solutions," Macromolecules 40, 5887-98 (August 2007).

Y. Chen, M. B. Stone, M. Kenzelmann, C. D. Batista, D. H. Reich, and C. Broholm, "Phase diagram and spin Hamiltonian of weakly-coupled a nisotropic $S=1 / 2$ chains in CuCl 2 (2((CD3)2SO)," Physical Review B 75 (J une 2007).

G. Cheng, Y. B. Melnic henko, G. D. Wignall, F. J. Hua, K. L. Hong, and J. W. Mays, “Conformation of oligo(ethylene glycol) grafted polystyrene in dilute aqueous solutions," Polymer 48, 4108-4113 (J une 2007).

S. Cheng, A. D. Stoic a, X. L. Wang, G. Y. Wang, H. Choo, and P. K. Lia w, "Fra c ture of Ni with gra insize from nanocrystalline to ultrafine scale under cyclic loading," Scripta Materialia 57, 217-220 (August 2007). 
S. Cheng, X. L. Wang, H. Choo, and P. K. Liaw, "Global melting of $\mathrm{Zr}_{57} \mathrm{Ti}_{5} \mathrm{Ni}_{8} \mathrm{Cu}_{20} \mathrm{Al}_{10}$ bulk metallic glass under mic rocompression," Applied Physics Letters 91 (November 2007).

S. Chi, F. Ye, P. Dai, J. A. Fernandez-Baca, Q. Huang, J. W. Lynn, E. W. Plummer, R. Mathieu, Y. Kaneko, and Y. Tokura, "Effect of a ntife rromagnetic spin correlations on lattice distortion and charge ordering in $\mathrm{Pr}_{0,5} \mathrm{Ca}_{1.5} \mathrm{MnO}_{4}$," Proceedings of the National Academy of Sciences of the United States of America 104, 10796-10801 (J une 2007).

W. M. Chien, J. Lamb, D. Chandra, A. Huq, J. Richardson, and E. Maxey, "Pha se evolution of Li ${ }_{2} N D$, $\mathrm{LiD}$ and $\mathrm{LiND}_{2}$ in hydriding/dehydriding of $\mathrm{Li}_{3} \mathrm{~N}$," J ournal of Alloys a nd Compounds 446, 363-367 (October 2007).

A. D. Christianson, J. S. Gardner, H. J. Kang, J. H. Chung, S. Bobev, J. L. Sarrao, and J. M. Lawrence, "Low temperature behavior of the heavy fermion $\mathrm{Ce}_{3} \mathrm{CO}_{4} \mathrm{Sn}_{13}$ " J ournal of Magnetism and Magnetic Materia Is 310, 266-267 (March 2007).

A.D. Christianson and S. Bobev, "Pr $\ln _{0}$ re-assessment of the cubic $P r_{3} I n$ crystal structure," Acta Crysallographic a E 63, i84 (2007).

J. W. Cobb, A. Geist, J. A. Kohl, S. D. Miller, P. F. Peterson, G. G. Pike, M. A. Reuter, T. Swain, S. S. Vazhkudai, and N. N. Vijayakumar, "The Neutron Science TeraG rid Gateway: A TeraGrid science gateway to support the Spallation Neutron Source," Concurrency and Computation-Practice and Experience 19, 809-826 (April 2007).

P. Dai, S. D. Wilson, and S. Li, “Evolution of sp in excitations in electron-doped $\operatorname{Pr}_{0.88} \mathrm{LaCe}_{0.12} \mathrm{CuO}_{4-}$ delta" "Physica C-Superc onductivity and Its Applic ations 460, 52-55 (September 2007).

A. Diama, M. Simpson, H. Ta ub, F. Y. Hansen, R. M. Dimeo, D. A. Neumann, K. W. Herwig, and U. G. Volkmann, "Studies of dynamic al layering in adsorbed organic films," p. 89 in Qua si-Ela stic Neutron Sc attering Conference 2006 (Q ENS2006), Wa rrendale, Pennsylva nia, February 2007.

S. A. Da nilkin, G. Horton, R. Moore, G. Broaudakis, and M. Hagen, "Thermal triple axis spectrometer at OPAL reactor," J ournal of Neutron Research 15, 55 (2007).

V. Danilov, A. Aleksandrov, S. Assadi, J. Barhen, W. Blokland, Y. Bra iman, D. Brown, C. Deibele, W. Grice, S. Henderson, J. Holmes, Y. Liu, A. Shishlo, and A. Webster, "Pro of-of-principle demonstration of high efficiency la ser-assisted H-beam conversion to protons," Physical Review Special TopicsAcc elerators and Beams 10 (May 2007).

G. De Geronimo, J. Fried, G. C. Smith, B. Yu, E. Vernon, C. L. Britton, W. L. Bryan, L. G. Clonts, and S. S. Frank, "ASIC for small angle neutron scattering experiments at the SNS," IEEE Transactions on Nuclear Science 54, 541-548 (J une 2007).

L. Di Costanzo, M. Moulin, M. Ha ertlein, F. Meilleur, and D. W. Christianson, “Expression, purific ation, a ssay, and crystal structure of perdeuterated human argina se I," Archives of Biochemistry a nd Biophysic s 465, 82-89 (September 2007).

W. Dmowski, C. Fan, M. L. Morrison, P. K. Liaw, and T. Egami, "Structural changes in bulk metallic glass after annealing below the glass-transition temperature," Materia Is Science and Engineering A-Struc tural Materia Is Properties Mic rostructure and Processing 471, 125-129 (December 2007).

T. Egami, "Essential role of the lattic e in the mechanism of high temperature superconductivity," p. 103 in High Tc Superc onductors and Related Transition Metal Oxides: Special Contributions in 
Honor of K. Alex Müller and the Occasion of his 80th Birthday, eds. A. Bussmann-Holder and H. Keller, Springer-Verlag, Berlin, 2007.

T. Egami, “Lattic e effects in the cuprates," Physic a C 460-462, 267 (2007).

G. Ehlers, "Low-temperature relaxation in kagome bilayer antiferromagnets," J ournal of PhysicsCondensed Matter 19(14), 145254+, Ap ril 2007.

G. Ehlers, C. Ritter, J. R. Stewart, A. D. Hillier, and H. Maletta, "Pha se transition of geometric ally frustrated Tb NiAl in a magnetic field," Physical Review B 75 (J a nuary 2007).

Z. Feng, X.-L. Wang, S. A. David, and P. S. Sklad, "Modeling of residual stresses a nd property distributions in fric tion stir welds of a luminum alloy 6061-T6," Science and Technology of Welding and J oining 12, 348-356 (2007).

F. Fernandez-Alonso, F. J. Bermejo, S. E. McLain, J. F. C. Turner, J. J. Molaison, and K. W. Herwig, "Observation of fractional Stokes-Einstein behavior in the simplest hydrogen-bonded liquid," Physical Review Letters 98 (February 2007).

P. Fouquet, G. Ehlers, B. Farago, C. Pappas, and F. Mezei, "The wide-angle neutron sp in echo spectrometer project WASP," J ournal of Neutron Research 15, 39 (2007).

E. Garlea, V. O. Garlea, H. Choo, C. R. Hubbard, and P. K. Liaw, Materia Is Science Forum 539-543, 1443 (2007).

V. O. Garlea, A. Zheludev, T. Masuda, H. Manaka, L. P. Regnault, E. Ressouche, B. Grenier, J. H. Chung, Y. Qiu, K. Habicht, K. Kiefer, and M. Boehm, "Excita tions from a Bo se-Einstein condensate of magnons in coupled spin ladders," Physical Review Letters 98 (April 2007).

G. E. Granroth, M. Chen, J. A. Kohl, M. E. Hagen, and J. W. Cobb, "Fast Monte Carlo simulation of a dispersive sample on the SEQ UOIA spectrometer at the SNS," J ournal of Neutron Research 15, 91 (2007).

W. Haeck and B. Verboomen, "An optimum approach to Monte Carlo burnup," Nuclear Science and Engineering 156(2), 180-96 (J une 2007).

J. He, R. J in, B. C. Chakoumakos, J. S. Gardner, D. Mandrus, and T. M. Tritt, "Crystal growth, structure, and sto ic hiometry of the superconducting pyrochlore $\mathrm{Cd}_{2} \mathrm{Re}_{2} \mathrm{O}_{7}$," J ournal of Electronic Materia Is 36, 740-745 (J uly 2007).

A. Huq, J. W. Ric hardson, E. R. Maxey, D. Chandra, and W. M. Chien, "Structural studies of $\mathrm{Li}_{3} \mathrm{~N}$ using neutron powder diffraction," J ournal of Alloys and Compounds 436, 256-260 (J une 2007).

A. Huq, J. W. Ric hardson, E. R. Maxey, D. Chandra, and W. M. Chien, "Structural studies of deuteration and dedeuteration of $\mathrm{Li}_{3} \mathrm{~N}$ by use of in situ neutron diffraction," J ournal of Physical Chemistry C 111, 10712-10717 (J uly 2007).

D. Jeon, "Benchmarking of multipartic le phase scan and acceptance scan techniques for the Spallation Neutron Source linac," Nuclear Instruments and Methods in Physics Research Section A-Accelerators, Spectrometers, Detectors, and Associa ted Equipment 578, 379-384 (August 2007).

D. Jeon, J. Stovall, H. Takeda, S. Nath, J. Billen, L. Young, I. Kisselev, A. Shishlo, A. Aleksandrov, S. Assadi, C. M. Chu, S. Cousineau, V. Danilov, J. Galambos, S. Henderson, S. Kim, L. Kra vchuk, 
and E. Tanke, "Acceptance scan technique for the drift tube linac of the Spallation

Neutron Source," Nuclear Instruments and Methods in Physic s Research Section A-Accelerators, Spectrometers, Detectors, and Associa ted Equipment 570, 187-191 (J a nuary 2007).

Z. Jiao, N. Ham, and G. S. Was, "Mic rostructure of helium-implanted and proton-irradiated T91 ferritic / martensitic steel," J ournal of Nuclear Materials 367, 440-445 (August 2007).

S. Y. Kamath, M. J. Arlen, W. A. Ha milton, and M. D. Dadmun, "The dynamics of copolymers in homopolymer matrices," European Physical J ournal-Special Topic s 141, 243-249 (Feb rua ry 2007).

H. J. Kang, P. C. Dai, B. J . Campbell, P. J. Chupas, S. Rosenkranz, P. L. Lee, Q. Z. Huang, S. L. Li, S. Komiya, and $Y$. Ando, "Mic roscopic annealing process and its impact on superconductivity in $T$ struc ture electron-doped copper oxides," Nature Materials 6, 224-229 (March 2007).

Y. W. Kang, A. V. Vassioutchenko, A. V. Aleksandrov, D. E. Anderson, M. Champion, M. T. Crofford, P. E. Gibson, T. W. Hardek, P. Ladd, M. McCarthy, and D. S. Stout, "Design and high power processing of RFQ input powercouplers," p. WEPMS074 in Proceedings of the 2007 Particle Accelerator Conference, Pisc a taway, New J ersey, August 2007.

Y. W. Kang, J. L. Wilson, M. Champion, T. W. Hardek, S.-H. Kim, M. McCarthy, A. V. Vassioutchenko, "Development and testing of high power rf vector modulators," p. WEPMS075 in Proceedings of the 2007 Particle Accelerator Conference, Piscataway, New Jersey, August 2007.

S. H. Kim and I. E. Campisi, "Commissioning of the superconducting Linac at the Spallation Neutron So urce (SNS)," IEEE Transactions on Applied Superc onductivity 17, 1299-1304 (J une 2007).

S. H. Kim and I. E. Campisi, "Optimization of pulsed operation of the superconducting radiofrequency (SRF) cavities at the Spallation Neutron Source (SNS)," IEEE Transactions on Applied Superc ond uc tivity 17, 1277-1280 (J une 2007).

S. H. Kim and I. E. Campisi, "Thermal stabilities and optimal operating pa rameters for the Oak Ridge Spallation Neutron Source superconducting linear accelerator," Physical Review Special Topics-Accelerators and Beams 10 (March 2007).

E. J. Kintzel, K. W. Herwig, M. Kidder, P. F. Britt, A. C. Buchanan III, and A. Chaffe, "A qua siela stic neutron scattering study of the dynamics of alkane and ether molecules tethered to the surface of MCM-41," p. 31 in Quasi-Ela stic Neutron Scattering Conference 2006 (Q ENS2006), Wa rrendale, Pennsylva nia, February 2007.

F. R. Klose and N. R. Holtkamp, "Neutronenfuer die Forschung," Physik J ournal 23-29, J a nua ry 2007.

V. V. Krishna murthy, J. C. Lang, D. Ha skel, D. J. Keavney, G. Srajer, J. L. Robertson, B. C. Sa les, D. G. Mandrus, D. J. Singh, and D. I. Bilc, "Ferrimagnetism in EuFe ${ }_{4} \mathrm{Sb}_{12}$ due to the interplay of f-electron moments and a nearly ferromagnetic host," Physical Review Letters 98 (March 2007).

F. Kruger, S. D. Wilson, L. Shan, S. L. Li, Y. Huang, H. H. Wen, S. C. Zhang, P. C. Dai, and J. Zaanen, "Magnetic fluctuations in n-type high-T-c superconductors reveal breakdown of fermiology: Experiments and Fermi-liquid/RPA calculations," Physic al Review B 76 (September 2007).

M. Li, T. S. Byun, N. Ha shimoto, L. L. Snead, and S. J. Zinkle, "The temperature dependence of the yield stress for neutron-irra diated molybdenum," J ournal of Nuclear Materia Is 371, 53-60 (September 2007). 
K. C. Littrell, S. te Velthuis, G. P. Felcher, S. Park, B. J. Kirby, and M. R. Fitzsimmons, "Magnetic compound refractive lens for focusing and polarizing cold neutron beams," Review of Scientific Instruments 78 (March 2007).

C. T. Liu, C. L. Fu, M. F. Chisholm, J. R. Thompson, M. Krcmar, and X.-L. Wang, “Magnetism a nd solid solution effects in NiAl (40\% Al) alloys," Progress in Materia Is Science 52(2-3), 352-370 (FebruaryMarch 2007).

A. Llobet, A. D. Christianson, W. Bao, J. S. Gardner, I. P. Swa inson, J. W. Lynn, J. M. Mignot, K. Prokes, P. G. Pagliuso, N. O. Moreno, J. L. Sarrao, J. D. Thompson, and A. H. Lacerda, "Novel coexistence of superconductivity with two distinct magnetic orders (Physical Review Letters 95, article 217002, 2005)," Physical Review Letters 99 (August 2007).

T. Lu, R. Samulyak, and J. Glimm, J ournal of Fluids Engineering, Transactions of the ASME 129(5), 595-604 (May 2007).

W. Lu and M. S. Wechsler, "The radiation damage database: Section on helium cross section," J ournal of Nuclear Materia Is 361, 282-288 (April 2007).

G. Ludtka, F. R. Klose, R. A. Kisner, J. A. Fernandez-Baca, G. M. Ludtka, J. B. Wilgen, R. A. J a ra millo, L. J. Santodonato, X.-L. Wang, C. R. Hubbard, and F. Tang, "Time-resolved a nalyses of mic rostructure in advanced materials under magnetic fields at elevated temperatures using neutrons," pp. 3-8 in Materials Processing Under the Influence of External Fields, Proceedings of the 2007 TMS Annual Meeting and Exhibition, Warrendale, Pennsylvania, February 2007.

D. Ma, A. D. Stoica, L. Yang, X. L. Wang, Z. P. Lu, J. Neuefeind, M. J. Kramer, J. W. Richard son, a nd T. Proffen, "Nearest-neighbor coordination and chemic al ordering in multicomponent bulk metallic glasses," Applied Physic s Letters 90 (May 2007).

D. Ma, A. D. Stoica, and X. L. Wang, "Volume conservation in bulk metallic glasses," Applied Physic s Letters 91 (J uly 2007).

E. Mamontov, "Mobility of water on oxide surfaces studied by QENS," pp. 13-20 in Qua si-Ela stic Neutron Sc attering Conference 2006 (QENS 2006), eds. P. E. Sokol, H. Ka iser, D. Baxter, R. Pynn, D. Bossev, and M. Leuschner, Materials Resea rch Society, Wa rrendale, Pennsylvania, 2007.

E. Mamontov, L. VIcek, D. J. Wesolowski, P. T. Cummings, W. Wang, L. M. Anovitz, J. Rosenqvist, C. M. Brown, and V. G. Sakai, "Dynamics and structure of hydration water on rutile and c a ssite rite nanopowders studied by quasielastic neutron scattering and molecular dynamics simulations," J ournal of Physic al Chemistry C 111, 4328-4341 (March 2007).

S. E. Mc Lain, A. K. Soper, and A. Luzar, "Investigations on the structure of dimethyl sulfoxide and acetone in aqueous solution," J ournal of Chemic al Physics 127 (November 2007).

Y. B. Melnichenko and G. D. Wignall, "Small-angle neutron sc attering in materials science: Recent practical applic ations," J ournal of Applied Physic s 102 (J uly 2007).

M. K. Miller, X.-L. Wang, D. J . Larson, and J. D. O Ison, "La ser LEAP c ha racterization of a $\mathrm{Zr}_{52.5} \mathrm{Cu}_{17.9} \mathrm{Ni}_{14.6} \mathrm{Al}_{10} \mathrm{Ti}_{5}$ bulk metallic glass," Mic rosc opy and Mic roanalysis 13(Suppl. 2), 1630-1631 (2007). 
W. Montfrooij, J. Lamsal, M. Aronson, M. Bennett, A. de Visser, H. Y. Kai, N. T. Huy, M. Yethiraj, M. Lumsden, and Y. M. Qiu, "G round sta te of a qua ntum critic al system: Neutron scattering on Ce(Ru1-xFex)(2)Ge-2," Physical Review B 76 (August 2007).

H. Mutka, C. Payen, G. Ehlers, J. R. Stewart, D. Bono, and P. Mendels, “Low-temperature relaxation in kagome bilayer antiferromagnets," J ournal of Physics-Condensed Matter 19 (April 2007).

T. Nakata, H. Tanigawa, K. Shiba, S. I. Komazaki, M. Fujiwara, Y. Kohno, and A. Kohyama,

"Evaluation of creep properties of reduced activation ferritic steels," J ournal of the Japan Institute of Metals 71, 239-243 (February 2007).

G. Newsome, L. L. Snead, T. Hinoki, Y. Katoh, and D. Peters, "Evaluation of neutron irradiated silic on carbide and silic on carbide composites," J ournal of Nuclear Materials 371, $76-89$ (September 2007).

F. C. Niestemski, S. Kunwar, S. Zhou, S. L. Li, H. Ding, Z. Q. Wang, P. C. Dai, and V. Madhavan, “A distinct bosonic mode in an electron-doped high-transition-temperature superconductor," Nature 450, 1058-1061 (December 2007).

N. Okubo, E. Wakai, S. Matsukawa, T. Sawai, S. Kitazawa, and S. J itsukawa, “Effects of heat treatment and irradiation on mechanical properties in F82H steel doped with boron and nitrogen," J ournal of Nuclear Materials 367, 107-111 (August 2007).

N. O kubo, E. Wakai, T. Tomita, and S. J itsukawa, "Mechanic al properties a nd mic rostructures in F82 H steel irradiated under alternating temperature," J ournal of Nuclear Materia Is 367, 112-116 (August 2007).

M. A. Plum, "Commissioning experience of SNS," p. 6 in Proceedings of the 2007 Asian Particle Accelerator Conference, Geneva, Switzerland, J uly 2007.

Y. S. Puzyrev, G. E. Ice, C. J. Sparks, and L. Robertson, "Automated softwa re for the recovery of the short range order parameters from diffuse X-ray sc a ttering data," Nuclear Instruments and Methods in Physics Research Section A-Accelerators, Spectrometers, Detectors, and Associated Equipment 582, 193-195 (November 2007).

P. Richard, M. Neupane, Y. M. Xu, P. Fournier, S. Li, P. C. Dai, Z. Wang, and H. Ding, “Competition between antiferromagnetism and superconductivity in the electron-doped cuprates triggered by oxygen reduction," Physic al Review Letters 99 (October 2007).

J. E. Rix, J. K. R. Weber, L. J. Sa ntodonato, B. Hill, L. M. Walker, R. McPherson, J. Wenzel, S. E. Hammons, J. Hodges, M. Rennich, and K. J. Volin, "Automated sample exchange and tracking system for neutron research at cryogenic temperatures," Review of Scientific Instruments $\mathbf{7 8}$ (J a nuary 2007).

Y. W. Rodriguez, I. E. Anderson, D. P. Belanger, H. Nojiri, F. Ye, and J. A. Fernandez-Baca, “Lowtemperature excitations in a dilute three-dimensional anisotropic a ntiferromagnet," Journal of Magnetism and Magnetic Materials 310,1546-1548 (March 2007).

G. Rother, Y. B. Melnichenko, D. R. Cole, H. Frielinghaus, and G. D. Wignall, "Mic rostructural characterization of adsorption and depletion regimes of superc ritic al fluids in na nopores," J ournal of Physical Chemistry C 111, 15736-15742 (November 2007). 
V. G. Sakai, E. Mamontov, J. W. Lynn, L. Viciu, and R. J. Cava, “Dynamics of water in the $\mathrm{Na}_{0.3} \mathrm{CoO}_{2}$

- 1.4H(2)O superconductor," Physical Review B 75 (J a nuary 2007).

L. L. Snead, Y. Katoh, and S. Connery, "Swelling of SiC at intermediate and high irradiation temperatures," J ournal of Nuclear Materials 367, 677-684 (August 2007).

M. A. Sokolov, A. Kimura, H. Ta nigawa, and S. Jitsuka wa, "Fra cture to ughness c ha ra c te riza tion of J LF-1 steel after irra diation in HFIR to $5 \mathrm{dpa}$," J ournal of Nuclear Materials 367, 644-647 (August 2007).

M. A. Sokolov, H. Tanigawa, G. R. Odette, K. Shiba, and R. L. Klueh, "Fra cture toughness a nd Charpy impact properties of several RAFMS before and after irra diation in HFIR," Journal of Nuclear Ma terials 367, 68-73 (August 2007).

M. Steinhart, C. D. Liang, G. W. Lynn, U. Goslee, and S. Dai, “Direct synthe sis of mesoporous carbon mic rowires and na nowires," Chemistry of Materia ls 19(10), 2383-2385 (Ma y 15, 2007).

R. E. Stoller, F. J. Walker, E. D. Specht, D. M. Nicholson, R. I. Barabash, P. Zschack, and G. E. Ice, “Diffuse X-ray scattering measurements of point defects and clusters in iron," J ournal of Nuclear Materia ls 367, 269-275 (August 2007).

M. B. Stone, C. Broholm, D. H. Reich, P. Schiffer, O. Tchernyshyov, P. Vorderwisch, a nd N. Ha rrison, “Field-driven phase transitions in a quasi-two-dimensional quantum a ntiferromagnet," New Journal of Physics 9 (February 2007).

M. B. Stone, F. Fernandez-Alonso, D. T. Adroja, N. S. Dalal, D. Villagrán, F. A. Cotton and S. E. Nagler, "Excitation spectrum of a model antiferromagnetic spin-trimer," Physical Review B 75, 214427 (2007).

M. B. Stone, F. Ferna ndez-Alonso, D. T. Adroja, N. S. Dalal, D. Villagran, F. A. Cotton, and S. E. Nagler, "Inelastic neutron scattering study of a quantum spin trimer," Physical Review B 75 (J une 2007).

M. B. Stone, W. Tian, M. D. Lumsden, G. E. Granroth, D. Mandrus, J. H. Chung, N. Ha rrison, and S. E. Nagler, "Quantum spin correlations in a n organometallic alternating-sign chain," Physical Review Letters 99 (August 2007).

T. Tajima, A. Canabal, Y. Zhao, A. Romanenko, B. H. Moeckly, C. D. Nantista, S. Tantawi, L. Phillips, Y. Iwa shita, a nd I. E. Campisi, "MgB, for a p plication to RF c a vities for a c celera tors," IEEE Transa ctions on Applied Superconductivity 17, 1330-1333 (J une 2007).

H. Tanigawa, H. Saka segawa, N. Ha shimoto, R. L. Klueh, M. Ando, and M. A. Sokolov, “Irra diation effects on precipitation and its impact on the mechanical properties of reduced-activation ferritic / ma rtensitic steels," J ournal of Nuclear Materia Is 367, 42-47 (August 2007).

H. Ta nigawa, H. Sa ka segawa, H. Ogiwara, H. Kishimoto, and A. Kohyama, "Ra diation induced phase instability of precipitates in reduced-activation ferritic/martensitic steels," J ournal of Nuclear Materia Is 367, 132-136 (August 2007).

E. Wakai, M. Ando, T. Sa wai, H. Tanigawa, T. Taguchi, R. E. Stoller, T. Yamamoto, Y. Ka to, a nd F. Takada, "Effect of heat treatments on tensile properties of F82H steel irradiated by neutrons," J ournal of Nuclear Materials 367, 74-80 (August 2007). 
W. Walter, M. Borlein, F. Eysselein, M. Gehring, T. Kozielewski, A. Kramer, M. Monkenbusch, M. Ohl, A. Paul, F. Schrauth, and C. Tiemann, "Design of a pair of superconducting solenoids for a neutron spin-ec ho spectrometer at the SNS," IEEE Transactions on Applied Superc onductivity 17, 1209-1212 (J une 2007).

J. G. Wang, "Particle optic s of quadrupole doublet magnets in Spallation Neutron So urce accumulator ring," Physical Review Special Topics-Accelerators and Beams 9 (December 2006).

J. J. Wang, K. An, E. Lara-Curzio, C. R. Hubbard, T. J. King, J r., J. Graziano, and J. Chan, "Residua I stress evaluation within a crimped splice connector assembly," pp. 391-404 in Electrical Transmission Line and Substation Structures, Proceedings of the 2006 Elec tric al Transmission Conference, Reston, Virginia, October 2006.

Y. D. Wang, Y. Ren, Z. H. Nie, D. M. Liu, L. Zuo, H. Choo, H. Li, P. K. Liaw, J. Q. Yan, R. J. McQueeney, J. W. Richardson, and A. Huq, "Structural transition of ferromagnetic Ni ${ }_{2} \mathrm{MhG}$ a nanoparticles," J ournal of Applied Physics 101, 063530 (2007).

Y. D. Wang, C. Ren, L. Shan, S. L. Li, P. C. Dai, and H. H. Wen, "Peak effect due to J osephson vortic es in superconducting $\operatorname{Pr}_{0.88} \mathrm{LaCe}_{0.12} \mathrm{CuO}_{4 \text {-delta }}$ single crystals," Physic al Review B 75 (April 2007).

S. D. Wilson, S. L. Li, J. Zhao, G. Mu, H. H. Wen, J. W. Lynn, P. G. Freeman, L. P. Regnault, K. Habic ht, and P. C. Dai, "Quantum spin correlations through the superconducting-to-normal phase transition in electron-doped superconducting $\operatorname{Pr}_{088} \mathrm{LaCe}_{012} \mathrm{CuO}_{4 \text {-delta }}$ " pp. 15259-15263 in Proceedings of the National Academy of Sciences of the United States of A Americ a 104 (September 2007).

W. Woo, Z. Feng, X-L. Wang, D. W. Brown, B. Calusen, K. An, H. Choo, C. Hubbard, and S. A. David, "In-situ neutron diffraction measurements of temperature and stresses during friction stir welding of 6061-T6 aluminum alloy," Science and Technology of Welding and J oining 12, 298-303 (2007).

W. Woo, Z. Feng, X.-L. Wang, D. W. Brown, B. Calusen, C.R. Hubbard, H. Choo, and S. A. David, "Quasi-steady state principle and in situ real-time investigation of transient stra ins in 6061-T6 Al alloy using neutron diffraction," Key Engineering Materia Is 345-346, 797-800 (2007).

T. Yamamoto, G. R. Odette, P. Miao, D. T. Hoelzer, J. Bentley, N. Hashimoto, H. Tanigawa, and R. J. Kurtz, "The transport and fate of helium in nanostructured ferritic alloys at fusion relevant $\mathrm{He} / \mathrm{dpa}$ ratios and dpa rates," J ournal of Nuclear Materials 367, 399-410 (August 2007).

J.-Q. Yan, J.-S. Zhou, J. B. Goodenough, Y. Ren, J. G. Cheng, S. Chang, J. Zarestky, O. Ga rlea, A. Liobet, H. D. Zhou, Y. Sui, W. H. Su, and R. J. McQueeney, Physical Review Letters 99, 197201 (2007).

J. Yang, G. P. Meisner, C. J. Rawn, H. Wang, B. C. Chakoumakos, J. Martin, G. S. Nolas, B. L. Pedersen, and J. K. Stalick, "Low temperature transport and structural properties of misch-metalfilled skutterudites," J ournal of Applied Physic s 102 (October 2007.

L. Yang, X. L. Wang, C. T. Liu, J. A. Fernandez-Baca, C. L. Fu, J. W. Richardson, and D. Shi, "Neutron diffraction study of the structure and low-temperature phase transformation in ternary NiAI+M (M = $\mathrm{Ni}, \mathrm{Fe}, \mathrm{Co}$ ) alloys," Scripta Materialia 56, 911-914 (Ma y 2007). 
F. Ye, J. A. Fernandez-Baca, R. S. Fishman, Y. Ren, H. J. Kang, Y. Qiu, a nd T. Kimura, “Magnetic interactions in the geometric ally frustrated triangular lattic e antiferromagnet $\mathrm{CuFeO}_{2}$," $\mathrm{Physical}$ Review Letters 99 (October 2007).

F. Ye, P. C. Dai, J. A. Fernandez-Baca, D. T. Adroja, T. G. Perring, Y. Tomioka, a nd Y. Tokura, “Spin waves throughout the Brillouin zone and magnetic exchange coupling in the ferromagnetic metallic manganites La ${ }_{1-x} \mathrm{Ca}_{x} \mathrm{MnO}_{3}(x=0.25,0.30)$," Physical Review B 75 (April 2007).

F. Ye, B. Lorenz, Q. Huang, Y. Q. Wang, Y. Y. Sun, C. W. Chu, J. A. Ferna ndez-Baca, P. C. Dai, and H. A. Mook, "Incommensurate magnetic structure in the orthorhombic perovskite ErMnO ${ }_{3}$ " Physical Review B 76 (August 2007).

J. A. Ye, Y. W. Rodriguez, D. P. Belanger, and J. A. Fernandez-Baca, “The order parameter critical exponent of the chiral phase transition in VF2," J ournal of Magnetism and Magnetic Materials 310 , 1410-1412 (March 2007).

J. Zhang, F. Ye, H. Sha, P. Dai, J. A. Fernandez-Baca, and E. W. Plummer, "Magnons in ferromagnetic metallic manganites," J ournal of Physic s-Condensed Matter 19 (August 2007).

Y. Zhang, I. E. Campisi, P. Chu, J. Galarnbos, and S. D. Henderson, “Determination of field amplitude and synchronous phase using the beam-induced signal in an unpowered superconducting cavity," Nuclear Instruments and Methods in Physics Research Section A-Accelerators, Spectrometers, Detectors, and Associated Equipment 571, 574-582 (February 2007).

Y. Zhang, I. E. Campisi, and S. D. Henderson, "The commissioning of the SNS superconducting linac," Nuclear Instruments and Methods in Physics Research Section B-Beam Interactions with Materials and Atoms 261, 1036-1039 (August 2007).

J. Zhao, P. C. Dai, S. L. Li, P. G. Freeman, Y. O nose, and Y. Tokura, “Neutron-spin resonance in the

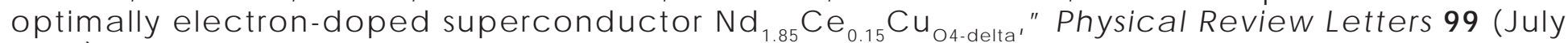
2007).

A. Zheludev, V. O. Garlea, T. Masuda, H. Manaka, L. P. Regnault, E. Ressouche, B. Grenier, J. H. Chung, Y. Qiu, K. Habicht, K. Kiefer, and M. Boehm, "Dynamics of qua ntum spin liquid a nd spin solid phases in IPA-CuCl under a n applied magnetic field studied with neutron scattering," Physical Review B 76 (August 2007).

A. Zheludev, V. O. Garlea, S. Nishihara, Y. Hosokoshi, A. Cousson, A. Guka sov, and K. Inoue, "Spindensity distribution in the partially magnetized organic quantum magnet F2PNNNO," Physical Review B 75 (March 2007).

A. Zheludev, T. Masuda, G. Dhalenne, A. Revcolevschi, C. Frost, and T. Perring, "Scaling of dynamic sp in correlations in $\mathrm{BaCu}_{2}\left(\mathrm{Si}_{0.5} \mathrm{Ge}_{0.5}\right)(2)$ O-7," Physical Review B 75 (February 2007).

H. D. Zhou, C. R. Wiebe, Y.J.Jo, L. Balicas, Y. Qiu, J. R. D. Copley, G. Ehlers, P. Fouquet, and J. S. Gardner, "The origin of persistent spin dynamics and residual entropy in the stuffed spin ice $\mathrm{Ho}_{2.3} \mathrm{Ti}_{1.7} \mathrm{O}_{7 \text {-delta, }}$ J J ournal of Physic S-Condensed Matter 19 (August 2007). 


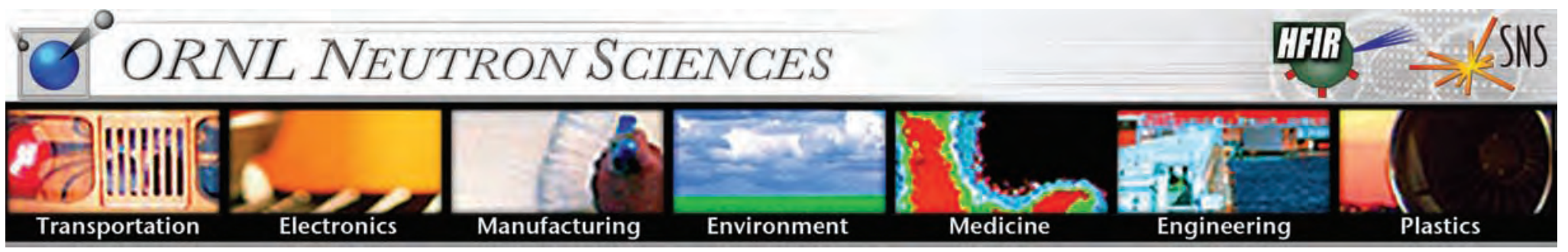

neutrons.ornl.gov

The ORNL Neutron Sciences Web site serves as virtual home for the Neutron Sciences user program, instruments, schedules, publications, and technical information about HFIR and SNS. Jobs, news and events, and visitor and contact information are also included. An important goal of the site is to provide educational material about neutron science to a variety of audiences, from kids $\mathrm{K}-12$ through postdoctoral students and researchers.

Our Web site is constantly changing, and we welcome comments about what you find useful, not so useful, and how the site might be improved. Please send comments to the webmaster at neutronscience@ornl.gov.

\section{Contact Information}

Office of the ORNL Associate Laboratory Director for Neutron Sciences lan Anderson (andersonian@ornl.gov)

865.574.0558

High Flux Isotope Reactor Oak Ridge National Laboratory

P.O. Box 2008 MS-6398

Oak Ridge, TN 37831-6398 Phone: 865.574.1301

Spallation Neutron Source Oak Ridge National Laboratory

P.O. Box 2008 MS-6477

Oak Ridge, TN 37831-6477 Phone: 865.574.0558

neutrons.ornl.gov neutronscience@ornl.gov

More about this publication: Neutron Sciences Communications Office horakcm@ornl.gov 
The next generation of materials research

UT-BATTELLE

OAK

SCIENCE 